$\mathrm{AD}$

Award Number: DAMD17-99-1-9151

TITLE: Murine Models of Breast Cancer: Assessment of the Role of c-Src in Mammary Tumorigenesis

PRINCIPAL INVESTIGATOR: Konstantina Alexandropoulos, Ph.D.

CONTRACTING ORGANIZATION: Columbia University

New York, NY 10032

REPORT DATE: October 2004

TYPE OF REPORT: Annual Summary

PREPARED FOR: U.S. Army Medical Research and Materiel Command Fort Detrick, Maryland 21702-5012

DISTRIBUTION STATEMENT: Approved for Public Release;

Distribution Unlimited

The views, opinions and/or findings contained in this report are those of the author(s) and should not be construed as an official Department of the Army position, policy or decision unless so designated by other documentation. 


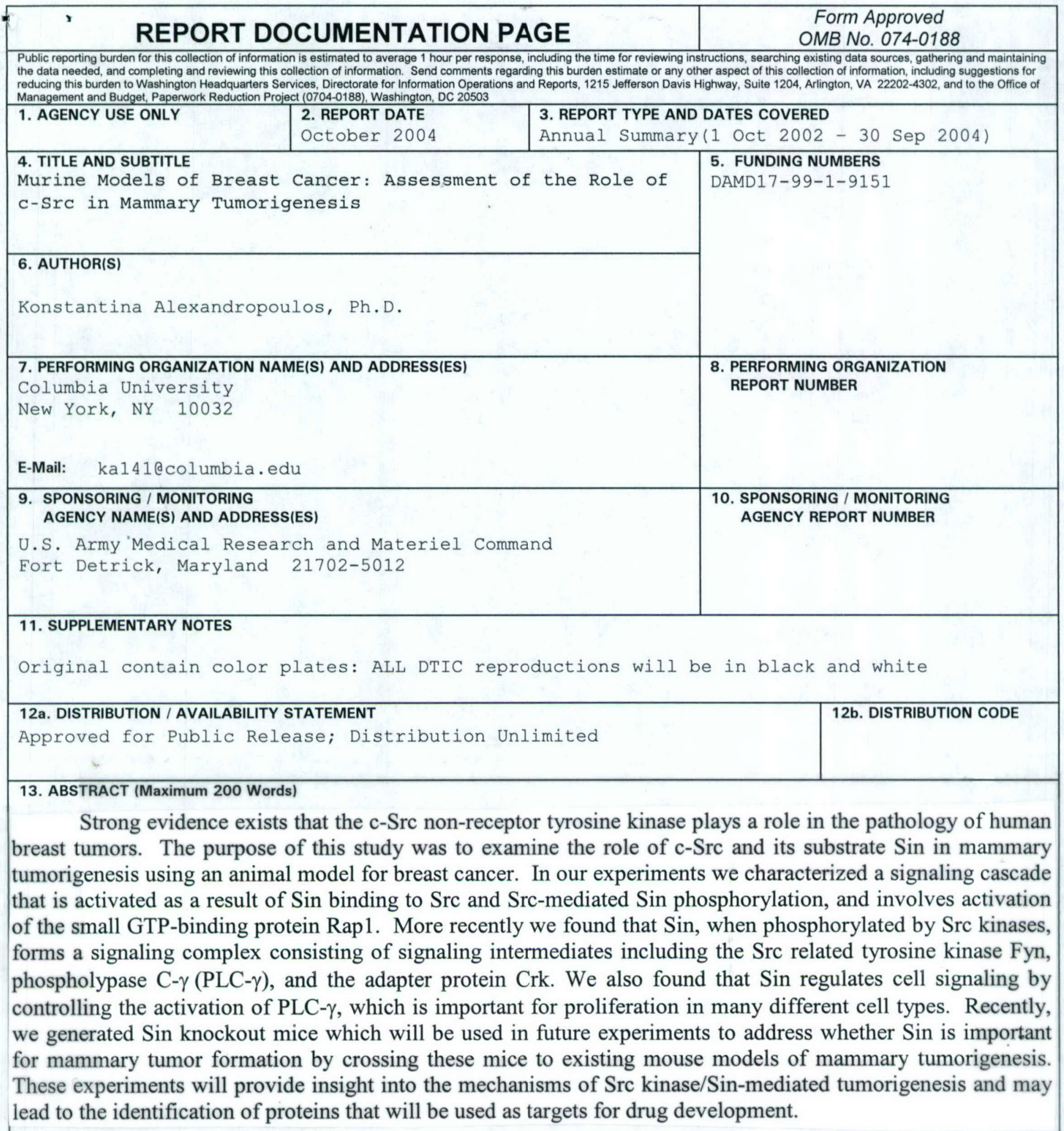

\begin{tabular}{|l|l|l|l|}
\hline \multicolumn{2}{|l|}{$\begin{array}{l}\text { 14. SUBJECT TERMS } \\
\text { Breast Cancer, SrC, Fyn, Sin }\end{array}$} & $\begin{array}{c}\text { 15. NUMBER OF PAGES } \\
98\end{array}$ \\
\cline { 2 - 4 } $\begin{array}{c}\text { 17. SECURITY CLASSIFICATION } \\
\text { OF REPORT } \\
\text { Unclassified }\end{array}$ & $\begin{array}{c}\text { 18. SECURITY CLASSIFICATION } \\
\text { OF THIS PAGE } \\
\text { Unclassified }\end{array}$ & $\begin{array}{c}\text { 19. SECURITY CLASSIFICATION } \\
\text { OF ABSTRACT } \\
\text { Unclassified }\end{array}$ & $\begin{array}{c}\text { 20. LIMITATION OF ABSTRACT } \\
\text { Unlimited }\end{array}$ \\
\hline
\end{tabular}


Table of Contents

Cover..

1

SF 298.

2

Table of Contents.

3

Introduction.

4

Body

4

Key Research Accomplishments.

6

Reportable Outcomes.

7

Conclusions.

9

References.

Appendices. 


\section{INTRODUCTION}

We are studying the role of the non-receptor tyrosine kinase c-Src and its substrates in mammary tumorigenesis in a murine animal model and in cell lines. Our purpose was to use c-Src substrates that cloned to gain insight into the molecular interactions that mediate Src-dependent intracellular signaling and transformation. The molecules we developed bind to a conserved regulatory region of c-Src activate Src's enzymatic activity and subsequently act as substrates and effector molecules for c-Src signaling [1]. In our experiments we are a novel adapter protein that we isolated, Sin, to identify factors which play a role in Src-mediated tumorigenesis in the mammary epithelium. As an adapter molecule, Sin binds to cellular proteins and forms a signaling multiprotein complex $[2,3]$. In our experiments we have identified some of the binding partners of Sin, including the Src family member Fyn, PLC- $\gamma$ and the adapter Crk [4]. We are studying Sin because in our experiments we found that this protein has the unique ability among the other c-Src ligands to activate the transforming potential of c-Src. In addition, the expression of full-length Sin and a truncated Sin mutant was recently shown to be upregulated in mouse mammary tumors. In our future studies we will a) use inhibitory RNA oligonucleotides and Sin knockout mice to inhibit Sin expression and assess the effect of lack of Sin on mammary tumorigenesis. b) Purify the Sin signaling complex to isolate proteins that mediate Sin-dependent c-Src tumorigenesis. These studies are important because they will elucidate the molecular mechanisms that drive mammary tumorigenesis and may lead to the development of strategies to interfere with aberrant Src/substrate activity and carcinogenesis. In addition, these studies may implicate endogenous Sin as a novel regulator of mammary tumorigenesis.

\section{$\underline{\text { BODY }}$}

c-Src is a non-receptor tyrosine kinase that is very important for cellular function [5]. The Src substrate $\mathrm{Sin}$ is a multi-adapter molecule that mediates the formation of multi-protein complexes in a phosphotyrosine-dependent manner [1]. Because phosphorylated Sin has the ability to bind to different proteins simultaneously, it also has the potential for activating multiple intracellular pathways with pleiotropic effects on cellular behavior. In our preliminary results we found that a truncated version of Sin, $\operatorname{Sin} \Delta \mathrm{C}$, activates two major signaling pathways and the transforming potential of c-Src. Consistent with this, recent experiments using cDNA microarrays have shown that Sin expression is upregulated in human breast tumors [6]. In addition, we recently identified a variant form of Sin, Sin-MTV (mammary tumor variant) whose expression is upregulated in mouse mammary tumors as compared to normal mammary epithelium. Sin-MTV was identified by screening an expressed sequence tag (EST) database, which was compiled by the National Cancer Institute as part of the Cancer Genome Anatomy Project (CGAP), created to determine the gene expression profiles of normal, pre-cancer, and cancer cells.

To further examine the role of Sin and Sin-MTV in mammary tumorigenesis and to be able to identify the expression of Sin and Sin-MTV in mammary tumor cell lines, we have been using the recently developed RNA interference (RNAi) [7] technology to downregulate expression of Sin and Sin-MTV in tumor-derived cell lines, and address 
whether downregulation of Sin expression can reverse the transformed phenotype of these cells. To this end, we used human-Sin-specific inhibitory RNA oligonucleotides which were transfected directly into $293 \mathrm{HEK}$ cells without the use of a plasmid vector. Using this approach we were able to identify two sequences that downregulate expression of cotransfected human Sin in these cells (Fig. 2). We are currently using these oligos to downregulate expression of endogenous Sin in human breast-tumor-derived cell lines and assess the effect of Sin downregulation in tumorigenic potential. In addition, we are currently developing lentiviral vectors for expressing short inhibitory RNA oligonucleotides that will allow the production of viral particles that can very effectively infect cells and produce RNAi to the gene of interest, in our case Sin and Sin-MTV. Infection of cells with lentiviral particles will also increase the number of cells that express the inhibitory RNA due to efficient infection of cells, and will allow us to assay the effect of lack of Sin and Sin-MTV in mammary cell transformation. Thus, RNAi oligonucleotides or leniviruses that exhibit an inhibitory effect on Sin expression will be transfected/virally transduced into MCF-7 and SKBR-3 transformed cell lines to assess the effect of Sin downregulation on tumorigenesis. If Sin is required for tumorigenesis, inhibition of Sin expression should reverse the transformed phenotype.

\section{HEK}

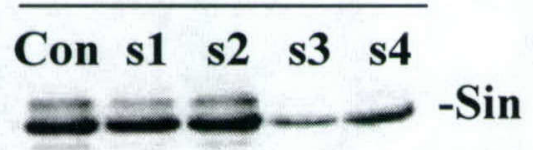

\section{Blot: anti-Sin}

Fig. 2. 293HEK cells were transfected with control (con) or Sin-specific (s1-4) RNA oligonucleotides along with a plasmid expressing full-length Sin. Cells were incubated for 24 hrs, then lysed and western blots of cell extracts were probed with specific antibody. Two of the Sin inhibitory oligonycleotides (s3 and s4) were found to inhibit Sin expression.

In aim 2 of the original application we proposed to use conserved sequences of Sin to identify elements that are important for the signaling properties of the protein and use these sequences as probes to identify proteins that mediate Sin-dependent Src signaling. Thus far we have characterized the signaling mechanisms of Sin and identified some of the proteins that are involved in mediating Src signaling using the human embryonic carcinoma 293HEK cell-culture system [2]. In this study, through the use of mutagenesis analysis and dominant negative inhibitors, we found that Src phosphorylated Sin forms a signaling complex that consists of the adapter protein Crk and $\mathrm{C} 3 \mathrm{G}$, a nucleotide exchange factor that promotes guanyl-triphosphate (GTP) binding on the GTP-binding protein Rap1.

In parallel experiments we aimed to address the in vivo role of Sin using organs of the immune system (thymus and spleen) as model tissues to address the biological function of Sin. These experiments are relevant since Sin is highly expressed in the thymus and to a lesser extent in the spleen. We found that in these cells Sin forms a multiprotein complex with other signaling molecules of which we identified the Srcrelated kinase Fyn and phospholypase-C- $\gamma$ (PLC- $\gamma)[3,4,8]$. Association of the Crk and 
C3G proteins with Sin was also observed in T cells, as well as Rap1 activation [2, 9]. We also found that Sin regulates the phosphorylation and activation of PLC- $\gamma$ and as a consequence intracellular calcium release, MAP kinase activation and $\mathrm{T}$ cell proliferation [4]. Activation of PLC- $\gamma$ and intracellular calcium release are important signaling events that mediate transcriptional activation and proliferation of many different cell types.

Given that Sin associates with other proteins and forms a multiprotein signaling complex that regulates cellular function, we believe that isolation of this complex will provide important insight into the function of Sin and its effect on cellular behavior. To this end we have generated a Sin construct that expresses full-length Sin fused to a small peptide comprising the flag epitope, which allows the purification of proteins that contain it over anti-flag-specific affinity columns. To purify proteins that may be relevant for Sin function in the mammary epithelium the flag-Sin construct will be expressed either transiently or stably in mammary tumor cell lines. Large-scale purification of flag-tagged Sin and associated proteins will then be performed over anti-flag columns, and acid eluted complexes will be separated by SDS-PAGE. Protein bands will be excised from Coomassie-stained SDS-PAGE gels and digested with trypsin. Extracted peptides will then be subjected to matrix-assisted laser (MALDI) or electrospray ionization (ESI) peptide mapping on a QSTAR XL mass spectrometer in the core spectrometry facility of Columbia University. Resulting peptide sequence data will be used to search the NCBI non-redundant protein database to identify proteins associated with Sin. We believe that this newly-developed purification approach is mote efficient in isolating proteins bound to Sin that using isolated Sin conserved sequences, since this approach will identify the entire Sin signaling complex. We anticipate that Sin complex purification will identify both known and novel proteins that associate with Sin and mediate/regulate its function in mammary epithelial cells, including the proteins mentioned above that we already identified as Sin binding proteins.

As part of this project, we also generated Sin knockout mice by targeting the sin genetic locus by homologous recombination. Sin-deficient mice are born normal, develop normally, and are fertile. Older Sin mice develop intestinal inflammation due to a compromised immune system [10] In future experiments these mice will be crossed to existing models of mammary tumorigenesis to examine the effect of Sin deficiency in the development of this phenotype. For example, Sin knockout animals will be crossed to transgenic mice overexpressing wild type of the protooncogen HER2/Neu, which is an animal model that closely represents the conditions under which human breast tumors occur. Overexpression and/or amplification of the neu protein have been implicated in the development of aggressive human breast cancer, and inversely correlate with survival rates. Overexpression of HER $2 / \mathrm{Neu}$ in mice results in the development of tumors after a long latency period and correlates with increased c-Src enzymatic activity. Thus, it will be of interest to examine the role of Src activation, Sin phosphorylation and development of tumors in $\mathrm{Sin}^{-/} / \mathrm{HER} 2 / \mathrm{Neu}$ transgenic mice as this may lead to insight into the mechanisms that control mammary tumorigenesis and may identify Sin as an important player in this process.

\section{KEY RESEARCH ACCOMPLISHMENTS}


1. We have shown that Sin interaction with Src leads to the activation of Src signaling as assayed by transcriptional activation.

2. We have for the first time described a novel pathway that mediates wild type c-Src signaling.

3. Our experiments have revealed mechanistic differences in the signaling mechanisms of wild type versus transforming Src alleles.

4. We have confirmed that this pathway operates in vivo downstream of Src kinases using thymocytes and $\mathrm{T}$ cells as a model system.

5. We have characterized the components of this pathway both in vitro and in vivo. These include Src/Sin, the signaling complex Crk/C3G, the G-protein Rap1 and the kinase ERK1.

6. We have found that the Src kinase Fyn is important for Sin phosphorylation in T lymphocytes and that Fyn mediates some of the inhibitory effects of Sin on T lymphocyte function.

7. We have also found that $\operatorname{Sin}$ is constitutively phosphorylated and bound to substrates in resting cells. These substrates include the Src-related kinase Fyn and PLC- $\gamma$. In addition, our data show that Sin regulates the activation of PLC- $\gamma$ and as a consequence intracellular signaling events important for cell proliferation.

8. We have generated Sin knockout mice that will be used to assess the role of this protein in tumorigenesis in different mouse models.

\section{REPORTABLE OUTCOME}

-We have published the following manuscripts:

1. Xing L., Ge, C, Zeltser R, Maskevitch GR, Mayer, BJ, and Alexandropoulos K. 2000. c-Src signaling induced by the adapters Sin and Cas is mediated by the Rap1 GTPase. Mol. Cell. Biol. 20:7363-7377.

2. Donlin, L.T., Roman, C.A., Adlam, M., Regelmann, A.G., and Alexandropoulos, K. 2002. Defective thymocyte maturation by transgenic expression of a truncated form of the lymphocyte adapter molecule and Fyn substrate, Sin. J. Immunol. 169:6900-6909.

3. Alexandropoulos, K., Donlin, L.T., Xing, L. and Regelmann, A.G. 2003. Sin: Good or Bad? A T lymphocyte perspective. Immonol. Rev. 192: 181-195.

4. Xing, L., Donlin, L.T., Miller, R.H., and Alexandropoulos, K. 2004. The Adapter Molecule Sin Regulates T-Cell-Receptor-Mediated Signal Transduction by Modulating Signaling Substrate Availability. Mol. Cell. Biol. 24: 4581-4592.

5. Donlin, L.T., Danzl, N., Wanjalla, C., and Alexandropoulos, K. 2005. Mice deficient in $\mathrm{Sin} / \mathrm{Efs}$, a protein that maps within the human inflammatory bowel disease 4 (IBD4) locus, develop mucosal inflammation. Submitted. 
-Oral presentations and posters at scientific meetings:

An oral presentation and an abstract were presented in an annual meeting: "Tyrosine Phosphorylation and Cell Signaling: The Third Decade". August 9-13, 2000, The Salk Institute, San Diego, CA.

An oral presentation was given at the FASEB annual meeting: "FASEB 2000, Signal Transduction in the Immune System". Saxton River, VT.

Two abstracts were presented at "The Fortieth Midwinter Conference of Immunologists: Immune System Development and Function”, January 27-30, 2001, Asilomar, CA

An oral presentation was presented at the International Symposium on: "The Molecular Basis of Immune Cell Activation and Immunological Disorders", February 15-18, 2001, San Diego, CA

An oral presentation was presented at the "Receptors and Signal Transduction" meeting, June 29-July-3, 2002, Salt Lake City, Utah

An oral presentation was presented at the " $2^{\text {nd }}$ Lymphocyte Signal Transduction Workshop" October 13-17, 2002, Santorini, Greece

A poster was presented at the "Era of Hope" meeting, September 25-28, 2002, Orlando, FL

A poster was presented at the FASEB Summer Research Conference, Signal Transduction in the Immune System, June 14-19, 2003, Snowmass, Colorado

A poster was presented at the Keystone Symposia, Lymphocyte Activation and Signaling, January 8-13, 2004, Steamboat Springs, Colorado

A poster was presented at the EMBO Workshop, Lymphocyte antigen receptor and coreceptor singaling, September 11-15, 2004, Siena, Italy

-No degrees obtained

-We have developed cell lines coexpressing $\operatorname{Src}$ and $\operatorname{Sin} \Delta \mathrm{C}$ using NIH3T3 cells, transgenic mice expressing $\operatorname{Sin}$ and $\operatorname{Sin} \Delta \mathrm{C}$, and Sin knockout mice.

-No informatics

-We have received funding from the National Institute of Allergy and Infectious Diseases (NIAID) on work supported by this award 
RO1 AI49387

$\$ 1,125,000$

Title: Examine the Role of Fyn and Rap1 in T cell activation and T cell-mediated Immune Responses.

-No changes in employment status.

-Personnel supported by this grant:

-Konstantina Alexandropoulos

Luzhou Xing

\section{CONCLUSIONS}

Oncogenic Src proteins have been extensively studied to gain insight into the signaling mechanisms of Src. To better understand signaling through wild-type Src, we cloned a substrate, Sin, which activates Src signaling by binding to the Src $\mathrm{SH} 3$ domain. To this end, we used full length and truncated versions of Sin to activate c-Src, and examined the intracellular pathways that mediate Src signaling under these conditions. We found that Sin-induced Src signaling is exclusively mediated through a pathway that consists of the $\mathrm{Crk} / \mathrm{C} 3 \mathrm{G} / \mathrm{Rap} 1$ signaling complex. The involvement of this pathway downstream of $\operatorname{Src}$ kinase-phosphorylated $\operatorname{Sin} \Delta \mathrm{C}$ was confirmed in vivo using thymocytes and T cells as model systems. Our experiments described above are aimed towards addressing the role of Sin in mammary tumorigenesis, either independently or in conjunction to Src, as well as the mechanisms through which Sin may exerts its tumorigenic effects. These experiments are important in that, they may reveal an important function for Sin in mammary tumorigenesis, as well as identify novel molecules that mediate Sin function. These molecules in turn may serve as putative therapeutic targets for treating human breast tumors.

\section{REFERENCES}

1. Alexandropoulos, K. and D. Baltimore, Coordinate activation of c-Src by SH3and SH2-binding sites on a novel p130Cas-related protein, Sin. Genes Dev, 1996. 10(11): p. 1341-55.

2. Xing, L., et al., $c$-Src signaling induced by the adapters Sin and Cas is mediated by Rap1 GTPase. Mol Cell Biol, 2000. 20(19): p. 7363-77.

3 Xing, L., et al., The Adapter Molecule Sin Regulates T-Cell-Receptor-Mediated Signal Transduction by Modulating Signaling Substrate Availability. Mol Cell Biol, 2004. 24(10): p. 4581-4592.

4 Brown, M.T. and J.A. Cooper, Regulation, substrates and functions of src. Biochim Biophys Acta, 1996. 1287(2-3): p. 121-49.

5 Ross, D.T., et al., Systematic variation in gene expression patterns in human cancer cell lines. Nat Genet, 2000. 24(3): p. 227-35.

6 Brummelkamp, T.R., R. Bernards, and R. Agami, A system for stable expression of short interfering RNAs in mammalian cells. Science, 2002. 296(5567): p. 5503. 
7 Donlin, L.T., et al., Defective thymocyte maturation by transgenic expression of a truncated form of the T lymphocyte adapter molecule and Fyn substrate, Sin. J Immunol, 2002. 169(12): p. 6900-9.

8 Alexandropoulos, K., et al., Sin: good or bad? A T lymphocyte perspective. Immunol Rev, 2003. 192: p. 181-95.

9. Donlin, L.T., Danzl, N.M., Wanjalla, C., and Alexandropoulos, K., Mice deficient in Sin/EFS, a protein that maps within the human inflammatory bowel disease 4 locus, develop mucosal inflammation. Submitted, 2005. 
APPENDIX 


\title{
c-Src Signaling Induced by the Adapters Sin and Cas Is Mediated by Rap1 GTPase $\dagger$
}

\author{
LUZHOU XING,${ }^{1}$ CHANG GE,${ }^{1}$ ROSS ZELTSER,${ }^{1}$ GREGORY MASKEVITCH, ${ }^{1}$ \\ BRUCE J. MAYER, ${ }^{2}$ AND KONSTANTINA ALEXANDROPOULOS ${ }^{1 *}$ \\ Department of Pharmacology, College of Physicians and Surgeons of Columbia University, New York, \\ New York 10032, ${ }^{1}$ and The Children's Hospital, Boston, Massachusetts $02115^{2}$
}

Received 24 March 2000/Returned for modification 24 May 2000/Accepted 29 June 2000

\begin{abstract}
Oncogenic Src proteins have been extensively studied to gain insight into the signaling mechanisms of Src. To better understand signaling through wild-type Src, we used an approach that involves activation of Src signaling through the binding of physiologic ligands to the Src SH3 domain. To this end, we used full-length and truncated versions of the multiadapter molecules Cas and Sin to activate c-Src, and we examined the intracellular pathways that mediate Sre signaling under these conditions. We show that although all proteins bind to and are phosphorylated by c-Src, quantitative differences exist in the ability of the different ligands to activate c-Src signaling. In addition, we show that Sin- and Cas-induced Src signaling, as assayed by transcriptional activation, is exclusively mediated through a pathway that involves the adapter Crk and the GTP-binding protein Rap1. These data are in contrast to previous observations showing Ras to mediate signaling downstream of transforming Src alleles. In our system, we found that signaling through the oncogenic SrcY527 mutant is indeed mediated by Ras. In addition, we found that Rap1 also mediates oncogenic Src signaling. Our results show for the first time that Rap1 mediates c-Src kinase signaling and reveal mechanistic differences in the signaling properties of wild-type and transforming Src proteins.
\end{abstract}

The nonreceptor protein tyrosine kinase Src is critical for normal cellular processes such as proliferation and differentiation, and certain mutations in Src cause uncontrolled cell proliferation and transformation (11). Under normal conditions, the enzymatic activity of Src is tightly regulated. Biochemical $(13,20,45,64)$ and structural $(75,92)$ analyses have shown that the kinase activity of the c-Src protein is intramolecularly regulated by conserved modular domains, the Src homology regions 2 and 3 (SH2 and SH3) (18). Consistent with their regulatory role, mutations within these domains render the kinase active and oncogenic (11). In addition, upon Src activation, these domains mediate protein-protein interactions and are thought to determine substrate selectivity and signaling specificity $(18,28)$.

Traditionally, studies aimed at elucidating the signaling properties of c-Src have used constitutively active and transforming Src alleles as models. Activated Src alleles exhibit deregulated kinase activity and are known to induce multiple signaling responses due to promiscuous substrate phosphorylation. Thus, it has been difficult to determine which of the many responses is responsible for the signaling properties of Src. In addition, despite the identification of a plethora of putative Src substrates in v-Src-transformed cells, the importance of these substrates in the physiologic and/or tumorigenic effects of c-Src has been difficult to ascertain.

To gain insight into the signaling mechanisms of wild-type $\mathrm{c}$-Src and given that the $\mathrm{c}-\mathrm{Src} \mathrm{SH} 3$ domain has been shown to participate in the intramolecular negative inhibition of the c-Src kinase activity $(55,79)$, we used physiological ligands for the conserved $\mathrm{SH} 3$ domain of c-Src to activate the enzyme. At

* Corresponding author. Mailing address: Department of Pharmacology, College of Physicians and Surgeons of Columbia University, PH 7W Rm. 318, 630 West 168th St., New York, NY 10027. Phone: (212) 305-2705. Fax: (212) 305-8780. E-mail: ka141@columbia.edu.

$\dagger$ This report is dedicated to the memory of Eugenia Spanopoulou, Andrew Hotchev, and Platon Spanopoulos-Hotchev. $\Delta \varepsilon v \sigma \alpha \varsigma \xi \xi \chi \nu \omega$. the same time, we used these ligands as links to downstream events to study the signaling mechanisms and specificity of c-Src. The molecules used for our studies consist of a protein that we previously identified, Sin, and the homologous protein p $130^{\text {Cas }}(1,72)$. Cas was first identified as a highly phosphorylated protein in v-Src- and v-Crk-transformed cells (72); Sin was independently cloned as the Fyn embryonic substrate Efs (40). These molecules specifically bind to Src family SH3 domains with high affinity through proline-rich motifs $(2,57,72)$. Sin and Cas comprise a multiadapter protein family that also includes HEF1/CasL independently cloned as a human enhancer of filamentation in yeast and as a focal adhesion kinase (FAK)-binding protein expressed in lymphocytes (48). All of these proteins exhibit conserved secondary structures, which in turn consist of many conserved modules that mediate proteinprotein interactions. Thus, Cas proteins have conserved $\mathrm{N}$ terminal SH3 domains, central regions comprised of repeated tyrosine-containing residues, Src SH3-binding proline-rich motifs (except HEF1/CasL), and conserved $\mathrm{C}$ termini that have been implicated in homo- or heterodimerization between family members (61). The presence of these conserved domains and their ability to promote protein-protein interactions suggest that members of the Cas family mediate the formation of multiprotein complexes in a phosphotyrosine-dependent manner. These protein-protein interactions are thought to subsequently activate intracellular signaling pathways with pleiotropic effects on cellular behavior $(52,61)$.

The most extensively studied member of this family, p130 Cas, becomes highly phosphorylated on multiple tyrosine residues in response to a variety of stimuli. For example, mitogens such as epidermal growth factor, platelet-derived growth factor, and lysophosphatidic acid have been shown to induce tyrosine phosphorylation of Cas $(15,59)$. In addition, integrin engagement or stimulation of serpentine receptors such as the bombesin and the endothelin receptors stimulate Cas phosphorylation $(15,47,87,88)$. Cas phosphorylation in turn has been implicated in multiple cellular processes such as integrin re- 
ceptor signaling $(36,50,58,88)$, cell migration and survival (14, $16,17,44)$, regulation of the cell cycle $(60,93)$, and apoptosis (7). Furthermore, Cas has been implicated in cellular transformation, as demonstrated by its presence as a tyrosine-phosphorylated protein in v-Src- and v-Crk-transformed cells (72), by the fact that $\mathrm{p} 130^{\mathrm{Cas}-1-}$ cells cannot be transformed by Src (37), and by antisense RNA experiments showing that Casspecific antisense RNA partially reverts v-Src transformation (6).

Multiadapter molecules, such as the Cas protein, depending on the type and number of conserved motifs they contain, can form interactions with unique sets of cytoplasmic intermediates and thus determine signaling specificity. These conserved motifs have tyrosine-containing sequences ( $\mathrm{Y}$ motifs) which upon phosphorylation by tyrosine kinases recruit cytoplasmic substrates through phosphotyrosine- $\mathrm{SH} 2$ domain interactions. The type and number of Y motifs present on the different members of the Cas family differ, suggesting that these proteins may have similar but not identical functions. Consistent with the model that $\mathrm{Y}$ motifs can determine signaling specificity, the multiadapters and insulin receptor substrates IRS1 and $-2(56,94)$ have been shown to mediate distinct functions of the insulin receptor $(5,80,89)$. The different signaling properties of each molecule have been attributed to unique Y motifs that bind to distinct $\mathrm{SH} 2$ domain-containing cytoplasmic intermediates.

We have previously shown that coexpression of Src and Sin activates Src signaling, as measured by serum response element (SRE)-mediated transcriptional activation (1). In this study we compared the abilities of the Src SH3-binding proteins Cas and Sin to bind to and stimulate the enzymatic activity of c-Src. We then analyzed the molecular events that mediate Sin-Cas-induced Src signaling, using the phosphorylated forms of these proteins as links to downstream signaling events. In addition, we compared the signaling mechanisms of ligand-activated c-Src to signaling mediated by a constitutively active and oncogenic Src mutant. In these experiments, we used full-length and truncated forms of Sin and Cas proteins, and we found quantitative differences in the ability of the different Sin and Cas proteins to activate c-Src signaling. In addition, we found that ligand-activated and constitutively active Src proteins utilize different signaling mechanisms to induce SRE-dependent transcription.

\section{MATERIALS AND METHODS}

Cells and antibodies. Human embryonic kidney carcinoma 293 cells were grown as previously described (62). Cells were maintained in Dulbecco modified Eagle medium containing $10 \%$ fetal bovine serum, penicillin $(100 \mathrm{U} / \mathrm{ml})$, and streptomycin $(100 \mathrm{mg} / \mathrm{ml})$. The Sin monoclonal antibody, raised against a fragment of Sin encompassing amino acids 142 to 258, was generated by Transduction Laboratories. Cas polyclonal antibody CasN-17 was purchased from Santa Cruz Biotechnology. The Src mouse monoclonal antibody 327 was provided by Joan Brugge (Harvard Medical School); the antiphosphotyrosine monoclonal antibody pY20 was purchased from Transduction Laboratories. Antiphosphoty rosine SrcY 416 was kindly provided by A. Laudano (University of New Hamp shire). Other reagents used were anti-phospho-ERK monoclonal antibody (E-4), anti-ERK, anti-C3G (Santa Cruz), anti-Ras, anti-Rap1, anti-Crk (Transduction Laboratories), and anti-hemagglutinin epitope (HA) (BAbCo, Richmond, Calif.).

DNA constructs. DNA manipulations were performed by standard protocols. Full-length $\operatorname{Sin}$ and truncated $\operatorname{Sin} \Delta \mathrm{C}$ (amino acids 1 to 335 ) were cloned into the SpeI-NotI sites of the pEBB expression vector. pEBB was derived from the pEF-BOS expression vector driven by the human elongation factor 1- $\alpha$ promote (53). In $\operatorname{Sin} \Delta C$, a deletion of amino acids 340 to 560 removes one of the proline-rich Src SH3-binding sites, the last three $\mathrm{Y}$ motifs in the substrate region, and the $\mathrm{C}$-terminal homologous region. $\mathrm{PCR}$-amplified $\mathrm{Cas}$ proteins were cloned into the Bam HI-NotI sites of pEBB. Full-length Cas expresses a short form of the protein that is alternatively spliced, missing amino acids 5 to 99 (72). Cas $\Delta$ UR contains an internal deletion of a Bsu36I fragment encompassing amino acids 496 to 713 that removes the unique region of Cas. Cas $\Delta U R \Delta C$ contains, in addition to the Bsu36I fragment deletion, a C-terminal deletion that encompasses amino acids 748 to 968 . This construct was generated by PCR amplification using Cas $\Delta \mathrm{UR}$ as a template and synthetic oligonucleotides containing 5 $B a m \mathrm{HI}$ and $3^{\prime}$ Not I restriction sites. Cas $\Delta \mathrm{UR} \Delta \mathrm{CP}^{*}$ was generated as the Cas $\Delta U R \Delta C$ construct except that the $3^{\prime}$ oligonucleotide that was used for PCR amplification contained two base pair substitutions that produce two point mutations (Ser-Ala and Pro-Leu) in the sequence within the core of the PXXP motif of Cas. These substitutions change the Src SH3-binding site of Cas for that of Sin (PSPP to PALP). All sequences were confirmed by automated sequence analysis The different Sin $\Delta C$ YDVP mutants were generated by PCR by substituting tyrosines 148,188 , and 253 with phenylalanine residues, using mutated oligonucleotides. The amplified fragments were cloned into the SpeI-NotI sites of pEBB and mutations were confirmed by automated sequencing. Plasmids expressing the RasN17 and CrkW170K mutants were previously described (30, 81). The RapN17 mutant was provided by Philip Stork (Oregon Health Sciences Univer sity) (86). The SRE-luciferase reporter construct was generated as previously described (1); the AP-1 luciferase reporter was provided by C. A. Hauser (La Jolla Cancer Research Foundation). Plasmids that expressed wild-type Src protein and SrcY527F have been described elsewhere (45), as has the $\mathrm{v}$-R $\mathrm{R}$ af construct (68).

Transfections. 293 cells were transfected as previously described $(1,62)$. Two micrograms of $\mathrm{pMHHB}(\mathrm{c}-\mathrm{Src})$ or $\mathrm{pc}-\mathrm{SrcY} 527 \mathrm{~F}$ expression vector or $\mathrm{pEVX}$ empty vector was used in all transfections. The transfection mixtures also in cluded $1 \mu \mathrm{g}$ of vector ( $\mathrm{pEBB}$ ) used to express the different Sin or Cas proteins or $1 \mu \mathrm{g}$ of Sin- and Cas-expressing pEBB and different concentrations of the inhibitors as shown in the figures. SRE and AP-1 luciferase reporters and the MFG-lacZ plasmid expressing $\beta$-galactosidase ( $1 \mu \mathrm{g}$ of each) were also included in the transfection mixtures. When necessary, the total amount of DNA in each transfection mixture was kept constant by the addition of empty vector in the DNA-calcium phosphate coprecipitate. Luciferase activity was determined using a Promega kit according to the manufacturer's protocol; $\beta$-galactosidase activity to normalize for transfection efficiency between the different samples was determined according to standard protocols (73).

Immunoprecipitations. Immunoprecipitations were performed as previously described (1). Briefly, cells were lysed in $1 \mathrm{ml}$ of ice-cold NP-40 lysis buffer (1\% $\mathrm{NP}-40,20 \mathrm{mM}$ Tris- $\mathrm{HCl}$ [pH 8.0], $150 \mathrm{mM} \mathrm{NaCl}, 10 \%$ glycerol, $10 \mathrm{mM} \mathrm{NaF}, 1$ $\mathrm{mM}$ sodium orthovanadate, $1 \mathrm{mM}$ phenylmethylsulfonyl fluoride, $10 \mu \mathrm{g}$ of apro$\operatorname{tinin} / \mathrm{ml}, 10 \mu \mathrm{g}$ of leupeptin/ $/ \mathrm{ml}$ ) and incubated on ice for $10 \mathrm{~min}$. The cell debris and nuclei were removed by centrifugation in an Eppendorf centrifuge for $10 \mathrm{~min}$ at $4^{\circ} \mathrm{C}$. The cell lysates were then incubated with the specified antibodies at concentrations suggested by the manufacturers for $2 \mathrm{~h}$ at $4^{\circ} \mathrm{C}$. The immune complexes were collected after the addition of $20 \mu \mathrm{l}$ of protein G-plus-protein A-agarose (Oncogene Science) and incubation at $4^{\circ} \mathrm{C}$ for $30 \mathrm{~min}$. The pellets of agarose beads were washed three times with $1 \mathrm{ml}$ of lysis buffer and then subjected to sodium dodecyl sulfate-polyacrylamide gel electrophoresis (SDSPAGE) and immunoblotting.

Western blot analysis. Total cell extracts or immunoprecipitates normalized for protein content were boiled in Laemmli sample buffer, separated by SDSPAGE on a $10 \%$ gel, and transferred to nitrocellulose membranes. Filters were blotted with the appropriate monoclonal antisera according to manufacturer's protocol in TBST-milk at $4^{\circ} \mathrm{C}$ overnight $(16 \mathrm{~h})$. Rabbit polyclonal antibodies were used at 1:500 dilution. Monoclonal antibodies were each used at $1 \mu \mathrm{g} / \mathrm{ml} \mathrm{o}$ TBST-milk. The filters were washed in TBST and consequently incubated with anti-mouse or anti-rabbit immunoglobulin G-conjugated horseradish peroxidase at a 1:4,000 dilution in TBST at room temperature for $1 \mathrm{~h}$. Filters were then washed and developed by enhanced chemiluminescence (ECL) (Amersham) as described by the manufacturer.

Ras and Rap1 binding assays. Transfected 293 cells were lysed with cold lysis buffer $(50 \mathrm{mM}$ Tris $[\mathrm{pH}$ 7.5], $1 \%$ Triton X-100, $1 \mathrm{mM}$ EDTA, $1 \mathrm{mM}$ EGTA, $0.1 \%$ 2-mercaptoethanol, $0.5 \mathrm{mM}$ sodium orthovanadate, $50 \mathrm{mM} \mathrm{NaF}, 5 \mathrm{mM}$ sodium pyrophosphate, $10 \mathrm{mM}$ sodium glycerophosphate, $0.1 \mathrm{mM}$ phenylmethylsulfonyl fluoride), and aliquots of the cell extracts containing $50 \mu \mathrm{g}$ of tota protein were mixed with $40 \mu \mathrm{l}$ crude bacterial extracts expressing glutathione $S$-transferase (GST)-RalGDS-RBD (Rap1-binding domain) or Raf1-RBD (Ras-binding domain) that had been precoupled to glutathione beads in the presence of $125 \mathrm{mM} \mathrm{NaCl}$. The aliquots were incubated $1 \mathrm{~h}$ at $4^{\circ} \mathrm{C}$ with rotation. The protein complexes were washed, separated by SDS-PAGE on a $15 \%$ polyacrylamide gel, transferred on nitrocellulose membranes, and blotted with Rasand Rap1-specific antibodies.

\section{RESULTS}

Differential activation of Src signaling by Sin and Cas. To gain insight into the specificity of c-Src signaling, we compared the abilities of wild-type and mutated forms of Sin and Cas proteins to bind to and activate Src. Although the Sin and Cas proteins do not share extensive primary sequence homology, they are closely related in their overall secondary structure (Fig. 1). For example, they both contain proline-rich consensus motifs that exhibit high binding affinity to the $\mathrm{Src} \mathrm{SH} 3$ domain 


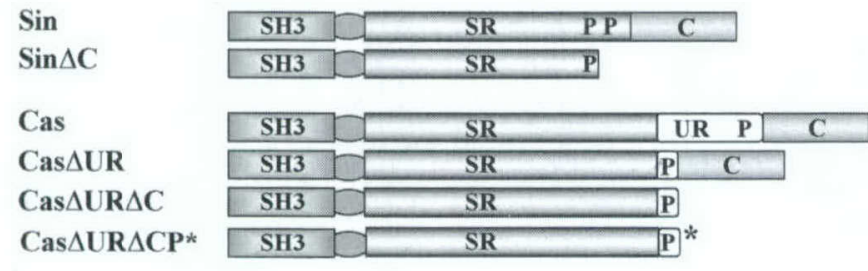

\begin{tabular}{|c|c|}
\hline $\operatorname{Sin}$ & p130Cas \\
\hline$\overline{Y V I P}$ & YDNV \\
\hline YKVP & YLVP \\
\hline YDVP & YQAP \\
\hline YD SP & YQVP \\
\hline YDVP & YQVP \\
\hline YAAP & YQVP \\
\hline YEAP & YDTP \\
\hline YDYP & YDVP \\
\hline $\mathrm{YCCO}$ & YDTP \\
\hline YEGI & $\begin{array}{l}\text { YDVP } \\
\text { YDVP }\end{array}$ \\
\hline \multirow{5}{*}{ YDYV } & YDVP \\
\hline & YDVP \\
\hline & $\begin{array}{l}\text { YDVP } \\
\text { YDYP }\end{array}$ \\
\hline & YAVP \\
\hline & YDY \\
\hline
\end{tabular}

FIG. 1. Schematic representation of full-length and truncated Sin and Cas proteins and comparison of their Y motifs. The constructs were generated as described in Materials and Methods. SR, substrate-binding regions of Sin and Cas that contain the motifs shown on the right; P, proline-rich sequences that bind to the Src SH3, RPLPALP, and RPLPPPP for Sin and RPLPSPP for Cas. Y motifs that are deleted in truncated Sin and Cas proteins are boxed. Cas $\triangle$ URACP* is the same as Cas $\triangle U R \Delta C$ except that the PSPP motif has been changed to PALP.

$(1,72)$ and are important for Src binding. The proline-rich motif of Cas has been shown to mediate association of this protein with Src and is important for Src-dependent phosphorylation of Cas (57). A point mutation within the proline-rich motif of a truncated fragment of Sin or deletion of the Sin proline-rich consensus leads to inhibition of Src signaling (reference 1 and unpublished observations). The N-terminal SH3 domains and the $\mathrm{C}$ termini of $\mathrm{Cas}$ and $\mathrm{Sin}$ are conserved (90 and $57 \%$, respectively), and their central regions contain multiple tyrosine motifs that mediate substrate binding through phosphotyrosine-SH2 domain interactions. In addition, Cas contains a unique region of unknown function between its substrate-binding region and its $\mathrm{C}$ terminus. Given the homology of these proteins, we compared the abilities of Sin and Cas to bind to and activate c-Src, as well as their abilities to become phosphorylated and promote Src-dependent intracellular signaling.

To this end, we generated full-length and truncated versions of the two proteins as shown in Fig. 1. The conserved $\mathrm{C}$ termini of both Sin and Cas were deleted, given that they negatively regulate the signaling properties of the proteins (see below), as well as the unique region of Cas to more closely approximate the overall structure of Sin. Furthermore, the proline-rich, Src SH3-binding site of Cas was exchanged for that of Sin, to test whether the affinities of these sites for the Src SH3 were functionally equivalent (Fig. 1). Finally, HA-tagged forms of truncated $\mathrm{Cas}$ and $\mathrm{Sin}$ proteins were generated and compared to unmodified full-length and truncated Cas and Sin proteins. Immunoprecipitation assays revealed that the Sin and Cas proteins associated with c-Src when coexpressed in 293 cells and were phosphorylated on tyrosine residues (Fig. 2A, top panel, lanes 2 to 9). The phosphorylation of the Sin and Cas proteins depended on c-Src coexpression, since only minor or undetectable phosphorylation of these proteins was observed in the absence of Src (pEVX vector) and in the presence of a Src kinase mutant (c-SrcK295R) (Fig. 2A, middle and bottom panels, respectively). These results suggest that these Sin and Cas proteins associate with $\mathrm{Src}$ and become phosphorylated in vivo in a Src-dependent manner.

To address whether association of Sin or Cas with Src directly stimulated the enzymatic activity of Src, we generated lysates from 293 cells coexpressing Src and Sin or Src and Cas proteins. Cell extracts were immunoprecipitated with anti-Srcspecific antibody and blotted with a polyclonal antiserum that specifically recognized the phosphorylated form of tyrosine 416 of c-Src but not the nonphosphorylated form or other phosphorylated tyrosines $(1,54)$. Tyrosine 416 is located within the activation loop of the Src kinase domain (92), and its phosphorylation correlates with increased Src activity (45). We found that all of the Cas and Sin proteins that we used were able to induce Y416 phosphorylation to various degrees (Fig. $2 \mathrm{~B}$, upper panel, lanes 2 to 9 ) compared to untransfected control cells or cells transfected with the vector backbone used to express Sin and Cas (pEBB; lane 1). Full-length Cas and a Cas mutant missing only the unique region of the protein (Cas $\Delta$ UR) were less able to induce Y416 phosphorylation when coexpressed with c-Src (Fig. 2B, upper panel, lanes 4 and 5), suggesting that the different proteins, although phosphorylated, differentially induce Src activation. The total amounts of Src were similar in the different samples (Fig. 2B, lower panel), showing that the effects on Y416 phosphorylation were specific and not due to differences in c-Src levels. These data suggest that both Sin and Cas can stimulate the enzymatic activity of Src but that some proteins may be more potent than others in promoting this activation.

Cas and Sin protein expression was confirmed using Sin-, Cas-, and HA epitope-specific antisera (Fig. 2C, upper panel). However, since we used different antisera which may exhibit different affinities for their cognate antigens, we could not directly compare the relative expression levels of the different proteins. To achieve this goal, we used a polyclonal antiserum, CasN-17, which recognizes amino acid residues 105 to 118 of the SH3 domain of Cas and cross-reacts with the Sin SH3 domain. This cross-reactivity was not unexpected because the sequence of the Cas peptide used to generate this antiserum is nearly identical to the corresponding sequence of Sin. Using this antibody, we determined that the different Sin and Cas proteins were expressed in similar amounts (Fig. 2C, lower panel).

We next examined whether Sin and Cas could elicit a signaling response as a result of their association with c-Src as measured by transcriptional activation. We used reporter constructs that drive the expression of luciferase from the SRE of the $e g r-1$ gene, a c-fos-like early-response gene $(1,84)$, or the AP-1-binding site of c-jun (33). The activation of transcription from the SRE promoter is mediated through the Raf/MEK1,2/ ERK and serum response factor (SRF) pathways, while AP-1dependent transcription is mediated by the MEKK/c-Jun Nterminal kinase (JNK) kinase/JNK pathway, as well as in response to increased Fos expression $(12,51)$. We found that 
A
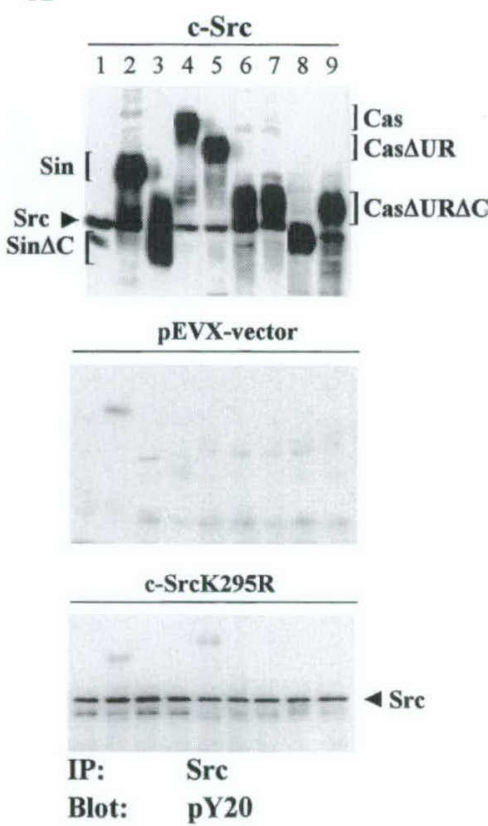

1 pEBB

2 Sin

$3 \operatorname{Sin} \Delta C$

4 Cas

5 Cas $\Delta U R$

6 Cas $\Delta$ UR- $\Delta C$

7 Cas $\Delta U R-\triangle C P$ *

8 Sin $\triangle \mathrm{C}$-HA

9 Cas $\triangle U R \Delta C-H A$
B
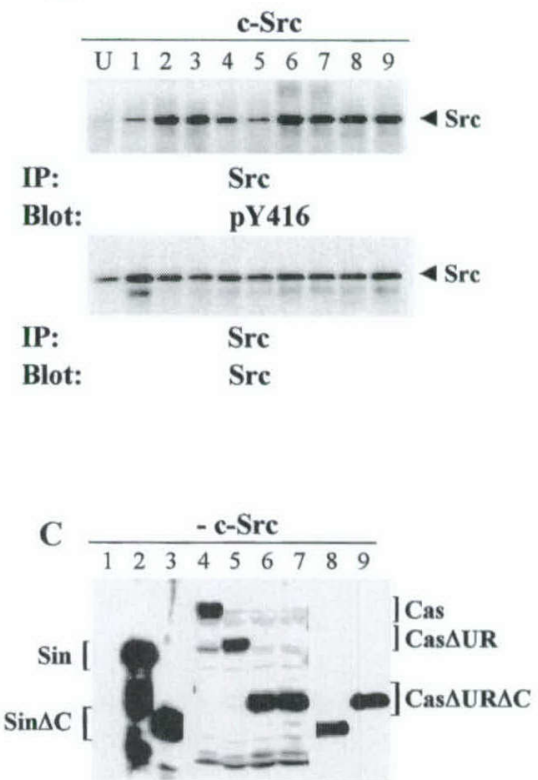

Blot: Sin CasN17 HA

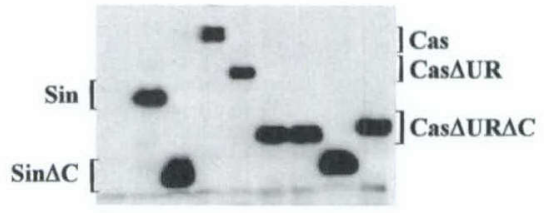

Blot: $\quad$ Cas-N17

FIG. 2. Sin and Cas associate with and are phosphorylated by c-Src. (A) 293 cells were cotransfected with a full-length or truncated Sin or Cas expression vector $(1 \mu \mathrm{g}$ of each) and a c-Src expression plasmid, the pEVX empty vector used to express Src, or the c-SrcK295R kinase mutant ( $2 \mu \mathrm{g}$ of each). Cell lysates were subjected to immunoprecipitation (IP) using anti-Src antiserum, and Western blots of the immunoprecipitates were blotted with pY20, an antibody against phosphotyrosine. In lane 1 , cells were transfected with pEBB vector backbone used to express Sin and Cas proteins; lanes 2 to 9 contain the different Sin and Cas proteins as shown at the bottom. (B) 293 cells were transfected with Src and Sin or Cas expression constructs as in panel A. Untransfected controls (U) were included to compare the levels of endogenous versus overexpressed Src. Cell lysates were immunoprecipitated with Src antibody; immune complexes were separated by SDS-PAGE, transferred to nitrocellulose, and blotted with antibody pY416, which recognizes the active form of Src (top panel). The blots were stripped and reprobed with anti-Src antibody to determine the relative levels of Src in the different lanes (lower panel). (C) The top panel represents total lysates from cells transfected with $1 \mu \mathrm{g}$ each of the Sin and Cas proteins on a Western blot probed with Sin-, Cas-, or HA-specific antibodies. The bottom panel contains the same extracts blotted with the CasN-17 antibody. Protein bands on the different blots were visualized using horseradish peroxidase-conjugated secondary antibody and ECL reagents. All blots were exposed on film for the same amount of time $(10 \mathrm{~s})$.

SRE- and AP-1-dependent transcription was activated 7- and 12-fold, respectively, when c-Src and full-length Sin were coexpressed (Fig. 3A and B, top, lanes 2), whereas full-length Cas had no effect (Fig. 3A and B, lanes 4). On the other hand, $\operatorname{Sin} \Delta \mathrm{C}$ (Fig. 1A) greatly stimulated Src-dependent activation of both promoters (about 33- and 34-fold [Fig. 3A and B, lanes 3]). Other Sin constructs that contained all the Y motifs as well as the second Src SH3-binding site, but lacked the conserved C terminus, behaved similarly to $\operatorname{Sin} \Delta C$ (data not shown), consistent with a negative regulatory role for the $\mathrm{C}$ terminus of $\mathrm{Sin}$.

In parallel experiments, we also tested Cas deletion mutants (Fig. 1A) for the ability to activate Src. We found that deletion of the internal unique domain of Cas (Cas $\Delta U R$ ), like the full-length protein, had little effect on the ability of this protein to activate transcription (Fig. 3A and B, lanes 5). The lack of an effect on transcriptional activation by Cas and Cas $\Delta U R$ correlated with little or no effect on Y416 phosphorylation and therefore Src activation (Fig. 2B, lanes 4 and 5), despite the fact that these proteins associated with and were phosphorylated by Src (Fig. 2A, lanes 4 and 5).
Introduction of an additional deletion that removed the $\mathrm{C}$ terminus of Cas (Cas $\Delta U R \Delta C$ ) resulted in a protein that induced transcription of both SRE and AP-1 promoters to levels similar to that of full-length Sin (10-fold [Fig. 3A and B, lanes 6]). This suggests that, as for Sin, the conserved $\mathrm{C}$ terminus of Cas is involved in the negative regulation of the molecule. However, although this protein grossly resembled $\operatorname{Sin} \Delta \mathrm{C}$ and activated Src to the same extent as $\operatorname{Sin} \Delta \mathrm{C}$ (Fig. 2B, lanes 3 and 6 ), it was less potent than $\operatorname{Sin} \Delta \mathrm{C}$ in inducing transcription. To exclude the possibility that this effect was due to the lower affinity of the Cas proline-rich motif for the Src SH3, we exchanged the proline motif of Cas for that of Sin (Cas $\Delta \mathrm{UR} \Delta \mathrm{CP}^{*}$ [Fig. 1A]). This substitution had no greater effect on Src-dependent transcriptional activation than unmodified Cas $\Delta U R \Delta C$, suggesting that the Sin and Cas proline-rich motifs exhibit similar affinities for the Src SH3 domain (Fig. 3A and B, lanes 7). As with phosphorylation of the different Sin and Cas proteins, we found that the effect of these proteins on transcriptional activation was dependent on c-Src, since no induction of the SRE- and AP-1-luciferase reporters was ob- 
A

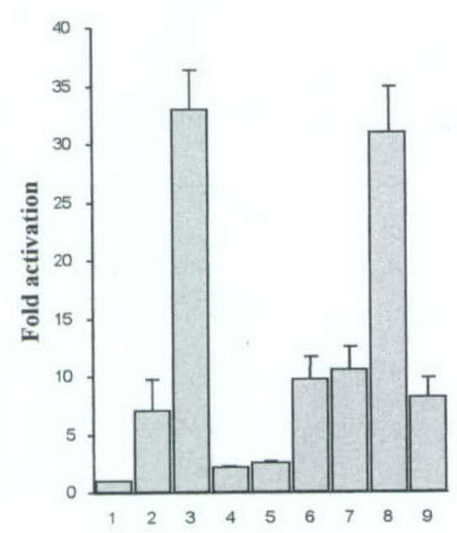

c-SrcK295R

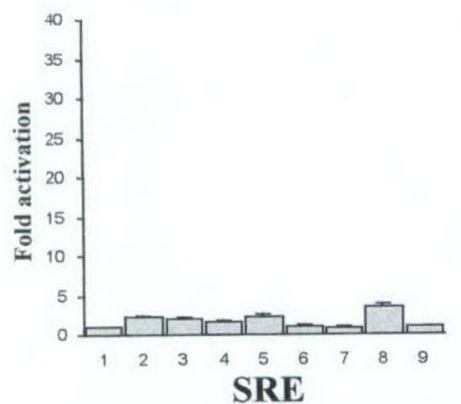

B

c-Src

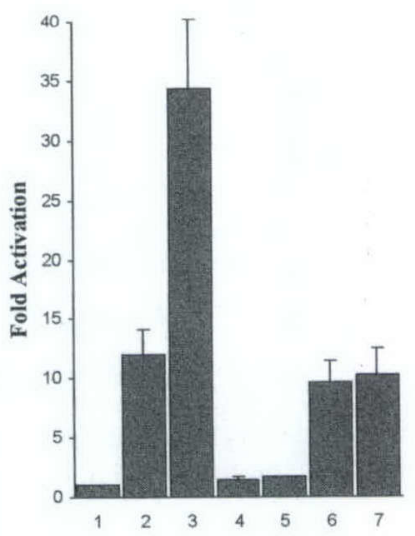

$3 \operatorname{Sin} \Delta \mathrm{C}$

$4 \mathrm{Cas}$

5 Cas $\Delta U R$

6 Cas $\Delta U R-\Delta C$

7 Cas $\triangle \mathrm{UR}-\Delta \mathrm{CP} *$

$8 \operatorname{Sin} \triangle \mathrm{C}-\mathrm{HA}$

9 Cas $\triangle$ UR $\Delta$ C-HA

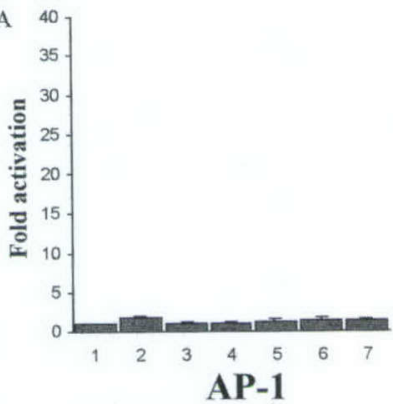

FIG. 3. The Sin and Cas proteins mediate differential activation of Src signaling. 293 cells were cotransfected as in Fig. 2 with a Sin or Cas expression construct (as shown, lanes 2 to 9) and wild-type c-Src (A and B, top) or the Src kinase mutant (A and B, bottom); $1 \mu \mathrm{g}$ of luciferase reporter construct containing the SRE (left) or AP-1 (right) promoter was included in the transfection mix, along with $\beta$-galactosidase expression plasmid ( $1 \mu \mathrm{g}$ ). Luciferase activity was measured as described in Materials and Methods. The results represent the average of at least five experiments and are expressed as fold activation relative to the values obtained with the vector backbone ( $\mathrm{pEBB})$ that was used to express Sin and Cas proteins and was given a value of 1 . The results shown represent the mean \pm standard deviation.

served in the presence of the SrcK295R kinase mutant (Fig. 3A and $\mathrm{B}$, bottom).

Our data showing that deletion of the $\mathrm{C}$ termini of Sin and Cas leads to increased Src activation (Fig. 2A and B) suggest that Sin and Cas may themselves be regulated through intra- or intermolecular interactions. Consistent with this observation, addition of GST or an HA tag to either the $\mathrm{N}$ or $\mathrm{C}$ terminus of Sin gives rise to a full-length $\mathrm{Sin}$ protein that activates Src to levels similar to those observed with the truncated Sin protein (reference 1 and unpublished observations). Thus, to examine functional differences between full-length and truncated Sin and Cas proteins, structural modifications as a result of epitope tagging were avoided. However, since the truncated Sin and Cas proteins are already deregulated, we generated HA-tagged $\operatorname{Sin} \Delta \mathrm{C}$ and $\operatorname{Cas} \Delta \mathrm{UR} \Delta \mathrm{C}$ and tested their ability to bind to and activate Src signaling. We found that although the two molecules were expressed at similar levels (Fig. 2C, upper panel, lanes 8 and 9) and associated with Src to similar extents (Fig. 2A, upper panel, lanes 8 and 9), Cas $\Delta U R \Delta C$ was still less potent than $\operatorname{Sin} \Delta \mathrm{C}$ in activating SRE-dependent transcription (Fig. 3A, lanes 8 and 9). Increases in the concentration of transfected plasmid DNA expressing different Cas proteins had no additional effect on their ability to induce Src signaling (data not shown). Thus, these results show that although all of the proteins we used associate with and are phosphorylated by
Src, they differ quantitatively in the ability to activate Src and mediate Src signaling.

Sin and Cas-induced Src signaling is independent or downstream of Ras. Given the quantitative differences between Sin and Cas, we next examined whether these proteins utilize the same or different pathways to propagate Src signaling. It has been previously shown that the small GTP-binding protein Ras mediates signaling by constitutive active and oncogenic Src alleles $(26,51,67)$. Thus, we further evaluated the pathway(s) that is activated as a result of Sin and Cas binding to Src and examined whether Ras also plays a role in Sin-Cas-induced Src signaling.

Tyrosine kinase-stimulated cell growth and proliferation in response to growth factor receptor stimulation induces the activity of the Ras proto-oncogene and the extracellular signalregulated kinases ERK1 and -2 $(23,49,71,91)$. To assess the role of Ras and ERK in ligand-mediated Src signaling, we used a well-characterized dominant negative inhibitor of Ras (RasN17) (30) and examined its effect on Sin-Cas-induced and Src-dependent ERK1,2 activation. For these experiments we used proteins that were the most active in inducing transcriptional activation, namely, $\operatorname{Sin} \Delta \mathrm{C}$ and $\operatorname{Cas} \Delta \mathrm{UR} \Delta \mathrm{C}$ (Fig. 1; Fig. $3 \mathrm{~A}$ and $\mathrm{B}$, top).

Using an antibody that specifically recognizes the phosphorylated, active forms of ERK1,2, we found that both $\operatorname{Sin} \Delta \mathrm{C}$ and 
A

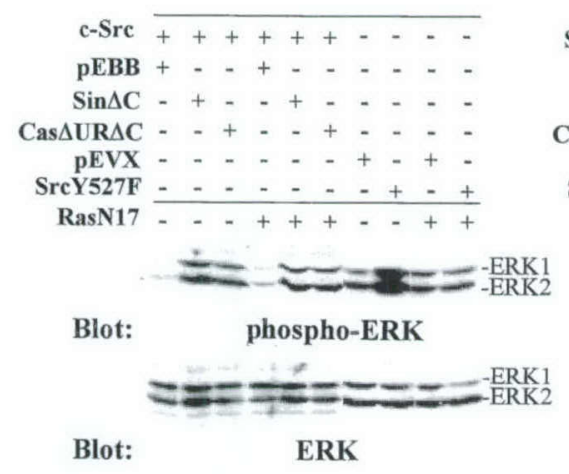

B

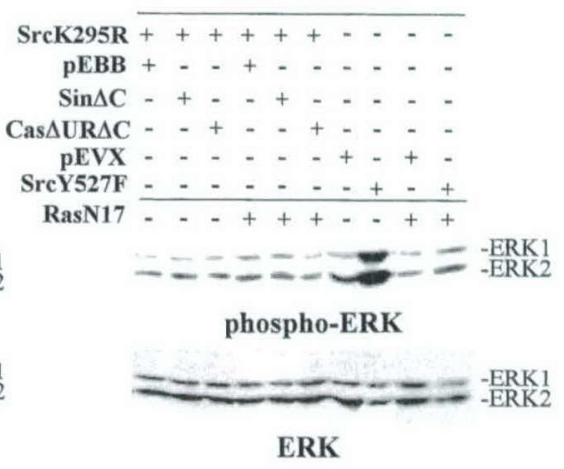

C

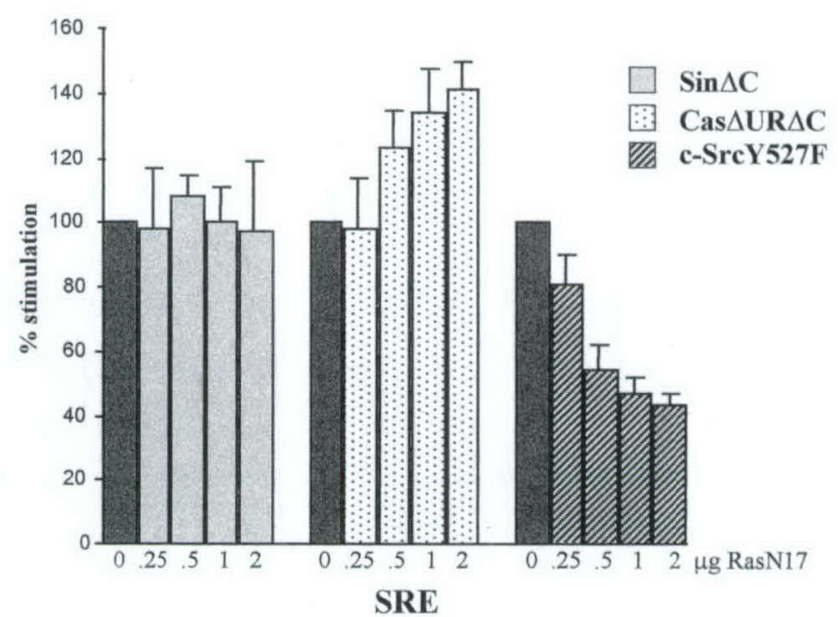

FIG. 4. Induction of ERK1,2 phosphorylation and SRE-dependent transcriptional activation by Cas and Sin are Ras independent. (A) 293 cells were transfected with c-Src and pEBB vector or Sin $\Delta C$ or Cas $\Delta U R \Delta C$ as shown. Also cells were transfected with SrcY527F alone, or empty vector used to express this Src mutant (pEVX), in the presence of the Ras inhibitor $(2 \mu \mathrm{g})$ or the Zipneo empty vector $(2 \mu \mathrm{g})$ as shown. Total cell extracts were normalized for protein content, resolved by SDS-PAGE, and blotted with anti-phospho-ERK antibody (E-4) (top panel). The lower panel represents a Western blot probed with anti-ERK antibody that recognizes both phosphorylated and unphosphorylated forms of ERK. (B) 293 cells were transfected as above but in the presence of the Src kinase mutant or SrcY527F as a positive control and in the presence of RasN17 inhibitor or empty vector. Western blots of cell extracts were processed as in panel A. (C) Cells were transfected with c-Src and Sin $\Delta C$ or Cas $\Delta U R \Delta C$ or with SrcY527F alone, as shown, with increasing concentrations of the RasN17 inhibitor in the presence of the SRE-luciferase reporter. Percent stimulation is relative to the activation of luciferase in cells transfected with c-Src and Sin $\Delta C$ or Cas $\Delta U R \Delta C$, or SrcY527F in the presence of the Zipneo empty vector $(2 \mu \mathrm{g})$ used to express the RasN17 inhibitor, each of which was given a value of 100 (dark gray bars). Actual fold activation in the absence of the RasN17 inhibitor (dark gray bars) was $32 \pm 3.2$ for $\operatorname{Sin} \Delta C, 14 \pm 2.4$ for Cas $\Delta U R \Delta C$, and $79 \pm 16$ for SrcY527F. The percent stimulation obtained with c-Src and Sin $\Delta C$ or with Cas $\Delta \mathrm{UR} \Delta \mathrm{C}$ or SrcY527F in the presence of the dominant negative inhibitors is the mean \pm standard deviation. The data represent the average of at least five experiments.

Cas $\Delta \mathrm{UR} \Delta \mathrm{C}$ induced ERK phosphorylation when coexpressed with c-Src (Fig. 4A, top panel). However, the induction of ERK phosphorylation by $\operatorname{Sin} \Delta C$ and Cas $\Delta U R \Delta C$ was not sensitive to the RasN17 dominant negative inhibitor, suggesting that the activation of ERK1,2 was downstream or independent of Ras (Fig. 4A, top panel). This result is in contrast to published observations showing Ras to be the main upstream positive regulator of ERK $(23,49,71,91)$. In addition, these results differ from published data that show Ras to act downstream of oncogenic src alleles $(26,51,67)$. Consistent with the published observations, in our system we found that activation of ERK1,2 by the constitutively active Src mutant (SrcY527F) was blocked by the RasN17 inhibitor (Fig. 4A, top panel). The effects of Sin and Cas on increased ERK1,2 phosphorylation were specific given that probing the blots with an ERK antiserum which recognizes both the phosphorylated and nonphosphorylated forms of the kinases revealed similar levels of the proteins (Fig. 4A, bottom panel). The effect of $\operatorname{Sin} \Delta \mathrm{C}$ and Cas $\Delta U R \Delta C$ on ERK1,2 activation was Src dependent, since coexpression of the SrcK295R kinase mutant with $\operatorname{Sin} \Delta \mathrm{C}$ and Cas $\Delta U R \Delta C$ did not induce ERK phosphorylation (Fig. 4B, top panel). In the same experiment, expression of the constitutively active SrcY527F mutant resulted in ERK1,2 activation; ERK1,2 phosphorylation was again blocked by the RasN17 inhibitor. Equal levels of total ERK were present in all lanes (Fig. 4B, bottom panel). Our data therefore suggest that the Sin and Cas proteins activate ERK1,2 independently or downstream of Ras and that this effect is dependent on Src kinase activity. 
In addition to ERK activation, we also tested the effect of the RasN17 inhibitor on SRE-dependent transcriptional activation. Consistent with the ERK activation described above, $\operatorname{Sin} \Delta \mathrm{C}$ and Cas $\Delta \mathrm{UR} \Delta \mathrm{C}$-mediated, Src-dependent SRE activation was not blocked by the Ras inhibitor (Fig. 4C), whereas activation of the SRE-luciferase reporter by the constitutively active SrcY527F mutant was inhibited in a concentration-dependent manner ( $\sim 60 \%$ inhibition [Fig. $4 \mathrm{C}]$ ). Thus, these data show that activation of ERK and SRE-mediated transcription as a result of $\operatorname{Sin} \Delta C$ and $\operatorname{Cas} \Delta U R \Delta C$ binding to $\mathrm{c}-\mathrm{Src}$ occur through a mechanism that is Ras independent. In addition, these results suggest that signaling through Sin-Cas-activated Src and signaling through constitutively active Src proteins are mediated by different mechanisms.

Sin- and Cas-induced Src signaling is mediated by Crk. In vitro studies have previously shown that a phosphorylated tyrosine within a YDVP consensus sequence (Y motif) exhibits preferential binding to the $\mathrm{c}-\mathrm{Crk} \mathrm{SH} 2$ domain (78). $\mathrm{c}-\mathrm{Crk}$ is a Grb2-like small adapter molecule with no known enzymatic activity, consisting mainly of modular regions such as $\mathrm{SH} 2$ and SH3 domains (31). Three of the Sin Y motifs and the majority of the Cas Y motifs are of the YDVP consensus, suggesting a c-Crk SH2 binding specificity (Fig. 1A). Consistent with the in vitro data, Sin and Cas interact with endogenous c-Crk in a c-Src- and phosphotyrosine-dependent manner $(1,72)$.

To determine whether the association of phosphorylated $\operatorname{Sin} \Delta \mathrm{C}$ and $\operatorname{Cas} \Delta \mathrm{UR} \Delta \mathrm{C}$ proteins with endogenous c-Crk was functionally significant, we tested whether an SH3 domain mutant of Crk could inhibit Sin-Cas-induced transcriptional activation. This c-Crk mutant has been previously described and was used to successfully block activation of ERK1 by oncogenic $\mathrm{v}-\mathrm{Abl}(81)$. The $\mathrm{W} 170 \mathrm{~K}$ point mutation within the $\mathrm{SH} 3$ domain of Crk acts by interfering with binding to downstream proline-rich containing effector molecules such as the guanine nucleotide exchange factor (GEF) C3G (82). As shown in Fig. 5A, the Crk mutant effectively inhibited SREdependent transcriptional activation by $\operatorname{Sin} \Delta \mathrm{C}$ and $\operatorname{Cas} \Delta \mathrm{UR} \Delta \mathrm{C}$ in a concentration-dependent manner, suggesting that c-Crk is required for Src signaling mediated by these proteins. The effects of the Crk inhibitor on Sin-Cas-induced Src signaling were specific, particularly when lower concentrations of inhibitor DNA were used. A small inhibition of v-Raf-induced SREluciferase activation was observed at the highest concentration of the inhibitor $(2 \mu \mathrm{g})$, suggesting a nonspecific effect possibly due to toxicity (Fig. 5A). Similar results were obtained using the AP-1 promoter (data not shown).

The experiments described above suggest that Src signaling is dependent on the substrates recruited by the conserved $\mathrm{Y}$ motifs of Sin and Cas. To further examine whether Crk recruitment by the YDVP motifs mediates the signaling effects of Sin, we introduced point mutations in the three YDVP motifs of $\operatorname{Sin} \Delta \mathrm{C}$, at positions Y148, Y188, and Y253. We concentrated on Sin because it contains fewer YDVP motifs than Cas. We found that double mutants containing different combinations of mutagenized tyrosine residues (as shown) or a single mutation on Y253 significantly blocked the ability of $\operatorname{Sin} \Delta \mathrm{C}$ to activate SRE-dependent transcription (Fig. 5B). In addition, a mutant containing substitutions on all three tyrosines (Y148, Y188, and Y253) inhibited about $90 \%$ of Src-induced transcriptional activation (Fig. 5B). Similar results were also obtained with the AP-1 reporter construct (data not shown).

The ability of the triple mutant to block transcription correlated with reduced phosphorylation of this protein by Src (Fig. 5C, middle panel, lane 6). This was despite the fact that the mutant was expressed to levels similar to those observed with wild-type $\operatorname{Sin} \Delta \mathrm{C}$ (Fig. 5C, upper panel, lane 6) and asso- ciated with Src, albeit to a lesser extent than $\operatorname{Sin} \Delta C$ (Fig. 5C, lower panel, lane 6). These results show that mutations within virtually identical motifs of $\operatorname{Sin} \Delta \mathrm{C}$ can behave differently in terms of mediating the effects of Src. These differences may be due to amino acids $\mathrm{N}$ terminal to the tyrosine that are involved in determining kinase specificity. Indeed, in vitro studies have shown that the presence of acidic amino acids (D or E) at positions -4 and $-3 \mathrm{~N}$ terminal to an unphosphorylated tyrosine residue correlates with Src-kinase specificity (77) (Fig. $5 \mathrm{C}$, bottom). Taken together, these data suggest that Crk recruitment by the YDVP motifs of Sin is important for Sinmediated Src signaling.

The Rap1 GTPase is involved in Cas- and Sin-induced Src signaling. It has been recently shown that the SH3 domain of c-Crk interacts with proline-rich sequences found on C3G (34, 46,82 ), a protein that promotes nucleotide exchange on the small GTP-binding protein Rap1 (38). In our system, we also found a Src-dependent association of endogenous Crk and $\mathrm{C} 3 \mathrm{G}$ with phosphorylated $\operatorname{Sin} \Delta \mathrm{C}$ and Cas $\Delta \mathrm{UR} \Delta \mathrm{C}$ (Fig. 6A). These interactions were dependent on the kinase activity of Src since the association of Sin and Cas with Crk and C3G was abolished in the presence of the Src kinase mutant (data not shown).

To address whether Rap1 was a downstream effector for Crk in our system, we used a dominant negative mutant of Rap1 that is analogous to the RasN17 inhibitor and blocks activation of the endogenous Rap1 protein (86). We found that, like the Crk inhibitor, Rap1N17 blocked Sin $\Delta C$ - and Cas $\Delta U R \Delta C$-induced transcriptional activation through the SRE-luciferase reporter, in a concentration-dependent manner (Fig. 6B). In the same experiments, SRE activation by $\mathrm{v}$-Raf was largely unaffected, particularly at lower concentrations of the inhibitor, suggesting that the effect of the Rap1 inhibitor is specific (Fig. 6B). Therefore, these results demonstrate that Rap1 acts downstream of phosphorylated $\operatorname{Sin} \Delta \mathrm{C}$ and $\operatorname{Cas} \Delta \mathrm{UR} \Delta \mathrm{C}$ to mediate Src signaling.

To further examine the involvement of Rap1 in Sin- and Cas-mediated Src signaling, we tested whether Src and $\operatorname{Sin} \Delta C$ or Cas $\Delta \mathrm{UR} \Delta \mathrm{C}$ coexpression resulted in increased levels of active, GTP-bound Rap1. For this purpose we used a recently developed technique that involves the use of the GST-RalGDS-RBD fusion protein in affinity binding assays. This molecule contains a fragment of the Rap1 effector RalGDS, which specifically binds to the effector-binding domain of activated, GTP-bound Rap1 $(32,90)$. We found that coexpression of $\operatorname{Sin} \Delta C$ or Cas $\Delta U R \Delta C$ with c-Src resulted in increased levels of active, GTP-bound Rap1 (Fig. 6C, upper panel). In the same experiment, we tested whether Ras was activated as a result of Sin-Cas-mediated activation of Src. To this end, we used GST fused to c-Raf-RBD, which contains a fragment of the Rasbinding domain of c-Raf, which is one of the downstream effector molecules for Ras (21). c-Raf-RBD specifically recognizes active GTP-bound Ras but not Rap1. We found that, in contrast to Rap1, coexpression of c-Src with $\operatorname{Sin} \Delta C$ or Cas $\Delta \mathrm{UR} \Delta \mathrm{C}$ did not induce Ras activation (Fig. 6C, bottom panel). This data are consistent with results for the dominant negative Ras and Rap inhibitors and further support the model that Sin- and Cas-induced activation of Src signaling is mediated exclusively by Rap1. These data further indicate that different signaling mechanisms are utilized by ligand-activated versus constitutively active Src.

Rap1 was originally discovered as a transformation suppressor of Ki-Ras (43), and it has been shown to antagonize Ras function in different cell systems $(9,10)$. However, in other cell types Rap1 has also been shown to have positive effects, i.e., induce proliferation and growth in Swiss 3 T3 cells $(29,96)$, 
A

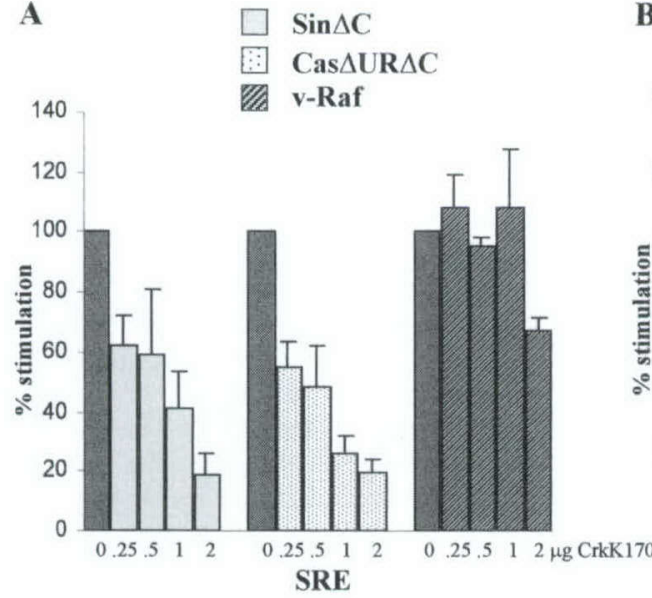

B

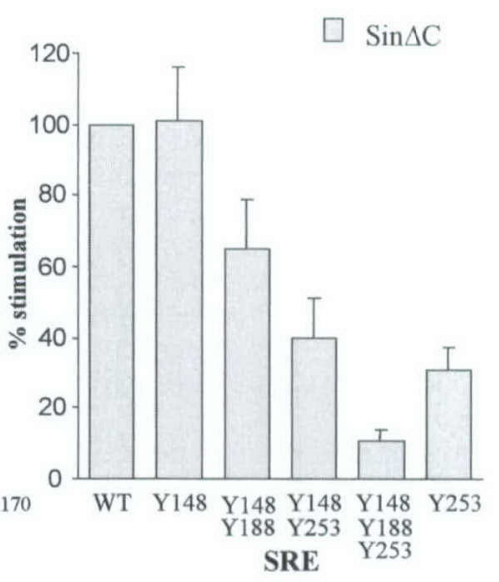

C

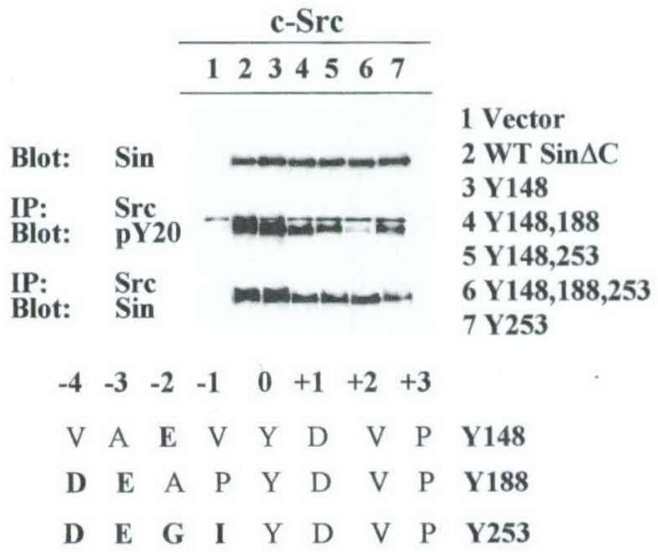

FIG. 5. The adapter Crk mediates Sin- and Cas-induced Src signaling. (A) 293 cells were cotransfected with c-Src ( $2 \mu \mathrm{g})$ and Sin $\Delta \mathrm{C}$ or Cas $\Delta \mathrm{UR} \Delta \mathrm{C}$ ( $1 \mu \mathrm{g}$ of each) or with a v-Raf expression plasmid $(2 \mu \mathrm{g})$ in the presence of empty pEBB vector or increasing concentrations of the CrkK170 inhibitor. Percent stimulation is relative to the activation of luciferase in cells transfected with c-Src and Sin $\Delta \mathrm{C}$ or Cas $\Delta \mathrm{UR} \Delta \mathrm{C}$, or v-Raf in the presence of the pEBB empty vector ( $2 \mu \mathrm{g})$ used to express the CrkK170 inhibitor, each of which was given a value of 100 (dark gray bars). Actual fold activation in the absence of the CrkK170 inhibitor (dark gray bars) was $39 \pm$ 11 for $\operatorname{Sin} \Delta \mathrm{C}, 12 \pm 2.8$ for Cas $\Delta \mathrm{UR} \Delta \mathrm{C}$, and $126 \pm 15$ for v-Raf. The percent stimulation obtained with c-Src and Sin $\Delta \mathrm{C}$ or with Cas $\Delta U R \Delta \mathrm{C}$ or v-Raf in the presence of the dominant negative inhibitors is the mean \pm standard deviation. The data represent the average of at least seven experiments. (B) 293 cells were cotransfected with c-Src and wild-type (WT) or mutant $\operatorname{Sin} \Delta \mathrm{C}(1 \mu \mathrm{g}$, as shown) in the presence of the SRE-luciferase reporter construct. Data from several experiments $(n=5)$ were averaged, and values for samples that expressed the mutant $\operatorname{Sin}$ proteins were normalized to the induction of luciferase activity observed with wild-type Sin $\Delta C$, which was given a value of 100 (actual increase with wild-type $\operatorname{Sin} \Delta \mathrm{C}$ was $42 \pm 4.7$-fold). The percent stimulation is the mean \pm standard deviation. (C) Lysates of 293 cells expressing c-Src and wild-type or tyrosine mutant Sin $\Delta \mathrm{C}$ were immunoprecipitated (IP) with anti-Src antibodies (middle and bottom panels). Immunoprecipitates were blotted and probed with antiphosphotyrosine antibody pY20 (middle) or anti-Sin antibody (bottom). Total cell extracts of the same samples were resolved by SDS-PAGE, and the membranes were blotted with anti-Sin antibody (top panel). Consensus sequences containing Y148, Y188, and Y253 are shown at the botton of panel B. Amino acids important for kinase specificity are shown in bold.

activate intermediates of the mitogen-activated protein (MAP) kinase cascade in PC12 cells $(86,95)$, and mediate bombesininduced phosphorylation of ERK (66). These observations are consistent with our results showing that Rap1 and ERK are activated in response to ligand-induced activation of Src. To show that ERK can be directly activated in our system, we expressed a constitutively active form of Rap1, Rap1V12, or wild-type Rap1 in 293 cells and assayed for increases in ERK1,2 phosphorylation. We found that expression of either RapV12 or wild-type Rap1 leads to increased ERK phosphorylation (Fig. 6D, upper panel), while equal levels of total ERK were observed in all lanes (Fig. 6D, lower panel). Thus, these data suggest that overexpressed Rap1 can indeed activate ERK in 293 cells.

We next examined the effect of the different inhibitors on ligand-induced JNK/stress-activated protein kinase (SAPK)mediated, AP-1-dependent gene expression. We found that, as with the SRE promoter, AP-1-dependent transcriptional activation by $\operatorname{Sin} \Delta \mathrm{C}$ and $\operatorname{Cas} \Delta \mathrm{UR} \Delta \mathrm{C}$ was Ras independent and was instead mediated by Crk and Rap1 (data not shown). However, we were unable to detect direct activation of the JNK/SAPK protein using either an antibody against the phosphorylated form of this kinase or in vitro phosphorylation of GST-c-Jun (data not shown). In addition, dominant negative inhibitors of intermediates of the JNK pathway such as JNKK1 and JNK had no effect on AP-1mediated gene expression. However, a dominant inhibitor of MEK-1 blocked both SRE- and AP-1-mediated transcriptional activation by all three ligands (data not shown). Thus, it appears that activation of gene expression through the 

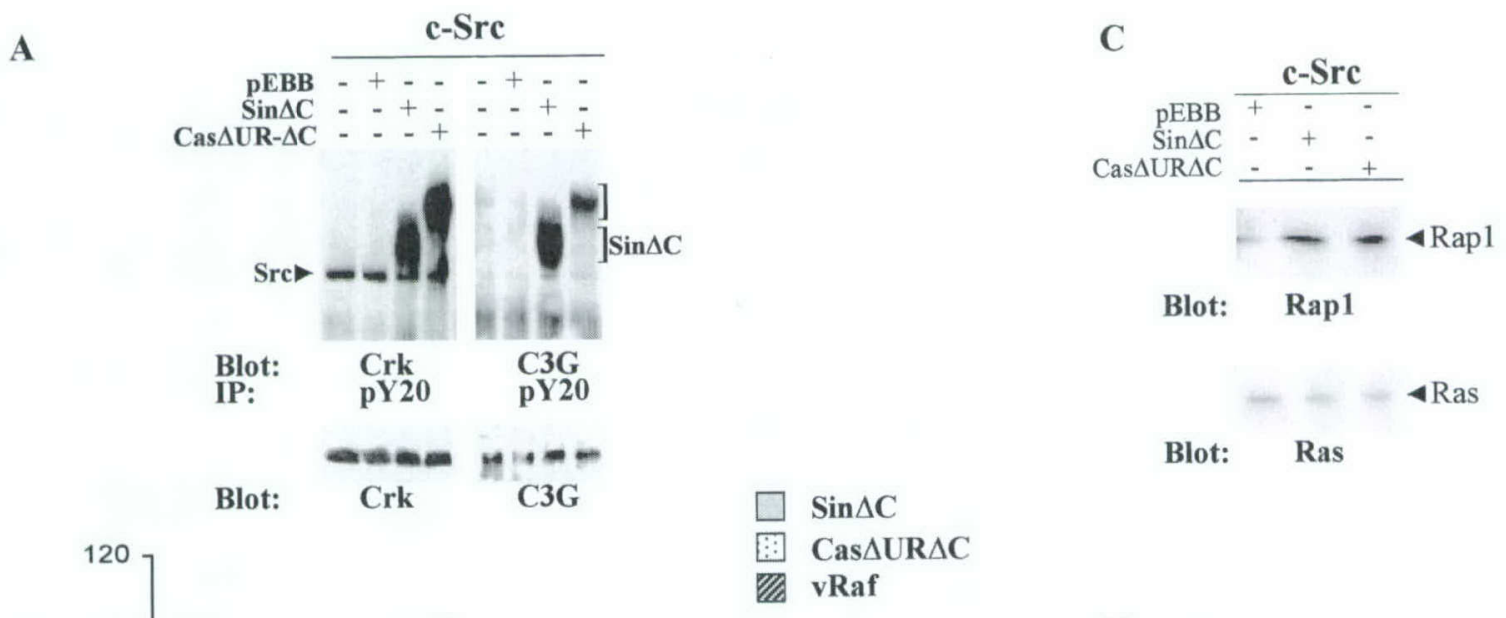

B

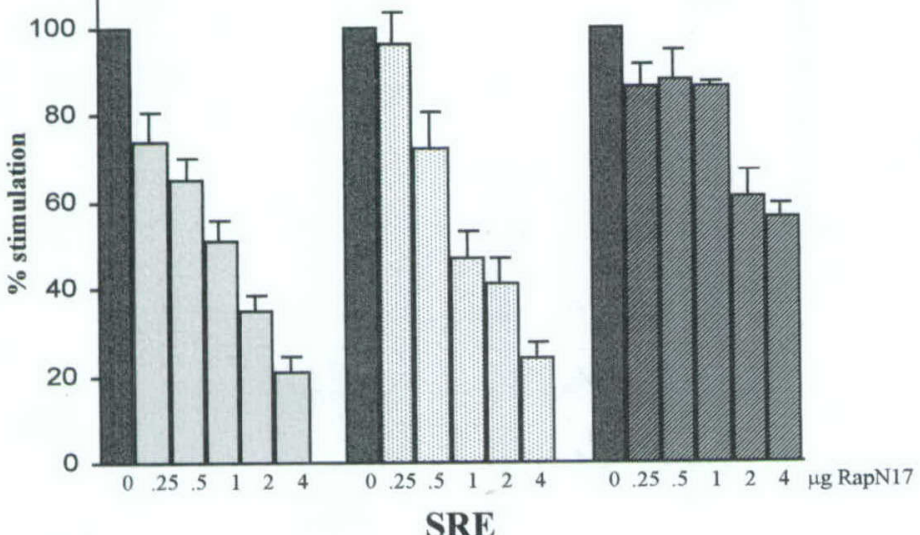

D

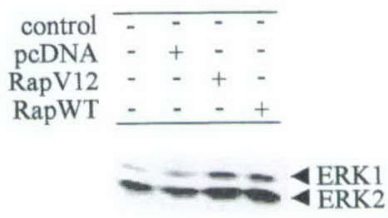

Blot: phospho-ERK

Blot:

ERK

FIG. 6. Sin- and Cas-induced Src signaling is mediated by the Rap1 GTPase. (A) 293 cell lysates expressing c-Src and Sin $\Delta C$ or Cas $\Delta$ UR $\Delta C$ were immunoprecipitated with Crk-specific (left) or C3G-specific (right) antibodies. Immunoprecipitates (IP) were blotted and probed with antibody pY20. Membranes were then stripped and blotted with anti-Crk (bottom left) or anti-C3G (bottom right) antibodies. (B) 293 cells were transfected as in Fig. 5A along with increasing concentrations of the RapN17 inhibitor as shown. Percent stimulation is relative to the activation of luciferase in cells transfected with c-Src and Sin $\Delta \mathrm{C}$ or Cas $\Delta \mathrm{UR} \Delta \mathrm{C}$, or $\mathrm{v}-\mathrm{Raf}$ in the presence of the pcDNA empty vector $(4 \mu \mathrm{g})$ used to express the Rap1N17 inhibitor, each of which was given a value of 100 (dark gray bars). Actual fold activation in the absence of the RapN17 inhibitor (black bars) was $26 \pm 6.5$ for Sin $\Delta \mathrm{C}, 10 \pm 3.3$ for Cas $\Delta \mathrm{UR} \Delta \mathrm{C}$, and $86 \pm 5.2$ for v-Raf. The percent stimulation obtained with c-Src and Sin $\Delta C$ or with Cas $\Delta U R \Delta C$ or $v$-Raf in the presence of the dominant negative inhibitors is the mean \pm standard deviation. The data represent the average of at least six experiments. (C) 293 cell extracts expressing c-Src and vector backbone, $\operatorname{Sin} \Delta \mathrm{C}$, or Cas $\Delta \mathrm{UR} \Delta \mathrm{C}$ were incubated with GST-RalGDS-RBD or GST-Raf-RBD; the protein complexes were harvested, separated by SDS-PAGE, and transferred onto nitrocellulose membranes. The membranes were blotted with Rap1-specific (top) or Ras-specific (bottom) antibodies. Protein bands were visualized using ECL. (D) Total extracts from untransfected or cells expressing pcDNA vector, constitutively active RapV12, or wild-type Rap (RapWT) were blotted with anti-phospho-ERK (top) or anti-ERK (bottom). Protein bands were visualized using ECL.

AP-1 site is not through independent activation of the JNK pathway but rather the result of ERK-mediated gene expression.

Signaling through the constitutively active SrcY527F mutant is mediated by both Ras and Rap1. The lack of an inhibitory effect with the Ras inhibitor on Sin and Cas induced activation of c-Src is surprising in that SRE-mediated transcription in response to tyrosine kinase activation is predominantly the result of Ras-mediated activation of the ERK1,2 MAP kinases $(23,49,71,91)$. It has also been shown that transcriptional activation induced by constitutively active and oncogenic forms of Src is Ras dependent $(45,63,67)$. Consistent with these observations, we found that the Ras inhibitor blocked SrcY527F-induced SRE activation (Fig. 4C). We next examined whether the SrcY527F constitutively active mutant could activate the Crk-Rap1 signaling pathway, using dominant negative inhibitors and assaying for Rap activation. We found that both the CrkK170 and RapN17 mutants inhibited SrcY527F-induced transcriptional activation of the SRE promoter in a concen- tration-dependent manner (Fig. 7A), suggesting that both the Ras and Rap1 signaling cascades are utilized by oncogenic Src. Consistent with this result, cotransfection of SrcY527F with both RasN17 and RapN17 resulted in maximal inhibition of transcription even at the lowest concentrations of Rap and Ras inhibitor DNA $(0.25 \mu \mathrm{g}$ of each [Fig. 7A]). In addition, in contrast to Sin and Cas, which preferentially activated Rap1 but not Ras, we found that expression of the SrcY527F mutant resulted in increased GTP-bound levels of both Ras and Rap1 (Fig. 7B). Furthermore, as with the RasN17 inhibitor (Fig. 4A), we found that SrcY527F-mediated activation of ERK1,2 phosphorylation was also sensitive to the RapN17 inhibitor, whereas v-Rafinduced ERK phosphorylation was unaffected under the same conditions (Fig. 7C). Thus, these data suggest that the oncogenic SrcY527F mutant utilizes at least two separate cascades to ERK phosphorylation and SRE promoter activation, whereas signaling through ligand-activated Src is more directed and is primarily mediated by Rap1. 


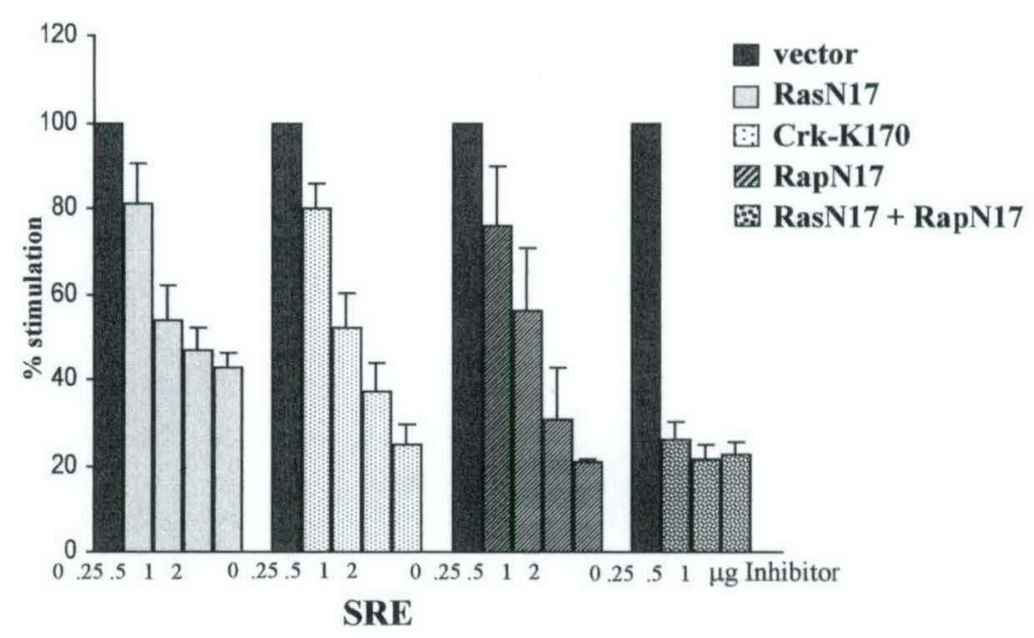

B

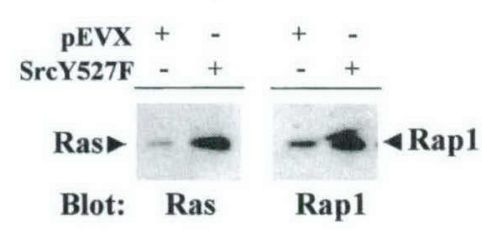

C

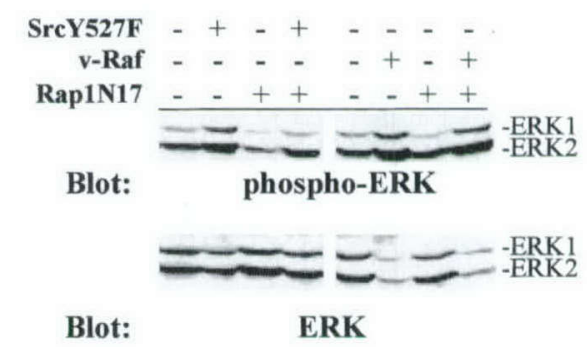

FIG. 7. Signaling through the constitutively active SrcY527F mutant is mediated by both Ras and Rap. (A) 293 cells were transfected with SrcY527F in the presence of the Ras, Crk, and Rap inhibitors and in the presence of the SRE-luciferase reporter. Percent stimulation represents the average data from four experiments and was determined from samples expressing SrcY527F in the presence of empty vectors (pZipneo, pEBB, and pcDNA) that were used to express the inhibitors (dark gray bars). Actual activation was $79 \pm 16$-fold in the presence of Zipneo, $130 \pm 28$-fold for pEBB, and $40 \pm 6.7$-fold for pCDNA. The difference in the SrcY527F fold activation observed in the presence of the different vectors is likely due to promoter competition of the transfected plasmids. Luciferase activation in the presence of the different inhibitors is expressed as a percentage of the dark gray bar controls \pm standard deviation. (B) Cell extracts expressing the pEVX vector or SrcY527F were incubated with GST-RalGD-RBD or GST-Raf-RBD; protein complexes were separated, transferred to membranes, and blotted with Rap- or Ras-specific antibodies, respectively. Protein bands were visualized using ECL. (C) 293 cell extracts expressing SrcY527F or v-Raf were assayed for ERK1,2 activation in the presence of the RapN17 inhibitor. SrcY527F or v-Raf $(2 \mu \mathrm{g}$ of each) and RapN17 $(4 \mu \mathrm{g})$ expression plasmids were used. Cell lysates were analyzed as described for Fig. 4 , using phospho-ERK- and ERK-specific antibodies.

\section{DISCUSSION}

Cas and Sin mediate Src-dependent transcriptional activation through the ERK MAP kinase. The Src-SH3 domain is important for c-Src regulation and signaling, and this domain is thought to participate in signaling specificity by determining the substrate selectivity of the enzyme (28). In this study we used the natural c-Src ligands Sin and Cas to activate Src and examine the mechanisms that mediate signaling under these conditions. In the experiments described above, we found that phosphorylated Sin and Cas act downstream of Src to activate transcription through an SRE-containing promoter. SRE-dependent transcriptional activation has been shown to depend on activation of Ras and the ERK1,2 MAP kinases. In our system, activation of transcription through the SRE was Ras independent and was instead mediated by the related protein Rap1. Our results for the first time implicate Rap1 in Src kinase signaling and show that this $\mathrm{G}$ protein acts downstream of phosphorylated Sin and Cas to activate ERK and SREdependent transcription.

Cas has been the focus of many studies, which show this protein to mediate a variety of cellular processes. Recent evidence suggests that extracellular signals, such as integrin engagement, lead to the formation of an active Cas-Crk signaling complex, which regulates cell migration and survival $(17,41)$, cell cycle progression (60), and transcriptional activation (24, 35). These responses are mediated by the ERK and JNK MAP kinase cascades, which are activated by distinct, upstreamacting signaling complexes. Thus, activation of the ERK1,2 kinases in response to extracellular stimuli is mediated by the Crb2-Sos or the Shc-Grb-2-Sos signaling modules, whereas activation of the JNK MAP kinase is mediated by the formation of an active Cas-Crk complex $(17,60,97)$. In the integrin receptor system, Cas-Crk coupling is facilitated by upstreamacting Src and FAK, and this coupling results in the activation of the small GTP-binding protein Rac. Activation of Rac, in turn, regulates JNK activation and cell invasion and adhesion (17). In our system, coupling of Cas and Sin with Crk as a result of Src-mediated phosphorylation of Cas and Sin induced ERK but not JNK activation. In addition, a dominant negative mutant of Rac was not able to block Cas-Sin-induced SRE- or 
AP-1-dependent transcriptional activation (unpublished observations).

The lack of an effect of Src-mediated phosphorylation of Sin-Cas and Crk coupling on JNK activation was unexpected given existing evidence suggesting that Src-induced Cas phosphorylation in response to integrin stimulation mediates integrin-dependent JNK activation $(8,60,74,87)$. However, to our knowledge there is no evidence that directly links Src-mediated Cas phosphorylation to JNK activation. On the other hand, consistent with our results showing that Cas and Sin are not involved in Src-dependent JNK activation is evidence suggesting that a dominant negative inhibitor of Cas does not inhibit $\mathrm{v}$-Src-induced JNK activation (24). It is possible therefore, that other kinases act downstream of Src to phosphorylate Cas and activate JNK in response to integrin stimulation. Indeed, it has been shown that although Cas phosphorylation is abolished in $\mathrm{Src}^{-1-}$ cells, expression of a truncated, kinase-deficient Src protein in the same cells restores Cas phosphorylation and promotes Cas and FAK association and FAK-mediated phosphorylation of Cas (74). These observations suggest that there are differences in the formation of signaling complexes in the case of activated Src (either oncogenic or ligand induced) and activated integrin receptors that may result in different signaling mechanisms through these proteins. Thus, additional elements may be recruited downstream of activated integrin receptors versus activated Src to induce JNK activation.

In contrast to the inability of the Cas and Sin proteins to activate JNK, we found that the ERK1,2 kinases were efficiently activated by these proteins in a Src-dependent manner (Fig. 4A and B). Although it has been suggested that Srcmediated phosphorylation of Cas may mediate ERK2 activation (74), the majority of existing evidence shows that Cas-Crk coupling in response to extracellular stimuli functions upstream of JNK $(17,60,97)$. In addition, integrin- and cytokineinduced activation of ERK1,2 is mediated predominantly by the Grb2-Sos complex, and dominant negative Cas or Crk mutants do not block ERK activation (8). Furthermore, Src has been shown to mediate ERK activation in response to integrin stimulation either by promoting binding of Grb2-Sos to FAK or Pyk2 or by promoting formation of the Shc-Grb2Sos complex (8). It has been previously suggested that Src may activate ERK through FAK-mediated phosphorylation of Cas in response to fibronectin, in the absence of Grb2 binding to FAK (74). Our experiments revealed that a dominant negative mutant of Ras had no effect on Sin- and Cas-mediated ERK phosphorylation and induction of transcription, whereas a dominant negative Crk mutant inhibited SRE-dependent transcriptional activation (Fig. 5), as well as ERK activation (data not shown). In the same experiments we also found that constitutively active Src can activate ERK through two distinct pathways: one that utilizes the Grb2-Sos-Ras cascade and another that involves the Crk-C3G-Rap1 signaling complex (Fig. 4 and $7 \mathrm{C}$ ). Thus, it is possible that under different stimulating conditions these pathways either independently or in concert mediate ERK activation and need not be mutually exclusive. The experiments presented here show that the Cas-Sin-CrkRap1 pathway can indeed activate the ERK cascade and mediate signaling downstream of activated Src.

Src SH3-binding proteins differentially activate c-Src signaling. In the experiments described above, we found that although the different $\mathrm{Sin}$ and Cas proteins bound to and were phosphorylated by Src to similar levels, they elicited quantitatively different responses as measured by transcriptional activation. Despite these quantitative differences, both Sin and Cas mediated Src signaling through the activation of the Crk-Rap1ERK1,2 signaling cascade.
The quantitative differences in transcriptional activation we observe with the Sin and Cas proteins do not appear to depend on differential binding affinities of these molecules for the Src $\mathrm{SH} 3$ domain. This is based on the observation that substitution of the Cas proline-rich motif with that of Sin did not increase the levels of transcriptional activation by Cas $\Delta \mathrm{UR} \Delta \mathrm{C}$ (Fig. $3 \mathrm{~A}$ and $\mathrm{B}$, lanes 7). Alternatively, the quantitatively different effects of $\operatorname{Sin} \Delta C$ and $\operatorname{Cas} \Delta U R \Delta C$ on transcription could be due to the tyrosine-containing motifs of these proteins. This hypothesis is supported by the observation that Sin-dependent transcriptional activation is dependent on specific YDVP motifs and that these motifs are not functionally equivalent (Fig. 5B). For example, Y188 and Y253 seem to have the strongest effect on the ability of Sin to mediate Src signaling (Fig. 5B). This correlates with the presence of amino acid positions -4 to $-1 \mathrm{~N}$ terminal to Y188 and Y253 that contain the acidic amino acids D and $E$, which have been shown to be important for Src kinase specificity (Fig. 5C) (77). Moreover, the sequence upstream of Y253 (DEGI) is identical to the sequence described as optimal for Src kinase recognition by Songyang et al. (77) (Fig. 5C). In contrast, amino acids upstream of Y148 contain only one E residue (Fig. 5C), and a mutation on Y148 has no effect on transcriptional activation (Fig. 5B).

Although Cas contains more YDVP motifs than Sin, it was not as efficient as Sin in promoting Src signaling. This could be due to phosphorylation of a small subset of these motifs by Src, given that only three of the seven YDVP motifs of Cas contain $\mathrm{D}$ and $\mathrm{E}$ residues upstream of the tyrosine. Thus, the quantitative differences in transcriptional activation levels that we observe between Sin and Cas could be due to more efficient phosphorylation of some Sin motifs versus those of Cas. This, in turn, could result in more effective activation of downstream signaling intermediates. In support of this model, we observed that the mechanism of signaling (in terms of transcriptional activation) is the same for both Sin and Cas and is mediated by Rap1. However, it is also possible that Crk binding to the phosphorylated YDVP motifs of Sin may recruit other kinases that can then phosphorylate the unique Y motifs of Sin, thus contributing to the stronger effects of Sin on transcription. In future experiments, the use of the YDVP mutants in conjunction with additional mutations on other motifs will address these questions and may identify other individual elements that are important for Sin-mediated transcription.

c-Sre signaling in response to ligand binding is mediated by Crk and Rap1, functioning upstream of ERK. The experiments presented above show that Cas and Sin can effectively activate the Crk-Rap1 signaling complex upstream of ERK and the SRE promoter and that this activation requires the binding of Crk to the phosphorylated YDVP motifs of Sin and Cas. Crk has been shown to bind to $\mathrm{C} 3 \mathrm{G}$ through a Crk SH3 and $\mathrm{C} 3 \mathrm{G}$ proline-rich motif interaction (82). Formation of the Crk-C3G complex in turn leads to Rap1 activation (34). In our experiments we found that both endogenous Crk and $\mathrm{C} 3 \mathrm{G}$ associated with phosphorylated Sin and Cas proteins (Fig. 6A). These results suggest that phosphorylated Cas-Sin-induced activation of Rap1 is mediated by the Crk-C3G complex. It has been shown recently that Rap1 activation is mediated by different signaling pathways, involving second messengers such as calcium, diacylglycerol, and cyclic AMP (cAMP) $(3,32,98)$. The formation of active, GTP-bound Rap1 is regulated by three different families of GEFs consisting of $\mathrm{C} 3 \mathrm{G}$, which regulates tyrosine kinase-induced Rap1 activation through Crk and $\mathrm{Cbl}$ $(39,69,76)$, the guanine nucleotide-releasing proteins, which contain calcium and diacylglycerol motifs (25), and the Epac family of proteins, which are regulated by cAMP $(22,41)$. More recently, another protein family, the PDZ-GEFs, was 

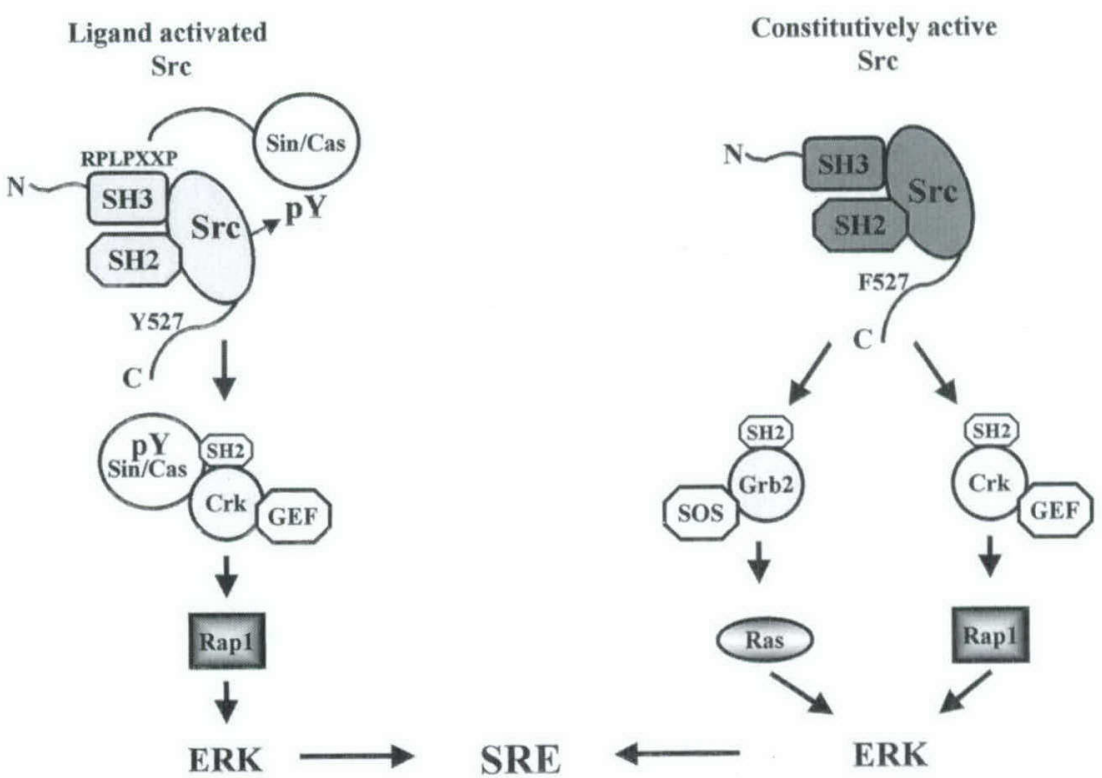

FIG. 8. Model for ligand-induced c-Src-dependent signal transduction leading to MAP kinase and transcriptional activation. Binding of the proline-rich motifs of $\mathrm{Sin}$ and Cas to the Src SH3 domain activates the c-Src tyrosine kinase activity, and the proteins become phosphorylated on tyrosine residues. Src-mediated phosphorylation of Sin and Cas results in the recruitment of the Crk-GEF signaling complex, which in turn activates Rap1 and ERK and induces SRE-mediated gene expression. On the other hand, mutations that disrupt the intramolecular interactions of Src, such as a point mutation on the C-terminal tyrosine 527 , result in an open conformation of the enzyme, which then interacts nonspecifically with multiple cellular substrates. This, in turn, leads to the activation of at least two signaling cascades mediated by the Ras and Rap GTPases.

characterized, members of which exhibit nucleotide exchange activity specific for Rap1 and -2 (41). Thus, we cannot exclude the possibility that other, newly discovered Rap1-specific GEFs are involved in Rap1 activation in our system. The involvement of different GEFs in Rap1 activation will be explored in future experiments.

Rap1 was originally identified as the product of a cDNA (Krev-1) capable of suppressing transformation by Ki-Ras (43). More recently, both positive and negative functional outcomes have been described for activated Rap1 (see reference 6 for review). Thus, in addition to the transformation-suppressing effects of Rap1 $(42,43,65)$, introduction of the active GTP-bound form of Rap1 into fibroblasts inhibits Ras-mediated activation of MAP kinase (19). Moreover, cAMP-dependent activation of Rap1 correlates with down-regulation of the MAPK-ERK pathway $(27,29,70)$. On the other hand, other studies in different cell types indicate that Rap1 has additional functions besides being an antagonist of Ras signaling (9). Recently, Rap1 was shown to act synergistically with Ras in mediating nerve growth factor-induced differentiation of the phaeochromocytoma cell line PC12 (95) and to mediate ERK phosphorylation in response to cAMP (86). In addition, the activity of Rap1 has been shown to increase upon treatment of NIH 3 T3 cells with the neuropeptide growth factor bombesin, and increased Rap1 activity correlates with increased phosphorylation of the MAP kinase ERK and increased proliferation $(9,66)$. Furthermore, Rap1 has been shown to induce DNA synthesis and oncogenic transformation in Swiss 3T3 cells $(4,96)$.

Rap 1 is $-50 \%$ homologous to Ras, and the two proteins have effector domains that exhibit striking similarity (10). The high degree of homology of the Ras and Rap1 effector domains suggested that these proteins bind to the same effector molecules. Consistent with this model, Rap1 has been shown to interact with the Ras effector Raf1, although this interaction does not appear to lead to activation of this protein. Based on these data, it has been proposed that Rap1 may antagonize the function of Ras by competing for downstream effector molecules $(19,85)$. However, recent evidence suggests that growth factors that activate the Ras/Raf pathway also activate Rap1 and that this activation does not interfere with growth factor receptor signaling (98). In addition, increasing the levels of GTP-bound Rap1 by tetradecanoyl phorbol acetate does not inhibit ERK activation by platelet-derived growth factor and epidermal growth factor (98). In our system, activation of Rap1 correlates with ERK activation and increased gene expression. Furthermore, in the case of the SrcY527 mutant, Rap1 appears to act in concert with Ras to promote Src signaling. Taken together, these observations suggest that Rap1 function in cellular pathways may be more complex than previously thought and that its effect on cellular processes may be determined by cellular context.

Ligand-activated versus oncogenic Src signaling. In the experiments described above, we show that truncated Sin and Cas proteins mediate c-Src signaling through the Rap1 GTPase. These observations are important because (i) our results for the first time implicate a GTPase other than Ras in Src signaling, (ii) ERK activation can be mediated by small GTP proteins other than Ras, and (iii) the mode of Src activation (oncogenic versus ligand induced) may determine the signaling pathways activated by Src. The latter observation is particularly interesting given the fact that studies using constitutively active and oncogenic forms of Src have shown Src to act upstream of Ras $(26,51,67)$. Consistent with this, our results show that signaling through the transforming allele SrcY527F is also Ras as well as Rap1 dependent (Fig. 7). In addition, a recent report by Hakak and Martin (35) showed that Cas mediates transcriptional activation of the Egr-1 SRE by $\mathrm{v}$-Src and that this activation was through Grb2 and the Ras-MEK-ERK pathway. However, the increase in transcriptional activation was not dependent on the substrate region of Cas that contains the YXXP motifs, since deletion of this 
region resulted in levels of luciferase activity equivalent to that induced by full-length Cas. Consistent with this observation, a Crk-II SH3 mutant had no effect on luciferase activity, suggesting that the effect of Cas on $\mathrm{v}$-Src-dependent transcriptional activation is mediated by a Ras-dependent mechanism which is different from the one we are describing.

These observations support our model that the signaling mechanisms through activated forms of Src are more complex than the mechanisms that mediate ligand-induced Src signaling (Fig. 8). The differences that we observe in ligand-induced Src signaling versus signaling through constitutively active Src proteins could be due to signaling constraints imposed by the activating ligands through the recruitment of defined, downstream-acting sets of substrates. This stands in contrast to the broader spectrum of responses elicited by deregulated Src kinase activity and interactions between cellular substrates and transforming Src proteins. For example, v-Src as well as the Y527F Src proteins contain mutations that result in the disruption of intramolecular inhibitory interactions between the regulatory and kinase domains of $\operatorname{Src}(34,45)$. This release of intramolecular inhibition abolishes the requirement for specific, high-affinity interactions of SrcY527F with putative substrates, resulting in a wider spectrum of cellular proteins interacting with and becoming phosphorylated by this mutant. As a result, multiple signaling pathways are activated. Indeed we found this to be the case in our system expressing the constitutive active SrcY527F in that this mutant activates at least two separate signaling cascades (Fig. 8).

In contrast to oncogenic alleles, activation of c-Src under physiologic conditions involves directed engagement of the conserved domains of c-Src by their ligands. For example, in response to growth factor binding, growth factor receptors activate Src by providing high-affinity ligands for the $\mathrm{Src} \mathrm{SH} 2$ domain in the form of phosphotyrosines (83). This mechanism of activation excludes nonspecific binding of other proteins and ensures activation of specific signaling pathways for each receptor type. The use of Src SH3 ligands to activate c-Src more closely resembles the in vivo conditions, in that these ligands provide high-affinity binding sites for the Src SH3 domain. Once bound to Src, these ligands induce Src activation and subsequently serve as Src substrates and effector molecules. Given that each phosphorylated adapter molecule can attract a defined set of cytoplasmic intermediates, Src signaling through the recruitment of natural Src SH3 ligands may be more specific than signaling through constitutively active forms of Src. Whether coexpression of Src SH3 ligands and active Src alleles affects the signaling and transforming properties of oncogenic Src proteins remains to be determined.

\section{ACKNOWLEDGMENTS}

The work was initiated in the laboratory of David Baltimore, and we thank him for support. We thank C. Roman and A. Koleske for critically reading the manuscript. We also thank C. Hauser for the AP-1 construct and P. Stork for the Rap1N17 mutant.

This work was supported in part by American Cancer Society grant RPG99-09-01MGO and by Department of Defense grant BC980976. L.X. is supported by American Cancer Society grant RPG99-0901MGO. K.A. was supported in part by Department of Defense grant BC980671.

\section{REFERENCES}

1. Alexandropoulos, K., and D. Baltimore. 1996. Coordinate activation of c-Src by SH3- and SH2-binding sites on a novel p130Cas-related protein, Sin. Genes Dev, 10:1341-1355.

2. Alexandropoulos, K., G. Cheng, and D. Baltimore. 1995. Proline-rich sequences that bind to Src homology 3 domains with individual specificities. Proc. Natl. Acad. Sci. USA 92:3110-3114.
3. Altschuler, D. L., S. N. Peterson, M. C. Ostrowski, and E. G. Lapetina. 1995 Cyclic AMP-dependent activation of Rap1b. J. Biol. Chem. 270:1037310376

4. Altschuler, D. L., and F. Ribeiro-Neto. 1998. Mitogenic and oncogenic properties of the small G protein Rap1b. Proc. Natl. Acad. Sci. USA 95:74757479.

5. Araki, E., M. A. Lipes, M. E. Patti, J. C. Bruning, B. Haag III, R. S. Johnson, and C. R. Kahn. 1994. Alternative pathway of insulin signalling in mice with targeted disruption of the IRS-1 gene. Nature 372:186-190.

6. Auvinen, M., A. Paasinen-Sohns, H. Hirai, L. C. Andersson, and E. Holtta. 1995. Ornithine decarboxylase- and Ras-induced cell transformations: reversal by protein tyrosine kinase inhibitors and role of pp130 CAS . Mol. Cell Biol. 15:6513-6525.

7. Bannerman, D. D., M. Sathyamoorthy, and S. E. Goldblum. 1998. Bacteria lipopolysaccharide disrupts endothelial monolayer integrity and survival signaling events through caspase cleavage of adherens junction proteins. J. Biol. Chem. 273:35371-35380

8. Blauket, A., I. Ivankovic-Dikic, E. Gronroos, F. Dolfi, G. Tokiwa, K. Vuori, and I. Dikic. 1999. Adaptor proteins Grb2 and Crk couple Pyk2 with activation of specific mitogen-activated protein kinase cascades. J. Biol. Chem. 274:14893-14901.

9. Bos, J. L. 1998. All in the family? New insights and questions regarding interconnectivity of Ras, Rap1 and Ral. EMBO J. 17:6776-6782.

10. Bos, J. L. 1997. Ras-like GTPases. Biochim. Biophys. Acta 1333:M19-M31

11. Brown, M. T., and J. A. Cooper. 1996. Regulation, substrates and functions of src. Biochim. Biophys. Acta 1287:121-149.

12. Canman, C. E., and M. B. Kastan. 1996. Signal transduction. Three paths to stress relief. Nature 384:213-214.

13. Cartwright, C. A., W. Eckhart, S. Simon, and P. L. Kaplan. 1987. Cell transformation by pp60c-src mutated in the carboxy-terminal regulatory domain. Cell 49:83-91.

14. Cary, L. A., D. C. Han, T. R. Polte, S. K. Hanks, and J. L. Guan. 1998 Identification of p130Cas as a mediator of focal adhesion kinase-promoted cell migration. J. Cell Biol, 140:211-221.

15. Casamassima, A., and E. Rozengurt. 1997. Tyrosine phosphorylation of p130(cas) by bombesin, lysophosphatidic acid, phorbol esters, and plateletderived growth factor. Signaling pathways and formation of a p130(cas)-Crk complex. J. Biol. Chem. 272:9363-9370.

16. Cheresh, D. A., J. Leng, and R. L. Klemke. 1999. Regulation of cell contraction and membrane ruffling by distinct signals in migratory cells. J. Cell Biol. 146:1107-1116.

17. Cho, S. Y., and R. L. Klemke. 2000. Extracellular-regulated kinase activation and CAS/Crk coupling regulate cell migration and suppress apoptosis during invasion of the extracellular matrix. J. Cell Biol. 149:223-236.

18. Cohen, G. B., R. Ren, and D. Baltimore. 1995. Modular binding domains in signal transduction. Cell 80:237-248.

19. Cook, S. J., and F. McCormick. 1993. Inhibition by cAMP of Ras-dependen activation of Raf. Science 262:1069-1072.

20. Cooper, J. A., and C. S. King. 1986. Dephosphorylation or antibody binding to the carboxy terminus stimulates pp60 $0^{\mathrm{c}-5 r}$. Mol. Cell. Biol. 6:4467-4477.

21. de Rooij, J., and J. L. Bos. 1997. Minimal Ras-binding domain of Raf1 can be used as an activation-specific probe for Ras. Oncogene 14:623-625.

22. de Rooij, J., F. J. Zwartkruis, M. H. Verheijen, R. H. Cool, S. M. Nijman, A. Wittinghofer, and J. L. Bos. 1998. Epac is a Rap1 guanine-nucleotideexchange factor directly activated by cyclic AMP. Nature 396:474-477.

23. de Vries-Smits, A. M., B. M. Burgering, S. J. Leevers, C. J. Marshall, and J. L. Bos. 1992. Involvement of p21ras in activation of extracellular signalregulated kinase 2. Nature 357:602-604

24. Dolfi, F., M. Garcia-Guzman, M. Ojaniemi, H. Nakamura, M. Matsuda, and K. Vuori. 1998. The adaptor protein Crk connects multiple cellular stimuli to the JNK signaling pathway. Proc. Natl. Acad. Sci. USA 95:15394-15399.

25. Ebinu, J. O., D. A. Bottorff, E. Y. Chan, S. L. Stang, R. J. Dunn, and J. C. Stone. 1998. RasGRP, a Ras guanyl nucleotide-releasing protein with calcium- and diacylglycerol-binding motifs. Science 280:1082-1086.

26. Ellis, C., M. Moran, F. McCormick, and T. Pawson. 1990. Phosphorylation of GAP and GAP-associated proteins by transforming and mitogenic tyrosine kinases. Nature 343:377-381.

27. Erhardt, P., J. Troppmair, U. R. Rapp, and G. M. Cooper. 1995. Differential regulation of Raf-1 and B-Raf and Ras-dependent activation of mitogenactivated protein kinase by cyclic AMP in PC12 cells. Mol. Cell. Biol. 15: 5524-5530.

28. Erpel, T., G. Alonso, S. Roche, and S. A. Courtneidge. 1996. The Sre $\mathrm{SH}_{3}$ domain is required for DNA synthesis induced by platelet-derived growth factor and epidermal growth factor. J. Biol. Chem. 271:16807-16812.

29. Faure, M., and H. R. Bourne. 1995. Differential effects on cAMP on the MAP kinase cascade: evidence for a cAMP-insensitive step that can bypass Raf-1. Mol. Biol. Cell 6:1025-1035.

30. Feig, L. A., and G. M. Cooper. 1988. Inhibition of NIH 3 T3 cell proliferation by a mutant Ras protein with preferential affinity for GDP. Mol. Cell. Biol. 8:3235-3243.

31. Feller, S. M., G. Posern, J. Voss, C. Kardinal, D. Sakkab, J. Zheng, and B. S. Knudsen. 1998. Physiological signals and oncogenesis mediated through Crk 
family adapter proteins. J. Cell. Physiol. 177:535-552.

32. Franke, B., J. W. Akkerman, and J. L. Bos. 1997. Rapid Ca2+-mediated activation of Rap1 in human platelets. EMBO J. 16:252-259.

33. Galang, C. K., C. J. Der, and C. A. Hauser. 1994. Oncogenic Ras can induce transcriptional activation through a variety of promoter elements, including tandem c-Ets-2 binding sites. Oncogene 9:2913-2921.

34. Gotoh, T., S. Hattori, S. Nakamura, H. Kitayama, M. Noda, Y. Takai, K. Kaibuchi, H. Matsui, O. Hatase, H. Takahashi, et al. 1995. Identification of Rap1 as a target for the Crk $\mathrm{SH} 3$ domain-binding guanine nucleotidereleasing factor C3G. Mol. Cell. Biol. 15:6746-6753.

35. Hakak, Y., and S. Martin. 1999. Cas mediates transcriptional activation of the serum response element by Src. Mol. Cell. Biol. 19:6953-6962.

36. Harte, M. T., J. D. Hildebrand, M. R. Burnham, A. H. Bouton, and J. T. Parsons. 1996. p130Cas, a substrate associated with v-Src and v-Crk, localizes to focal adhesions and binds to focal adhesion kinase. J. Biol. Chem. 271:13649-13655

37. Honda, H., H. Oda, T. Nakamoto, Z. Honda, R. Sakai, T. Suzuki, T. Saito, K. Nakamura, K. Nakao, T. Ishikawa, M. Katsuki, Y. Yazaki, and H. Hirai. 1998. Cardiovascular anomaly, impaired actin bundling and resistance to Src-induced transformation in mice lacking p130Cas. Nat. Genet. 19:361365

38. Ichiba, T., Y. Kuraishi, O. Sakai, S. Nagata, J. Groffen, T. Kurata, S. Hattori, and M. Matsuda. 1997. Enhancement of guanine-nucleotide exchange activity of C3G for Rap1 by the expression of Crk, CrkL, and Grb2. J. Biol. Chem. 272:22215-22220.

39. Ishiki, M., T. Sasaoka, H. Ishihara, T. Imamura, I. Usui, Y. Takata, and M. Kobayashi. 1997. Evidence for functional roles of Crk-II in insulin and epidermal growth factor signaling in Rat-1 fibroblasts overexpressing insulin receptors. Endocrinology 138:4950-4958.

40. Ishino, M., T. Ohba, H. Sasaki, and T. Sasaki. 1995. Molecular cloning of a cDNA encoding a phosphoprotein, Efs, which contains a Src homology 3 domain and associates with Fyn. Oncogene 11:2331-2338.

41. Kawasaki, H., G. M. Springett, S. Toki, J. J. Canales, P. Harlan, J. P. Blumenstiel, E. J. Chen, I. A. Bany, N. Mochizuki, A. Ashbacher, M. Matsuda, D. E. Housman, and A. M. Graybiel. 1998. A Rap guanine nucleotide exchange factor enriched highly in the basal ganglia. Proc. Natl. Acad. Sci. USA 95:13278-13283. (Erratum, 96:318, 1999.)

42. Kawata, M., Y. Matsui, J. Kondo, T. Hishida, Y. Teranishi, and Y. Takai. 1988. A novel small molecular weight GTP-binding protein with the same putative effector domain as the ras proteins in bovine brain membranes. Purification, determination of primary structure, and characterization. J. Biol. Chem. 263:18965-18971.

43. Kitayama, H., Y. Sugimoto, T. Matsuzaki, Y. Ikawa, and M. Noda. 1989. A ras-related gene with transformation suppressor activity. Cell 56:77-84.

44. Klemke, R. L., J. Leng, R. Molander, P. C. Brooks, K. Vuori, and D. A. Cheresh. 1998. CAS/Crk coupling serves as a "molecular switch" for induction of cell migration. J. Cell Biol. 140:961-972.

45. Kmiecik, T. E., and D. Shalloway, 1987. Activation and suppression of pp60c-src transforming ability by mutation of its primary sites of tyrosine phosphorylation. Cell 49:65-73

46. Knudsen, B. S., S. M. Feller, and H. Hanafusa. 1994. Four proline-rich sequences of the guanine-nucleotide exchange factor $\mathrm{C} 3 \mathrm{G}$ bind with unique specificity to the first Src homology 3 domain of Crk. J. Biol. Chem. 269: 32781-32787

47. Kumagai, N., N. Morii, K. Fujisawa, T. Yoshimasa, K. Nakao, and S. Narumiya. 1993. Lysophosphatidic acid induces tyrosine phosphorylation and activation of MAP-kinase and focal adhesion kinase in cultured Swiss 3T3 cells. FEBS Lett. 329:273-276.

48. Law, S., J. Estojak, B. Wang, T. Mysliwiec, G. Kruh, and F. A. Golemis. 1996. Human enhancer of filamentation 1, a novel p130 ${ }^{\text {Cas }}$-like docking protein, associated with focal adhesion kinase and induces pseudohyphal growth in Saccharomyces cerevisiae. Mol. Cell. Biol. 16:3327-3337.

49. Leevers, S. J., and C. J. Marshall. 1992. Activation of extracellular signalregulated kinase, ERK2, by p21ras oncoprotein. EMBO J. 11:569-574.

50. Manie, S. N., A. R. Beck, A. Astier, S. F. Law, T. Canty, H. Hirai, B. J. Druker, H. Avraham, N. Haghayeghi, M. Sattler, R. Salgia, J. D. Griffin, E. A. Golemis, and A. S. Freedman. 1997. Involvement of p130(Cas) and p105(HEF1), a novel Cas-like docking protein, in a cytoskeleton-dependent signaling pathway initiated by ligation of integrin or antigen receptor on human B cells. J. Biol. Chem. 272:4230-4236.

51. Minden, A., A. Lin, F. X. Claret, A. Abo, and M. Karin. 1995. Selective activation of the JNK signaling cascade and c-Jun transcriptional activity by the small GTPases Rac and Cdc42Hs. Cell 81:1147-1157.

52. Minegishi, M., K. Tachibana, T. Sato, S. Iwata, Y. Nojima, and C. Morimoto. 1996. Structure and function of Cas-L, a 105-kD Crk-associated substraterelated protein that is involved in beta 1 integrin-mediated signaling in lymphocytes. J. Exp. Med. 184:1365-1375.

53. Mizushima, S., and S. Nagata. 1990. pEF-BOS, a powerful mammalian expression vector. Nucleic Acids Res. 18:5322.

54. Mukhopadhyay, D., L. Tsiokas, X. M. Zhou, D. Foster, J. S. Brugge, and V. P. Sukhatme. 1995. Hypoxic induction of human vascular endothelial growth factor expression through c-Src activation. Nature 375:577-581.
55. Murphy, S. M., M. Bergman, and D. O. Morgan. 1993. Suppression of c-Src activity by C-terminal Src kinase involves the c-Src $\mathrm{SH} 2$ and $\mathrm{SH} 3$ domains: analysis with Saccharomyces cerevisiae. Mol. Cell. Biol. 13:5290-5300.

56. Myers, M. G., and M. F. White. 1996. Insulin signal transduction and the IRS proteins. Annu. Rev. Pharmacol. Toxicol. 36:615-658.

57. Nakamoto, T., R. Sakai, K. Ozawa, Y. Yazaki, and H. Hirai. 1996. Direct binding of C-terminal region of p130Cas to $\mathrm{SH} 2$ and $\mathrm{SH} 3$ domains of $\mathrm{Src}$ kinase. J. Biol. Chem. 271:8959-8965

58. Nojima, Y., N. Morino, T. Mimura, K. Hamasaki, H. Furuya, R. Sakai, T. Sato, K. Tachibana, C. Morimoto, Y. Yazaki, et al. 1995. Integrin-mediated cell adhesion promotes tyrosine phosphorylation of p130Cas, a Src homology 3-containing molecule having multiple Src homology 2-binding motifs. J. Biol. Chem. 270:15398-15402.

59. Ojaniemi, M., and K. Vuori. 1997. Epidermal growth factor modulates tyrosine phosphorylation of p130Cas. Involvement of phosphatidylinositol $3^{\prime}$ kinase and actin cytoskeleton. J. Biol. Chem. 272:25993-25998.

60. Oktay, M., K. K. Wary, M. Dans, R. B. Birge, and F. G. Giancotti. 1999 Integrin-mediated activation of focal adhesion kinase is required for signaling to Jun NH2-terminal kinase and progression through the G1 phase of the cell cycle. J. Cell Biol, 145:1461-1469.

61. O'Neill, G. M., S. J. Fashena, and E. A. Golemis. 2000. Integrin signalling: a new Cas(t) of characters enters the stage. Trends Cell Biol. 10:111-119.

62. Pear, W. S., G. P. Nolan, M. L. Scott, and D. Baltimore. 1993. Production of high-titer helper-free retroviruses by transient transfection. Proc. Natl. Acad Sci. USA 90:8392-8396.

63. Pickett, C. A., and A. Gutierrez-Hartmann. 1994. Ras mediates Src but not epidermal growth factor-receptor tyrosine kinase signaling pathways in $\mathrm{GH} 4$ neuroendocrine cells. Proc. Natl. Acad. Sci. USA 91:8612-8616.

64. Piwnica-Worms, H., K. B. Saunders, T. M. Roberts, A. E. Smith, and S. H. Cheng. 1987. Tyrosine phosphorylation regulates the biochemical and biological properties of pp60c-src. Cell 49:75-82.

65. Pizon, V., I. Lerosey, P. Chardin, and A. Tavitian. 1988. Nucleotide sequence of a human cDNA encoding a ras-related protein (rap1B). Nucleic Acids Res. 16:7719

66. Posern, G., C. K. Weber, U. R. Rapp, and S. M. Feller. 1998. Activity of Rap1 is regulated by bombesin, cell adhesion, and cell density in NIH3T3 fibroblasts. J. Biol. Chem. 273:24297-24300.

67. Qureshi, S. A., K. Alexandropoulos, M. Rim, C. K. Joseph, J. T. Bruder, U. R. Rapp, and D. A. Foster. 1992. Evidence that Ha-Ras mediates two distinguishable intracellular signals activated by v-Src. J. Biol. Chem. 267: $17635-17639$.

68. Qureshi, S. A., M. Rim, J. Bruder, W. Kolch, U. Rapp, V. P. Sukhatme, and D. A. Foster. 1991. An inhibitory mutant of c-Raf-1 blocks v-Src-induced activation of the Egr-1 promoter. J. Biol. Chem. 266:20594-20597.

69. Reedquist, K. A., and J. L. Bos. 1998. Costimulation through CD28 sup presses $\mathrm{T}$ cell receptor-dependent activation of the Ras-like small GTPase Rap1 in human T lymphocytes. J. Biol. Chem. 273:4944 4949.

70. Reuter, C. W., A. D. Catling, T. Jelinek, and M. J. Weber. 1995. Biochemical analysis of MEK activation in NIH3T3 fibroblasts. Identification of B-Raf and other activators. J. Biol. Chem. 270:7644-7655.

71. Robbins, D. J., M. Cheng, E. Zhen, C. A. Vanderbilt, L. A. Feig, and M. H. Cobb. 1992. Evidence for a Ras-dependent extracellular signal-regulated protein kinase (ERK) cascade. Proc. Natl. Acad. Sci. USA 89:6924-6928.

72. Sakai, R., A. Iwamatsu, N. Hirano, S. Ogawa, T. Tanaka, H. Mano, Y. Yazaki, and H. Hirai. 1994. A novel signaling molecule, p130, forms stable complexes in vivo with $\mathrm{v}$-Crk and $\mathrm{v}$-Src in a tyrosine phosphorylation-dependent manner. EMBO J. 13:3748-3756.

73. Sambrook, J., E. F. Fritsch, and T. Maniatis. 1989. Molecular cloning: laboratory manual. Cold Spring Harbor Laboratory, Cold Spring Harbor, N.Y.

74. Schlaepfer, D. D., M. A. Broome, and T. Hunter. 1997. Fibronectin-stimulated signaling from a focal adhesion kinase-c-Src complex: involvement of the Grb2, p130 cas , and Nck adaptor proteins. Mol. Cell. Biol. 17:1702-1713

75. Sicheri, F., I. Moarefi, and J. Kuriyan. 1997. Crystal structure of the Src family tyrosine kinase Hck. Nature 385:602-609.

76. Smit, L., G. van der Horst, and J. Borst. 1996. Formation of Shc/Grb2- and Crk adaptor complexes containing tyrosine phosphorylated $\mathrm{Cb} 1$ upon stimulation of the B-cell antigen receptor. Oncogene 13:381-389.

77. Songyang, Z., K. L. Carraway III, M. J. Eck, S. C. Harrison, R. A. Feldman, M. Mohammadi, J. Schlessinger, S. R. Hubbard, D. P. Smith, C. Eng, et al. 1995. Catalytic specificity of protein-tyrosine kinases is critical for selective signaling. Nature 373:536-539.

78. Songyang, Z., S. E. Shoelson, M. Chaunduri, G. Gish, T. Pawson, W. G Haser, F. King, T. Roberts, S. Ratnofsky, and R. J. Lechleider, et al. 1993 SH2 domains recognize specific phosphopeptides sequences. Cell 72:767778

79. Superti-Furga, G., S. Fumagalli, M. Koegl, S. A. Courtneidge, and G. Draetta. 1993. Csk inhibition of c-Src activity requires both the $\mathrm{SH}_{2}$ and $\mathrm{SH}_{3}$ domains of Src. EMBO J. 12:2625-2634.

80. Tamemoto, H., T. Kadowaki, K. Tobe, T. Yagi, H. Sakura, T. Hayakawa, Y. Terauchi, K. Ueki, Y. Kaburagi, S. Satoh, et al. 1994. Insulin resistance and 
growth retardation in mice lacking insulin receptor substrate-1. Nature 372: 182-186.

81. Tanaka, M., R. Gupta, and B. J. Mayer. 1995. Differential inhibition of signaling pathways by dominant-negative $\mathrm{SH} 2 / \mathrm{SH} 3$ adapter proteins. Mol. Cell. Biol. 15:6829-6837.

82. Tanaka, S., T. Morishita, Y. Hashimoto, S. Hattori, S. Nakamura, M. Shibuya, K. Matuoka, T. Takenawa, T. Kurata, K. Nagashima, et al. 1994. $\mathrm{C} 3 \mathrm{G}$, a guanine nucleotide-releasing protein expressed ubiquitously, binds to the Src homology 3 domains of CRK and GRB2/ASH proteins. Proc. Natl. Acad. Sci. USA 91:3443-3447.

83. Thomas, S., and J. S. Brugge. 1997. Cellular junctions regulated by Src family kinases. Annu. Rev. Cell Dev. Biol. 13:513-609.

84. Tsai-Morris, C. H., X. M. Cao, and V. P. Sukhatme. 1988. 5' flanking sequence and genomic structure of Egr-1, a murine mitogen inducible zinc finger encoding gene. Nucleic Acids Res. 16:8835-8846.

85. Urano, T., R. Emkey, and L. A. Feig. 1996. Ral-GTPases mediate a distinct downstream signaling pathway from Ras that facilitates cellular transformation. EMBO J. 15:810-816.

86. Vossler, M. R., H. Yao, R. D. York, M. G. Pan, C. S. Rim, and P. J. Stork. 1997. cAMP activates MAP kinase and Elk-1 through a B-Raf- and Rap1dependent pathway. Cell 89:73-82.

87. Vuori, K., H. Hirai, S. Aizawa, and E. Ruoslahti. 1996. Introduction of p130 $0^{\text {cas }}$ signaling complex formation upon integrin-mediated cell adhesion: a role for Src family kinases. Mol. Cell. Biol. 16:2606-2613.

88. Vuori, K., and E. Ruoslahti. 1995. Tyrosine phosphorylation of p130Cas and cortactin accompanies integrin-mediated cell adhesion to extracellular matrix. J. Biol. Chem. 270:22259-22262.

89. Withers, D. J., J. S. Gutierrez, H. Towery, D. Burks, J. M. Ren, S. Previs, Y. Zhang, D. Bernal, S. Pons, G. I. Shulman, S. Bonner-Weir, and M. F. White.
1998. Disruption of IRS-2 causes type 2 diabetes in mice. Nature 391:900904

90. Wolthuis, R. M., B. Franke, M. van Triest, B. Bauer, R. H. Cool, J. H Camonis, J. W. Akkerman, and J. L. Bos. 1998. Activation of the small GTPase Ral in platelets. Mol. Cell. Biol. 18:2486-2491.

91. Wood, K. W., C. Sarnecki, T. M. Roberts, and J. Blenis. 1992. Ras mediates nerve growth factor receptor modulation of three signal-transducing protein kinases: MAP kinase, Raf-1, and RSK. Cell 68:1041-1050.

92. Xu, W., S. C. Harrison, and M. J. Eck. 1997. Three-dimensional structure of the tyrosine kinase c-Src. Nature 385:595-602

93. Yamakita, Y., G. Totsukawa, S. Yamashiro, D. Fry, X. Zhang, S. K. Hanks, and F. Matsumura. 1999. Dissociation of FAK/p130(CAS)/c-Src complex during mitosis: role of mitosis-specific serine phosphorylation of FAK. J. Cell Biol. 144:315-324.

94. Yenush, L., and M. F. White. 1997. The IRS-signaling system during insulin and cytokine action. Bioessays 19:491-500.

95. York, R. D., H. Yao, T. Dillon, C. L. Ellig, S. P. Eckert, E. W. McCleskey, and P. J. Stork. 1998. Rap1 mediates sustained MAP kinase activation induced by nerve growth factor. Nature 392:622-626.

96. Yoshida, Y., M. Kawata, Y. Miura, T. Musha, T. Sasaki, A. Kikuchi, and Y. Takai. 1992. Microinjection of smg/rap1/Krev-1 p21 into Swiss 3 T3 cells induces DNA synthesis and morphological changes. Mol. Cell. Biol. 12:34073414

97. Zhu, T., E. L. Goh, D. LeRoith, and P. E. Lobie. 1998. Growth hormone stimulates the formation of a multiprotein signaling complex involving p130(Cas) and CrkII. Resultant activation of c-Jun N-terminal kinase/stress activated protein kinase (JNK/SAPK). J. Biol. Chem. 273:33864-33875.

98. Zwartkruis, F. J., R. M. Wolthuis, N. M. Nabben, B. Franke, and J. L. Bos. 1998. Extracellular signal-regulated activation of Rap1 fails to interfere in Ras effector signalling. EMBO J. 17:5905-5912. 


\title{
Defective Thymocyte Maturation by Transgenic Expression of a Truncated Form of the T Lymphocyte Adapter Molecule and Fyn Substrate, Sin $^{1}$
}

\author{
Laura T. Donlin,* Christopher A. Roman,${ }^{\S}$ Matthew Adlam, ${ }^{\dagger}$ Adam G. Regelmann, ${ }^{\ddagger}$ and \\ Konstantina Alexandropoulos ${ }^{2 *}$
}

Adapter molecules that promote protein-protein interactions play a central role in $\mathbf{T}$ lymphocyte differentiation and activation. In this study, we examined the role of the $T$ lymphocyte-expressed adapter protein and Src kinase substrate, Sin, on thymocyte function using transgenic mice expressing an activated, truncated allele of $\operatorname{Sin}(\operatorname{Sin} \Delta \mathrm{C})$. We found that $\operatorname{Sin} \Delta \mathrm{C}$ expression led to reduced numbers of $\mathrm{CD4}^{+}$and $\mathrm{CD8}^{+}$single-positive cells and reduced thymic cellularity due to increased thymocyte apoptosis. Because the adapter properties of Sin are mediated by tyrosine-based motifs and given that Sin is a substrate for Src tyrosine kinases, we examined the involvement of these kinases in the inhibitory effects of Sin $\Delta \mathrm{C}$. We found that in transgenic thymocytes, $\operatorname{Sin} \Delta \mathrm{C}$ was constitutively phosphorylated by the Src kinase Fyn, but not by the related kinase Lck. Using Sin $\Delta \mathrm{C}$ and fyn ${ }^{-/-}$ animals, we also found that the expression of Fyn was required for the inhibitory effect of $\operatorname{Sin} \Delta \mathrm{C}$ on thymocyte apoptosis but not for Sin $\Delta \mathrm{C}$-mediated inhibition of $\mathrm{T}$ cell maturation. The inhibitory effect of $\operatorname{Sin} \Delta \mathrm{C}$ on thymocyte maturation correlated with defective activation of the mitogen-activated protein kinase extracellular signal-regulated kinase. Our results suggest that the Sin mutant inhibits thymocyte differentiation through Fyn-dependent and -independent mechanisms and that endogenous Sin may be an important regulator of thymocyte development. The Journal of Immunology, 2002, 169: 6900-6909.

$\mathrm{I}$ $\mathrm{n}$ recent years, adapter proteins have been shown to play important roles in the signaling mechanisms of a variety of cell types including $\mathrm{T}$ and B lymphocytes. Adapter proteins by definition lack enzymatic or transcriptional activity and control cellular behavior by mediating constitutive or inducible proteinprotein or protein-lipid interactions through modular interaction domains (1-6). T lymphocytes express a variety of adapter molecules that act as positive or negative regulators of TCR-dependent signaling. Positive regulators include linker for activation of $\mathrm{T}$ cells, Src homology 2 domain-containing leukocyte protein of 76 $\mathrm{kDa}$ (SLP76), ${ }^{3}$ and Grb2-related adapter downstream of Shc whereas negative regulators include Casitas B cell lymphoma

Departments of *Pharmacology and ${ }^{\dagger}$ Microbiology and ${ }^{*}$ The Integrated MD/PhD Program, College of Physicians and Surgeons, Columbia University, New York, NY 10032; and ${ }^{5}$ Department of Microbiology and Immunology, State University of New York-Downstate Medical Center, Brooklyn, NY 11203

Received for publication July 18, 2002. Accepted for publication October 15, 2002.

The costs of publication of this article were defrayed in part by the payment of page charges. This article must therefore be hereby marked advertisement in accordance with 18 U.S.C. Section 1734 solely to indicate this fact.

${ }^{1}$ This work was supported in part by American Cancer Society Grant RPG99-09-01 MGO, Department of Defense Grants DAMD17-99-1-9151 and DAMD17-99-1-915 National Institute of Allergy and Infectious Diseases Grant RO1 AI49387-01, American Cancer Society Institutional Research Grant No. 177F, and the Herbert Irving Comprehensive Cancer Center. L.T.D. was supported by National Institutes of Health Grant 5 T32 AI07525. A.G.R. was supported by National Institutes of Health Gran 5 T32 GM03767-26. K.A. was supported in part by Department of Defense Grants DAMD17-99-1-9151 and DAMD17-99-1-915, National Institute of Allergy and In fectious Diseases Grant RO1 AI49387-01, and American Cancer Society Grant RPG99-09-01 MGO.

${ }^{2}$ Address correspondence and reprint requests to Dr. Konstantina Alexandropoulos, Department of Pharmacology, College of Physicians and Surgeons, Columbia University, New York, NY 10032. E-mail address: ka141@columbia.edu

${ }^{3}$ Abbreviations used in this paper: SLP76, Src homology 2 domain-containing leukocyte protein of $76 \mathrm{kDa}$; Cbl, Casitas B cell lymphoma; ERK, extracellular signalregulated kinase; $\mathrm{SH}, \mathrm{Src}$ homology; $\mathrm{SP}$, single positive; JNK, jun N-terminal kinase 7AAD, 7-amino actinomycin D; MAPK, mitogen-activated protein kinase; DN, double negative; DP, double positive.
(Cbl), SLP76-associated protein, protein associated with glycosphingolipid-enriched microdomains/CSK-binding protein (2-7). The important roles of these adapters in $\mathrm{T}$ lymphocyte function have been substantiated with gene targeting experiments showing that SLP76, Grb2-related adapter downstream of Shc, and linker for activation of $\mathrm{T}$ cells are absolutely required for normal thymocyte development (8-10). In contrast, mice deficient for negative regulators of TCR signaling such as c-Cbl, Cbl-b, and Src-like adapter protein exhibit opposite phenotypes. These phenotypes include increased positive selection, increased expression of the surface molecules CD3, CD4, and CD5, markedly up-regulated activity of $\zeta$-associated protein of $70 \mathrm{kDa}$, and extracellular signalregulated kinase (ERK) (11-13), as well as spontaneous autoimmunity due to reduced $\mathrm{T}$ cell activation thresholds $(14,15)$.

Our previous studies have concentrated on addressing the role of the novel adapter molecule Sin in the signaling pathways of Src family nonreceptor tyrosine kinases (16). Sin/Efs 1 was cloned as a high affinity ligand for the Src- and Fyn-Src homology (SH)3 domains $(16,17)$ and belongs to a family of proteins, the other members being $\mathrm{p} 130^{\text {Cas }}$ and human enhancer of yeast filamentation 1/Crk-associated substrate in lymphocytes (18), (19-22). The adapter properties of Sin and the other family members are due to conserved sequence motifs that mediate protein-protein interactions. These conserved motifs consist of: 1) proline-rich sequences that bind to SH3 domains such as those found on Src kinases (19, $23)$; 2) conserved tyrosine residues which, when phosphorylated by $\mathrm{Src}$ and other kinases, mediate interactions with $\mathrm{SH} 2$-domaincontaining substrates (24); and 3) an SH3 domain that is highly conserved among the three family members (19).

Given that $\mathrm{Sin}$ was isolated as a protein that binds to Src-kinase SH3 domains, we previously examined its functional properties in relation to Src kinases. The enzymatic activity of Src kinases is regulated intramolecularly through interactions of the conserved Src SH3 and SH2 domains with specific sequences within the Src 
kinase molecules (25-28). Mutations that disrupt these interactions lead to constitutively active Src proteins and cellular transformation. In our experiments, instead of Src-constitutively active mutants, we used Sin as a high affinity ligand for the Src-SH3 domain, to outcompete the inhibitory intramolecular interactions of Src and activate the enzyme (16). We found that whereas full-length Sin only moderately induced Src enzymatic activity and signaling, a C-terminal deletion mutant of $\operatorname{Sin}, \operatorname{Sin} \Delta C$, was a potent activator of Src kinase activity and signaling (29).

The physiologic function of Sin is currently not known. In this report, we examined the role of Sin in T lymphocyte function because the thymus is one of the tissues in which endogenous Sin is most highly expressed. In addition, $\mathrm{Sin}$ is a Src kinase substrate and two Src kinases, Fyn and Lck, are known to play important roles in T lymphocyte physiology (30-32). Given that Sin-mediated protein-protein interactions are facilitated by Src kinase-phosphorylated tyrosine motifs $(29,33)$, we thought it was important to address the function of $\mathrm{Sin}$ in relation to these kinases. In previous experiments we found that the truncated form of $\operatorname{Sin}, \operatorname{Sin} \Delta C$, was a better activator of and was more efficiently phosphorylated by Src kinases than the full-length Sin (29). Therefore, we used this protein for our studies. We found that specific expression of $\operatorname{Sin} \Delta \mathrm{C}$ in thymocytes of transgenic animals inhibited thymocyte development and survival, shown by reduced percentages of mature CD4 ${ }^{+}$ and $\mathrm{CD}^{+}$single-positive (SP) $\mathrm{T}$ cells and increased thymocyte apoptosis. We also found that Sin was a substrate for Fyn but not Lck, and that Fyn was required for Sin-mediated thymocyte apoptosis but not for the block in thymocyte maturation. Moreover, $\operatorname{Sin} \Delta \mathrm{C}$ expression correlated with reduced ERK activation, which is required for proper selection of thymocytes. These experiments are the first to address the role of $\mathrm{Sin}$ in T lymphocyte function in vivo and suggest that truncated $\mathrm{Sin}$ is a negative regulator of $\mathrm{T}$ lymphocytes through Fyn-dependent and -independent mechanisms and that endogenous Sin may be an important regulator of $\mathrm{T}$ lymphocyte function.

\section{Materials and Methods Generation of transgenic mice}

A cDNA fragment encoding aa 1-335 of full-length Sin was cloned into the EcoRI/SmaI site of the CD2 expression cassette containing the human $\mathrm{CD} 2$ minigene previously described to express the transgene both in immature thymocytes and in mature T cells (34). An 11.2-kb KpnI/Not I fragment containing the transgene was microinjected into $(\mathrm{C} 57 \mathrm{BL} / 6 \times \mathrm{CBA}$ ) $\mathrm{J}_{\mathrm{F}}$, fertilized eggs derived from hyperovulated donor females. Transgenic founders were identified by PCR and Southern blot analysis of tail DNA and transgenic lines were established by backcrossing to C57BL/6 mice.

Mice

C57BL/6 and $\mathrm{fyn}^{-1-}$ animals were purchased from The Jackson Laboratory (Bar Harbor, ME).

\section{Abs and reagents}

Mouse mAbs: anti-Sin-specific $\mathrm{Ab}$ was obtained from BD Transduction Laboratories (Lexington, KY); anti-Fyn, anti-Lck, and anti-phospho-ERK were obtained from Santa Cruz Biotechnology (Santa Cruz, CA); antiphosphotyrosine-specific Ab was obtained from Upstate Biotechnology (Lake Placid, NY). Rabbit polyclonal anti-jun N-terminal kinase (JNK), and phospho-JNK were obtained from New England Biolabs (Beverly, MA) and anti-ERK goat polyclonal was obtained from Santa Cruz Biotechnology. Dexamethasone and enolase were purchased from SigmaAldrich (St. Louis, MO).

\section{Flow cytometry}

Freshly isolated thymocytes $\left(1 \times 10^{6}\right)$ from 6- to 8-wk-old mice were incubated with the appropriate Abs in staining medium (3\% FCS, $0.1 \%$ sodium azide in PBS) for $15 \mathrm{~min}$ on ice. Cells were spun down and washed three times with staining medium and analyzed by flow cytometry using a FACSCalibur and CellQuest software. Anti-CD4-allophycocyanin, CD8-
PerCP, CD3-FITC, CD69-FITC, CD5-FITC, TCR- $\beta$-FITC-conjugated Abs were purchased from BD PharMingen (San Diego, CA). Purified mouse monoclonal anti-CD3 Ab used for cross-linking was obtained from BD PharMingen.

\section{Apoptosis assays}

For analyzing spontaneous thymocyte apoptosis in vitro, $5 \times 10^{5}$ thymocytes from Sin $\Delta \mathrm{C}$ transgenic and negative littermate controls were cultured in tissue culture medium for different time points. Dexamethasone $(10 \mu \mathrm{M})$ was added in parallel cultures as a control for apoptosis. Thymocyte apoptosis was assayed by Annexin $\mathrm{V}^{\mathrm{PE}}$ and 7-amino actinomycin D (7AAD) staining, using an apoptosis detection kit (BD PharMingen) according to the manufacturer's protocol and a FACSCalibur with CellQuest software. Cell debris was gated out on the basis of forward and side scatter analysis. Percent apoptosis is expressed as the amount of cells staining positive for annexin $\mathrm{V}$ and negative for 7AAD (early stage) and survival is represented as percent of cells that were annexin $\mathrm{V}$ - and 7AAD-negative.

\section{TCR cross-linking}

Thymocytes $\left(1 \times 10^{7}\right)$ were incubated with $2 \mu \mathrm{g}$ of anti-CD3 Ab on ice for $15 \mathrm{~min}$, washed with cold PBS, and supercross-linked with $5 \mu \mathrm{g}$ of goatanti-mouse IgG for $20 \mathrm{~min}$ on ice. Cells were then incubated at $37^{\circ} \mathrm{C}$ for different points, spun down, and immediately lysed. Cell lysates were used for immunoblot analysis.

\section{Mitogen-activated protein kinase (MAPK) assays}

Thymocytes $\left(0.5-1 \times 10^{7}\right)$ were cross-linked with anti-CD3 for different time points. Total cell lysates were subjected to SDS-PAGE, transferred to nitrocellulose membranes, and probed with anti-phospho-ERK or antiphospho-JNK to reveal the phosphorylated forms of these kinases. Blots were stripped and reprobed with anti-ERK and anti-JNK Abs to determine the amounts of total ERK and JNK.

\section{Immunoprecipitations}

Immunoprecipitations were performed as previously described (16). Briefly, cells were lysed in $1 \mathrm{ml}$ of ice-cold Nonidet P-40 lysis buffer (1\% Nonidet P-40, $20 \mathrm{mM}$ Tris- $\mathrm{HCl}$ ( $\mathrm{pH} 8.0$ ), $150 \mathrm{mM} \mathrm{NaCl}, 10 \%$ glycerol, 10 $\mathrm{mM} \mathrm{NaF}, 1 \mathrm{mM}$ sodium orthovanadate, $1 \mathrm{mM}$ PMSF, $10 \mu \mathrm{g} / \mathrm{ml}$ aprotinin, $10 \mu \mathrm{g} / \mathrm{ml}$ leupeptin) and incubated on ice for $30 \mathrm{~min}$. The cell debris and nuclei were removed by centrifugation for $10 \mathrm{~min}$ at $4^{\circ} \mathrm{C}$. The cell lysates were then incubated with the specified $\mathrm{Abs}$ at concentrations suggested by the manufacturers for $2 \mathrm{~h}$ at $4^{\circ} \mathrm{C}$. The immune complexes were collected after the addition of $20 \mu \mathrm{l}$ of protein $\mathrm{G}$ - plus protein A-agarose (Oncogene Research Products, San Diego, CA) and incubation at $4^{\circ} \mathrm{C}$ for $30 \mathrm{~min}$. The pellets of agarose beads were washed three times with $1 \mathrm{ml}$ of lysis buffer and then subjected to SDS-PAGE and immunoblotting.

\section{In vitro kinase assays}

Protein complexes obtained by immunoprecipitation were washed three times in kinase buffer and reactions were conducted in $20 \mu \mathrm{l}$ of kinase buffer containing $20 \mathrm{mM}$ HEPES, pH 7.4, $5 \mathrm{mM} \mathrm{MnCl}, 10 \mu \mathrm{M} \mathrm{ATP}$, and $1 \mu$ of $\left[\gamma^{32} \mathrm{P}\right]$ ATP $(5000 \mathrm{Ci} / \mathrm{mmol})$ at room temperature for $5 \mathrm{~min}$. When required, $5 \mu \mathrm{g}$ of the exogenous substrate enolase was added to the samples as shown and as previously described (35). The pellets were resuspended in $1 \times$ Laemmli buffer, boiled for $5 \mathrm{~min}$, and phosphorylated proteins were analyzed by SDS-PAGE and autoradiography.

\section{Western blot analysis}

Total cell extracts or immunoprecipitates normalized for protein content were boiled in Laemmli sample buffer, electrophoretically separated on $10 \%$ SDS-PAGE, and transferred to nitrocellulose membranes. Filters were blotted with the appropriate monoclonal antisera according to manufacturer's protocol in TBST/milk at $4^{\circ} \mathrm{C}$ overnight $(16 \mathrm{~h})$. Rabbit polyclonal Abs were used at a $1 / 500$ dilution. mAbs were used at $1 \mu \mathrm{g} / \mathrm{ml}$ TBST/milk each. The filters were washed in TBST and consequently incubated with antimouse or anti-rabbit IgG-conjugated HRP at a 1/4000 dilution in TBST at room temperature for $1 \mathrm{~h}$. Filters were then washed and developed with ECL (Amersham, Piscataway, NJ), as described by the manufacturer.

\section{Results}

Generation of $\operatorname{Sin} \Delta C$-expressing transgenic animals

On Northern blots endogenous Sin is most highly expressed in the adult thymus and brain, while Sin can be detected in multiple tissues by RT-PCR (36). At least two Sin isoforms can be detected 
in thymocyte and T cell extracts on Western blots of total lysates and Sin immunoprecipitates; full-length Sin and the previously described Efs2 (36), a Sin alternative splice form in which the $\mathrm{SH} 3$ domain is deleted (Fig. 1, $A, B$, and $D$ ) (36).

To explore the function of $\mathrm{Sin}$ in $\mathrm{T}$ lymphocytes, we generated transgenic mice expressing the truncated form of $\operatorname{Sin}, \operatorname{Sin} \Delta \mathrm{C}$ (Fig. $1 A)$. The truncation removes a C-terminal portion of Sin and exposes one of the proline-rich motifs of Sin that binds to Src kinase SH3 domains with high affinity. We have previously shown that the $\mathrm{C}$ terminus of Sin inhibits the ability of Sin to mediate Src signaling. Deletion of this region results in a protein that is a better activator and transducer of Src kinase signaling than the full-length Sin protein (29). In the experiments described in this study we used this activated mutant because efficient Src kinase-mediated phosphorylation of tyrosine residues within $\mathrm{Sin}$ is required for Sin

\section{$\mathbf{A}$}

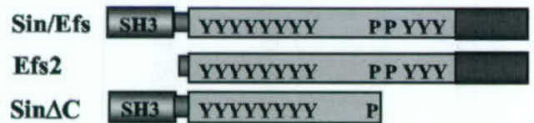

B

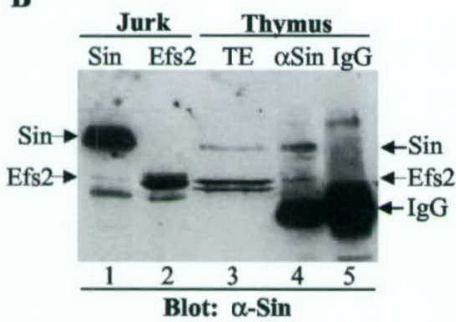

C

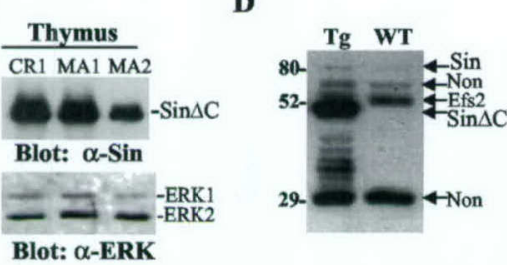

FIGURE 1. Two different $\mathrm{Sin}$ isoforms are expressed in the thymus. A, Schematic representation of Sin isoforms and $\operatorname{Sin} \Delta \mathrm{C}$. Full-length Sin consists of a SH3 domain, a central region containing eleven tyrosine residues, and two proline-rich motifs (RPLPALP and RPLPPPP) that have high binding affinity and specificity for Src kinase SH3 domains. Efs2 is a naturally occurring isoform that is missing 93 aa consisting of the entire SH3 domain and additional residues before the central substrate-binding region of the protein. Sin $\Delta \mathrm{C}$ is missing an $\sim 200$ aa fragment, which contains the second proline-rich motif (RPLPPPP), three tyrosine residues, and a conserved region of $\sim 140$ aa at the extreme $\mathrm{C}$ terminus. $\mathrm{Y}$ represents tyrosinecontaining sequences ( $\mathrm{Y}$ motifs), $\mathrm{P}$ represents proline-rich motifs. $B$, Western blots of thymocyte and Jurkat $\mathrm{T}$ cell extracts probed with a Sin-specific $\mathrm{mAb}$ to reveal expression of the Sin isoforms. Lanes 1 and 2 represent total cell lysates from Jurkat cells overexpressing full-length Sin and Efs2 as controls. TE represents total thymocyte extract (lane 3) probed with antiSin-specific $\mathrm{Ab}$. In lanes 4 and 5 , cell extracts from $10^{7}$ thymocytes were immunoprecipitated with anti-Sin or isotype-matched control IgG, proteins were separated on SDS-PAGE and Western blotted with Sin-specific Ab. $C$, Thymocyte cell extracts from three different founders expressing $\operatorname{Sin} \Delta C$ were separated on SDS-PAGE and Western blotted with anti-Sin Ab. The blot was stripped and reprobed with ERK-specific $\mathrm{Ab}$ as a loading control. $D$, Endogenous Sin expression was compared with expression of $\operatorname{Sin} \Delta C$ from CR1 mice on Western blots of thymocyte total cell extracts probed with Sin-specific Ab. Two nonspecific bands (Non) are recognized by the $\mathrm{Sin} \mathrm{Ab}$ on Western blots. The lower nonspecific band was included as a control for equal loading. adapter function (29). $\operatorname{Sin} \Delta \mathrm{C}$ expression in the transgenic animals is regulated by the human $\mathrm{CD} 2$ promoter, which allows transgene expression in both thymocytes and mature $\mathrm{T}$ cells (34).

Transgenic progeny from three founder mice were identified by PCR and Southern blot analysis and expression of the transgene was confirmed in thymocyte extracts using a Sin-specific Ab (Fig. $1 C$ ). Two transgenic lines CR1 and MA2 with 22 and 13 integrated copies of the transgene, respectively, were chosen for further studies. Expression of the transgene in CR1 mice was compared with the endogenous full-length Sin and Efs2 proteins on Western blots of total thymocyte lysates probed with Sin-specific $\mathrm{Ab}$ as shown (Fig. 1D). Expression of Efs2 is more pronounced than full-length $\operatorname{Sin}$ and in transgenic lysates Efs 2 migrates slightly above $\operatorname{Sin} \Delta \mathrm{C}$. The physiologic significance for the presence of two different isoforms is currently not clear and is under investigation.

\section{Effect of $\operatorname{Sin} \Delta C$ expression on thymocyte development}

Thymocyte development is a series of complex developmental events that culminates in the production of mature $\mathrm{T}$ cells from immature precursors. The different stages of thymocyte development are characterized by the sequential expression of surface markers such as CD44 and CD25, the pre-TCR, and the CD4 and CD8 coreceptors. $\mathrm{CD}^{-}{ }^{-} \mathrm{CD} 8^{-}$double-negative (DN) cells undergo rearrangement of the TCR $\beta$ and successful rearrangement together with pre-TCR engagement allows their progression to the $\mathrm{CD} 4{ }^{+} \mathrm{CD} 8{ }^{+}$double-positive (DP) stage (37-41). $\mathrm{CD} 4^{+} \mathrm{CD} 8^{+} \mathrm{DP}$ cells that have successfully rearranged their TCR $\alpha$ locus subsequently undergo positive or negative selection. Positively selected thymocytes down-regulate expression of either their CD4 or CD8 coreceptors to become mature $\mathrm{CD} 4^{+}$or $\mathrm{CD}^{+}{ }^{+} \mathrm{SP}$ mature $\mathrm{T}$ cells $(41,42)$.

Initial analysis of transgenic animals revealed that the thymi of the $\operatorname{Sin} \Delta \mathrm{C}$-expressing animals were smaller in size than the wildtype controls. Analysis of multiple animals showed that, consistent with the smaller thymus, the total transgenic thymocyte numbers recovered were $\sim 40 \%$ of wild-type levels (Fig. $2 A$ ). The decrease in total number of thymocytes was due to significant decreases in the number of cells in the DP, CD4, and CD8 SP populations, and an observed, however, not significant reduction in the DN population, (Fig. 2B).

To further examine the effect of $\operatorname{Sin} \Delta C$ expression on thymocyte development, thymocytes from wild-type and transgenic littermates were stained with fluorescently labeled mAbs against different surface molecules such as CD4, CD8, CD3 $\epsilon$, and CD69. A representative flow cytometric analysis of thymocytes from two founder lines, CR1 and MA2, is shown in Fig. $2 C$. In addition, the percentage of cells within different thymocyte populations in relation to total thymocytes is shown at the bottom of Fig. $2 C$. When equal numbers of thymocytes were stained, we found that the percentage of cells that were negative for CD4/CD8 expression (DN), as well as cells bearing both CD4 and CD8 coreceptors (DP thymocytes), were unaffected in the transgenic animals (Fig. 2C). However, the same phenotypic analysis of these thymocytes revealed a substantial decrease in the percentages of mature $\mathrm{CD} 4^{+} 8^{-}$and $\mathrm{CD} 4{ }^{-} 8^{+}$SP cells (Fig. $2 C$ ). The $\mathrm{CD} 8^{+}$population in particular was most severely affected as the proportion of these cells was decreased by $\sim 70-90 \%$ as compared with normal controls (Fig. $2 C$ ). The effect of transgene expression on the percentage of $\mathrm{CD}^{+}$SP cells was a reduction by $\sim 50-60 \%$ (Fig. $2 C$ ). Taken together, these data suggest that $\operatorname{Sin} \Delta \mathrm{C}$ expression compromises the viability, but not the development of, DP thymocytes while specifically perturbing the maturation of SP cells.

To further characterize the maturation of thymocytes, we analyzed the expression of several thymocyte cell surface markers. 
FIGURE 2. Expression of $\operatorname{Sin} \Delta \mathrm{C}$ in the thymus interferes with normal thymocyte maturation. A, Total thymocytes from 6- to 8-wk-old wild-type and transgenic animals were counted and averaged as shown. At least five animals from two different transgenic lines were used. $B$, Cells within each thymic subset were enumerated by FACS analysis. Results from at least 10 wild-type and $18 \mathrm{CR} 1$ mice are represented as the mean $\pm \mathrm{SD}$. Similar results were obtained with the MA2 transgenic animals (data not shown). $C$, Thymocytes from 6- to 8-wk-old mice were stained with CD4-allophycocyanin and CD8PerCP mAbs $\left(1 \times 10^{6}\right.$ cells/well $)$ and analyzed by flow cytometry. Shown are CD4 vs CD8 plots of normal littermate controls and two transgenic lines CR1 and MA2 as shown. WT1 is litter-mate control for CR1 and WT2 for MA2. The numbers represent the percentage of thymocytes in the boxed areas. The bottom graphs represent percentages of cells within each population as shown, expressed in relation to total thymocyte numbers (mean $\pm \mathrm{SD}$ ). $D$, The histograms represent profiles of total thymocytes from wild type and transgenic animals stained with $\mathrm{CD} 3$ or CD69 Abs as shown. $E$, Histograms of $\mathrm{DP}, \mathrm{CD}^{+}{ }^{+}$and $\mathrm{CD} 8^{+}$cells stained with $\mathrm{CD} 4 / \mathrm{CD} 8$ $\mathrm{Abs}$ and FITC-conjugated $\mathrm{Ab}$ specific for different surface markers as shown. Wild-type cell populations are represented by the gray line, transgenic cells by the filled curve.
$\mathbf{A}$
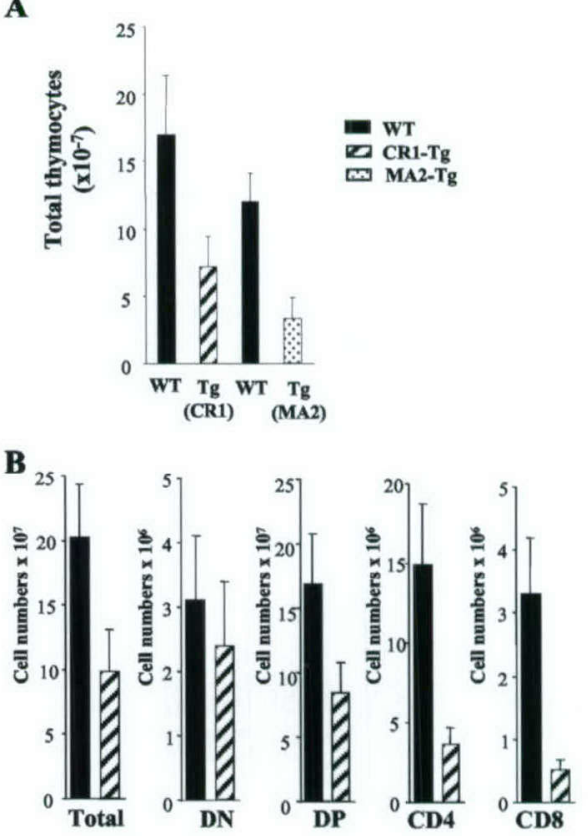

C
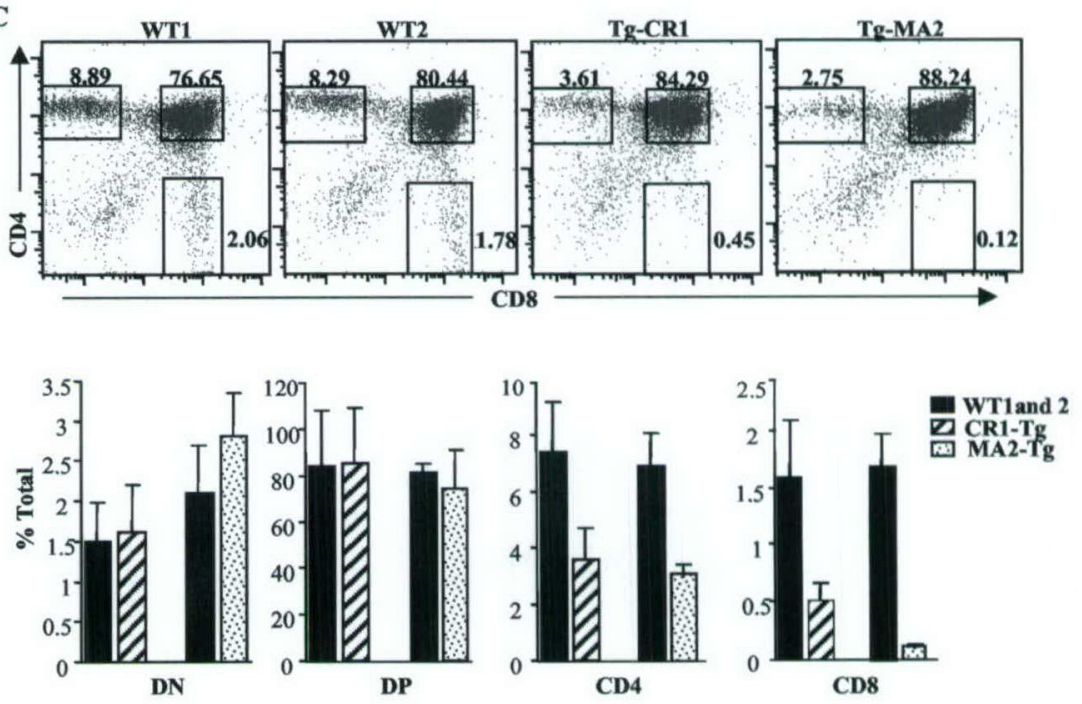

D

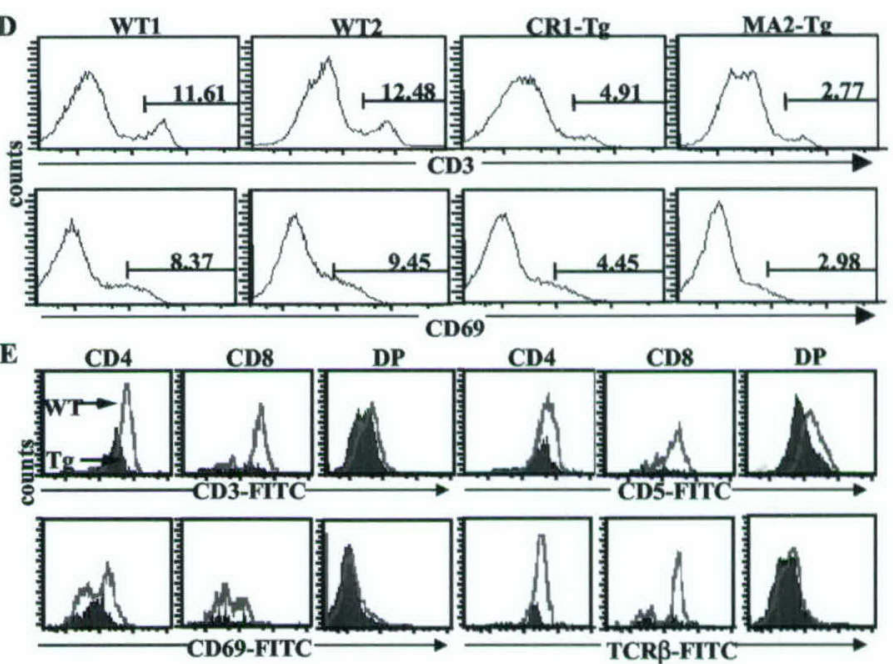


The first, CD3 3 , is a component of the TCR whose expression is up-regulated as thymocytes mature from the DP to the SP stage (43). The total $\mathrm{CD} 3^{\text {high }}$ mature $\mathrm{T}$ cell population normally represents $\sim 15 \%$ of total thymocytes. Staining of $\operatorname{Sin} \Delta \mathrm{C}$ transgenic thymocytes revealed a 2 - to 3 -fold decrease in the total $\mathrm{CD} 3^{\text {high }}$ population (Fig. 2D, CD3, top histograms). Additionally, for total thymocytes we observed reduced expression levels of CD69 (Fig. $2 D$, bottom histograms), a maturation marker whose expression correlates with positively selected, maturing thymocytes (44). Decreased expression of the CD3 and CD69 markers in the total thymocyte population could be explained by the decrease in SP cell populations (Fig. $2 B$ ) or by abnormally low levels of expression in the SP population.

To decipher between these two possibilities, we further examined the role of $\operatorname{Sin} \Delta \mathrm{C}$ expression on thymocyte development by analyzing the levels of several cell surface markers on the individual DP and $\mathrm{CD}^{+}{ }^{+}$and $\mathrm{CD} 8^{+} \mathrm{SP}$ cell populations. In addition to $\mathrm{CD} 3 \epsilon$ and $\mathrm{CD} 69$, we also analyzed the expression levels of the $\beta$ component of the TCR and CD5. CD5 is another maturation marker whose levels rise steadily during thymocyte maturation and is dependent on TCR signaling (45). Thus, thymocytes were triplestained with $\mathrm{CD} 4 / \mathrm{CD} 8$ and $\mathrm{CD} 3 \epsilon, \mathrm{TCR} \alpha \beta, \mathrm{CD} 5$, or CD69 mAbs. The different thymocyte populations from wild-type and transgenic animals were defined on the basis of CD4/CD 8 fluorescence intensity, and fluorescence histograms depicting CD3, CD5, CD69, or TCR $\beta$ expression on DP and SP cells are shown (Fig. 2E). The expression patterns for the different markers in all subpopulations were similar to the wild type, while the absolute numbers of cells in the $\mathrm{CD}^{+}{ }^{+}$and $\mathrm{CD}^{+}$compartments were less in the transgenic animals (Fig. 2E). Thus, the reduction in CD3 and CD69 expression in the entire thymocyte population is solely due to the reduc- tion of the $\mathrm{CD}^{+}$and $\mathrm{CD} 8^{+} \mathrm{SP}$ population, rather than lower levels of $\mathrm{CD} 3 / \mathrm{CD} 69$ expression. Consistent with this, we also found that the decrease in T lymphocyte numbers was not confined to the thymus because the numbers of mature splenic $\mathrm{T}$ cells of both the CD4 and CD8 lineages were substantially reduced $(\sim 50 \%)$ in transgenic animals as compared with normal littermate controls (data not shown). In addition, staining of splenocytes with B cell-specific Abs (B220, IgM) revealed that the B cell compartment was intact, consistent with CD2-promoter-mediated, $\mathrm{T}$ cellspecific expression of $\operatorname{Sin} \Delta \mathrm{C}$ (data not shown). In summary, our results show that expression of $\operatorname{Sin} \Delta \mathrm{C}$ in thymocytes inhibits production of normal numbers of mature $\mathrm{T}$ cells and suggest that the truncated Sin mutant is a negative regulator of $\mathrm{T}$ lymphocyte differentiation.

\section{Effect of Sin $\Delta C$ expression on thymocyte apoptosis}

As shown above in Fig. $2 A$, the total transgenic thymocyte numbers recovered were $\sim 40 \%$ of wild-type levels. DP thymocytes constitute the bulk of the thymus and we found that the actual cell numbers of transgenic DP thymocytes were reduced by $50 \%$ (Fig. $2 B$ ). However, the percentage of transgenic DP thymocytes recovered were similar to wild-type controls, suggesting that $\operatorname{Sin} \Delta C$ expression affects the survival, but not the development, of these thymocytes. Thus, we examined whether the inhibitory effect of $\operatorname{Sin} \Delta \mathrm{C}$ was caused by enhanced levels of thymocyte apoptosis.

Freshly prepared thymocytes from wild-type and CR1 transgenic animals were cultured in medium for $6 \mathrm{~h}$ before staining with the vital dye 7AAD and annexin V. Typical results from twoparameter analyses are shown in Fig. $3 A$ (dot plots). Indeed, we observed a higher percentage of annexin V-positive cells from transgenic animals $(28.59 \%)$ as compared with wild type $(9.60 \%)$,
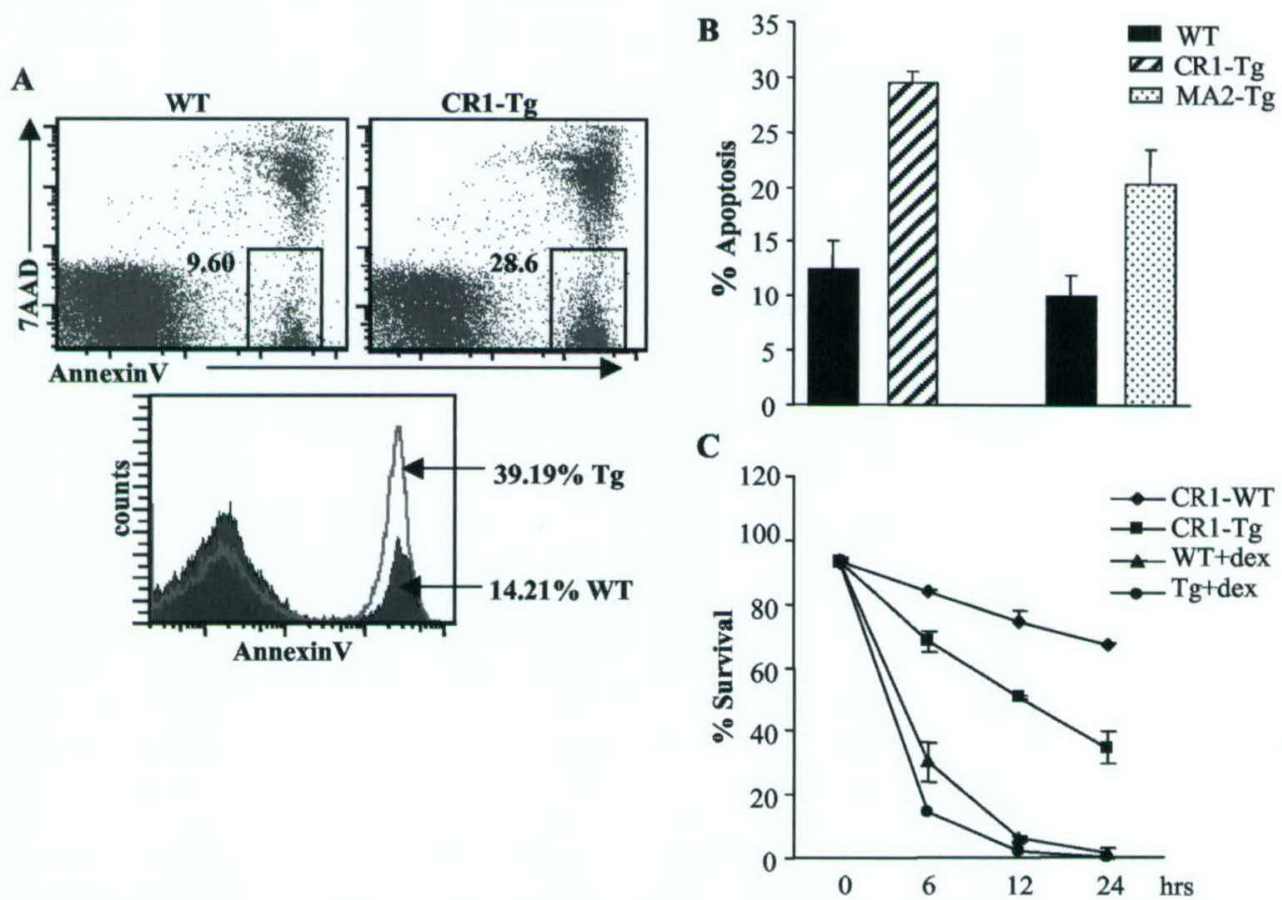

FIGURE 3. Sin $\Delta C$ expression increases thymocyte apoptosis. A, Total thymocytes from CR 1 animals were cultured for $6 \mathrm{~h}$ and then stained with Annexin $\mathrm{V}^{\mathrm{PE}}$ and 7AAD. Representative dot plots of a two-parameter FACS analysis are presented for wild-type and transgenic thymocytes. Boxed areas represent the percentages of cells undergoing early apoptosis (annexin $\mathrm{V}^{+}, 7 \mathrm{AAD}^{-}$). A histogram of total annexin $\mathrm{V}$ staining is shown at the bottom along with percentages of wild-type and transgenic cells undergoing cell death. $B$, Wild-type and transgenic thymocytes from CR1 and MA2 mice were harvested, cultured for $6 \mathrm{~h}$, and then stained with 7AAD and annexin V. Percent apoptosis is represented as the number of cells that are annexin $\mathrm{V}^{+} / 7 \mathrm{AAD}^{-}$(early apoptosis) averaged from three different experiments expressed as mean $\pm \mathrm{SD}$, for two transgenic founders as shown. $C$, Thymocytes from wild-type and transgenic CR1 mice were cultured with or without dexamethasone for the indicated times and then stained with 7AAD and annexin V. Percent survival is represented as the number of live cells (7AAD and annexin $\mathrm{V}$-negative) remaining at each time interval. 
thus revealing that there is enhanced spontaneous apoptosis in the transgenic thymocytes (Fig. 3A). This increase was consistent in cells undergoing early apoptosis $\left(7 \mathrm{AAD}^{-}\right.$/annexin $\left.\mathrm{V}^{+}\right)$as well as in thymocytes at a later stage of cell death $\left(7 \mathrm{AAD}^{+} /\right.$annexin $\mathrm{V}^{+}$) (Fig. 3A, right and bottom panels). Results from several experiments using two different founder lines (CR1 and MA2) show a $>2$-fold increase in spontaneous thymocyte apoptosis in transgenic mice as compared with normal controls (Fig. 3B). We also found a concurrent decrease in transgenic thymocyte survival as determined by decreased numbers of live $7 \mathrm{AAD}^{-}$/annexin $\mathrm{V}^{-}$ cells over a 24-h period (Fig. $3 C$ ). Dexamethasone treatment of wild-type and transgenic cells was included in these experiments as a control for thymocyte apoptosis (Fig. 3C). These results suggest that expression of $\operatorname{Sin} \Delta \mathrm{C}$ reduces thymic cellularity by increasing thymocyte apoptosis, thus negatively regulating thymocyte survival.

\section{Role of the Src kinases in Sin $\Delta C$-mediated inhibition of} thymocyte survival and maturation

Sin and similar adapter molecules exhibit no known enzymatic activity and modulate signaling through the formation of proteinprotein interactions mediated by proline-rich and tyrosine-based motifs (29). Phosphorylation of the tyrosine-based motifs by tyrosine kinases is essential for binding of these residues to their ligands, which are SH2-domain-containing signaling intermediates $(19,33)$. In previous experiments, we found that the truncated form of Sin, used in this study as the transgene, can very efficiently bind to the Fyn- and Src-SH3 domains through its proline-containing motif, activate Src kinase signaling, and become constitutively phosphorylated on tyrosine residues $(23,29)$. We speculated that expression of the truncated mutant in thymocytes should then lead to Src kinase-mediated constitutive $\operatorname{Sin} \Delta \mathrm{C}$ phosphorylation and signaling. Given that Sin was cloned as a Src kinase ligand and Fyn and Lck are the most prevalent Src kinases in thymocytes, we tested whether Fyn and/or Lck could interact with $\operatorname{Sin} \Delta \mathrm{C}$ in transgenic thymocytes.

Thymocyte cell extracts from wild-type and transgenic animals were immunoprecipitated with Fyn- and Lck-specific Abs, and the immune complexes were incubated in the presence of radioactive ATP. We found that the $\operatorname{Sin} \Delta \mathrm{C}$ protein associated with and was phosphorylated by Fyn in vitro (Fig. $4 A$, left panels). In addition, we found that Fyn associated with phosphorylated Sin in anti-Sin immunoprecipitates (Fig. 4A, right panels). This was expected, given the specificity of the proline-rich motif of $\operatorname{Sin} \Delta \mathrm{C}$ for the Src and Fyn SH3 domains (23) which is a prerequisite for stable association of $\operatorname{Sin}$ with these kinases (16). In addition to $\operatorname{Sin} \Delta C$, we also tested the phosphorylation of the exogenous substrate, enolase, which has traditionally been used to assay for increased Src kinase activity (35). As with $\operatorname{Sin} \Delta C$, enolase was also phosphorylated in transgenic, but not wild-type, cell extracts, consistent with the proposed $\operatorname{Sin} \Delta C$-induced activation of Fyn (Fig. $4 B$ ). In contrast to Fyn, we did not observe $\operatorname{Sin} \Delta \mathrm{C}$ binding to Lck (Fig. $4 A$, middle panels). This observation is not surprising given that the proline-rich motifs of Sin do not recognize the Lck-SH3 domain (16). This is due to the fact that the Lck SH3 domain is the most divergent within the Src family, recognizing a different consensus sequence than the Fyn and Src SH3 domains which is not present on $\operatorname{Sin}(23,46,47)$. Thus, these results show that $\operatorname{Sin} \Delta C$ preferentially binds to Fyn in thymocytes and suggest that Fyn-dependent phosphorylation of $\operatorname{Sin} \Delta \mathrm{C}$ may be important for the inhibitory effects of $\operatorname{Sin} \Delta \mathrm{C}$ in thymocyte development.
$\mathbf{A}$

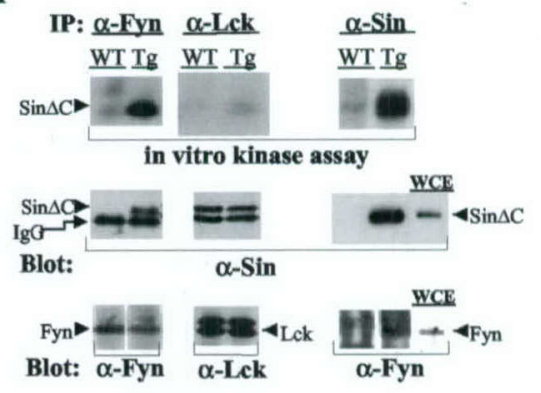

B

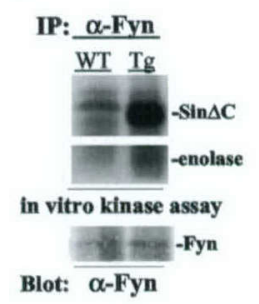

C

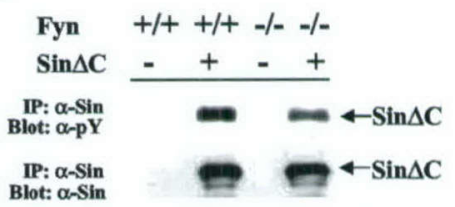

FIGURE 4. $\operatorname{Sin} \Delta \mathrm{C}$ interacts with the Src kinase Fyn in thymocytes. Thymocyte cell extracts from wild-type and $\operatorname{Sin} \Delta \mathrm{C}$ transgenic mice were immunoprecipitated with Fyn-, Lck- and Sin-specific Abs, and immune complexes were incubated in vitro with $\left[\gamma^{32}\right.$-P]ATP for $10 \mathrm{~min}$. Proteins were separated by electrophoresis and blotted onto nitrocellulose membrane. The membrane was exposed on film for $24 \mathrm{~h}$ at $-70^{\circ} \mathrm{C}$ (top panels). Then the same membrane was first incubated with Sin-specific Ab (middle panels), and then were stripped and reprobed with either Fyn- or Lckspecific Abs as shown (bottom panels). Protein bands were visualized by ECL. In the middle panel, the bands from the Lck immunoprecipitation probed with the $\mathrm{Sin} \mathrm{Ab}$ are nonspecific bands. $B$, Thymocyte cell extracts were immunoprecipitated and kinase assays performed as in $A$, except that $5 \mu \mathrm{g}$ of purified enolase were exogenously added to each tube. The membrane was stripped and reprobed with Fyn-specific Ab. $C$, Sin $\Delta \mathrm{C}$-expressing thymocytes from wild-type or $\mathrm{fyn}^{-1-}$ animals were immunoprecipitated with anti-Sin Ab and Western blotted first with antiphosphotyrosine and then with Sin-specific Abs. Protein bands were visualized by ECL.

Fyn is required for Sin $\Delta C$-mediated thymocyte apoptosis but not for $\operatorname{Sin} \Delta C$-mediated inhibition of thymocyte maturation

Given that $\operatorname{Sin} \Delta \mathrm{C}$ preferentially binds to and is phosphorylated by Fyn in thymocytes (Fig. 4A), we speculated that Fyn-mediated phosphorylation of $\operatorname{Sin} \Delta \mathrm{C}$ in the thymus may regulate the inhibitory effects of $\operatorname{Sin} \Delta \mathrm{C}$ on thymocyte survival and maturation. To test the role of Fyn in $\operatorname{Sin} \Delta \mathrm{C}$-mediated inhibition of thymocyte maturation and survival, we crossed the $\operatorname{Sin} \Delta \mathrm{C}$-expressing mice to $f y n^{-1-}$ animals $(31,32)$. Thymocytes from normal and $\operatorname{Sin} \Delta \mathrm{C}$ expressing animals in a fyn $n^{+/-}$or $f_{y n^{-1-}}$ background were stained with CD4/CD8 and analyzed by flow cytometry. We found that in the absence of Fyn, Sin $\Delta \mathrm{C}$ still blocked thymocyte maturation, again shown by reduced percentages of $\mathrm{CD}^{+}{ }^{+}$, and especially $\mathrm{CD}^{+}$, SP cells (Fig. 5A). Thus, these data suggest that Fyn is not required for the inhibitory effect of $\operatorname{Sin} \Delta \mathrm{C}$ in thymocyte differentiation. Fyn ${ }^{-1-} / \mathrm{Sin} \Delta \mathrm{C}^{-}$thymocytes were also analyzed and found to be similar to $\mathrm{Fyn}^{+/-} / \mathrm{Sin} \Delta \mathrm{C}^{-}$thymocytes (not shown), consistent with data obtained with $f y n^{-1-}$ animals showing that the absence of Fyn has no effect on thymocyte development $(31,32)$. In 
FIGURE 5. Fyn is dispensable for the inhibitory effect of $\operatorname{Sin} \Delta \mathrm{C}$ on thymocyte maturation but is required for Sin $\Delta C$-mediated thymocyte apoptosis. A, Thymocytes from 6- to 8-wk-old mice were stained with antiCD4 and anti-CD8 Abs and analyzed by flow cytometry as in Fig. 2. Shown are CD4 vs CD8 plots of normal or transgenic mice from two transgenic lines (CR1, MA2) in heterozygous or null fyn background as shown. The numbers represent the percentages of thymocytes in the boxed areas. A representative analysis of four experiments is shown. $B$, Freshly isolated thymocytes were counted and total cell numbers were plotted as shown expressed as mean $\pm \operatorname{SD}(n=5)$. $C$, Cells from wild-type or $\mathrm{fyn}^{-1-}$ animals in the presence or absence of $\operatorname{Sin} \Delta \mathrm{C}$ were also incubated at $37^{\circ} \mathrm{C}$ for $6 \mathrm{~h}$, stained with annexin $\mathrm{V}$ and 7AAD and analyzed by flow cytometry. $D$, Percent apoptosis is represented as the percentage of cells that are annexin $\mathrm{V}^{+} / 7 \mathrm{AAD}^{-}$ (early apoptosis) from different samples, normalized to percent apoptosis obtained from staining $\mathrm{Fyn}^{+/+}$, $\operatorname{Sin} \Delta \mathrm{C}^{+}$thymocytes which was given an arbitrary value of 100 .

$\mathbf{B}$
$\mathbf{A}$
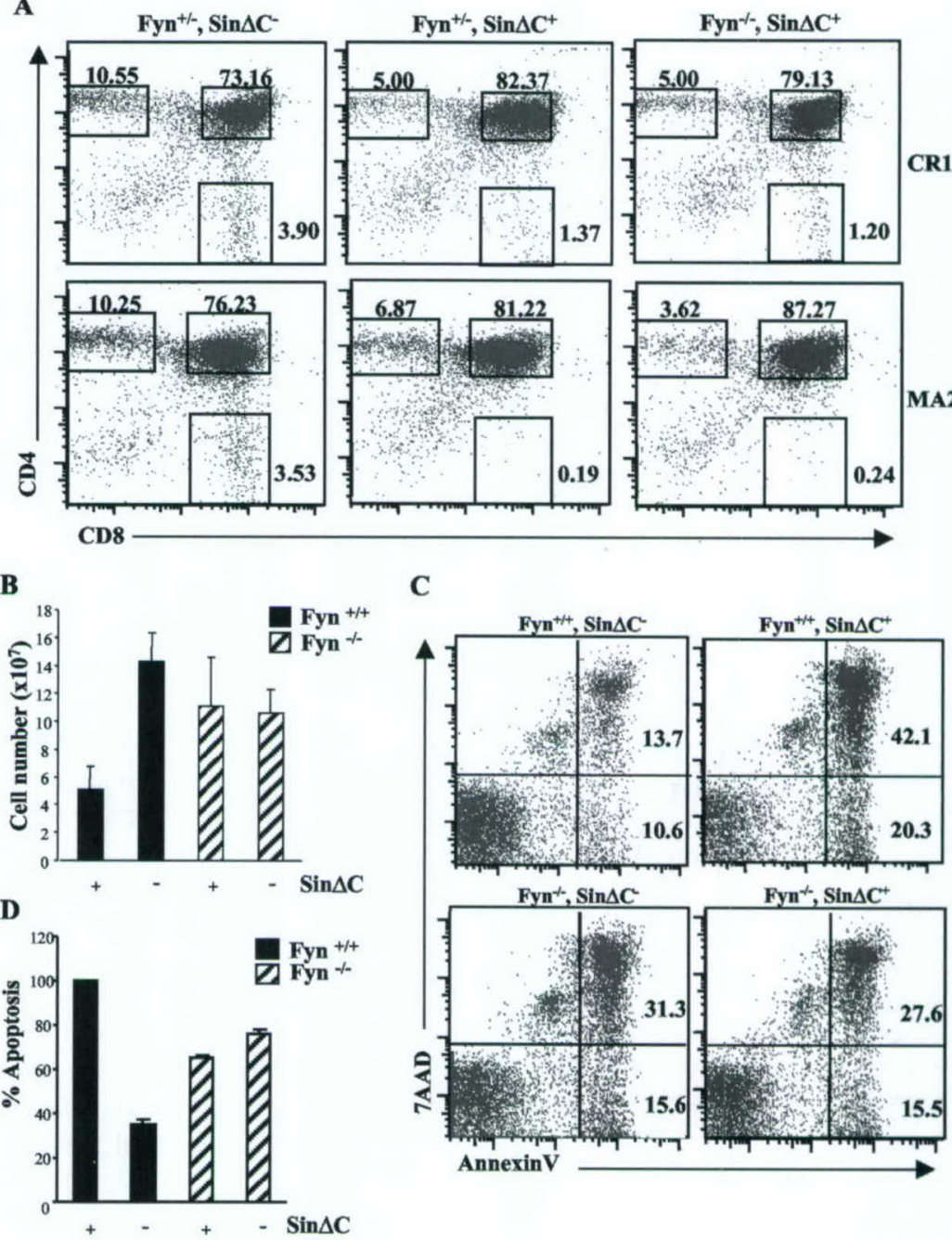

C

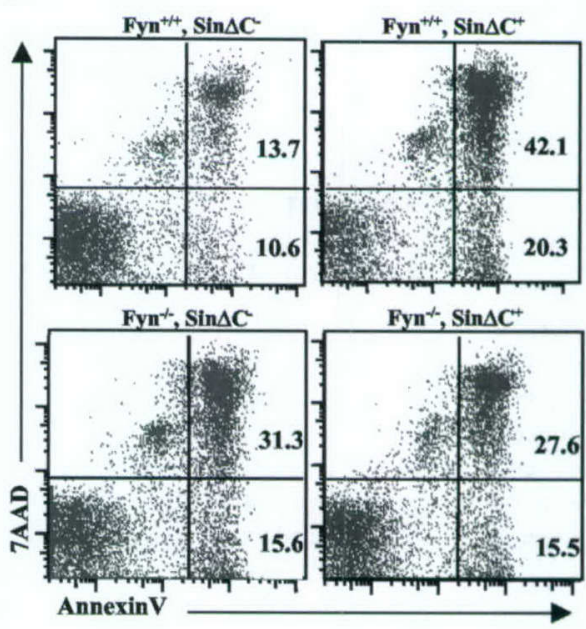

addition, we found that although $\operatorname{Sin} \Delta \mathrm{C}$ is a substrate of, and is phosphorylated by Fyn in vitro (Fig. $4 A$ ), immunoprecipitation of $\operatorname{Sin} \Delta \mathrm{C}$ from $f y n^{-/-} / \mathrm{Sin} \Delta \mathrm{C}^{+}$thymocytes shows reduced but significant residual $\operatorname{Sin} \Delta \mathrm{C}$ phosphorylation (Fig. $4 \mathrm{C}$ ). These results suggest that in addition to Fyn, other kinases phosphorylate $\operatorname{Sin} \Delta \mathrm{C}$ and may regulate the effects of this protein on thymocyte maturation.

Subsequently, we examined whether the effect of $\operatorname{Sin} \Delta C$-mediated reduction in total thymocyte numbers required Fyn. Consistent with the results shown above (Fig. $2 A$ ) we found a substantial reduction in total thymocyte numbers in cells expressing $\operatorname{Sin} \Delta \mathrm{C}$ in a wild-type Fyn background as compared with normal thymocytes (Fig. $5 B$ ). However, in the absence of Fyn, $\operatorname{Sin} \Delta \mathrm{C}$ expression had no effect on thymocyte numbers, suggesting that Fyn is required for the decrease in thymic cellularity observed in $\operatorname{Sin} \Delta \mathrm{C}$ transgenic animals (Fig. 5B). To further address the role of Fyn in Sin $\Delta C$ mediated thymic atrophy, we examined thymocyte apoptosis in a $\operatorname{Sin} \Delta \mathrm{C} / \mathrm{fyn}^{-1-}$ background. To this end, thymocytes from wildtype and transgenic animals in a wild-type or null fyn background were analyzed as in Fig. 3. Annexin V and 7AAD staining revealed that $\operatorname{Sin} \Delta \mathrm{C}$ expression led to increased spontaneous thymocyte apoptosis (Fig. 5C) consistent with the results presented in Fig. 3. In contrast, although we observed higher levels of apoptosis in $f_{y} n^{-1}$ thymocytes, no further effect was observed in the presence of $\operatorname{Sin} \Delta C$ (Fig. 5, $C$ and $D$ ), again suggesting that Fyn is required for the effects of $\operatorname{Sin} \Delta \mathrm{C}$ on thymocyte apoptosis. Similar results were obtained with thymocytes from MA2 transgenic animals (not shown).

\section{$\operatorname{Sin} \Delta C$ expression does not inhibit phosphorylation events proximal to the TCR}

Given that Fyn regulates phosphorylation events proximal to the TCR after receptor cross-linking $(31,32)$, we examined whether $\operatorname{Sin} \Delta C$ expression had an effect on total protein tyrosine phosphorylation induced in response to TCR cross-linking. Thymocytes from wild type and $\operatorname{Sin} \Delta \mathrm{C}$ animals were stimulated for the indicated times by TCR cross-linking using anti-CD3 $\epsilon$-specific Ab and Western blots of total cell lysates were immunoblotted with antiphosphotyrosine-specific Ab. We found no discernible differences in the pattern of tyrosine phosphorylated proteins between wild type and transgenic lysates with the notable exception of $\operatorname{Sin} \Delta C$, which is prominently and constitutively phosphorylated in transgenic cell lysates (Fig. 6A). This observation was consistent with previous experiments (29) and our rationale that the truncated mutant would efficiently interact with Src kinases and be effectively phosphorylated. Thus, our results suggest that $\operatorname{Sin} \Delta \mathrm{C}$ expression has no effect on Lck/Fyn-mediated phosphorylation events proximal to the TCR and that $\operatorname{Sin} \Delta \mathrm{C}$ may exert its inhibitory effects downstream of the receptor and the signal-initiating phosphorylation events. These results also suggest that $\operatorname{Sin} \Delta \mathrm{C}$ is 
$\mathbf{A}$

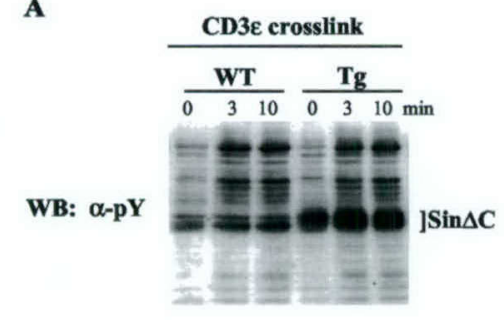

B

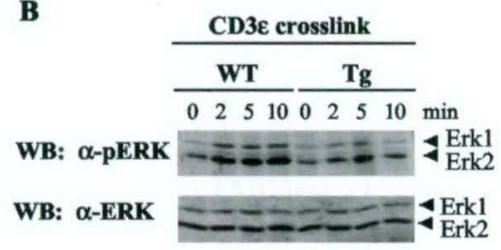

C

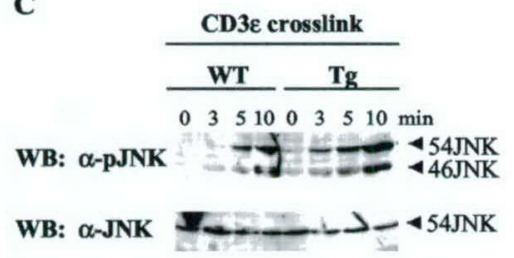

FIGURE 6. Normal total tyrosine phosphorylation but reduced ERK activation in $\operatorname{Sin} \Delta \mathrm{C}$-expressing thymocytes. Thymocytes were cross-linked with anti-CD3 $\mathrm{Ab}$ for the indicated times at $37^{\circ} \mathrm{C}$. Western blots of total cell extracts were incubated with the following Abs: anti-phosphotyrosine $(A)$, anti-phospho-ERK and anti-phospho-JNK ( $B$ and $C$, top panels), stripped and reprobed with anti-ERK or anti-JNK as shown ( $B$ and $C$, bottom panels). Protein bands were visualized using ECL.

not acting as a competitive inhibitor for Fyn/Lck-mediated substrate phosphorylation due to overexpression.

\section{Sin $\triangle C$ expression inhibits ERK, but not JNK, MAPK phosphorylation}

Given the lack of an effect of $\operatorname{Sin} \Delta \mathrm{C}$ expression on tyrosine phosphorylation events proximal to the TCR, we examined the effect of $\operatorname{Sin} \Delta \mathrm{C}$ on downstream signaling events such as phosphorylation of the MAPKs ERK and JNK. Activation of these kinases in thymocytes is the result of TCR-mediated activation of the Ras signaling cascade $(48,49)$. Total thymocytes from normal or Sin $\Delta \mathrm{C}$ mice were incubated with anti $\mathrm{CD} 3 \epsilon \mathrm{Ab}$ for different times at $37^{\circ} \mathrm{C}$. Total cell extracts were fractionated and blotted with antiphospho-ERK or JNK Abs which recognize the phosphorylated, active forms of ERK1,2 and JNK. In normal thymocyte cell extracts, phosphorylation of ERK1,2 was rapidly stimulated in response to TCR cross-linking, and was sustained for at least $10 \mathrm{~min}$ (Fig. 6B, top panel). In contrast, ERK1,2 phosphorylation in thymocyte cell extracts from $\operatorname{Sin} \Delta C$ mice was less pronounced and was rapidly down-regulated (Fig. 6B, top panel). In contrast, JNK phosphorylation was intact in transgenic lysates immunoblotted with phospho-JNK-specific Ab (Fig. 6C, top panel). The levels of total ERK1,2 and JNK proteins, revealed by immunoblotting with specific Abs against total ERK and JNK, were similar in all cases (Fig. 6, $B$ and $C$, bottom panels). These data show that the levels as well as the kinetics of ERK1,2 stimulation in $\operatorname{Sin} \Delta \mathrm{C}$ thymocytes are inhibited as compared with normal controls and suggest that $\operatorname{Sin} \Delta \mathrm{C}$ may inhibit thymocyte function by interfering with normal ERK activation.

\section{Discussion}

In this report, we examined the role of the novel adapter molecule $\mathrm{Sin}$ in T lymphocyte function. We used this system for our studies because the thymus is one of the tissues in which Sin is most highly expressed. In addition, two Src kinases, Lck and Fyn, potentially involved in Sin phosphorylation, are also expressed in the thymus and are important for T lymphocyte function. In previous studies, we showed that full-length Sin is less potent in its ability to mediate Src kinase signaling as compared with a truncated form, $\operatorname{Sin} \Delta \mathrm{C}$. Therefore, in the present study we expressed $\operatorname{Sin} \Delta \mathrm{C}$ in the thymocytes of transgenic animals with the assumption that truncated Sin would act as an activated mutant that would more efficiently interact with and become phosphorylated by endogenous Src kinases. Efficient phosphorylation of Sin by Src and possibly other kinases is essential for the adapter function of Sin. Consistent with this, $\operatorname{Sin} \Delta \mathrm{C}$ was constitutively phosphorylated by Fyn in transgenic thymocytes. We found that expression of Sin $\Delta C$ inhibited thymocyte maturation, shown by reduced percentages of $\mathrm{CD}^{+}{ }^{+}$and particularly $\mathrm{CD} 8^{+}$cells, and induced thymocyte apoptosis. We also found that Fyn was required for the effect of $\operatorname{Sin} \Delta \mathrm{C}$ on thymocyte apoptosis but not for inhibition of thymocyte transition to SP cells. In the same experiments, $\operatorname{Sin} \Delta \mathrm{C}$ failed to associate with and become phosphorylated by Lck.

The observation that Fyn is not required for the negative effects of $\operatorname{Sin} \Delta \mathrm{C}$ on mature $\mathrm{T}$ cell production is not surprising given that $\mathrm{fyn}^{-1-}$ animals exhibit normal $\mathrm{T}$ cell maturation $(31,32)$. Therefore, $\operatorname{Sin} \Delta \mathrm{C}$ may be exerting this inhibitory effect through association with other kinases and/or intracellular signaling molecules. Consistent with the involvement of kinase(s) other than Fyn or Lck is our observation that there is significant residual tyrosine phosphorylation of $\operatorname{Sin} \Delta \mathrm{C}$ in $f y n^{-/-}$thymocytes. Although the identity of this kinase(s) is currently unknown, efforts are under way to identify additional proteins that may phosphorylate $\operatorname{Sin} \Delta \mathrm{C}$ on tyrosine residues. Alternatively, other conserved domains mediating protein-protein interactions such as proline-rich motifs may be mediating the effects of Sin.

Although Fyn is not required for $\operatorname{Sin} \Delta \mathrm{C}$-mediated inhibition of thymocyte maturation, Fyn is necessary for the effects of $\operatorname{Sin} \Delta C$ on thymic cellularity and thymocyte apoptosis. Indeed, we found that in the absence of Fyn, $\operatorname{Sin} \Delta \mathrm{C}$ had no effect on thymocyte numbers and thymocyte apoptosis (Fig. 5, $B$ and $C$ ). We also observed a consistent reduction of total thymocyte numbers in $\mathrm{fyn}^{-/-}$animals and increased apoptosis as compared with wild-type cells (Fig. 5, $B$ and $C$ ). This finding could be explained by existing evidence suggesting that Fyn contributes to the generation of DP thymocytes. In lck null animals, the production of mature SP T cells is severely impaired whereas DP thymocytes are being produced albeit at reduced levels (30). However, the presence of these DP cells is completely obliterated in the $f y n^{-1-} / l c k^{-1-}$ double null background, suggesting that Fyn can compensate for Lck in the production of DP cells $(50,51)$. This could explain the reduction in thymocyte numbers and increased apoptosis we observe with

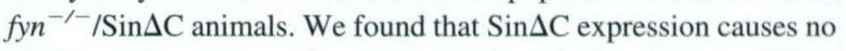
additional decrease on thymocyte numbers in the absence of Fyn, suggesting that $\operatorname{Sin} \Delta \mathrm{C}$-induced apoptosis requires Fyn. Thus, the increase in thymocyte apoptosis in transgenic animals could be the result of either a novel inhibitory signal mediated by phosphorylated $\operatorname{Sin} \Delta \mathrm{C}$ or of dominant inhibition of Fyn function by overexpressed $\operatorname{Sin} \Delta \mathrm{C}$.

In our experiments, we found that $\operatorname{Sin} \Delta \mathrm{C}$ is prominently phosphorylated in unstimulated transgenic cells, and that there may be 
a small increase in its phosphorylation in response to TCR crosslinking (Fig. 6A). More importantly, there are no apparent differences in the total protein tyrosine phosphorylation in the transgenic cells as compared with wild-type controls, in cell extracts from stimulated or unstimulated cells (Fig. 6A), unlike the reduced phosphorylation of substrates observed in fyn null thymocytes (31). The lack of a positive or negative effect of $\operatorname{Sin} \Delta \mathrm{C}$ expression on tyrosine phosphorylation has two implications. First, data presented in Fig. 4 suggest that expression of $\operatorname{Sin} \Delta \mathrm{C}$ in thymocytes leads to Fyn activation and $\operatorname{Sin} \Delta \mathrm{C}$ phosphorylation. If Fyn is indeed activated, we should observe increased substrate phosphorylation and a phenotype similar to that of mice overexpressing Fyn, i.e., hyperstimulatable thymocytes and increased substrate phosphorylation (52). This is opposite to our results with $\operatorname{Sin} \Delta \mathrm{C}$-activated Fyn. We believe this is due to the fact that ligand-activated Src kinases behave differently than their constitutively active counterparts that are induced as a result of mutations or overexpression. Thus, in contrast to constitutively activated Src kinases, expression of $\operatorname{Sin} \Delta C$ with Src kinase in a cell culture system does not lead to increased substrate phosphorylation and the signaling mechanism of $\operatorname{Sin} \Delta \mathrm{C}$-activated $\mathrm{Src}$ is different from signaling through constitutively active $\operatorname{Src}(16,29)$.

Second, the lack of a negative effect of $\operatorname{Sin} \Delta \mathrm{C}$ expression on substrate phosphorylation argues against a dominant inhibitory effect for Sin $\Delta \mathrm{C}$ on Fyn- and/or Lck-mediated phosphorylation due to $\operatorname{Sin} \Delta \mathrm{C}$ overexpression and supports the existence of a novel inhibitory signal(s) mediated by $\operatorname{Sin} \Delta \mathrm{C}$. Consistent with this, we found that phosphorylation of the MAPK ERK was impaired in $\operatorname{Sin} \Delta \mathrm{C}$-expressing cells as compared with normal controls. This effect was specific to ERK because phosphorylation of the related MAPK JNK was normal. These results suggest that $\operatorname{Sin} \Delta \mathrm{C}$ may be specifically inhibiting ERK activation through a mechanism downstream of the phosphorylation events proximal to the TCR.

During thymocyte maturation, $\alpha \beta$ T cells undergo positive or negative selection, events that are regulated by TCR ligation of self-peptide-MHC complexes on epithelial cells of the cortex. There is substantial evidence that ERK kinase is an important regulator of positive selection of thymocytes. Early experiments with dominant negative inhibitors of the Ras-MAP or ERK kinase pathway showed that ERK activation through the Ras signaling cascade is required for positive selection and thymocyte maturation whereas negative selection proceeds unimpaired $(53,54)$. More recent evidence has shown that ERK activation can regulate both selection processes in immature thymocytes $(55,56)$. The threshold model can explain these apparently conflicting results. This model suggests that the kinetics and extent of ERK activation in response to TCR ligation determine positive vs negative selection (57-59). Collectively, these data suggest that ERK activation is an important signaling event in thymocyte maturation.

In our system, we found that ERK activation is impaired in thymocytes expressing $\operatorname{Sin} \Delta C$ (Fig. $6 B$ ). The effect of $\operatorname{Sin} \Delta C$ on thymocyte maturation is strikingly similar to the effects observed in p44 MAPK (ERK1)-deficient mice. In these mice, thymocyte maturation beyond the DP CD $4{ }^{+} \mathrm{CD} 8^{+}$stage is reduced by half, with a similar decrease in thymocytes expressing high levels of the TCR (CD $\left.{ }^{\text {high }}\right)(60)$. These same phenotypic features are present in the $\operatorname{Sin} \Delta \mathrm{C}$ transgenic thymocytes. It is thus possible that reduced ERK activation and, as a consequence, alteration of signaling thresholds is responsible for the effects of $\operatorname{Sin} \Delta \mathrm{C}$ on thymocyte maturation in our system. $\operatorname{Sin} \Delta \mathrm{C}$-mediated changes in TCR-dependent signaling thresholds could in turn affect the positive and/or negative selection of $\operatorname{Sin} \Delta \mathrm{C}$-expressing DP thymocytes. Efforts are currently under way to elucidate the molecular mechanisms of $\operatorname{Sin} \Delta C$-mediated inhibition of ERK phosphorylation and its effects on positive and negative selection. To this end, $\operatorname{Sin} \Delta \mathrm{C}$ mice that have been sufficiently backcrossed to the C57/B6 background will be crossed to TCR transgenic mice, such as the H-Y TCR transgenic animals, to address the role of $\operatorname{Sin} \Delta \mathrm{C}$ expression on positive and/or negative selection.

Finally, because in our experiments we are using an activated form of $\operatorname{Sin}, \operatorname{Sin} \Delta C$, we believe that the effects of the truncated mutant on thymocyte maturation and apoptosis reflect the function of endogenous Sin and that endogenous $\mathrm{Sin}$ is a negative regulator of T lymphocyte function. This is supported by experiments in Jurkat cells showing that both full-length $\operatorname{Sin}$ and $\operatorname{Sin} \Delta C$ inhibit activation of NFAT and AP-1 reporter constructs in response to TCR stimulation and act as negative regulators of $\mathrm{T}$ cell activation (our unpublished observations). Experiments to further explore these observations are currently under way in the form of generating transgenic mice expressing full-length Sin and Sin knockout animals. We anticipate that these experiments will support a role for $\mathrm{Sin}$ as a negative regulator of $\mathrm{T}$ lymphocyte function and will provide novel insight into TCR-mediated signaling pathways.

\section{Acknowledgments}

We thank Jerry Siu and Yong-Rui Zou for critically reading the manuscript and Michael Weston for his input and helpful discussions.

\section{References}

1. Smith, F. D., and J. D. Scott. 2002. Signaling complexes: junctions on the intracellular information super highway. Curr. Biol. 12:R32.

2. Norian, L. A., and G. A. Koretzky. 2000. Intracellular adapter molecules. Semin. Immunol, 12:43.

3. Leo, A., and B. Schraven. 2001. Adapters in lymphocyte signalling. Curr. Opin. Immunol. 13:307.

4. Leo, A., J. Wienands, G. Baier, V. Horejsi, and B. Schraven. 2002. Adapters in lymphocyte signaling. J. Clin. Invest. 109:301.

5. Tomlinson, M. G., J. Lin, and A. Weiss. 2000. Lymphocytes with a complex: adapter proteins in antigen receptor signaling. Immunol. Today 21:584

6. Kennedy, J. S., M. Raab, and C. E. Rudd. 1999. Signaling scaffolds in immune cells. Cell Calcium 26:227.

7. Clements, J. L., N. J. Boerth, J. R. Lee, and G. A. Koretzky. 1999. Integration of T cell receptor-dependent signaling pathways by adapter proteins. Annu. Rev. Immunol. 17:89.

8. Pivniouk, V., E. Tsitsikov, P. Swinton, G. Rathbun, F. W. Alt, and R. S. Geha. 1998. Impaired viability and profound block in thymocyte development in mice lacking the adaptor protein SLP-76. Cell 94:229.

9. Sommers, C. L., R. K. Menon, A. Grinberg, W. Zhang, L. E. Samelson, and P. E. Love. 2001. Knock-in mutation of the distal four tyrosines of linker for activation of T cells blocks murine T cell development. J. Exp. Med. 194:135.

10. Zhang, W., C. L. Sommers, D. N. Burshtyn, C. C. Stebbins, J. B. DeJarnette, R. P. Trible, A. Grinberg, H. C. Tsay, H. M. Jacobs, C. M. Kessler, et al. 1999. Essential role of LAT in T cell development. Immunity 10:323.

11. Naramura, M., H. K. Kole, R. J. Hu, and H. Gu. 1998. Altered thymic positive selection and intracellular signals in Cbl-deficient mice. Proc. Natl. Acad. Sci. USA 95:15547.

12. Murphy, M. A., R. G. Schnall, D. J. Venter, L. Barnett, I. Bertoncello, C. B. Thien, W. Y. Langdon, and D. D. Bowtell. 1998. Tissue hyperplasia and enhanced T-cell signalling via ZAP-70 in c-Cbl-deficient mice. Mol. Cell. Biol. 18:4872.

13. Sosinowski, T., N. Killeen, and A. Weiss. 2001. The Src-like adaptor protein downregulates the $\mathrm{T}$ cell receptor on $\mathrm{CD} 4{ }^{+} \mathrm{CD}^{+}$thymocytes and regulates positive selection. Immunity 15:457.

14. Chiang, Y. J., H. K. Kole, K. Brown, M. Naramura, S. Fukuhara, R. J. Hu I. K. Jang, J. S. Gutkind, E. Shevach, and H. Gu. 2000. Cbl-b regulates the CD28 dependence of T-cell activation. Nature 403:216

15. Bachmaier, K., C. Krawczyk, I. Kozieradzki, Y. Y. Kong, T. Sasaki, A. Oliveira-dos-Santos, S. Mariathasan, D. Bouchard, A. Wakeham, A. Itie, et al 2000. Negative regulation of lymphocyte activation and autoimmunity by the molecular adaptor Cbl-b. Nature 403:211.

16. Alexandropoulos, K., and D. Baltimore. 1996. Coordinate activation of $\mathrm{c}-\mathrm{Src}$ by SH3- and SH2-binding sites on a novel p130Cas-related protein, Sin. Genes Dev. 10:1341.

17. Ishino, M., T. Ohba, H. Sasaki, and T. Sasaki. 1995. Molecular cloning of a cDNA encoding a phosphoprotein, Efs, which contains a Src homology 3 domain and associates with Fyn. Oncogene 11:2331.

18. Law, S. F., J. Estojak, B. Wang, T. Mysliwiec, G. Kruh, and E. A. Golemis. 1996 Human enhancer of filamentation 1, a novel p130 cas -like docking protein, associates with focal adhesion kinase and induces pseudohyphal growth in Saccharomyces cerevisiae. Mol. Cell. Biol. 16:3327.

19. O'Neill, G. M., S. J. Fashena, and E. A. Golemis. 2000. Integrin signalling: a new $\mathrm{Cas}^{\mathrm{t}}$ of characters enters the stage. Trends Cell Biol. 10:111. 
20. Minegishi, M., K. Tachibana, T. Sato, S. Iwata, Y. Nojima, and C. Morimoto. 1996. Structure and function of Cas-L, a 105-kD Crk-associated substrate-related protein that is involved in $\beta_{1}$ integrin-mediated signaling in lymphocytes. J. Exp. Med. 184:1365.

21. Iwata, S., Y. Ohashi, K. Kamiguchi, and C. Morimoto. 2000. $\beta_{1}$-integrin-mediated cell signaling in T lymphocytes. J. Dermatol. Sci. 23:75.

22. Feller, S. M., G. Posern, J. Voss, C. Kardinal, D. Sakkab, J. Zheng, and B. S. Knudsen. 1998. Physiological signals and oncogenesis mediated through Crk family adapter proteins. J. Cell. Physiol. 177:535.

23. Alexandropoulos, K., G. Cheng, and D. Baltimore. 1995. Proline-rich sequences that bind to Src homology 3 domains with individual specificities. Proc. Natl. Acad. Sci. USA 92:3110.

24. Songyang, Z., S. E. Shoelson, M. Chaudhuri, G. Gish, T. Pawson, W. G. Haser, F. King, T. Roberts, S. Ratnofsky, R. J. Lechleider, et al. 1993. SH2 domains recognize specific phosphopeptide sequences. Cell 72:767.

25. Cartwright, C. A., W. Eckhart, S. Simon, and P. L. Kaplan. 1987. Cell transformation by $\mathrm{pp} 60 \mathrm{c}^{s r c}$ mutated in the carboxy-terminal regulatory domain. Cell 49 : 83.

26. Cooper, J. A., and C. S. King. 1986. Dephosphorylation or antibody binding to the carboxy terminus stimulates pp60 ${ }^{\text {src }}$. Mol. Cell. Biol. 6:4467.

27. Kmiecik, T. E., and D. Shalloway. 1987. Activation and suppression of pp60e ${ }^{s r c}$ transforming ability by mutation of its primary sites of tyrosine phosphorylation. Cell 49:65.

28. Piwnica-Worms, H., K. B. Saunders, T. M. Roberts, A. E. Smith, and S. H. Cheng. 1987. Tyrosine phosphorylation regulates the biochemical and biological properties of pp60 $\mathrm{c}^{\text {src }}$. Cell 49:75.

29. Xing, L., C. Ge, R. Zeltser, G. Maskevitch, B. J. Mayer, and K. Alexandropoulos. 2000. c-Src signaling induced by the adapters Sin and Cas is mediated by Rap1 GTPase. Mol. Cell. Biol. 20:7363.

30. Molina, T. J., K. Kishihara, D. P. Siderovski, W. van Ewijk, A. Narendran, E. Timms, A. Wakeham, C. J. Paige, K. U. Hartmann, A. Veillette, et al. 1992. Profound block in thymocyte development in mice lacking $\mathrm{p} 56^{l c k}$. Nature 357 : 161.

31. Appleby, M. W., J. A. Gross, M. P. Cooke, S. D. Levin, X. Qian, and R. M. Perlmutter. 1992. Defective T cell receptor signaling in mice lacking the thymic isoform of p59fyn. Cell 70:751.

32. Stein, P. L., H. M. Lee, S. Rich, and P. Soriano. 1992. pp59 $9^{f y n}$ mutant mice display differential signaling in thymocytes and peripheral T cells. Cell 70:741.

33. Sakai, R., A. Iwamatsu, N. Hirano, S. Ogawa, T. Tanaka, H. Mano, Y. Yazaki, and H. Hirai. 1994. A novel signaling molecule, p130, forms stable complexes in vivo with $\mathrm{v}$-Crk and $\mathrm{v}$-Src in a tyrosine phosphorylation-dependent manner. EMBO J. 13:3748.

34. Zhumabekov, T., P. Corbella, M. Tolaini, and D. Kioussis. 1995. Improved version of a human CD2 minigene based vector for T cell-specific expression in transgenic mice. J. Immunol. Methods 185:133.

35. Cooper, J. A., F. S. Esch, S. S. Taylor, and T. Hunter. 1984. Phosphorylation sites in enolase and lactate dehydrogenase utilized by tyrosine protein kinases in vivo and in vitro. J. Biol. Chem. 259:7835.

36. Ishino, M., T. Ohba, J. Inazawa, H. Sasaki, Y. Ariyama, and T. Sasaki. 1997. Identification of an Efs isoform that lacks the $\mathrm{SH} 3$ domain and chromosomal mapping of human Efs. Oncogene 15:1741.

37. Godfrey, D. I., J. Kennedy, P. Mombaerts, S. Tonegawa, and A. Zlotnik. 1994. Onset of TCR- $\beta$ gene rearrangement and role of TCR- $\beta$ expression during $\mathrm{CD} 3^{-} \mathrm{CD} 4^{-} \mathrm{CD} 8^{-}$thymocyte differentiation. J. Immunol. 152:4783.

38. Hoffman, E. S., L. Passoni, T. Crompton, T. M. Leu, D. G. Schatz, A. Koff, M. J. Owen, and A. C. Hayday, 1996. Productive T-cell receptor $\beta$-chain gene rearrangement: coincident regulation of cell cycle and clonality during development in vivo. Genes Dev. 10:948.

39. Petrie, H. T., F. Livak, D. Burtrum, and S. Mazel. 1995. T cell receptor gene recombination patterns and mechanisms: cell death, rescue, and $\mathrm{T}$ cell production. J. Exp. Med. 182:121.
40. Tourigny, M. R., S. Mazel, D. B. Burtrum, and H. T. Petrie. 1997. T cell receptor (TCR)- $\beta$ gene recombination: dissociation from cell cycle regulation and developmental progression during T cell ontogeny. J. Exp. Med. 185:1549.

41. Berg, L. J., and J. Kang. 2001. Molecular determinants of TCR expression and selection. Curr. Opin. Immunol. 13:232.

42. Kisielow, P., and H. Von Boehmer. 1995. Development and selection of T cells: facts and puzzles. Adv. Immunol 58:87.

43. Takahama, Y., and A. Singer. 1992. Post-transcriptional regulation of early T cell development by $\mathrm{T}$ cell receptor signals. Science $258: 1456$.

44. Bendelac, A., P. Matzinger, R. A. Seder, W. E. Paul, and R. H. Schwartz. 1992. Activation events during thymic selection. J. Exp. Med. 175:731.

45. Azzam, H. S., A. Grinberg, K. Lui, H. Shen, E. W. Shores, and P. E. Love. 1998. CD5 expression is developmentally regulated by $\mathrm{T}$ cell receptor (TCR) signals and TCR avidity. J. Exp. Med. 188:2301.

46. Holdorf, A. D., J. M. Green, S. D. Levin, M. F. Denny, D. B. Straus, V. Link, P. S. Changelian, P. M. Allen, and A. S. Shaw. 1999. Proline residues in CD28 and the Src homology (SH)3 domain of Lck are required for T cell costimulation. J. Exp. Med. 190:375.

47. Takemoto, Y., M. Furuta, X. K. Li, W. J. Strong-Sparks, and Y. Hashimoto. 1995. LckBP1, a proline-rich protein expressed in haematopoietic lineage cells, directly associates with the $\mathrm{SH} 3$ domain of protein tyrosine kinase $\mathrm{p} 56^{\text {lck. }}$. EMBO J. 14:3403.

48. Izquierdo Pastor, M., K. Reif, and D. Cantrell. 1995. The regulation and function of $\mathrm{p} 21^{\text {ras }}$ during T-cell activation and growth. Immunol. Today 16:159.

49. Schraven, B., A. Marie-Cardine, C. Hubener, E. Bruyns, and I. Ding. 1999. Integration of receptor-mediated signals in $\mathrm{T}$ cells by transmembrane adaptor proteins. Immunol. Today 20:431.

50. van Oers, N. S., B. Lowin-Kropf, D. Finlay, K. Connolly, and A. Weiss. 1996. $\alpha \beta$ $\mathrm{T}$ cell development is abolished in mice lacking both Lck and Fyn protein tyrosine kinases. Immunity 5:429.

51. Groves, T., P. Smiley, M. P. Cooke, K. Forbush, R. M. Perlmutter, and C. J. Guidos. 1996. Fyn can partially substitute for Lck in T lymphocyte development. Immunity 5:417.

52. Cooke, M. P. K. M. Abraham, K. A. Forbush, and R. M. Perlmutter 1991 Regulation of $\mathrm{T}$ cell receptor signaling by a src family protein-tyrosine kinase (p59 fyn $)$. Cell 65:281.

53. Swan, K. A., J. Alberola-Ila, J. A. Gross, M. W. Appleby, K. A. Forbush, J. F. Thomas, and R. M. Perlmutter. 1995. Involvement of $\mathrm{p} 21^{\text {ras }}$ distinguishes positive and negative selection in thymocytes. EMBO J. 14:276.

54. Alberola-Ila, J., K. A. Hogquist, K. A. Swan, M. J. Bevan, and R. M. Perlmutter. 1996. Positive and negative selection invoke distinct signaling pathways. J. Exp. Med. 184:9.

55. Mariathasan, S., S. S. Ho, A. Zakarian, and P. S. Ohashi. 2000. Degree of ERK activation influences both positive and negative thymocyte selection. Eur. J. Immunol. 30:1060.

56. Mariathasan, S., A. Zakarian, D. Bouchard, A. M. Michie, J. C. Zuniga-Pflucker, and P. S. Ohashi. 2001. Duration and strength of extracellular signal-regulated kinase signals are altered during positive versus negative thymocyte selection. J. Immunol. 167:4966.

57. Alam, S. M., P. J. Travers, J. L. Wung, W. Nasholds, S. Redpath, S. C. Jameson, and N. R. Gascoigne. 1996. T-cell-receptor affinity and thymocyte positive selection. Nature 381:616.

58. Williams, C. B., D. L. Engle, G. J. Kersh, J. Michael White, and P. M. Allen. 1999. A kinetic threshold between negative and positive selection based on the longevity of the T cell receptor-ligand complex. J. Exp. Med. 189:1531.

59. Sebzda, E., S. Mariathasan, T. Ohteki, R. Jones, M. F. Bachmann, and P. S. Ohashi. 1999. Selection of the T cell repertoire. Annu. Rev. Immunol. 17:829.

60. Pages, G., S. Guerin, D. Grall, F. Bonino, A. Smith, F. Anjuere, P. Auberger, and J. Pouyssegur. 1999. Defective thymocyte maturation, in p44 MAP kinase (Erk1) knockout mice. Science 286:1374. 


\author{
Konstantina Alexandropoulos \\ Laura T. Donlin \\ Luzhou Xing \\ Adam G. Regelmann
}

\section{Sin: good or bad? A T lymphocyte perspective}

\author{
Authors' addresses \\ Konstantina Alexandropoulos ${ }^{1}$, Laura T. Donlin ${ }^{1}$, Luzhou \\ Xing $^{1}$, Adam G. Regelmann ${ }^{2}$, \\ ${ }^{1}$ Department of Pharmacology and \\ ${ }^{2}$ The Integrated Program, College of Physicians \\ and Surgeons of Columbia University, \\ New York, USA.

\section{Correspondence to:} \\ Konstantina Alexandropoulos \\ College of Physicians and Surgeons of Columbia \\ University \\ Department of Pharmacology, PH 7W, Rm 318 \\ 630 West 168 th Street \\ New York, NY 10032 \\ USA \\ Tel.: 2123052705 \\ Fax: 2123058780 \\ e-mail:ka141@columbia.edu
}

\section{Acknowledgements}

This work was supported in part by the American Cancer Society Grant RPG99-09-01MGO, by the Department of Defense Grants DAMD17-99-1-9151 and DAMD17-99-

1-915, by the National Institute of Allergy and Infectious Disease (NIAID) Grant RO1 AI49387-01, and the American Cancer Society's Institutional Research Grant \#177F and the Herbert Irving Comprehensive Cancer Center. L.D. and was supported by NIH grant 5 T32 AI07525 and A.R. by NIH grant 5 T32 GM03767-26. L.X. was supported in part by the American Cancer Society Grant RPG99-09-01MGO. K.A. was supported in part by the Department of Defense Grants DAMD17-991-9151 and DAMD17-99-1-915, the National Institute of Allergy and Infectious Disease (NIAID) Grant RO1 AI49387-01, and the American Cancer Society Grant RPG99-09-01MGO.

Immunological Reviews 2003

Vol. 192: 181-195

Printed in Denmark. All rights reserved

Copyright (C) Blackwell Munksgaard 2003

Immunological Reviews

0105-2896
Summary: Stimulation of $\mathrm{T}$ cells through their antigen receptor induces a multitude of signaling networks that regulate $\mathrm{T}$ cell activation in the form of cytokine production and $\mathrm{T}$ cell proliferation. Multiple signal integration sites exist along these pathways in the form of multiprotein signaling complexes, the formation of which is facilitated by adapter and scaffold molecules. In recent years a number of adapter and scaffold molecules have been described in $\mathrm{T}$ cells and shown to play an integral part in $\mathrm{T}$ cell function. Among these molecules are proteins that function as positive or negative regulators of $\mathrm{T}$ cell activation downstream of the activated $\mathrm{T}$ cell receptor (TCR). Here, we discuss the role of a small family of multiadapter proteins on $\mathrm{T}$ cell activation, the p130Cas family, with emphasis on one of its members, Sin (Src-interacting protein). Our results suggest that Sin inhibits thymocyte development and $\mathrm{T}$ cell activation and is a novel negative regulator of $\mathrm{T}$ lymphocyte function.

\section{Introduction}

Adapter proteins have no known enzymatic or transcriptional activity but participate in signaling events by mediating protein -protein interactions that lead to the formation of multiprotein complexes or signalosomes (1). The formation of signalosomes is mediated by reciprocal interactions between conserved domains and their binding motifs present on the adapter molecules and their interacting partmers. The most widely expressed conserved domains found on adapters include the Src homology regions 2 and 3 (SH2 and SH3, approximately 100 and 50 amino acids long, respectively) (2), the phosphotyrosinebinding (PTB) domain $(3,4)$, the tryptophan-tryptophan (WW) (5), pleckstrin homology $(\mathrm{PH})(6)$, and postsynaptic density-disk large-zo1 (PDZ) domains (4). SH2 and PTB domains bind to phosphorylated tyrosine residues on target molecules $(7,8)$; $\mathrm{SH} 3$ and WW domains recognize and bind to proline-rich sequences $(5,9,10)$. PH domains bind to phospholipids (11), and PDZ domains bind short sequences that contain conserved, hydrophobic residues in their C-terminus $(4,12)$. In addition to these conserved domains, most adapter molecules themselves contain proline- and tyrosine-based motifs that bind to respective 
SH3 and SH2 modular domains and promote complex reciprocal interactions between adapters and their cellular partners.

Molecules that mediate protein-protein interactions can be classified as adapter or scaffold proteins depending on their combination of conserved modular domains and/or proline/ tyrosine-based motifs. Bona fide adapters are molecules that consist predominantly of modular domains serving to bridge two signaling molecules, whereas scaffold proteins contain modular domains as well as tyrosine and proline motifs and bind to two or more proteins simultaneously (13). T cells express both adapter and scaffold molecules, and several excellent reviews have been published recently discussing the function of these molecules in T cell receptor (TCR) signaling (14-19). Therefore, we discuss briefly only those molecules whose function has been supported by gene targeted experiments in mice. For the most part, we focus our attention on the p130Cas family of scaffold molecules, a small protein family consisting of three members, with emphasis on the least characterized member, Sin. We start our discussion with a description of the structural characteristics shared by the three proteins. Then we give an overview of the literature pertaining to the function of p130Cas and Cas-L in Tlymphocytes, and proceed with a more detailed discussion on the role of Sin in Tlymphocytes based on evidence generated in our laboratory.

\section{Adapters and scaffolds in T cells}

T cells express a variety of both adapter and scaffold molecules. Adapters include the Grb2 and Gads proteins, which link linker for activation of $\mathrm{T}$ cells (LAT) to the son of sevenless (Sos) nucleotide exchange factor and SLP-76, respectively (20-23). Both adapters consist mainly of $\mathrm{SH} 2$ and $\mathrm{SH} 3$ domains, one $\mathrm{N}$ - and one C-terminal SH3 domain flanking a central $\mathrm{SH} 2$ domain. The importance of these molecules in Tlymphocyte function has been confirmed by targeted disruption of the genetic loci encoding for these adapters. Thus, targeted disruption of the Gads locus leads to defective thymocyte development and uncouples the association of SLP-76 and LAT (24), whereas haploid insufficiency of Grb2 inhibits negative selection of thymocytes and reduces TCR-induced activation of the c-Jun N-terminal kinase (JNK) and p38 mitogenactivated protein (MAP) kinases (25). The Src-like adapter protein (SLAP) is yet another recently identified molecule that consists of one $\mathrm{SH} 2$ and one $\mathrm{SH} 3$ domain, shares structural homology with Lck and is a negative regulator of Tlymphocytes $(26,27)$. Like Lck, SLAP consists of an N-terminal SH3 followed by an $\mathrm{SH} 2$ domain (these are $50 \%$ and $51 \%$ homologous to those of Lck), as well as a unique C-terminal tail of unknown function. Unlike Lck, SLAP has no kinase domain and is therefore classified as an adapter. SLAP expression is restricted to lymphoid tissues (28), and mice deficient in SLAP exhibit marked upregulation of TCR and CD5 expression at the double positive (DP, $\mathrm{CD} 4{ }^{+} \mathrm{CD} 8^{+}$) stage, as well as increased positive selection (29). Thus, SLAP is thought to regulate Tlymphocyte function by mediating TCR downregulation at the DP stage and thus regulating positive selection of thymocytes (29).

A number of scaffold molecules are also expressed in T lymphocytes that positively or negatively regulate Tlymphocyte responses. The best-characterized positive regulators of Tlymphocytes include LAT, SLP-76, and SLAP-130/FYB (14-19). SLP-76 and LAT are scaffold molecules that mediate the formation of a signaling complex that stimulates intracellular calcium release through the activation of phospholipase $\mathrm{C}$ (PLC- $\gamma)$. The important roles of these proteins in Tlymphocyte function have been substantiated with gene targeting experiments showing that SLP-76 and LAT are required for normal thymocyte development (30-32). Reconstitution experiments, in which mutant forms of SLP-76 and LAT were introduced into the SLP-76 and LAT null backgrounds, showed that these proteins are also important in mature $\mathrm{T}$ cell signaling. These experiments also revealed differential requirements for different conserved domains in $\mathrm{T}$ cell development and activation $(31,33,34)$. A third scaffold protein ADAP/SLAP130 /Fyb has been recently shown to link the TCR to the actin cytoskeleton through LAT and SLP-76 and to bind to proteins such as Nck, Wiskott-Aldrich syndrome protein (WASP), Vasp and Arp2/3 involved in actin polymerization (35). ADAP/ SLAP-130/FYB knockout mice exhibit reduced T cell proliferation and cytokine production, as well as impaired TCR-induced integrin clustering and adhesion $(36,37)$.

Scaffold proteins involved in the negative regulation of TCR signaling include the Cbl family of proteins $(17,38,39)$, and a recently characterized transmembrane regulator of TCR signaling PAG/Cbp (protein associated with glycosphingolipidenriched microdomains/Csk-binding protein), among others $(40,41)$. The function of $\mathrm{Cbl}$ in Tlymphocytes has been studied extensively and represents the prototype of negative regulators of $\mathrm{T}$ cells. This protein associates with a variety of signaling molecules such as Src kinases, Crk, Grb2, PI3K and ZAP-70, and regulates TCR signaling through different mechanisms (39). These mechanisms include downregulation of enzymatic activity of tyrosine kinases, interference with normal Ras activation by increasing Rap1 GTP levels and 
sequestering Raf away from Ras (42), or degradation of proteins through E3 ligase-mediated ubiquitination (43-45). Two types of Cbl-deficient animals have been described, $\mathrm{Cbl}^{-\mathrm{b}^{-1}}$ and c-Cbl. Cbl- $\mathrm{b}^{-1-}$ mice show normal thymocyte development but develop spontaneous autoimmunity due to reduced $\mathrm{T}$ cell activation thresholds $(46,47)$. c-Cbl-deficient thymocytes, on the other hand, exhibit increased expression of CD3 and CD4 molecules, display increased positive selection and markedly upregulated activity of ZAP-70 and the MAP kinase ERK $(48,49)$. Collectively, these observations implicate these molecules as important negative regulators of $\mathrm{T}$ lymphocyte function.

PAG/Cbp is a transmembrane protein that localizes to glycosphingolipid-enriched microdomains of the plasma membrane $(40,41)$. PAG/Cbp is thought to regulate the activity of Src kinases by linking them to Csk kinase, a known Src inhibitor that induces the inactive conformation of Src kinases. PAG/Cbp is constitutively phosphorylated in unstimulated cells and bound to the Csk kinase through Cbp-tyrosine motifs/Csk-SH2 domain interactions. Upon TCR stimulation, PAG/Cbp becomes dephosphorylated rapidly and releases Csk to the cytoplasm, which allows Src kinases to become activated and initiate TCR signaling. Thus, PAG/Cbp appears to regulate $\mathrm{T}$ cell activation by controlling the activity of Src kinases through reversible recruitment of Csk $(14,15)$. PAG/Cbp-deficient mice have not yet been reported.

\section{Characteristics of the Cas family of proteins}

The Cas family of proteins is a relatively recently identified group of proteins consisting of three members: p130Cas, HEF1/CasL and Sin/Efs. p130Cas (Crk-associated substrate) was the first member of the family to be identified. It is ubiquitously expressed, and substantial evidence suggests a role for this protein in integrin receptor signaling and in the processes of cell adhesion and motility $(50,51)$. The second member, HEF1 (human enhancer of filamentation), was isolated in a screen for human proteins that conferred morphological changes leading to budding in yeast (52) and also as CasL (Crk-associated substrate in lymphocytes), a protein involved in $\mathrm{T}$ cell receptor and $\beta-1$ integrin-mediated signaling in Tlymphocytes $(53,54)$. HEF1 expression is highest in epithelial cells and $\mathrm{T}$ and B lymphocytes. Sin (Src-interacting protein), cloned by us and independently by Ishino et al. as Efs (embryonal Fyn substrate), is a substrate for Src kinases and is most highly expressed in the embryo, brain and thymus (55-57). Evidence generated in our laboratory suggests that Sin plays a role in TCR-mediated Tlymphocyte development and activation (58). In our subsequent discussion we refer to Sin/Efs as Sin, and the terms HEF1 and CasL are used interchangeably as pertaining to specific studies.

The Cas proteins are defined as multiadapter/scaffold/ docking molecules that lack any known enzymatic activity but instead mediate signaling by promoting protein-protein interactions through conserved sequence motifs $(51,54,59)$. These conserved motifs consist of the following: (a) $\mathrm{SH} 3$ domains that are highly conserved (80-90\%) among the three family members and have the potential to bind to proline-rich motif-containing proteins; (b) a central substratebinding region containing tyrosine residues embedded within specific conserved sequences that determine the binding specificity of these tyrosines for different $\mathrm{SH} 2$ domains (7). Once phosphorylated by Src or other kinases, these tyrosine residues bind to the SH2 domains of defined cytoplasmic intermediates, thus forming unique multiprotein signaling complexes; (c) proline-rich sequences with binding specificity for Src kinase SH3 domains; and (d) a conserved C-terminus $(\sim 60 \%)$ of approximately 135 amino acids of unknown function (Fig. 1).

In agreement with the originally predicted function of the Cas proteins as docking proteins, a plethora of in vitro and in vivo interacting partners have been identified to date (reviewed in 51). For example, the N-terminal SH3 domains of the Cas proteins have been shown to interact with proline-rich motifs found on the focal adhesion kinase (FAK) and the related protein $\mathrm{Pyk} 2 / \mathrm{RAFTK} / \mathrm{Cak} \beta$. These proteins are tyrosine kinases involved in integrin receptor signaling and were shown to interact with the SH3 domains of p130Cas and HEF 1 in vivo and with all three Cas proteins in vitro. In addition, the phosphatases PTP-1B and PTB-PEST have been shown to interact with the SH3 domains of Cas, HEF1 and Sin in vitro (51).

The central, substrate-binding regions of the Cas proteins contain multiple tyrosine-based motifs that, when phosphorylated by Src and other kinases, can bind to SH2-domain-containing signaling intermediates (Tables 1 and 2). In addition, Cas and Sin contain one and two proline-rich motifs, respectively, that exhibit high binding specificity for Src kinase SH3 domains (Table 3). The overall conserved motifs of the Cas proteins in these regions suggest that these molecules may have overlapping functions. However, the types and numbers of the conserved motifs differ and together with the varied length and amino acid composition of the Cas proteins argue for unique functional roles for these molecules. Indeed, a motif-based profiling of potential binding partners for the Cas proteins using a peptide-based searching algorithm (60) 


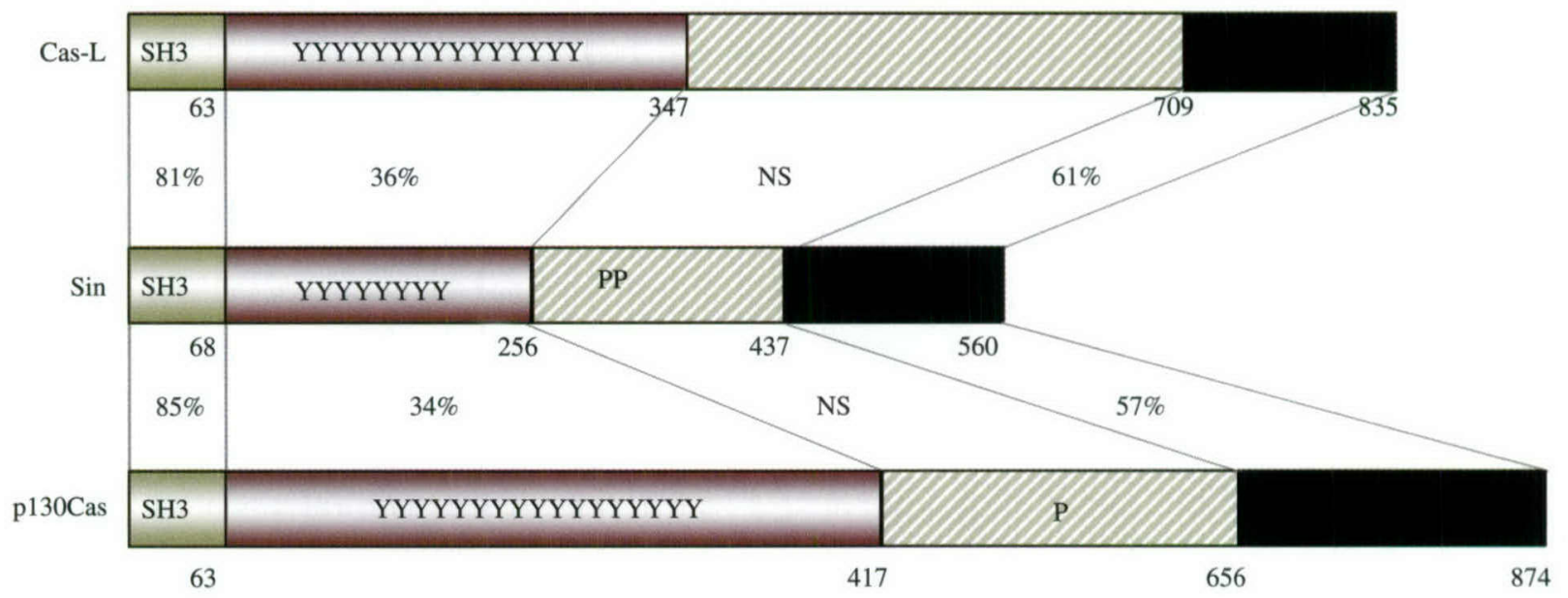

Fig. 1. Schematic structure representation and homology comparison of the Cas protein family. Amino acid homologies within the $\mathrm{SH}$, substrate and C-terminal domains are as shown. Homologies were determined by pairwise sequence alignment between Sin and CasL and

revealed common as well as unique binding partners, supporting both overlapping and divergent functional roles for these proteins (Table 1). The search results show that all Cas proteins contain tyrosine motifs that are potential phosphorylation sites

Table 1. Predicted binding partners of Cas family members

\begin{tabular}{|c|c|c|c|}
\hline \multirow[b]{2}{*}{ Binding partners } & \multicolumn{3}{|c|}{ Binding sites on: } \\
\hline & $\operatorname{Sin}$ & CasL & pl30Cas \\
\hline \multicolumn{4}{|l|}{ Kinase domains } \\
\hline Abl-kinase & 2 & 4 & 9 \\
\hline Akt-kinase & 1 & - & - \\
\hline $\begin{array}{l}\text { Calmodulin- } \\
\text { dependent kinase }\end{array}$ & - & 1 & - \\
\hline Lck-kinase & - & - & 1 \\
\hline DNA-PK & - & 1 & - \\
\hline ERK-I & 1 & - & - \\
\hline GSK3 kinase & 2 & - & - \\
\hline$P K C-\varepsilon$ & - & 1 & - \\
\hline \multicolumn{4}{|l|}{ SH2 domains } \\
\hline $\begin{array}{l}\mathrm{Abl}-\mathrm{SH} 2 \\
\mathrm{Crk}-\mathrm{SH} 2\end{array}$ & $\overline{4}$ & 10 & $\begin{array}{l}6 \\
12\end{array}$ \\
\hline Grb2-SH2 & - & 1 & - \\
\hline ltk-SH2 & । & 2 & 3 \\
\hline Nck-SH2 & 3 & 6 & 8 \\
\hline $\mathrm{PLC}-\gamma \mathrm{SH} 2$ & I & - & 2 \\
\hline Src-SH2 & 1 & 1 & 1 \\
\hline \multicolumn{4}{|l|}{ SH3 domains } \\
\hline Cortactin-SH3 & 1 & - & - \\
\hline Grb2-SH3 & 2 & - & - \\
\hline Crk-SK3 & - & - & 1 \\
\hline Nck-SH3 & 1 & - & - \\
\hline PLC- $\gamma$ SH3 & । & - & 1 \\
\hline Src, Fyn-SH3 & 2 & - & I \\
\hline
\end{tabular}

Sin and p130Cas. Numbers below each domain correspond to the last amino acid residue in the domain. NS represents no significant homology. Y represents the YXXP motifs on each protein, while P represents the proline-rich motifs that bind to Src kinase SH3 domains.

for the Abl kinase and binding sites for the Crk, Nck and Itk SH2 domains. In addition, Sin and Cas (but not CasL) can bind to the $\mathrm{SH} 2$ and $\mathrm{SH} 3$ domains of PLC- $\gamma$ as well as to Src kinase SH3 domains (Table 3). Remarkably, although Sin has the least number of tyrosine-based motifs, it exhibits the highest degree of divergence in the number and type of potential binding partners (Table 1). Whether this finding has physiological significance or contributes to functional divergence as compared to Cas and CasL remains to be determined.

Some of the predicted interactions between the tyrosine motifs of the Cas proteins and proteins listed in Table 1 have been previously shown to occur in vitro and in vivo. Thus, Sin, Cas and HEF1 interact with Crk in vivo (61-64), and HEF 1 interacts with $\mathrm{Abl}, \mathrm{Nck}$ and Lck in vitro $(53,65,66)$. We have also shown that the proline-rich motifs of Sin interact with Src kinase SH3 domains invitro (67); Sin and Src interact in vivo (61). Fyn also interacts with Sin (Efs) in vivo (56). While most of these associations have been studied in cell systems other than Tlymphocytes, the interactions of the Cas proteins with Src kinases, Crk, Itk, Nck and PLC- $\gamma$ are also likely to be important in $\mathrm{T}$ cell signaling, given that the involvement of these molecules in Tlymphocyte activation is well established. The association of the Cas proteins with other molecules and their physiological significance are discussed further in the following sections.

As mentioned above, the Cas family members have a conserved C-terminus consisting of approximately 135 amino acids of unknown function. It has previously been shown that the C-terminal domain of HEF-1 contains a divergent helix-loop-helix motif that can homodimerize or promote 
Table 2. Binding partners for Sin, CasL and p130Cas tyrosine-based motifs

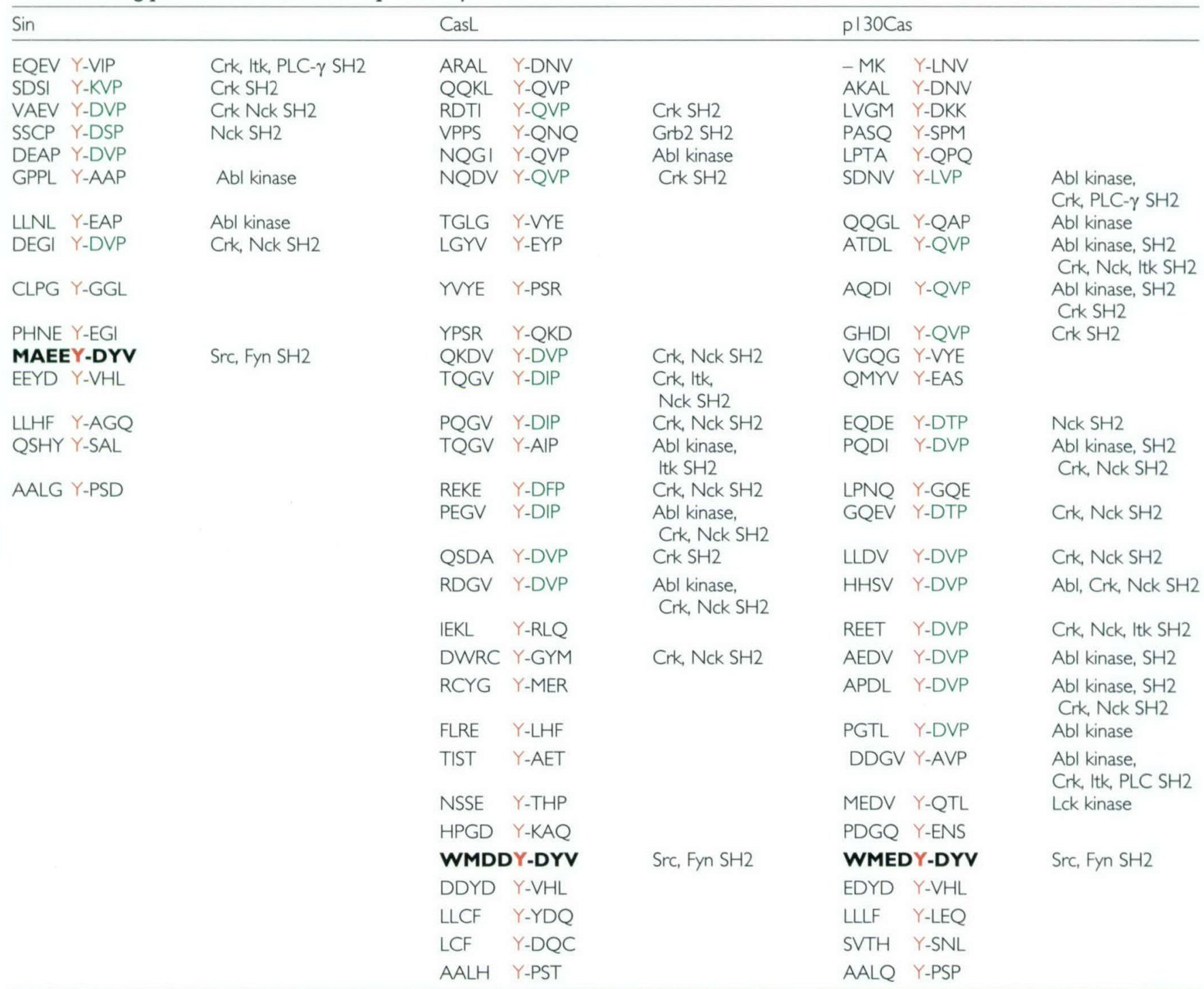

The tyrosine-based motifs of the Cas proteins and potential binding $\mathrm{SH} 2$ domains were determined using the scansite algorithm as described in Table 1 . Phosphaylated tyrosine residues are shown in red YXXP and YDXP motifs that bind to Crk and Nck SH2 domains, respectively, are shown in green. The YDYV (bold) motif is present in Cas proteins and binds to $\mathrm{Src}$ kinase $\mathrm{SH} 2$ domains.

heterodimerization with other proteins (68). Recently, it has also been shown that the conserved C-terminal domain of p130Cas binds to Chat, a novel guanine nucleotide exchange factor (GEF) with specificity for the Rap1 and R-Ras GTPases. Two Chat isoforms have been described thus far, one that is expressed ubiquitously (Chat) and one that is expressed only in hematopoietic cells, the thymus, lymph node and spleen (Chat-H) (69). We have recently obtained evidence that Sin also binds to Chat and Chat- $\mathrm{H}$ and that this interaction requires the conserved C-terminus of Sin (unpublished data). The

Table 3. Binding partners for Sin and p130Cas proline-rich motifs

\begin{tabular}{llll}
\hline Sin & & CasL & PI 30Cas \\
\hline QDRPL-PPPP & Src, Nck, & - & TPAQ-PLVP \\
Grt2, SH3 Cortactin, & PLC- $\gamma$ SH3 & - & QSRPL-PSPP \\
PPQHR-PRLP & Src, Fyn, Lyn & - & Crk SH3 \\
SRRPL-PALP & Hck, SH3 & & \\
& H SH3 \\
\hline
\end{tabular}

The proline-rich motifs of Sin and p /30Cas and potential interacting SH3 domain partners are shown and were determined using the scansite algorithm as described in Table I. The core PXXP, SH3 binding motifs are shown in red. 
physiological significance of these interactions is under investigation.

\section{PI30Cas and HEFI/CasL function in nonlymphoid cells}

p130Cas was isolated as a $130-\mathrm{kDa}$ protein that was highly phosphorylated in v-Crk and v-Src transformed cells and it was named Cas based on its ability to associate with Crk (Crkassociated substrate) (50). HEF1/CasL is a $105-\mathrm{kDa}$ protein that was isolated as HEF1 in a screen for human proteins that confer morphological changes in yeast leading to hyphae projections and filamentous budding (52). It was also identified as CasL, a previously uncharacterized, p130Cas-related protein that was phosphorylated in response to integrin receptor engagement in T-lymphoblastoid $\mathrm{H} 9$ and peripheral T cells $(53,54)$. Existing evidence supports a role for Cas and HEF1 in integrin signaling and the integrin-dependent processes of cell adhesion and migration (51). Studies in nonlymphoid cells have shown that p130Cas and HEF1 localize mainly at focal adhesions and stress fibers, although the proteins also exhibit some cytosolic distribution. Phosphorylation of the proteins correlates with the presence of the proteins in membranous and insoluble cytoskeletal fractions, whereas nonphosphorylated proteins localize mainly to the soluble cytosolic fraction. Localization of the Cas proteins to the focal adhesions is mediated by interaction of the Cas family SH3 domain with proline-rich regions on FAK, a kinase that has been implicated in integrin receptor signaling (70). Upon integrin receptor stimulation, FAK becomes autophosphorylated creating a binding site for Src-family kinases. Cas proteins then become phosphorylated by Src kinases or by the concerted action of FAK and Src kinases, leading to the recruitment of other proteins and the formation of a multiprotein signaling complex that transduces integrin-dependent signals to the nucleus $(51,71,72)$.

Given that integrin receptors regulate the ability of cells to form and disrupt extracellular attachments, the presence of the Cas proteins in focal adhesions and their interactions with FAK and other molecules suggest a physiological role for these proteins in cell adhesion and motility. This suggested role is supported by gene knockout experiments that show that p130Cas- and FAK-deficient fibroblasts exhibit reduced motility, which correlates with increased numbers of focal adhesions and, as a consequence, increased cell adhesion (73).

Although the role of $\mathrm{p} 130 \mathrm{Cas}$ in cell adhesion and migration has been extensively studied in nonlymphoid cells, limited evidence exists about the role of this protein in Tlymphocytes. Recently, p130Cas was implicated in $\mathrm{T}$ cell chemotaxis in response to SDF- $1 \alpha$ chemokine stimulation of human Jurkat T cells. In this cell system, it was shown that WASP, p130Cas, Nck and FAK are all phosphorylated in response to Jurkat $T$ cell stimulation with SDF- $1 \alpha$, and that Nck, Cas and FAK associate with one another in immunoprecipitation assays (74). Together these data support a role for p130Cas in cell migration and suggest that Cas may be required for $\mathrm{T}$ cell chemotaxis.

\section{Role of CasL in Tlymphocytes}

CasL, a protein predominantly expressed in cells of lymphoid lineage, was identified as a $105-\mathrm{kDa}$ protein in H9 human T cells and is inducibly phosphorylated in response to integrin receptor stimulation (53). Cloning of the CasL cDNA revealed a novel protein with structural homology to p130Cas. Initial studies showed that integrin-induced CasL phosphorylation leads to in vivo interaction of CasL with cellular proteins such as FAK, the adapters Crk and Nck, and the tyrosine phosphatase SHP2 (53). As described earlier for p130Cas, phosphorylation of CasL is triggered through integrin-mediated activation of FAK. FAK subsequently phosphorylates CasL as a result of interactions between the CasL-SH3 domain and proline-rich motifs on FAK (75). FAK-mediated phosphorylation of CasL then leads to the recruitment of the Src kinase Fyn, through interactions of the Fyn-SH2 domains with the YDYVHL tyrosine-containing motif of CasL (Table 2). Fyn either independently or together with FAK then further phosphorylates CasL on tyrosine residues (75).

CasL has also been demonstrated to play a role in antigen receptor signal transduction in response to TCR crosslinking in human $\mathrm{H} 9$ and peripheral $\mathrm{T}$ cells $(65,76)$. As with integrin stimulation, TCR crosslinking leads to transient CasL phosphorylation and CasL association with the $\mathrm{Crk} / \mathrm{C} 3 \mathrm{G}$ protein complex in vivo $(65,76)$. In contrast to integrin ligation, FAK activation and phosphorylation is not required for TCRinduced CasL phosphorylation, because a CasL-SH3 domain deletion mutant that does not bind to FAK is still phosphorylated in response to TCR stimulation (76). Consistent with this observation, FAK fails to become phosphorylated in response to TCR crosslinking. Instead, TCR-dependent phosphorylation of CasL is mediated by the Src kinases Fyn and Lck. This phosphorylation is specific, as the related kinase ZAP-70, which is also important in TCR signaling, does not associate with or phosphorylate CasL in the same experiments (77).

CasL is also phosphorylated when antibodies against integrin receptors and the TCR are used for costimulation of T cells (78). Thus, under these conditions it was found that CasL is 
required for interleukin-2 (IL-2) production upon costimulation of TCR/integrin receptors, and that the SH3 domain of CasL is necessary for integrin receptor- but not TCR-mediated stimulation. Using human Jurkat T cells, which have impaired integrin signaling, the authors showed that overexpression of full-length CasL is able to restore integrin/TCR-induced IL-2 production, whereas an SH3 deletion mutant of CasL was unable to do so (78). This inability is due to the absence of CasL-SH3/FAK proline motif interaction, which is required for integrin receptor-mediated Cas phosphorylation (76). These results suggest that CasL is involved in integrin and TCR receptor signaling and that CasL is a positive regulator of $\mathrm{T}$ cell function. Definitive evidence for the role of CasL in T lymphocyte function awaits the generation of CasL-deficient animals.

\section{Cloning of Sin/Efs}

We isolated Sin as an Src-interacting protein by screening a 16-day mouse embryonic expression library using the biotinylated SH3 domains of Src kinases as probes (67). In the initial screen, a partial cDNA clone was isolated that contained two 7-amino-acid-long sequences with core proline-rich motifs (PXXP) that bound with high affinity to the Src, Fyn, Hck and Lyn SH3 domains in vitro (Table 3) (67). The binding specificity of the Sin proline-rich motifs was restricted to Src kinase SH3 domains and did not recognize the SH3 domain of the related Abl protein tyrosine kinase, suggesting that Sin was a specific Src kinase ligand. Isolation of a full-length cDNA clone revealed that Sin displayed structural and primary sequence homology to p130Cas and HEF1 and thus was the third member of this family of proteins to be cloned (55). Sin was also independently cloned as Efs from the same embryonic expression library using biotinylated Fyn-SH3 domain as a probe (56). The expression patterns of Sin/Efs were confirmed by Northern blots, which demonstrated that Sin is indeed expressed in the mouse embryo and that in adult tissues Sin is highly expressed in the brain, brainstem, thymus and skeletal muscle (56) (Fig. 2B,C). Subsequent analysis by reverse transcriptase polymerase chain reaction (RT-PCR) revealed more widespread expression of Sin/Efs (57).

At least two different Sin mRNAs can be detected on Northern blots with RNA from brain and thymus (Fig. 2B) (57). Consistent with this two protein isoforms of Sin have been cloned thus far, full-length Sin and Efs2, a truncated Sin/Efs isoform that is missing the conserved N-terminal SH3 domain (55-57). Efs2 was isolated from a normal, 2-year-old human female hippocampus (57). Thymocytes and T cells from adult mice express at least three isoforms that are recognized by a Sin-specific antibody whereas the adult mouse brain expresses only full-length Sin (Fig. 2C) (58). In addition, we have isolated full-length and Efs2 cDNA clones from a mouse thymus library as well as a third partial cDNA clone (Sin-III) that contains an internal deletion that removes the proline-rich motifs of Sin that mediate interactions with Src kinase SH3 domains (Fig. 2A). We believe that the third protein band that appears in Sin immunoprecipitates is Sin-III, although definitive proof requires the isolation of full-length cDNA clone. The functional significance of these different isoforms is not clear at present, and is under investigation. However, given the data mentioned above that an SH3 deletion mutant of CasL is involved in $\mathrm{T}$ cell but not integrin receptor signaling, it is possible that these different isoforms are differentially involved in signaling through these receptors. In our experiments thus far, we have not examined the involvement of Sin in integrin receptor signaling. Given the evidence implicating Cas and CasL as important signaling intermediates downstream of these receptors, it is important to address the role of Sin and Sin isoforms in this receptor system.

\section{Role of Sin in Src kinase signaling}

Given that Sin was isolated as a protein that binds to Src-kinase SH3 domains, we previously examined the functional properties of Sin in relation to Src kinases (61). The enzymatic activity of Src kinases is regulated intramolecularly by the conserved Src SH3 and SH2 domains (79-82). The SH3 domain inhibits Src kinase activity by binding to a 14 amino acid linker region located between the $\mathrm{SH} 2$ and kinase domains of the molecule (Fig. 3) $(83,84)$. The SH2 domain contributes to this inhibition by binding to a conserved, phosphotyrosine-containing motif at the C-terminus of Src $(79,83,84)$. Mutations that disrupt these interactions lead to constitutively active Src enzymes and cellular transformation.

In our experiments, we used Sin as a high-affinity ligand for the Src-SH3 domain to outcompete these intramolecular interactions and activate Src enzymatic activity and signaling (Fig. 3, step 1) $(55,61)$. We found that whereas full-length Sin only moderately activates Src, a C-terminal deletion mutant of $\operatorname{Sin}, \operatorname{Sin} \Delta C$ (Fig. $2 A$ ), is a better inducer of Src kinase activity, mediates signaling and becomes highly phosphorylated on conserved tyrosine residues in an Src kinase-dependent manner (Fig. 3, step 1). As mentioned earlier, Sin and the other Cas proteins have tyrosine-based motifs that exhibit specificity for the Crk-SH2 domain (Table 2). Through mutagenesis analysis 
A

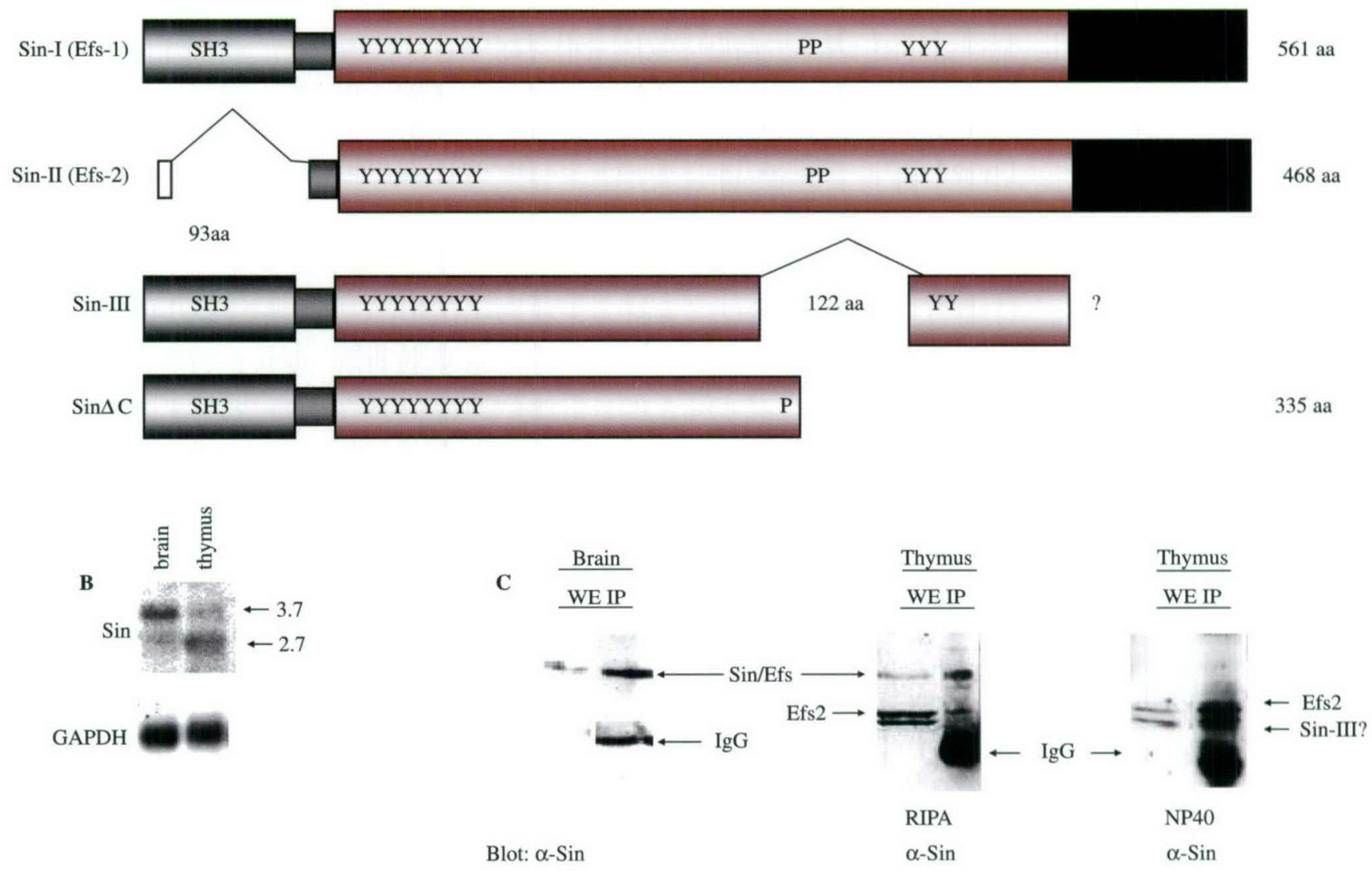

Fig. 2. Schematic representation of Sin isoforms and expression of Sin in the thymus and brain. (A) The structures of Sin isoforms: full-length Sin, Efs2, which contains a deletion of 93 amino acids encompassing the SH3 domain, and Sin III, a partial cDNA clone isolated from a mouse thymus cDNA library containing an internal deletion of 122 amino acids. $\operatorname{Sin} \Delta C$ represents an activated deletion mutant that was used in previous experiments to study the function of $\operatorname{Sin}(55,61)$. (B) Northern blot of total RNA probed with a Sin-specific probe. Total RNA $(10 \mu \mathrm{g})$ from mouse brain and thymus was run on an agarose gel, transferred to nitrocellulose and probed with a Sin cDNA fragment corresponding to amino acids 244-335 (55) and exposed on film for 2 days. The membrane was then stripped and reprobed with GAPDH cDNA to normalize for RNA content. Two different RNA species that exhibit differential expression patterns between brain and thymus are shown. (C) Brain and thymus cell extracts were lyzed in 0.1 sodium dodecyl sulphate (SDS) Radio immuno precipitation assay buffer (RIPA) or 1 NP-40-containing buffers as shown, and cell lysates were normalized for protein content. Extracts were then immunoprecipitated (IP) with Sin-specific antibody, immune complexes separated on SDSpolyacrylamide gel electrophoresis (PAGE), transferred to nitrocellulose and Western blotted with Sin-specific antibody. Total cell extracts (WE), also normalized for protein content, were included on the blots as controls (58). Protein bands were visualized by enhanced chemiluminescence (ECL; Amersham).

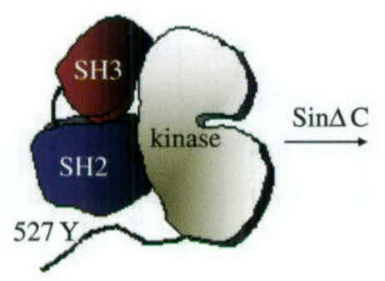

Inactive kinase

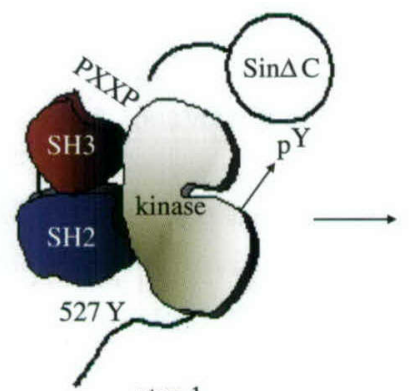

step 1

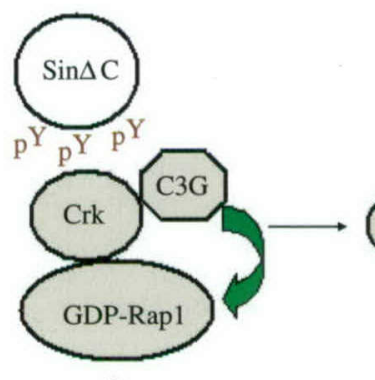

2

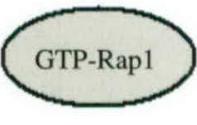

Activation

3

Fig. 3. Model for truncated Sin-induced Src activation and signaling. Coexpression of $\operatorname{Sin} \Delta \mathrm{C}$ and Src kinases in 293HEK cells leads to interaction of the Sin proline-rich motifs with the Src-SH3 domain. This leads to increased Src kinase activity and $\operatorname{Sin} \Delta \mathrm{C}$ phosphorylation (step 1).

Phosphorylated $\operatorname{Sin} \Delta \mathrm{C}$ then recruits the $\mathrm{Crk} / \mathrm{C} 3 \mathrm{G}$ complex through specific phosphorylated tyrosine motifs, which in turn activates Rap1 (step 2). In this cell system, activation of Rapl leads to ERK phosphorylation and transcriptional activation (step 3) (61). 
we identified three phosphotyrosine residues (Y148, Y188, and Y253) that bind to the adapter Crk and are important for the ability of Sin to mediate Src signaling (Fig. 3, step 2). In cells coexpressing $\operatorname{Src}$ and $\operatorname{Sin} \Delta \mathrm{C}, \operatorname{Sin} \Delta \mathrm{C}$ is found in a complex with Crk and C3G, a protein known to act as a GEF for Rap1 (Fig. 3, step 2). Consistently, we found that $\operatorname{Sin} \Delta \mathrm{C}$-mediated Src signaling is dependent on the small GTP-binding protein Rap1 (Fig. 3, step 3). In addition, using dominant negative inhibitors of Crk and Rap1, we were able to show that these proteins indeed are required for $\operatorname{Sin} \Delta \mathrm{C}$-mediated Src signaling. In the same experiments, we found no involvement of the related Ras protein downstream of $\operatorname{Sin} \Delta \mathrm{C}$-activated $\operatorname{Src}$ (61). These experiments for the first time identified Rap1 as a signaling mediator acting downstream of Src kinases and provided clues to the function of Sin.

\section{Role of Sin in thymocyte development}

To gain insight into the physiologic properties of Sin in relation to Src kinases, we examined the role of Sin in Tlymphocyte function. We used Tlymphocytes as our model system, because the thymus is one of the tissues in which endogenous Sin is most highly expressed (Fig. 2B,C). In addition, Sin is an Src kinase substrate, and two Src kinases, Fyn and Lck, are known to play important roles in Tlymphocyte physiology (85-87). Because in previous experiments we found that the truncated protein $\operatorname{Sin} \Delta C$ (61) more efficiently binds to and becomes phosphorylated by Src kinases, we used this protein for our studies. Using transgenic mice, we found that specific expression of $\operatorname{Sin} \Delta \mathrm{C}$ in thymocytes resulted in reduced cell numbers ( $40 \%$ of wild-type) evidenced by an overall reduction in the size of the thymus (58). This phenotype correlated with decreased thymocyte survival and increased $\operatorname{Sin} \Delta \mathrm{C}$ mediated thymocyte apoptosis assayed by AnnexinV and 7AAD staining. We also found that thymocyte maturation was compromised in $\operatorname{Sin} \Delta \mathrm{C}$-expressing animals. Thus, whereas the percentages of the precursor $\mathrm{CD} 4$ and $\mathrm{CD} 8$ double-negative $\left(\mathrm{CD}^{-}{ }^{-} \mathrm{CD} 8^{-}, \mathrm{DN}\right)$ and double-positive $\left(\mathrm{CD}^{+}{ }^{+} \mathrm{CD} 8^{+}, \mathrm{DP}\right)$ populations were normal, we found reduced percentages of mature $\mathrm{CD}^{+}$and $\mathrm{CD} 8^{+}$single-positive (SP) $\mathrm{T}$ cells $(60 \%$ and $90 \%$ inhibition, respectively) (58). These data are summarized schematically in Fig. 4.

We found that $\operatorname{Sin} \Delta \mathrm{C}$ is consistutively phosphorylated by the Src kinase Fyn but not by the related kinase Lck (58). Crossing the $\operatorname{Sin} \Delta \mathrm{C}$ mice to $\mathrm{fyn}^{-/-}$animals revealed that the expression of Fyn is required for $\operatorname{Sin} \Delta \mathrm{C}$-mediated thymocyte apoptosis but not for $\operatorname{Sin} \Delta \mathrm{C}$-mediated inhibition of thymocyte maturation (Fig. 4). Consistent with the $\operatorname{Sin} \Delta \mathrm{C}$-induced block in thymocyte maturation even in the absence of Fyn, we found reduced but significant phosphorylation of $\operatorname{Sin} \Delta \mathrm{C}$ in the $\mathrm{fyn}^{-1-}$ background (58). This observation suggests that $\operatorname{Sin} \Delta C$ is phosphorylated by tyrosine kinases other than Fyn, which regulate the ability of Sin to inhibit thymocyte maturation. As Sin contains a tyrosine motif that can potentially bind to the Itk-SH2 domain (Table 2), it is possible that Tec kinases may also be involved in Sin phosphorylation. This possibility is currently under investigation.

The inhibitory effect of $\operatorname{Sin} \Delta \mathrm{C}$ on thymocyte maturation correlated with defective activation of the extracellular signal regulated kinase (ERK) MAP kinase, which has been shown to play an important role in thymocyte selection (58). In the same experiments, activation of the JNK kinase was intact, suggesting that the effect of $\operatorname{Sin} \Delta \mathrm{C}$ on ERK was specific and that $\operatorname{Sin} \Delta \mathrm{C}$ may inhibit $\mathrm{T}$ cell maturation by interfering with normal selection of thymocytes. Experiments addressing the effect of $\operatorname{Sin} \Delta \mathrm{C}$ on thymocyte positive and negative selection using TCR transgenic animals are currently under way. Expression of $\operatorname{Sin} \Delta \mathrm{C}$ had no effect on upstream phosphorylation events proximal to the TCR, suggesting that $\operatorname{Sin} \Delta$ C expression does not interfere with Src kinase (Fyn/Lck) phosphorylation of substrates, which is required for normal signaling, and that the effect of $\operatorname{Sin} \Delta C$ is downstream of these phosphorylation events (58). From these experiments, we conclude that the truncated Sin mutant inhibits thymocyte differentiation through Fyn-dependent and -independent mechanisms and that endogenous Sin may be an important regulator of Tlymphocyte development.

\section{Role of $\operatorname{Sin}$ in T cell activation}

Consistent with the reduction in the SP T cell populations in the thymi of transgenic animals, we also found reduced numbers of mature $\mathrm{CD} 4^{+}$and $\mathrm{CD} 8^{+} \mathrm{T}$ cells in the spleen of transgenic animals. Thus, the number of mature $\mathrm{CD}^{+} \mathrm{SP}$ transgenic $\mathrm{T}$ cells is approximately $50 \%$ of normal littermate controls (Fig. 4). The B cell population, on the other hand, is unaffected, given the $\mathrm{CD} 2$ promoter-driven, $\mathrm{T}$ cell-specific expression of $\operatorname{Sin} \Delta \mathrm{C}$. $\mathrm{T}$ cells purified from the spleens of transgenic animals fail to proliferate and do not produce IL-2 in response to TCR stimulation, suggesting that $\operatorname{Sin} \Delta \mathrm{C}$ expression interferes with TCR signaling that leads to IL-2 expression (Fig. 5A, and unpublished observations).

We further analyzed the mechanism of $\operatorname{Sin} \Delta \mathrm{C}$-mediated inhibition of $\mathrm{T}$ cell proliferation and whether $\operatorname{Sin} \Delta \mathrm{C}$ reflected the function of full-length Sin in Jurkat $\mathrm{T}$ cells. To this end we used Jurkat $\mathrm{T}$ cell lines stably overexpressing Sin or cells 


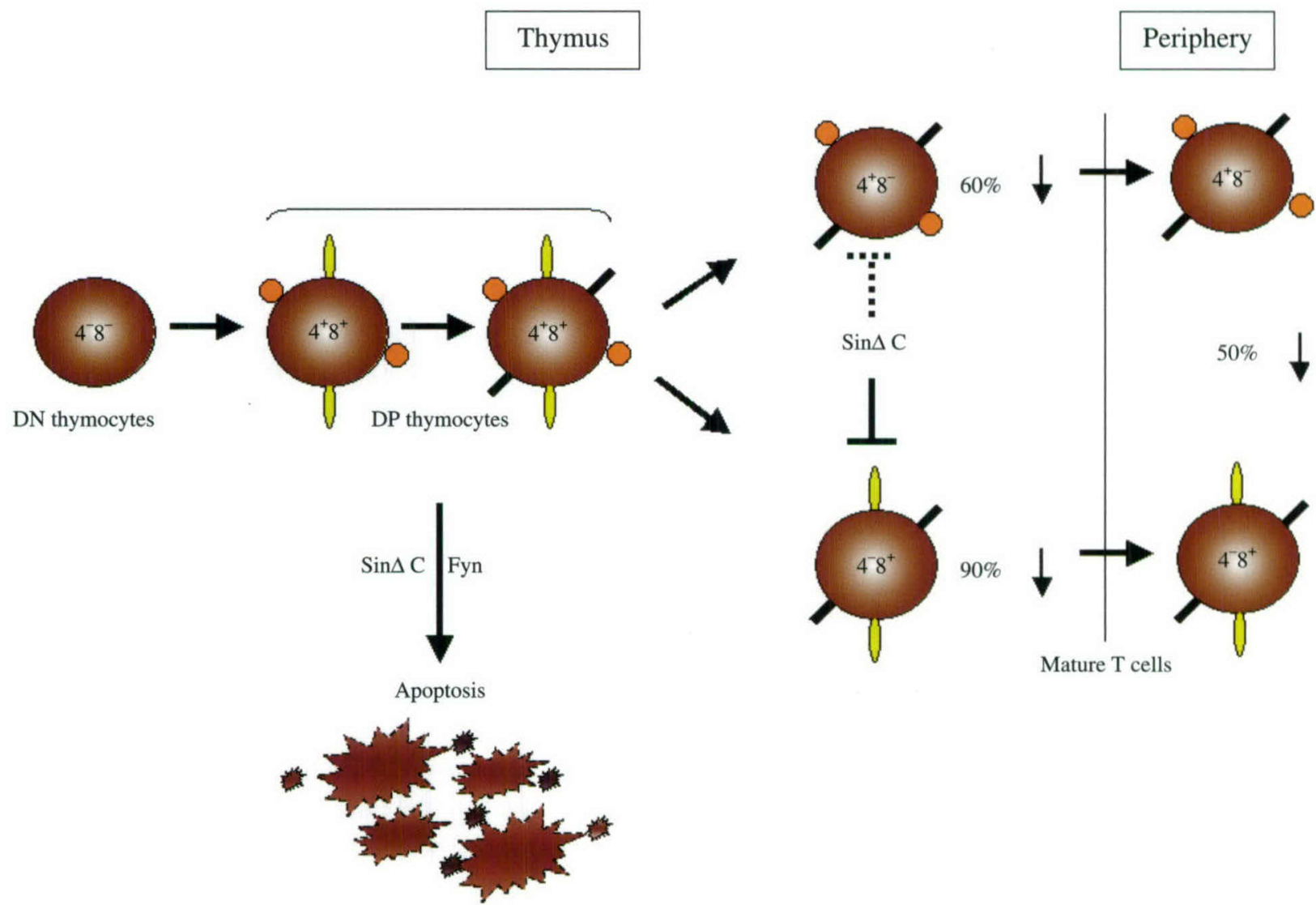

Fig. 4. Effect of $\operatorname{Sin} \Delta \mathrm{C}$ expression on thymocyte development. Expression of the truncated Sin mutant reduces thymic cellularity by inducing thymocyte apoptosis in a Fyn-dependent manner. On the other hand, Fyn-independent $\operatorname{Sin} \Delta \mathrm{C}$-mediated inhibition of $\mathrm{T}$ cell maturation leads to reduced percentages of $\mathrm{CD}^{+}$and particularly $\mathrm{CD} 8^{+} \mathrm{SP}$ cells in the thymus as well as in the spleen. transiently transfected with $\operatorname{Sin}$ or $\operatorname{Sin} \Delta \mathrm{C}$ together with luciferase reporter constructs. These constructs contain DNA binding sites for nuclear factor of activated T cells (NFAT) and AP-1 transcription factors from the IL-2 promoter as well as the complete IL-2 transcriptional unit. We found that both the full-length protein and $\operatorname{Sin} \Delta \mathrm{C}$ inhibit TCR-induced NFAT and AP-1 activation, consistent with the defect in proliferation and IL-2 production we observe in transgenic $\operatorname{Sin} \Delta \mathrm{C}$-expressing $\mathrm{T}$ cells (Xing et al., in preparation) (Fig. $5 \mathrm{~A}$ ). Sin expression very effectively inhibits NFAT activation $(\sim 80 \%)$, whereas the Sin-mediated AP-1 inhibition is partial $(\sim 50 \%)$. The effects of $\operatorname{Sin}$ and $\operatorname{Sin} \Delta \mathrm{C}$ on transcriptional inhibition are similar, suggesting that both proteins behave as negative regulators of TCR-stimulated $\mathrm{T}$ cell activation and that $\operatorname{Sin} \Delta C$ reflects the function of endogenous Sin.

To further analyze the inhibitory effects of Sin on transcriptional activation, we examined the mechanisms of Sin-mediated inhibition on NFAT and AP-1 activation. We first examined the effect of Sin on AP-1-mediated transcription. The AP-1 transcription factor consists of heterodimers of the Fos and
Jun proteins, whose expression and activation is regulated by the upstream MAP kinases ERK and JNK. Consistent with the inhibitory effect of Sin on AP-1-dependent transcriptional activation, we found that ERK phosphorylation in response to TCR crosslinking was compromised in $\operatorname{Sin} \Delta \mathrm{C}$ expressing transgenic and Sin overexpressing $\mathrm{T}$ cells. In contrast, JNK phosphorylation was normal, suggesting that the partial inhibitory effect of Sin on AP-1-mediated gene expression was the result of defective ERK, but not JNK, activation (Xing et al., in preparation).

The defect in ERK activation appears to be the result of a downstream inhibitory event, as phosphorylation of substrates proximal to the TCR appeared normal in $\operatorname{Sin} \Delta \mathrm{C}$ transgenic and Sin-expressing Jurkat $\mathrm{T}$ cells, consistent with our results in thymocytes (58). The nature of this inhibitory event is not clear at present. However, it has been shown that, in T cells, regulation of phosphorylation of MAP kinases is modulated by the GTPases Ras and Rap1. Whereas Ras plays a positive role in MAP kinase activation, Rap1 can play an inhibitory role in $\mathrm{T}$ cell activation and proliferation. In fact, suboptimally 
A

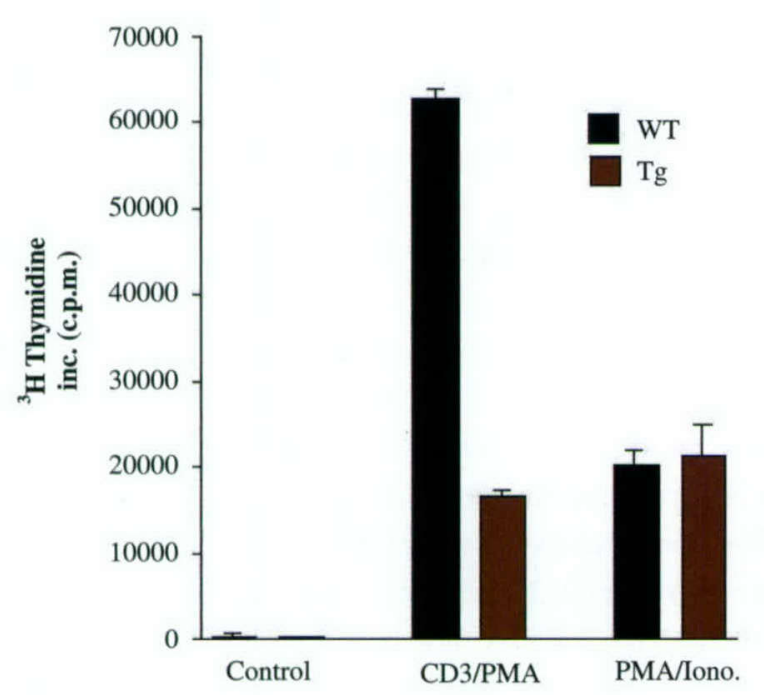

Fig. 5. Sin $\Delta \mathrm{C}$-mediated inhibition of proliferation correlates with Rap1 activation. (A) Purified T cells $\left(1 \times 10^{5}\right)$ isolated from the spleens of $\operatorname{Sin} \Delta C$ transgenic animals were left untreated (control) or stimulated with CD3/PMA $(0.5 \mu \mathrm{g} / \mathrm{mL})$ or PMA/ionomycin $(50 \mathrm{ng} / \mathrm{mL} / 1 \mu \mathrm{M})$. After 2 days in culture, cells were labeled with ${ }^{3} \mathrm{H}$ thymidine $(1 \mu \mathrm{Ci})$ for $18 \mathrm{~h}$, cells were then harvested and incorporation of radiolabeled thymidine was determined using a scintillation counter. (B) Splenocytes $\left(1 \times 10^{7}\right.$ per sample) from wild-type or transgenic animals were stimulated with $2 \mu \mathrm{g} \mathrm{CD} 3$-specific antibody for the indicated times. Cell extracts were then immunoprecipitated with antibody against the lymphocyte-specific isoform of $\mathrm{Crk}$, CrkL, immune complexes were

stimulated $\mathrm{T}$ cells (without costimulation through $\mathrm{CD} 28$ coreceptor) exhibit constitutive Fyn activity and increased levels of GTP-Rap1 (42). This correlates with inhibition of $\mathrm{IL}-2$ production and T cell proliferation (42). Based on this and other studies (88-90) it has been proposed that in certain cell types, such as Tlymphocytes, Rap1 activation plays an inhibitory role in cellular function by interfering with normal Ras signaling and ERK activation. However, more recent evidence suggests that Rap1 plays a positive role in thymocyte development and $\mathrm{T}$ cell activation and that TCR-activated Rap1 does not interfere with positive selection and ERK phosphorylation (91).

We mentioned earlier that in a cell culture system Srcphosphorylated $\operatorname{Sin} \Delta \mathrm{C}$ binds to the adapter $\mathrm{Crk}$ and the nucleotide exchange factor $\mathrm{C} 3 \mathrm{G}$, both upstream activators of Rap1 (61). We have also shown that $\operatorname{Sin} \Delta \mathrm{C}$ mediates $\operatorname{Src}$ signaling through the activation of the small GTP-binding protein Rap1, whose activation leads to increased phosphorylation of ERK and activation of transcription (61). In
B

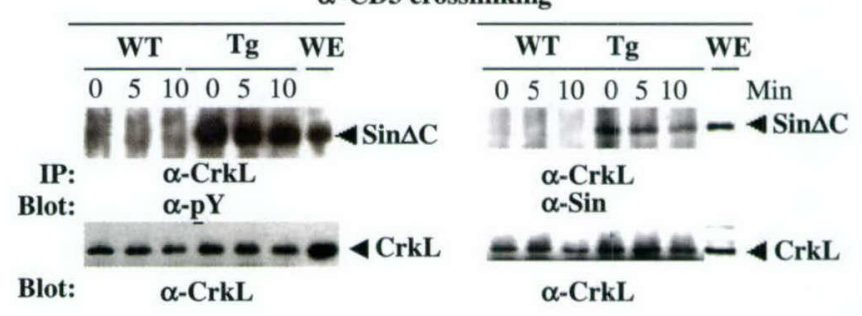

C

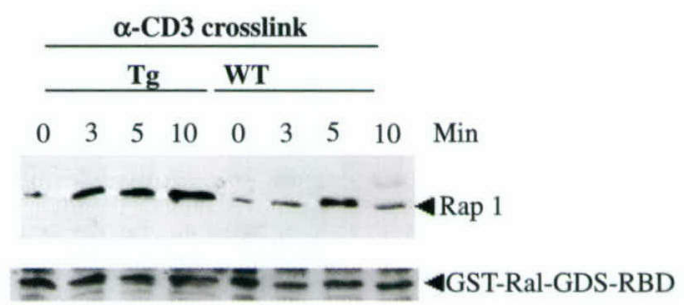

separated on SDS-PAGE, transferred to nitrocellulose membranes and Western blotted with antiphosphotyrosine- (left panel) or Sin-specific (right panel) antibodies. The membranes were then stripped and reprobed with CrkL-specific antibody. Protein bands were visualized by ECL. WE represents whole cell extracts. (C) Splenocytes were stimulated as in (B) with an antibody against CD3, lysed and GTP-bound Rap1 was precipitated with a GST-fusion protein containing the Rap1-binding domain of Ral-GDS-RBD as described previously (61). GTP-Rap1 was visualized using a Rap1-specific antibody. The nitrocellulose membranes were stripped and reprobed with anti-GST antibody to visualize GST-RalGDS-RBD to control for equal loading.

$\operatorname{Sin} \Delta \mathrm{C}$-expressing thymocytes, we have observed constitutive association of phosphorylated $\operatorname{Sin} \Delta \mathrm{C}$ with the lymphocytespecific isoform of Crk, CrkL, and increased Rapl activation compared to normal cells (Figs $5 B, C$ ). It is thus possible that $\mathrm{Sin}$ expression leads to activation of Rap1 through CrkL recruitment, which in turn interferes with ERK phosphorylation. In addition, we have evidence that Sin binds to the thymusspecific isoform of the GEF Chat, Chat-H (as mentioned earlier), which was previously shown to bind to the Ras family of proteins Rap1 and R-Ras. Moreover, AND-34, a molecule related to Chat-H, binds to and promotes guanine nucleotide exchange on Ral, Rap1 and R-Ras. Thus, Sin can potentially modulate the GTP levels of Ras proteins and subsequent phosphorylation of MAP kinases in T cells through two different mechanisms; that is, through the recruitment of the CrkL/C3G complex and through association with Chat-H. Modulation of the relative GTP levels of the Ras and Rap1 proteins through these mechanisms may thus lead to inhibition of ERK phosphorylation. Given the conflicting evidence about the role of 
Rap1 in Tlymphocytes, further experiments are required to address the role of Rap1 in inhibition of ERK phosphorylation in our system.

We subsequently examined the mechanisms of Sinmediated NFAT transcriptional activation. Given that NFAT activation is regulated through PLC- $\gamma$-induced intracellular calcium release, we examined the effect of Sin on intracellular calcium mobilization in response to TCR stimulation in Jurkat T cell lines stably transfected with Sin. Consistent with the defective NFAT activation we observed in the luciferase reporter assays, we found that Sin expression inhibited intracellular calcium release as compared to $\mathrm{T}$ cells stably transfected with a control vector. These results suggested that Sin expression blocks NFAT activation by interfering with intracellular calcium mobilization. As increases in the intracellular calcium concentrations are regulated by TCR-induced PLC- $\gamma$ activation, we also examined whether PLC- $\gamma$ phosphorylation was compromised in the presence of Sin. Consistent with our observation that Sin-overexpressing cells exhibit defective calcium mobilization, we found that expression of Sin in Jurkat T cells correlated with inhibition of PLC- $\gamma$ phosphorylation in response to TCR crosslinking (Xing et al. in preparation). These results suggest that Sin blocks NFAT activation and, as a result, IL-2 production by inhibiting PLC- $\gamma$ activation and intracellular calcium release.

The mechanism of Sin-mediated inhibition of PLC- $\gamma$ is not yet clear. As shown in Table 2, Sin contains conserved motifs that can act as potential binding sites for the $\mathrm{SH} 2$ and $\mathrm{SH} 3$ domains of PLC- $\gamma$. Experiments are in progress to determine the in vivo association of endogenous and overexpressed Sin with PLC- $\gamma$ under resting and TCR-stimulated conditions. Our hypothesis is that endogenous Sin regulates TCR signaling by setting a threshold of activation for, and regulating the activity of, signaling intermediates and that overexpression of Sin reveals this inhibitory function. A similar mechanism has been described previously for the adapter molecule $\mathrm{Cbl}$ in the regulation of immune receptor signaling. It has been shown that $\mathrm{Cbl}$ binds to and inhibits the phosphorylation and activation of the tyrosine kinase Syk in response to FcERI receptor stimulation in mast cells, effectively blocking degranulation (43). Sin could be acting in a similar fashion by binding to PLC- $\gamma$ and inhibiting its association with LAT and/or its phosphorylation by ZAP70 and Itk, which are both required for the induction of phospholipase enzymatic activity (14). As all Cas proteins contain potential binding sites for Itk (Table 2), it would be of interest to determine whether Itk binds to Sin and whether that affects PLC- $\gamma$ phosphorylation. These possibilities are currently under investigation.

\section{Concluding remarks}

We have reviewed evidence pertaining to the function of the three structurally related proteins of the Cas family. Although very limited information exists about the function of p130Cas in T lymphocytes, evidence generated in our laboratory as well as by other groups suggests that Sin and CasL (54) are both regulators of $\mathrm{T}$ cell signaling and activation. However, while existing evidence suggests that CasL is a positive regulator of $\mathrm{T}$ cell signaling, we found that $\mathrm{Sin}$ has the opposite effect and acts as a negative regulator of $\mathrm{T}$ cell proliferation. Given the structural similarity of Sin and CasL and their potential to bind to some common intermediates (Table 1), the existing data thus far argue against functional similarity and overlap. Additional evidence supporting functional divergence for Sin and CasL is the observation that, whereas CasL is transiently phosphorylated in peripheral blood $\mathrm{T}$ cells and Jurkat cells overexpressing full-length CasL, we have not been able to detect increased Sin phosphorylation in Jurkat cells stably overexpressing Sin. In contrast, in the same cell system we find that overexpressed Sin is constitutively phosphorylated and becomes rapidly and transiently dephosphorylated in response to TCR crosslinking (unpublished observations). A similar mechanism of regulating the ability of scaffold molecules to assemble protein complexes has been reported recently in the case of the PAG/Cbp protein. TCR-induced dephosphorylation of PAG/Cbp results in the release and relocalization of Csk to the cytosol and activation of Src kinases. Experiments are in progress to determine whether this reflects endogenous regulation of Sin phosphorylation.

The differential in the phosphorylation patterns of Sinvs. CasL could be due to structural differences, including the presence of proline-rich motifs on Sin but not on CasL. These motifs can influence the binding of kinases, Src kinases in particular, and as a consequence affect the mode of phosphorylation of the two proteins. Consistent with the idea of differential binding of Src kinases are the observations that although Fyn and Lck both bind to and phosphorylate CasL in response to the TCR (77), we only find association of Sin with Fyn and not with Lck (58). The fact that the Src kinases interact with CasL in the absence of proline-rich motifs also supports the existence of differential mechanisms for recruiting Src kinases by Sin vs. Cas.

In addition to the different biochemical properties of Sin and CasL, the expression patterns of Sin also provide evidence in support of functional divergence between Sin and Cas. Our data show that at least two other Sin proteins (Sin II and III) are expressed in the thymus in the form of alternatively spliced isoforms of the full-length protein. To our knowledge, no 
splice variants of CasL and p130Cas have yet been described. The expression patterns of Sin in the thymus vs. the brain are also different, since we have not yet been able to detect the spliced isoforms of $\operatorname{Sin}$ in the adult mouse brain. The existence of the Sin III isoform is particularly intriguing, given that the introduced deletion removes the two proline-rich motifs that bind to Src kinase $\mathrm{SH} 3$ domains as well as one of the Sin tyrosine motifs (Fig. 2A). Collectively, these observations argue for unique roles for the CasL/Sin proteins in Tlymphocyte function and $\mathrm{T}$ cell physiology. We anticipate that the generation of Sin null animals will provide important insights into the role of $\operatorname{Sin}$ in $\mathrm{T}$ cell physiology.

\section{References}

1. Burack WR, Shaw AS. Signal transduction: hanging on a scaffold. Curr Opin Cell Biol 2000;12:211-216.

2. Schlessinger J. SH2/SH3 signaling proteins. Curr Opin Genet Dev 1994:4:25-30.

3. van der Geer P, Pawson T. The PTB domain: a new protein module implicated in signal transduction. Trends Biochem Sci 1995;20:277-280.

4. Cowburn D. Peptide recognition by PTB and PDZ domains. Curr Opin Struct Biol 1997; 7:835-838.

5. Sudol M, Chen HI, Bougeret C, Einbond A, Bork P. Characterization of a novel proteinbinding module - the WW domain. FEBS Lett 1995;369:67-71.

6. Musacchio A, Gibson T, Rice P, Thompson J, Saraste M. The PH domain: a common piece in the structural patchwork of signalling proteins. Trends Biochem Sci 1993;18: 343-348.

7. Songyang Z, et al. $\mathrm{SH} 2$ domains recognize specific phosphopeptide sequences. Cell 1993;72:767-778.

8. Kavanaugh WM, Turck CW, Williams LT. PTB domain binding to signaling proteins through a sequence motif containing phosphotyrosine. Science 1995;268: 1177-1179.

9. Cicchetti P, Mayer BJ, Thiel G, Baltimore D. Identification of a protein that binds to the $\mathrm{SH} 3$ region of $\mathrm{Abl}$ and is similar to $\mathrm{Bcr}$ and GAP-rho. Science 1992;257:803-806.

10. Ren R, Mayer BJ, Cicchetti P, Baltimore D. Identification of a ten-amino acid proline-rich SH3 binding site. Science 1993;259:1157-1161.

11. Harlan JE, Hajduk PJ, Yoon HS, Fesik SW. Pleckstrin homology domains bind to phosphatidylinositol-4,5-bisphosphate. Nature 1994;371:168-170.

12. Songyang $Z$, et al. Recognition of unique carboxyl-terminal motifs by distinct PDZ domains. Science 1997;275:73-77.

13. Burack WR, Cheng AM, Shaw AS. Scaffolds, adaptors and linkers of TCR signaling: theory and practice. Curr Opin Immunol 2002;14:312-316.
14. Leo A, Schraven B. Adapters in lymphocyte signalling. Curr Opin Immunol 2001;13:307-316.

15. Leo A, Wienands J, Baier G, Horejsi V, Schraven B. Adapters in lymphocyte signaling. J Clin Invest 2002;109:301-309.

16. Norian LA, Koretzky GA. Intracellular adapter molecules. Semin Immunol 2000;12:43-54.

17. Clements JL, Boerth NJ, Lee JR, Koretzky GA. Integration of $\mathrm{T}$ cell receptor-dependent signaling pathways by adapter proteins. Annu Rev Immunol 1999;17:89-108.

18. Tomlinson MG, Lin J, Weiss A. Lymphocytes with a complex: adapter proteins in antigen receptor signaling. Immunol Today 2000;21:584-591.

19. Kennedy JS, Raab M, Rudd CE. Signaling scaffolds in immune cells. Cell Calcium 1999;26:227-235.

20. Koretzky GA. The role of Grb2-associated proteins in T-cell activation. Immunol Today 1997;18:401-406.

21. Asada H, et al. Grf40, a novel Grb2 family member, is involved in T cell signaling through interaction with SLP-76 and LAT. J Exp Med 1999;189:1383-1390.

22. Bourette RP, Arnaud S, Myles GM, Blanchet JP, Rohrschneider LR, Mouchiroud G. Mona, a novel hematopoietic-specific adaptor interacting with the macrophage colonystimulating factor receptor, is implicated in monocyte/macrophage development. EMBO J 1998;17:7273-7281.

23. Law CL, et al. GrpL, a Grb2-related adaptor protein, interacts with SLP-76 to regulate nuclear factor of activated T cell activation. J Exp Med 1999;189:1243-1253.

24. Yoder J, et al. Requirement for the SLP-76 adaptor GADS in T cell development. Science 2001;291:1987-1991.

25. Gong Q, et al. Disruption of $\mathrm{T}$ cell signaling networks and development by Grb2 haploid insufficiency. Nat Immunol 2001;2:29-36.

26. Pandey A, Duan H, Dixit VM. Characterization of a novel Src-like adapter protein that associates with the Eck receptor tyrosine kinase. J Biol Chem 1995;270:19201-19204.
27. Tang J, Sawasdikosol S, Chang JH, Burakoff SJ. SLAP, a dimeric adapter protein, plays a functional role in T cell receptor signaling. Proc Natl Acad Sci USA 1999;96:9775-9780.

28. Sosinowski T, Pandey A, Dixit VM, Weiss A. Src-like adaptor protein (SLAP) is a negative regulator of $\mathrm{T}$ cell receptor signaling. J Exp Med 2000;191:463-474.

29. Sosinowski T, Killeen N, Weiss A. The Src-like adaptor protein downregulates the $\mathrm{T}$ cell receptor on $\mathrm{CD} 4+\mathrm{CD} 8+$ thymocytes and regulates positive selection. Immunity 2001; 15:457-466.

30. Pivniouk V, Tsitsikov E, Swinton P, Rathbun G, Alt FW, Geha RS. Impaired viability and profound block in thymocyte development in mice lacking the adaptor protein SLP-76. Cell 1998;94:229-238.

31. Sommers CL, Menon RK, Grinberg A, Zhang W, Samelson LE, Love PE. Knock-in mutation of the distal four tyrosines of linker for activation of $\mathrm{T}$ cells blocks murine $\mathrm{T}$ cell development. J Exp Med 2001;194:135-142.

32. Zhang W, et al. Essential role of LAT in $\mathrm{T}$ cell development. Immunity 1999;10:323-332.

33. Myung PS, et al. Differential requirement for SLP-76 domains in T cell development and function. Immunity 2001;15:1011-1026.

34. Kumar L, Pivniouk V, de la Fuente MA Laouini D, Geha RS. Differential role of SLP-76 domains in T cell development and function. Proc Natl Acad Sci USA 2002;99:884-889.

35. Krause M, Sechi AS, Konradt M, Monner D, Gertler FB, Wehland J. Fyn-binding protein (Fyb)/SLP-76-associated protein (SLAP), Ena/vasodilator-stimulated phosphoprotein (VASP) proteins and the Arp2/3 complex link $\mathrm{T}$ cell receptor (TCR) signaling to the actin cytoskeleton. J Cell Biol 2000;149:181-194.

36. Griffiths EK, et al. Positive regulation of $\mathrm{T}$ cell activation and integrin adhesion by the adapter Fyb/Slap. Science 2001;293: 2260-2263.

37. Peterson EJ, et al. Coupling of the TCR to integrin activation by Slap-130/Fyb. Science 2001;293:2263-2265. 
38. Thien CB, Langdon WY. Cbl: many adaptations to regulate protein tyrosine kinases. Nat Rev Mol Cell Biol 2001;2: 294-307.

39. Rao N, Dodge I, Band $\mathrm{H}$. The Cbl family of ubiquitin ligases: critical negative regulators of tyrosine kinase signaling in the immune system. J Leukoc Biol 2002;71:753-763

40. Brdicka T, et al. Phosphoprotein associated with glycosphingolipid-enriched microdomains (PAG), a novel ubiquitously expressed transmembrane adaptor protein, binds the protein tyrosine kinase csk and is involved in regulation of $\mathrm{T}$ cell activation. J Exp Med 2000;191:1591-1604.

41. Kawabuchi M, et al. Transmembrane phosphoprotein Cbp regulates the activities of Src-family tyrosine kinases. Nature 2000;404:999-1003.

42. Boussiotis VA, Freeman GJ, Berezovskaya A, Barber DL, Nadler LM. Maintenance of human T cell anergy. blocking of IL-2 gene transcription by activated Rap1. Science 1997;278:124-128.

43. Ota Y, Samelson LE. The product of the proto-oncogene c-cbl: a negative regulator of the Syk tyrosine kinase. Science $1997 ; 276: 418-420$.

44. van Leeuwen JE, Paik PK, Samelson LE. The oncogenic $70 \mathrm{Z} \mathrm{Cbl} \mathrm{mutation} \mathrm{blocks} \mathrm{the}$ phosphotyrosine binding domain-dependent negative regulation of $\mathrm{ZAP}-70$ by $\mathrm{c}-\mathrm{Cbl}$ in Jurkat T cells. Mol Cell Biol 1999;19: 6652-6664.

45. Kong G, Dalton M, Wardenburg JB, Straus D, Kurosaki T, Chan AC. Distinct tyrosine phosphorylation sites in ZAP-70 mediate activation and negative regulation of antigen receptor function. Mol Cell Biol 1996;16:5026-5035.

46. Chiang YJ, et al. Cbl-b regulates the CD28 dependence of T-cell activation. Nature 2000;403:216-220.

47. Bachmaier K, et al. Negative regulation of lymphocyte activation and autoimmunity by the molecular adaptor Cbl-b. Nature 2000;403:211-216.

48. Naramura M, Kole HK, Hu RJ, Gu H. Altered thymic positive selection and intracellular signals in Cbl-deficient mice. Proc Natl Acad Sci USA 1998;95:15547-15552.

49. Murphy MA, et al. Tissue hyperplasia and enhanced T-cell signalling via ZAP-70 in c-Cbl-deficient mice. Mol Cell Biol 1998; 18:4872-4882

50. Sakai R, et al. A novel signaling molecule, p130, forms stable complexes in vivo with $\mathrm{v}$-Crk and v-Src in a tyrosine phosphorylationdependent manner. EMBO J 1994;13: 3748-3756.

51. O'Neill GM, Fashena SJ, Golemis EA. Integrin signalling: a new Cas $(\mathrm{t})$ of characters enters the stage. Trends Cell Biol 2000;10:111-119.
52. Law SF, Estojak J, Wang B, Mysliwiec T, Kruh G, Golemis EA. Human enhancer of filamentation 1 , a novel p 130cas-like docking protein, associates with focal adhesion kinase and induces pseudohyphal growth in Saccharomyces cerevisiae. Mol Cell Biol 1996; 16:3327-3337.

53. Minegishi M, Tachibana K, Sato T, Iwata $S$, Nojima Y, Morimoto C. Structure and function of Cas-L, a 105-kD Crk-associated substrate-related protein that is involved in beta 1 integrin-mediated signaling in lymphocytes. J Exp Med 1996;184: 1365-1375.

54. Iwata S, Ohashi Y, Kamiguchi K, Morimoto C. Beta 1-integrin-mediated cell signaling in T lymphocytes. J Dermatol Sci 2000;23: 75-86.

55. Alexandropoulos K, Baltimore D. Coordinate activation of c-Src by SH3-and SH2-binding sites on a novel p130Cas-related protein, Sin. Genes Dev 1996;10:1341-1355.

56. Ishino M, Ohba T, Sasaki H, Sasaki T. Molecular cloning of a cDNA encoding a phosphoprotein, Efs, which contains a Src homology 3 domain and associates with Fyn. Oncogene 1995;11:2331-2338

57. Ishino M, Ohba T, Inazawa J, Sasaki $H$, Ariyama Y, Sasaki T. Identification of an Efs isoform that lacks the SH3 domain and chromosomal mapping of human Efs. Oncogene 1997;15:1741-1745

58. Donlin L, Roman CA, Adlam M, Regelmann AG, Alexandropoulos K. Defective thymcoyte maturation by transgenic expression of a truncated form of the $\mathrm{T}$ lymphocyte adapter molecule and Fyn substrate, Sin. J Immunol. 2002, Vol 169: 6900-6909.

59. Cote JF, Charest A, Wagner J, Tremblay ML. Combination of gene targeting and substrate trapping to identify substrates of protein tyrosine phosphatases using PTP-PEST as a model. Biochemistry 1998;37: 13128-13137.

60. Yaffe MB, Leparc GG, Lai J, Obata T, Volinia S, Cantley LC. A motif-based profile scanning approach for genome-wide prediction of signaling pathways. Nat Biotechnol 2001;19:348-353.

61. Xing L, Ge C, Zeltser R, Maskevitch G, Mayer BJ, Alexandropoulos K. c-Src signaling induced by the adapters Sin and Cas is mediated by Rap1 GTPase. Mol Cell Biol 2000;20:7363-7377.

62. Manie $\mathrm{SN}$, et al. Involvement of p130(Cas) and p105(HEF1), a novel Cas-like docking protein, in a cytoskeletondependent signaling pathway initiated by ligation of integrin or antigen receptor on human B cells. J Biol Chem 1997; 272:4230-4236.
63. Petruzzelli L, Takami M, Herrera R. Adhesion through the interaction of lymphocyte function-associated antigen-1 with intracellular adhesion molecule-1 induces tyrosine phosphorylation of p130Ccas and its association with c-CrkII. J Biol Chem 1996;271:7796-7801.

64. Hamasaki K, et al. Src kinase plays an essential role in integrin-mediated tyrosine phosphorylation of Crk-associated substrate p130Cas. Biochem Biophys Res Commun 1996;222:338-343.

65. Kanda $H$, et al. Ligation of the $\mathrm{T}$ cell antigen receptor induces tyrosine phosphorylation of p105CasL, a member of the p130Cas-related docking protein family, and its subsequent binding to the Src homology 2 domain of c-Crk. Eur J Immunol 1997;27:2113-2117.

66. Law SF, Zhang YZ, Klein-Szanto AJ, Golemis EA. Cell cycle-regulated processing of HEF1 to multiple protein forms differentially targeted to multiple subcellular compartments. Mol Cell Biol 1998;18: 3540-3551

67. Alexandropoulos K, Cheng G, Baltimore D. Proline-rich sequences that bind to Src homology 3 domains with individual specificities. Proc Natl Acad Sci USA 1995;92:3110-3114

68. Law SF, Zhang YZ, Fashena SJ, Toby G, Estojak J, Golemis EA. Dimerization of the docking/adaptor protein HEF1 via a carboxyterminal helix-loop-helix domain. Exp Cell Res 1999;252:224-235.

69. Sakakibara A, Hattori S. Chat, a Cas/HEF1associated adaptor protein that integrates multiple signaling pathways. J Biol Chem 2000;275:6404-6410.

70. Parsons JT, Martin KH, Slack JK, Taylor JM, Weed SA. Focal adhesion kinase: a regulator of focal adhesion dynamics and cell movement. Oncogene 2000;19:5606-5613.

71. Cary LA, Guan JL. Focal adhesion kinase in integrin-mediated signaling. Front Biosci 1999;4:D102-D113.

72. Schlaepfer DD, Hauck CR, Sieg DJ. Signaling through focal adhesion kinase. Prog Biophys Mol Biol 1999;71:435-478.

73. Honda $\mathrm{H}$, et al. Cardiovascular anomaly, impaired actin bundling and resistance to Src-induced transformation in mice lacking p130Cas. Nat Genet 1998;19: 361-365.

74. Okabe S, Fukuda S, Broxmeyer HE. Activation of Wiskott-Aldrich syndrome protein and its association with other proteins by stromal cell-derived factor-1a is associated with cell migration in a T-lymphocyte line. Exp Hematol 2002;30:761-766.

75. Tachibana K, et al. Tyrosine phosphorylation of Crk-associated substrates by focal adhesion kinase. J Biol Chem 1997;272: 29083-29090. 
76. Ohashi Y, Tachibana K, Kamiguchi K, Fujita H, Morimoto C. T cell receptor-mediated tyrosine phosphorylation of CasL, a $105 \mathrm{kDa}$ Crk-associated substrate-related protein, and its association of Crk and C3G. J Biol Chem 1998;273:6451.

77. Kanda $\mathrm{H}$, et al. Fyn and Lck tyrosine kinases regulate tyrosine phosphorylation of p105CasL, a member of the p130Cas docking protein family, in T-cell receptor-mediated signaling. Immunology 1999;97:56-61.

78. Kamiguchi K, Tachibana K, Iwata S, Ohashi Y, Morimoto C. CasL is required for b1 integrinmediated costimulation in human T cells. J Immunol 1999;163:563-568.

79. Cartwright CA, Eckhart W, Simon S, Kaplan PL. Cell transformation by pp60c-src mutated in the carboxy-terminal regulatory domain. Cell 1987;49:83-91.

80. Cooper JA, King CS. Dephosphorylation or antibody binding to the carboxy terminus stimulates pp60c-src. Mol Cell Biol 1986;6:4467-4477.
81. Kmiecik TE, Shalloway D. Activation and suppression of pp60c-src transforming ability by mutation of its primary sites of tyrosine phosphorylation. Cell 1987;49:65-73.

82. Piwnica-Worms H, Saunders KB, Roberts TM, Smith AE, Cheng SH. Tyrosine phosphorylation regulates the biochemical and biological properties of pp60c-src. Cell 1987:49:75-82.

83. Sicheri F, Moarefi I, Kuriyan J. Crystal structure of the Src family tyrosine kinase Hck. Nature 1997;385:602-609.

84. Xu W, Doshi A, Lei M, Eck MJ, Harrison SC. Crystal structures of c-Src reveal features of its autoinhibitory mechanism. Mol Cell 1999;3:629-638.

85. Molina TJ, et al. Profound block in thymocyte development in mice lacking p56lck. Nature 1992;357:161-164

86. Appleby MW, Gross JA, Cooke MP, Levin SD, Qian X, Perlmutter RM. Defective T cell receptor signaling in mice lacking the thymic isoform of p59fyn. Cell 1992;70:751-763.
87. Stein PL, Lee HM, Rich S, Soriano P. pp59fyn mutant mice display differential signaling in thymocytes and peripheral $\mathrm{T}$ cells. Cell 1992;70:741-750.

88. Carey $\mathrm{KD}$, et al. CD28 and the tyrosine kinase lck stimulate mitogen-activated protein kinase activity in $\mathrm{T}$ cells via inhibition of the small G protein Rap1. Mol Cell Biol 2000;20:8409-8419.

89. Reedquist KA, Bos JL. Costimulation through CD28 suppresses $\mathrm{T}$ cell receptor-dependent activation of the Ras-like small GTPase Rap1 in human $\mathrm{T}$ lymphocytes. J Biol Chem 1998;273:4944-4949.

90. Czyzyk J, Leitenberg D, Taylor T, Bottomly K Combinatorial effect of T-cell receptor ligation and $\mathrm{CD} 45$ isoform expression on the signaling contribution of the small GTPases Ras and Rap1. Mol Cell Biol 2000;20: 8740-8747.

91. Sebzda E, Bracke M, Tugal T, Hogg N, Cantrell DA. Rap 1 A positively regulates $T$ cells via integrin activation rather than inhibiting lymphocyte signaling. Nat Immunol 2002;3:251-258. 


\title{
The Adapter Molecule Sin Regulates T-Cell-Receptor-Mediated Signal Transduction by Modulating Signaling Substrate Availability
}

\author{
Luzhou Xing ${ }^{1} \dagger$ Laura T. Donlin, ${ }^{1} \dagger$ Rebecca H. Miller, ${ }^{2}$ and Konstantina Alexandropoulos ${ }^{1 *}$ \\ Department of Pharmacology ${ }^{1}$ and Department of Nutrition, ${ }^{2}$ College of Physicians and Surgeons of \\ Columbia University, New York, New York 10032
}

Received 11 August 2003/Returned for modification 3 October 2003/Accepted 14 February 2004

\begin{abstract}
Engagement of the T-cell receptor (TCR) results in the activation of a multitude of signaling events that regulate the function of $\mathrm{T}$ lymphocytes. These signaling events are in turn modulated by adapter molecules, which control the final functional output through the formation of multiprotein complexes. In this report, we identified the adapter molecule Sin as a new regulator of T-cell activation. We found that the expression of Sin in transgenic $\mathbf{T}$ lymphocytes and Jurkat $\mathrm{T}$ cells inhibited interleukin-2 expression and $\mathrm{T}$-cell proliferation. This inhibitory effect was specific and was due to defective phospholipase C- $\gamma$ (PLC- $\gamma$ ) phosphorylation and activation. In contrast to other adapters that become phosphorylated upon TCR stimulation, Sin was constitutively phosphorylated in resting cells by the Src kinase Fyn and bound to signaling intermediates, including PLC- $\gamma$. In stimulated cells, Sin was transiently dephosphorylated, which coincided with transient dissociation of Fyn and PLC- $\gamma$. Downregulation of Sin expression using Sin-specific short interfering RNA oligonucleotides inhibited transcriptional activation in response to TCR stimulation. Our results suggest that endogenous Sin influences T-lymphocyte signaling by sequestering signaling substrates and regulating their availability and/or activity in resting cells, while Sin is required for targeting these intermediates to the TCR for fast signal transmission during stimulation.
\end{abstract}

In recent years, adapter molecules have emerged as critical regulators of intracellular signaling pathways and function in $\mathrm{T}$ cells. While these molecules lack intrinsic enzymatic activity, they regulate and integrate signaling events through proteinprotein and protein-lipid interactions. $T$ cells express a variety of adapter molecules that act as positive or negative regulators of T-cell receptor (TCR) signaling. Positive regulators of T-cell function include the bona fide adapters Grb-2 and Gads, as well as the scaffold proteins Src homology 2 domain containing leukocyte protein 76 (SLP-76), linker of activation of T cells (LAT), and degranulation-promoting adapter protein (ADAP), whereas negative regulators consist of the $\mathrm{Cbl}$ family of proteins, SLAP (Src-like adapter protein), and the protein associated with glycosphingolipid-enriched microdomains PAG/ Cbp $(19,26,37)$.

Gene targeting experiments with Jurkat T-cell lines and mice indicate that the deletion of positive regulators in general exhibit defective thymocyte development or T-cell signaling ( 8 , $30,31,40,43$ ), whereas mice lacking negative regulators have opposite phenotypes manifested as increased thymocyte positive selection and the development of autoimmunity $(23,25$, 34). Similarly, studies describing the overexpression of adapter molecules in T lymphocytes have helped to further define these molecules and have shown that negative and positive regulators either suppress or promote excessive T-lymphocyte development and function, respectively $(20,35,36,38)$.

Our studies are concentrated on elucidating the molecular mechanisms involved in TCR signaling, with particular empha-

\footnotetext{
* Corresponding author. Mailing address: Department of Pharmacology, College of Physicians and Surgeons of Columbia University, 630 West 168th St., New York, NY 10032. Phone: (212) 305-2705. Fax: (212) 305-8780. E-mail: ka141@columbia.edu.

$\dagger$ L.X. and L.T.D. made equal contributions to this work.
}

sis on the role of adapter/scaffold molecules in this process. More specifically, we are interested in examining the role of the novel adapter molecule Sin in T-cell signaling and activation. Sin belongs to a small family of related proteins, the other members being p130Cas and CasL (28). These proteins share a conserved Src homology region 3 (SH3) domain, repeated tyrosine-based and proline-rich motifs, and a conserved $\mathrm{C}$ terminus. All three members of the p130Cas family are substrates for Src kinases, and Src kinase-mediated phosphorylation of these proteins is important for their adapter/scaffold signaling properties (2).

We became interested in determining whether Sin regulates TCR signaling because Sin was cloned as a substrate for the key TCR signaling molecule Fyn $(1,13)$ and because the thymus expresses higher levels of Sin than other tissues do $(2,12)$. Thus, in previous experiments we examined the role of $\mathrm{Sin}$ in thymocyte development using transgenic mice expressing a truncated form of $\operatorname{Sin}, \operatorname{Sin} \Delta C$. Sin $\Delta C$ expression in the mouse thymus resulted in reduced thymic cellularity due to increased thymocyte apoptosis as well as defective thymocyte differentiation manifested as reduced numbers of mature CD4 and CD8 single-positive (SP) cells (6). We also found that the Src kinase Fyn was important for Sin-mediated thymocyte apoptosis but not for the inhibition of thymocyte maturation (6). These results suggest that $\operatorname{Sin}$ is a negative regulator of thymocyte differentiation and survival.

In this report, we addressed the role of Sin in TCR signaling and T-cell activation using Sin-expressing Jurkat and transgenic $\mathrm{T}$ cells as well as Sin-specific short interfering RNA (siRNA). We found that Sin expression inhibited TCR-induced T-cell activation and proliferation by blocking expression of the interleukin-2 (IL-2) gene. The defect in IL-2 expression correlated with reduced phospholipase C- $\gamma$ (PLC- $\gamma$ ) 
phosphorylation, intracellular calcium release, and NFAT and AP-1 activation. Downregulation of endogenous Sin expression also inhibited TCR-induced transcriptional activation, an observation seemingly paradoxical to our overexpression data. Strikingly, however, we found that Sin was constitutively phosphorylated in resting cells, which correlated with the association of phosphorylated Sin with multiple signaling molecules of which we identified Fyn and PLC- $\gamma$. This adapter function of Sin was modulated through the TCR because Sin was dephosphorylated after TCR stimulation, which coincided with the release of proteins bound to Sin in resting cells including Fyn and PLC- $\gamma$. Taken together, these data suggest that $\operatorname{Sin}$ is a dual positive-negative regulator which influences T-lymphocyte signaling first by sequestering signaling substrates and preventing them from acting on their substrates in resting cells and second by releasing and targeting these substrates to the TCR for signal transmission upon stimulation.

\section{MATERIALS AND METHODS}

Mice. A cDNA fragment encoding amino acids 1 to 335 of full-length Sin was cloned into the EcoRI-SmaI site of the CD2 expression cassette (44), and $\operatorname{Sin} \Delta \mathrm{C}$ transgenic mice were generated as previously described (6). C57BL/6 animals were purchased from the Jackson Laboratory (Bar Harbor, Maine).

cDNA constructs and Sin-specific siRNA oligos. DNA manipulations were performed by standard protocols. Full-length Sin, Efs 2 (missing amino acids 4 to 99), and $\operatorname{Sin} \Delta \mathrm{C}$ (amino acids 1 to 335 ) were cloned into the SpeI-NotI sites of the pEBB expression vector. $\mathrm{pEBB}$ was derived from the pEF-BOS expression vector driven by the human elongation factor $1-\alpha$ promoter (21). Four different siRNA oligonucleotide duplexes were synthesized (QIAGEN), corresponding to target sequences on human full-length $\mathrm{Sin}$. The target sequences were as follows: for SRi1, 5'AACGAGCGTCAGCCTTACTCA; for SRi2, 5'AGTATGACTAT GTCCACCTGA; for SRi3, 5'AAGAGATGGTGCAGTGTGTAA; and for SRi4, 5'AATTCACTACCCTGCTCACTA. A nonsilencing control siRNA duplex sequence (catalog number 1022076; QIAGEN) was used as a control for the transfections. The same fluorescently labeled siRNA duplex (catalog number 80-11320; QIAGEN) was used to monitor transfection efficiency.

Cell lines and antibodies. Jurkat cells transfected with the simian virus 40 large $\mathrm{T}$ antigen (SV40 Tag) (provided by A. Weiss, University of California at San Francisco, San Francisco, Calif.), the parental Jurkat E6-1, and primary splenic T cells were maintained in RPMI 1640 medium supplemented with $10 \%$ fetal calf serum, penicillin, streptomycin, and glutamine. Stable cells lines were generated by cotransfecting $2 \times 10^{6}$ Jurkat Tag cells with $1 \mu \mathrm{g}$ of pEBB-Sin and $0.2 \mu \mathrm{g}$ of MSC-puro vector expressing puromycin using the FuGENE-6 transfection reagent (Roche). Transfected cells were serially diluted in 96-well plates and selected in culture medium containing $300 \mathrm{ng}$ of puromycin $/ \mathrm{ml}$.

For mouse monoclonal antibodies, anti-Sin-specific and isotype-matched control clone MOPC-31C (MOPC) were obtained from BD Transduction Laboratories; anti-Fyn, anti-Lck, and PLC- $\gamma$ (clone sc-81) were obtained from Santa Cruz; antiphosphotyrosine-specific antibody was obtained from Upstate Biotechnology. Purified mouse monoclonal anti-CD3 and anti-CD28 antibodies used for cross-linking were obtained from BD Pharmingen.

Flow cytometry. Freshly isolated splenocytes $\left(10^{6}\right)$ were incubated with the appropriate antibodies in staining medium (3\% fetal calf serum, $0.1 \%$ sodium azide in phosphate-buffered saline) for $15 \mathrm{~min}$ on ice. Cells were spun down and washed three times with staining medium and analyzed by flow cytometry using FACSCalibur and CELLQUEST software. Anti-CD4-allophycocyanin-, antiCD8-peridinin chlorophyll-a protein-, and anti-CD3-fluorescein isothiocyanateconjugated antibodies were purchased from BD Pharmingen.

T-cell purification and proliferation assays. Splenic $\mathrm{CD} 4^{+} \mathrm{T}$ cells were purified by using the Dynabead/DETACHaBEAD mouse $\mathrm{CD}^{+}{ }^{+}$system (DYNAL Biotech). A total of $10^{5} \mathrm{~T}$ cells were plated per well of a 96-well plate. Cells were left untreated or induced with plate-bound mouse anti-CD $3 \varepsilon(0.5 \mu \mathrm{g} / \mathrm{ml})$ and anti-CD28 $(5 \mu \mathrm{g} / \mathrm{ml})$ or anti-CD3ع $(0.05 \mu \mathrm{g} / \mathrm{ml})$ with or without recombinant mouse IL-2 (20 ng/ml) (BD Pharmingen). At $72 \mathrm{~h}$, cells were labeled overnight with $1 \mu \mathrm{Ci}$ of $\left[{ }^{3} \mathrm{H}\right]$ thymidine, and the proliferative response was determined by levels of $\left[{ }^{3} \mathrm{H}\right]$ thymidine incorporation on a scintillation counter. In the proliferation assay, $5 \mu \mathrm{l}$ of supernatant from each well was collected at 24,48 , and $72 \mathrm{~h}$ and assayed for IL-2 concentration (mouse IL-2 enzyme-linked immunosorbent assay kit; R\&D Systems).

Transfections and luciferase assays. For luciferase reporter assays, $2 \times 10^{6}$ Jurkat Tag cells were transfected with the indicated amounts of plasmid DNA expressing Sin, Sin $\Delta C$, Efs2, CasL, or SLP-76 proteins plus 200 ng of NFAT- or AP-1-firefly-luciferase and $5 \mathrm{ng}$ of pRL-thymidine kinase (TK)-Renilla-luciferase reporter constructs using FuGENE-6 transfection reagent according to manufacturer's protocol. Expression of the Renilla luciferase is under the influence of the herpes simplex virus (HSV)-TK promoter (Promega). After overnight incubation, half of the transfected cells were stimulated either by plate-bound OKT3 antibody $(5 \mu \mathrm{g} / \mathrm{ml})$, or by phorbol myristate acetate (PMA) $(10 \mathrm{ng} / \mathrm{ml})$ plus ionomycin $(1 \mu \mathrm{M})$ for $8 \mathrm{~h}$. Induced and uninduced cells were lysed in $50 \mu \mathrm{l}$ of lysis buffer, and $20 \mu \mathrm{l}$ of cell lysates was assayed by using a Dual-Luciferase reporter assay system (Promega) according to the manufacturer's protocol.

siRNA transfection in Jurkat and 293 HEK cells. Jurkat cells were washed with RPMI 1640 medium to remove serum and antibiotics. A total of $4 \times 10^{5}$ cells were seeded per well in a 24-well plate in $300 \mu$ l of RPMI 1640 medium. Four hundred nanograms of annealed double-stranded siRNA, 40 ng of NFATfirefly-luciferase, and $1 \mathrm{ng}$ of pRL-TK-Renilla-luciferase plasmid DNA were transfected into the cells by using TransMessenger transfection reagent (QIAGEN) according to the manufacturer's protocol. After overnight incubation, cells were induced with OKT 3 for $8 \mathrm{~h}$, and cells were harvested and processed for luciferase assays as described above. In the transfection of 293 HEK cells, $100 \mathrm{ng}$ of plasmid expressing human SinII/EFS2 (Image Clone ID number 4214788) and $200 \mathrm{ng}$ of siRNA were transfected with the same reagent. After $36 \mathrm{~h}$, the cells were harvested, and cell extracts were processed on Western blots.

Measurement of intracellular calcium. Jurkat Tag cells $\left(4 \times 10^{6}\right)$ were incubated with $1 \mu \mathrm{M}$ indo- $1 / \mathrm{AM}$ for $1 \mathrm{~h}$ at $37^{\circ} \mathrm{C}$ in RPMI 1640 medium plus $1 \%$ fetal bovine serum. Cells were washed three times in buffer A (10 mM HEPES [pH 7.4], $3 \mathrm{mM} \mathrm{KCl}, 1 \mathrm{mM} \mathrm{MgCl}, 1 \mathrm{mM} \mathrm{CaCl}_{2}, 140 \mathrm{mM} \mathrm{NaCl}, 0.1 \%$ glucose, $1 \%$ fetal bovine serum) and suspended at a final concentration of $10^{6}$ in buffer A. Cells were stimulated with $1 \mu \mathrm{g}$ of OKT $3 / \mathrm{ml}$. The fluorescence ratio (405/485 $\mathrm{nm}$ ) with excitation at $350 \mathrm{~nm}$ was obtained from a spectrofluorometer (Photo Technology International, Lawrenceville, N.J.). Ionomycin was added to a final concentration of $15 \mu \mathrm{M}$ in order to obtain maximum fluorescence under saturating calcium concentrations followed by $10 \mathrm{mM}$ EGTA to obtain minimum fluorescence in the absence of calcium. Calibrations and calculation of intracellular calcium concentration were conducted as previously described $(9,32)$.

Analysis of IP3 release. A total of $4 \times 10^{6}$ cells were induced with soluble OKT3 antibody $(1 \mu \mathrm{g} / \mathrm{ml})$ for $3 \mathrm{~min}$, and cell extracts were generated by adding $80 \mu \mathrm{l}$ of ice-cold $100 \%$ trichloroacetic acid. Inositol 3-phosphate (IP3) levels were assessed by using the IP3 Radioreceptor assay kit (NEN Life Science Products, Boston, Mass.) according to the manufacturer's protocol.

TCR cross-linking. Splenocytes $\left(10^{7}\right)$ were incubated with $2 \mu \mathrm{g}$ of anti-CD3 and anti-CD28 antibodies on ice for $15 \mathrm{~min}$, washed with cold phosphatebuffered saline, and super-cross-linked with $5 \mu \mathrm{g}$ of goat anti-hamster immunoglobulin $\mathrm{G}$ (IgG) for $20 \mathrm{~min}$ on ice. Cells were then incubated at $37^{\circ} \mathrm{C}$ at different time points, spun down, and immediately lysed. Cell lysates were used for immunoprecipitation and immunoblot analysis.

Immunoprecipitations. Immunoprecipitations were performed as previously described (1). Briefly, cells were lysed in $1 \mathrm{ml}$ of ice-cold NP-40 lysis buffer (1\% NP-40, $20 \mathrm{mM}$ Tris- $\mathrm{HCl}[\mathrm{pH} 8.0], 150 \mathrm{mM} \mathrm{NaCl}, 10 \%$ glycerol, $10 \mathrm{mM} \mathrm{NaF}, 1$ $\mathrm{mM}$ sodium orthovanadate, $1 \mathrm{mM}$ phenylmethylsulfonyl fluoride, $10 \mu \mathrm{g}$ of apro$\operatorname{tinin} / \mathrm{ml}, 10 \mu \mathrm{g}$ of leupeptin $/ \mathrm{ml}$ ). Cell extracts were then incubated with the specified antibodies at concentrations suggested by the manufacturers for $2 \mathrm{~h}$ at $4^{\circ} \mathrm{C}$, and the immune complexes were subjected to sodium dodecyl sulfatepolyacrylamide gel electrophoresis (SDS-PAGE) and immunoblotting. Western blots were performed as previously described (39).

In vitro kinase assays. Protein complexes obtained by immunoprecipitation were washed three times in kinase buffer, and reactions were carried out in $20 \mu \mathrm{l}$ of kinase buffer containing $20 \mathrm{mM}$ HEPES ( $\mathrm{pH} 7.4$ ), $5 \mathrm{mM} \mathrm{MnCl}, 10 \mu \mathrm{M} \mathrm{ATP}$, and $1 \mu \mathrm{l}$ of $\left[\gamma^{32} \mathrm{P}\right] \mathrm{ATP}(5,000 \mathrm{Ci} / \mathrm{mmol})$ at room temperature for $10 \mathrm{~min}$. The pellets were resuspended in $1 \times$ Laemmli buffer and boiled for $2 \mathrm{~min}$, and phosphorylated proteins were analyzed by SDS-PAGE and autoradiography.

\section{RESULTS}

Expression of Sin isoforms in T cells. At least three isoforms of Sin can be detected on Northern and Western blots of the mouse thymus $(2,6)$ and with a Sin-specific monoclonal antibody in immunoprecipitates of mouse splenocyte extracts: the 
A
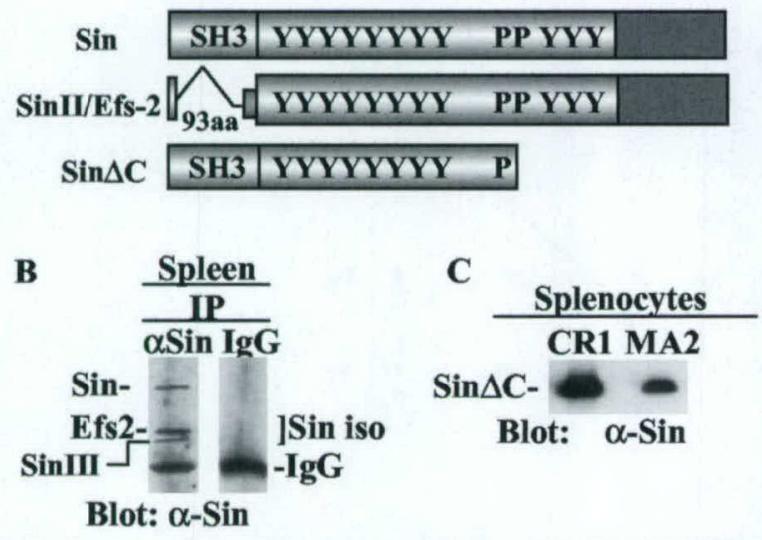

FIG. 1. Expression of Sin isoforms in mature T cells. (A) Schematic structure of Sin, SinII/Efs2, and the truncated protein Sin $\Delta$ C. Y, tyrosine-containing sequences; $\mathrm{P}$, proline-rich motifs; aa, amino acids. (B) Splenocytes $\left(3 \times 10^{7}\right)$ were immunoprecipitated (IP) with Sinspecific or isotype-matched IgG control antibodies, and Western blots of the immune complexes were probed with a Sin-specific monoclonal antibody to reveal expression of the Sin isoforms as indicated. (C) Western blot of splenocytes from two different founders expressing $\operatorname{Sin} \Delta \mathrm{C}$ probed with anti-Sin $(\alpha-\operatorname{Sin})$ antibody.

$\sim 80$-kDa full-length Sin and two additional protein bands that may correspond to SinII/Efs2 and SinIII (Fig. 1B), collectively shown as Sin isoforms. SinII/Efs2 is a previously described alternative splice form of Sin in which the SH3 domain is deleted (12), whereas Sin III migrates slightly faster than SinII/ Efs2 and may correspond to a different Sin isoform we isolated from the mouse thymus (2).

As mentioned above, transgenic mice expressing a truncated form of Sin, Sin $\Delta C$ (Fig. 1A), were previously used to explore the physiologic role of Sin in vivo (6). This truncated Sin mutant was chosen based on the finding that it enhanced Src kinase signaling more than the full-length protein (39). Two founder transgenic lines, CR1 and MA2, were generated expressing approximately 27 - and 9-fold more $\operatorname{Sin} \Delta \mathrm{C}$, respectively, than endogenous SinII/Efs2 (6). The expression of $\operatorname{Sin} \Delta \mathrm{C}$ was regulated by the human $\mathrm{CD} 2$ promoter, which allows expression of cloned genes in both thymocytes and mature T cells (44). Expression of the Sin $\Delta \mathrm{C}$ transgene was demonstrated in splenocytes from two different founder mice (Fig. 1C).

$\operatorname{Sin} \Delta \mathbf{C}$ expression reduces numbers of peripheral $\mathrm{T}$ cells. It was previously found that $\operatorname{Sin} \Delta \mathrm{C}$ expression inhibited thymocyte development, manifested as a reduced percentage of mature CD4 and CD8 SP cells in the thymus and increased thymocyte apoptosis, suggesting a negative function for $\operatorname{Sin} \Delta \mathrm{C}$ in $T$ lymphocytes (6). Here, we used the $\operatorname{Sin} \Delta C$ mice to examine the effect of $\operatorname{Sin} \Delta \mathrm{C}$ on mature T-cell activation and proliferation. First, we examined the effect of $\operatorname{Sin} \Delta C$ protein expression on the production of mature $\mathrm{T}$ cells in the spleen. Fluorescence-activated cell sorting analysis of total splenocytes revealed that the percentages of mature splenic $\mathrm{T}$ cells of both the $\mathrm{CD}^{+}$and $\mathrm{CD}^{+}$lineages were substantially reduced in transgenic CR1 and MA2 animals compared to normal littermate controls (Fig. 2A, dot plots). Nevertheless, splenic T cells from transgenic animals expressed normal levels of $\mathrm{CD} 3 \varepsilon$ compared to wild-type controls (Fig. 2A, histograms). Consistent with this finding, it was previously found that in addition to normal TCR levels, the expression levels of maturation markers such as CD69 and CD5 in thymic T cells were also normal (6). This finding suggests that although the percentages of cells are reduced, the existing mature $\mathrm{T}$ cells have undergone positive selection. Analysis of several MA2 Sin $\Delta \mathrm{C}$ animals further revealed a consistently dramatic decrease in total $\mathrm{CD}^{+}$-T-cell

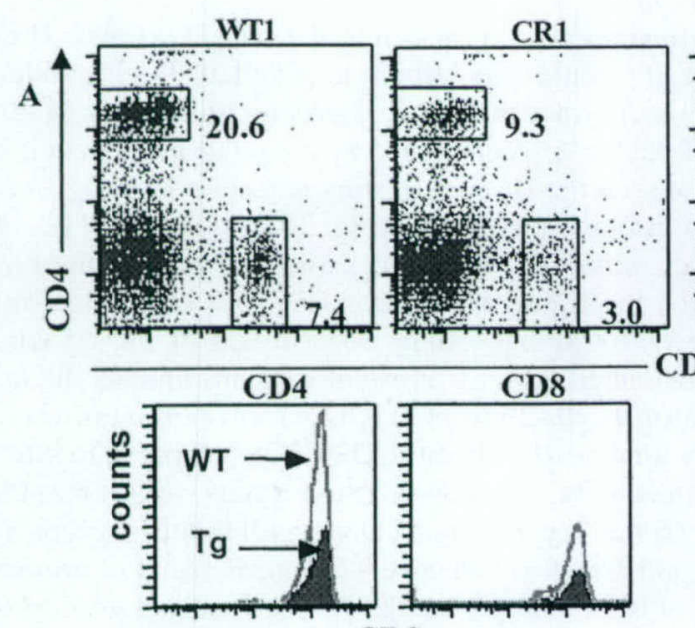

CD3

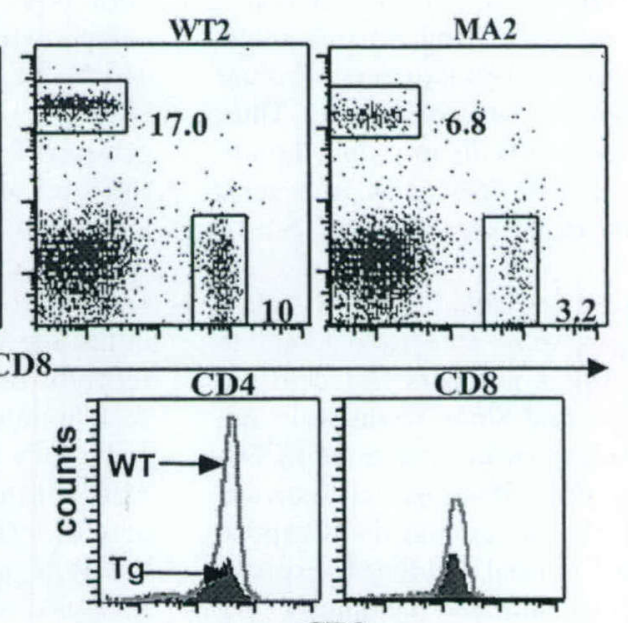

CD3

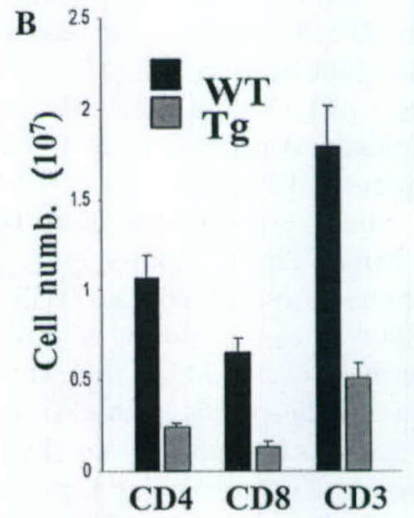

FIG. 2. Sin $\Delta C$ expression inhibits production of mature T cells. (A) Splenocytes $\left(10^{6}\right)$ from 6-to-8-week-old wild-type (WT) and transgenic ( $\mathrm{Tg}$ ) animals were triply stained with CD4-allophycocyanin/CD8-peridinin chlorophyll-a protein and CD3-fluorescein isothiocyanate and analyzed by flow cytometry. In the dot plots, the numbers indicate the percentage of cells in each region. Histograms represent CD3 expression within the CD4 and CD8 SP populations in the dot plots. Two different transgenic founder lines, CR1 and MA2, with their respective wild-type controls, are shown. (B) Splenocytes were counted and stained, and the percentages of total CD3 T cells and CD $4^{+}$and CD $8^{+}$subpopulations were determined by fluorescence-activated cell sorting analysis and used to calculate the actual cell numbers for each population. Results from at least five wild-type and MA2 transgenic mice are represented as the mean \pm the standard deviation (SD). 
A
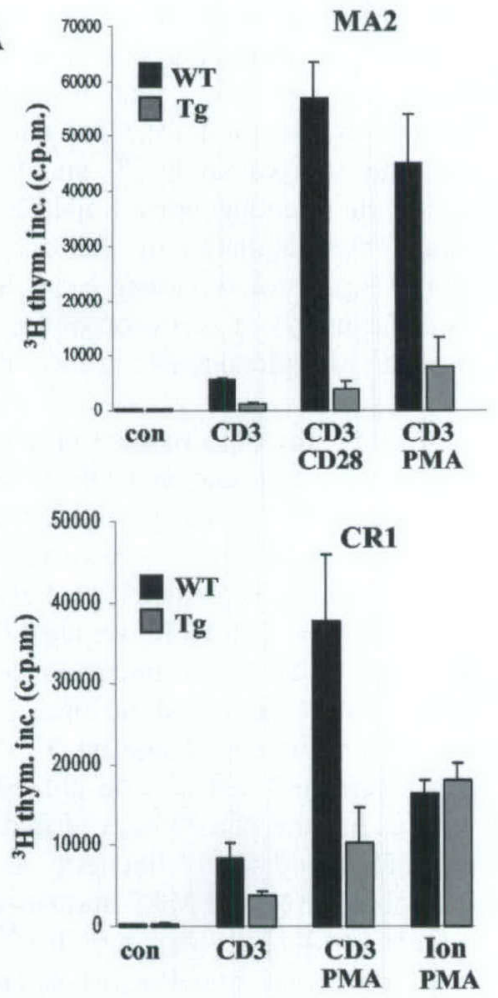

B
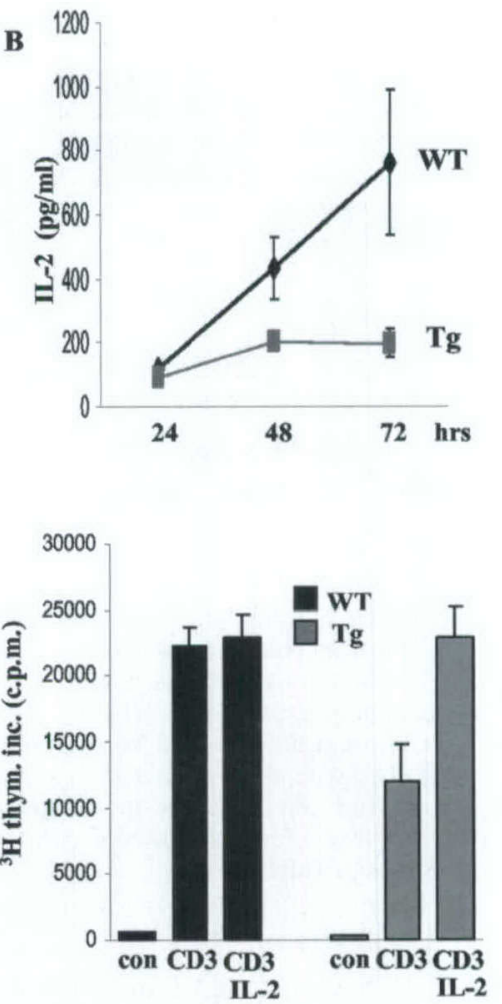

FIG. 3. Sin $\Delta C$ expression inhibits T-cell proliferation and IL-2 production. (A) T cells $\left(10^{5}\right)$ purified from the spleens of 6- to 8-week-old normal and Sin $\triangle C$ animals (CR1 and MA2) were stimulated with plate-bound CD3 and CD28 antibodies and PMA and ionomycin as indicated and as described in Materials and Methods. Proliferation was calculated by $\left[{ }^{3} \mathrm{H}\right]$ thymidine incorporation $\left({ }^{3} \mathrm{H}\right.$ thym. inc.) as the mean $\pm \mathrm{SD}$ of radioactive counts in triplicate wells. Shown are data representative of at least three experiments with two different transgenic lines (MA2, top panel; CR1, bottom panel). (B) Five microliters of the supernatants was removed from stimulated cells at the indicated times and analyzed by enzyme-linked immunosorbent assay for the presence of secreted IL-2 (top graph). Purified T cells were stimulated with plate-bound anti-CD3 antibody $(0.05 \mu \mathrm{g} / \mathrm{ml})$ in the presence or absence of $\mathrm{IL}-2(20 \mathrm{ng} / \mathrm{ml})$. Proliferation was determined by $\left[{ }^{3} \mathrm{H}\right]$ thymidine incorporation (bottom graph). $\mathrm{Tg}$, transgenic; WT, wild type.

numbers, due to a decrease of both $\mathrm{CD} 4^{+}$and $\mathrm{CD} 8^{+}$mature T-cell populations (Fig. 2B). Relative proportions of $\mathrm{T}$ and $\mathrm{B}$ cells in the spleen, determined by Thy1.2 and B220 staining, also revealed a dramatic decrease in T-cell numbers, whereas the B-cell compartment was normal (data not shown). Thus, our data show that $\operatorname{Sin} \Delta \mathrm{C}$ expression results in reduced numbers of CD4 and CD8 SP cells in the spleens of transgenic animals, consistent with $\mathrm{T}$-cell-specific expression of $\operatorname{Sin} \Delta \mathrm{C}$ from the CD2 promoter.

$\operatorname{Sin} \Delta \mathbf{C}$ expression inhibits T-cell activation. We next tested whether $\operatorname{Sin} \Delta \mathrm{C}$-expressing $\mathrm{T}$ cells were able to respond to stimulation through their TCR. Equal numbers of T cells purified from the spleens of normal and $\operatorname{Sin} \Delta \mathrm{C}$ transgenic animals (CR1 and MA2) were stimulated with plate-bound CD3and CD28-specific antibodies and PMA-ionomycin as shown in Fig. 3. As indicated above (Fig. 2A, histograms), TCR expression levels were similar in purified normal and $\operatorname{Sin} \Delta \mathrm{C}$-expressing cells assayed by CD3 staining and flow cytometry. We found that $\operatorname{Sin} \Delta C$-expressing $T$ cells stimulated through their TCR with CD3, CD3 and CD28, or PMA exhibited dramatically reduced proliferation compared to normal controls (Fig. 3A). In contrast, transgenic T cells stimulated with PMA and ionomycin, a nonphysiologic stimulus that bypasses the TCR, proliferated to the same extent as their wild-type counterparts, suggesting that the inhibitory effect of $\operatorname{Sin} \Delta \mathrm{C}$ on $\mathrm{T}$-cell prolif- eration is specific to proximal TCR signaling events (Fig. 3A, bottom graph).

Upon stimulation, T cells secrete the critical cytokine IL-2, which acts in an autocrine fashion to stimulate T-cell proliferation. We found that the reduced proliferation of $\operatorname{Sin} \Delta C$-expressing $\mathrm{T}$ cells was accompanied by a significant reduction in the level of secreted IL-2, suggesting defective TCR signaling leading to cytokine production (Fig. 3B, top graph). The addition of exogenous IL-2, however, restored the proliferative response of the transgenic $\mathrm{T}$ cells (Fig. 3B, bottom graph), indicating that signaling events downstream of the cytokine receptor remained intact. Consistent with this finding, the upregulation of the IL-2 receptor (CD25) was normal in transgenic cells stimulated with anti-CD3/CD28 compared to littermate controls (data not shown). These results suggest that the inability of $\operatorname{Sin} \Delta \mathrm{C}$-expressing $\mathrm{T}$ cells to proliferate is specific to the TCR and is due to defective TCR-mediated IL-2 production and not to an inherent inability of these cells to respond to stimuli.

Full-length Sin expression inhibits TCR-mediated transcriptional activation in human Jurkat $\mathbf{T}$ cells. The results presented above suggest that $\operatorname{Sin} \Delta \mathrm{C}$ inhibits $\mathrm{T}$-cell activation by rendering cells incapable of IL-2 production. To further analyze the inhibitory effect of Sin on TCR signaling and to examine whether $\operatorname{Sin} \Delta \mathrm{C}$ mimics the function of Sin, we used 

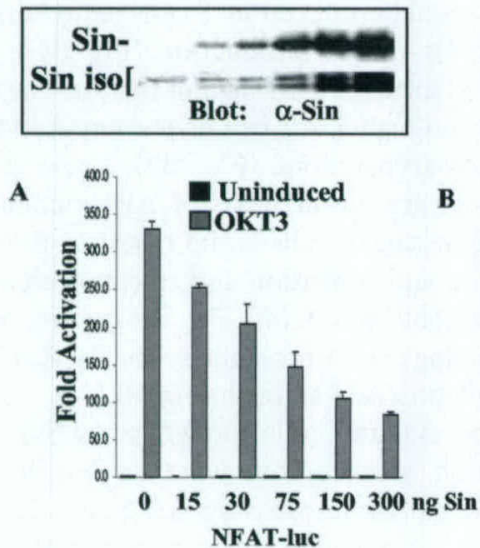

B
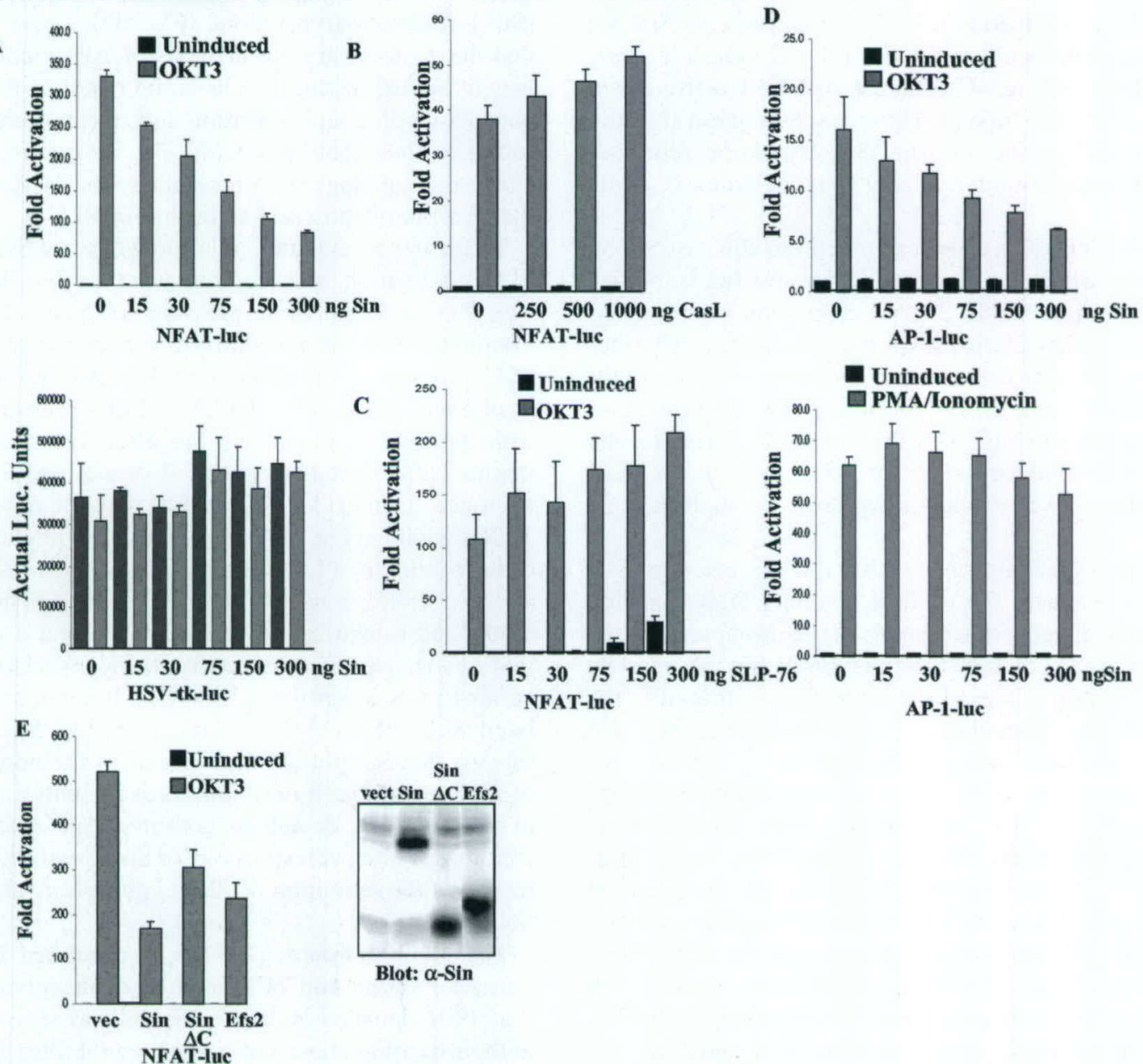

FIG. 4. Sin expression inhibits TCR-induced transcriptional activation. Jurkat Tag cells were transiently transfected with increasing amounts of plasmid DNA expressing Sin (A and D), CasL (B), or SLP-76 (C) in the presence of NFAT- or AP-1-firefly-luciferase (luc) as shown along with the HSV-TK-Renilla-luciferase reporter (A to E). The fold activation for NFAT-and AP-1-firefly-luciferase and actual luciferase units for HSV-TK-Renilla-luciferase are shown (A, bottom graph). (E) Jurkat Tag cells were transfected with a pEBB vector (vec) expressing Sin, SinII/Efs2, or $\operatorname{Sin} \Delta \mathrm{C}(300 \mathrm{ng}$ each) in the presence of the NFAT- and HSV-TK-luciferase reporters as shown. The results represent one of at least three experiments each performed in triplicate, and fold activation is relative to the value obtained with pEBB vector backbone used to express Sin, CasL, or SLP-76 in unstimulated cells, which was given a value of 1 . The results shown represent the mean \pm SD. Whole-cell lysates of the transfected cells were separated on SDS-PAGE and Western blotted with anti-Sin $(\alpha-\operatorname{Sin})$ or anti-p130Cas $(\alpha-$ p130Cas) antibodies to reveal levels of Sin and CasL protein expression, respectively (A, B, and $\mathrm{E}$, insets).

transiently or stably transfected human Jurkat $\mathrm{T}$ cells. Jurkat Tag cells were transfected with increasing concentrations of a mammalian vector expressing Sin along with two reporter plasmids expressing two different luciferase proteins: one from firefly under three copies of the distal NFAT/AP-1 or multimerized AP- 1 binding sites from the IL- 2 promoter $(10,33)$ and the other from the sea pansy Renilla under the HSV-TK promoter, which was included as an internal control for transfection efficiency. We found that the expression of Sin in Jurkat cells efficiently inhibited NFAT promoter activation in response to TCR stimulation in a concentration-dependent manner (Fig. 4A, top graph). In contrast, in the same experiments, activation of the Renilla-luciferase reporter (HSV promoter) remained constant, suggesting that the inhibition we observed is not because of cell toxicity due to Sin overexpression (Fig. $4 \mathrm{~A}$, bottom graph). Importantly, the inhibitory effect of Sin was evident even when it was expressed at levels similar to those of the endogenous Sin isoforms, arguing against a negative effect of Sin due to gross overexpression (Fig. 4A, inset). As the Sin-related protein HEF1/CasL has been shown to dimerize through its C-terminal conserved region (17), the increased amounts of endogenous Sin isoforms observed at high concentrations of overexpressed Sin (Fig. 4A, inset) may be due to dimerization and stabilization of these isoforms by overexpressed Sin.

To further address whether the inhibitory effect on NFAT 
activation is specific to Sin, we also examined the effect of other adapter molecules on T-cell activation. To this end, we used SLP-76, an established positive regulator of T-cell function $(24,31)$, as well as CasL, a Sin-related protein also shown to stimulate T-cell signaling $(15,27)$. In contrast to Sin, we found that the expression of the Sin-related molecule CasL (Fig. 4B), or SLP-76 (Fig. 4C), stimulated NFAT activation in response to TCR cross-linking. These results suggest that the effects of Sin are specific and that Sin expression represses TCR-induced transcriptional activity that regulates IL-2 expression.

In addition to NFAT, we also examined the effect of Sin on AP-1 activation, which is a complex of Fos and Jun transcription factors required for IL-2 gene expression. Similarly to NFAT, we found that Sin expression also inhibited AP-1-dependent transcriptional activation in response to TCR stimulation (Fig. 4D, top graph) but not in response to stimulation with PMA-ionomycin (Fig. 4D, bottom graph). These results suggest that the inhibitory effect of $\mathrm{Sin}$ is specific to TCR signaling and that this effect can be bypassed by nonphysiologic stimuli.

These and previous data suggest that the expression of Sin, as well as the truncated $\operatorname{Sin} \Delta \mathrm{C}$ form, inhibits TCR signaling and transcriptional activation from the IL-2 promoter. To address whether $\operatorname{Sin} \Delta \mathrm{C}$ mimics the function of Sin, we directly compared the ability of these proteins as well as that of SinII/ Efs2 to inhibit T-cell signaling in Jurkat T cells (Fig. 4E). We found that all proteins share similar inhibitory function, although $\operatorname{Sin} \Delta \mathrm{C}$ was somewhat less potent in inhibiting transcription than Sin or SinII/Efs2 (Fig. 4E) when the proteins were expressed at similar levels (Fig. 4E, inset). These results suggest that the $\mathrm{C}$ terminus of $\mathrm{Sin}$ contributes to the maximal inhibition of signaling observed with the full-length protein but is not by itself sufficient for complete inhibition of signaling since a significant block of NFAT activation is observed with $\operatorname{Sin} \Delta C$, which lacks this region. Thus, $\operatorname{Sin} \Delta C$ behaves similarly to $\mathrm{Sin}$ and acts as a negative regulator of TCR signaling.

Sin expression inhibits PLC- $\gamma$ phosphorylation and activation. We next examined the mechanism of Sin-mediated inhibition of transcriptional activation by examining upstream signaling events that control the activation of the NFAT and AP-1 transcription factors. It has been established that TCR-induced PLC $-\gamma$ phosphorylation and activation lead to the release of the second messengers IP3 and diacyl-glycerol (DAG). The production of IP3 induces intracellular calcium release and NFAT activation, whereas DAG controls AP-1 activation through the stimulation of protein kinase C- $\theta$ (PKC- $\theta)$ and Ras-guanyl-releasing protein $(11,19,37)$. We thus examined whether these signaling events were compromised by Sin expression using Jurkat T-cell lines stably overexpressing Sin. Consistent with the results obtained from transient assays, we found that the expression of Sin blocked NFAT-luciferase activation in response to TCR stimulation in three different cell lines (Fig. 5A).

Using these cell lines, we then examined the effect of Sin expression on PLC- $\gamma$ phosphorylation and activation. We found that TCR-mediated PLC- $\gamma$ phosphorylation was reduced in Sin-expressing Jurkat $\mathrm{T}$ cells compared to control cells transfected with vector alone (Fig. 5B). Consistent with decreased phosphorylation, we found that the enzymatic activ- ity of PLC- $\gamma$ was also reduced in T cells expressing Sin, shown by reduced levels of IP3 production (Fig. 5C). As a result, TCR-stimulated intracellular calcium release was also compromised in these Sin-expressing cell lines compared to cells stably transfected with vector alone (Fig. 5D). These results suggest that the defective activation of NFAT/AP1-mediated transcription in Sin-expressing T cells is the result of defective PLC- $\gamma$ phosphorylation and activation and calcium release. These results also show that Sin inhibits T-cell signaling by exerting its effects on signaling events proximal to the TCR, which regulate the phosphorylation and activation of PLC- $\gamma$.

To further analyze the inhibitory effects of Sin expression on PLC- $\gamma$ activation, we examined whether Sin directly interacts with PLC- $\gamma$ in the Sin-expressing cell lines. Surprisingly, we found that Sin was constitutively associated with endogenous PLC- $\gamma$ in resting T cells and that this association was disrupted in stimulated cells (Fig. 5E). Thus, PLC- $\gamma$ activation correlated with its disassociation from Sin after TCR stimulation. Ten minutes after stimulation, the association of Sin with PLC- $\gamma$ was once again evident, coinciding with the downregulation of TCR signaling (Fig. 5E). To address the physiological significance of the Sin-PLC- $\gamma$ interaction, we also tested the association of endogenous Sin and PLC- $\gamma$ in splenocytes. Importantly, and similar to our results with Jurkat T cells, we found that endogenous Sin was constitutively associated with endogenous PLC- $\gamma$ in resting splenocytes, but less so in cells stimulated with anti-CD3/CD28 for $3 \mathrm{~min}$ (Fig. 5F). These results suggest that $\mathrm{Sin}$ preferentially binds to the nonactivated form of PLC- $\gamma$ and that it may limit its availability and/or activation in unstimulated as well as activated cells under physiologic conditions. The overexpression of Sin reveals this function and results in the inhibition of PLC- $\gamma$ phosphorylation and activation.

The adapter function of $\mathrm{Sin}$ is regulated by constitutive phosphorylation and TCR-induced dephosphorylation. Given that TCR signaling molecules typically experience an increase in their tyrosine phosphorylation content after TCR induction, we sought to determine whether Sin also underwent such a modification. The majority of adapter proteins that regulate TCR signaling, such as LAT, SLP-76, and Cbl, are rapidly phosphorylated after T-cell receptor cross-linking under endogenous or overexpressing conditions (7, 22, 42). In stark contrast, we found that Sin was constitutively phosphorylated in resting cells and was rapidly dephosphorylated after TCR stimulation in total cell extracts and in Sin immunoprecipitates (Fig. 6A, left and right panels, respectively). The basal constitutive phosphorylation of Sin returned after $10 \mathrm{~min}$ of TCR stimulation, which coincided with a reduction of total cellular phosphotyrosine levels (Fig. 6A, left panels). The dephosphorylation of Sin after TCR stimulation is likely due to phosphatase activity, considering the rapid rate of dephosphorylation ( $2 \mathrm{~min}$ ). Thus, $\mathrm{Sin}$ is regulated differently from other signaling phosphoproteins, as Sin becomes dephosphorylated rather than phosphorylated upon TCR stimulation.

To further characterize the regulation of Sin phosphorylation and to determine if the pattern of phosphorylation for overexpressed Sin reflects that of endogenous Sin, we performed in vitro kinase assays using immune complexes precipitated with Sin-specific antibody. In these assays, we sought to compare the levels of kinase activity associated with Sin under 

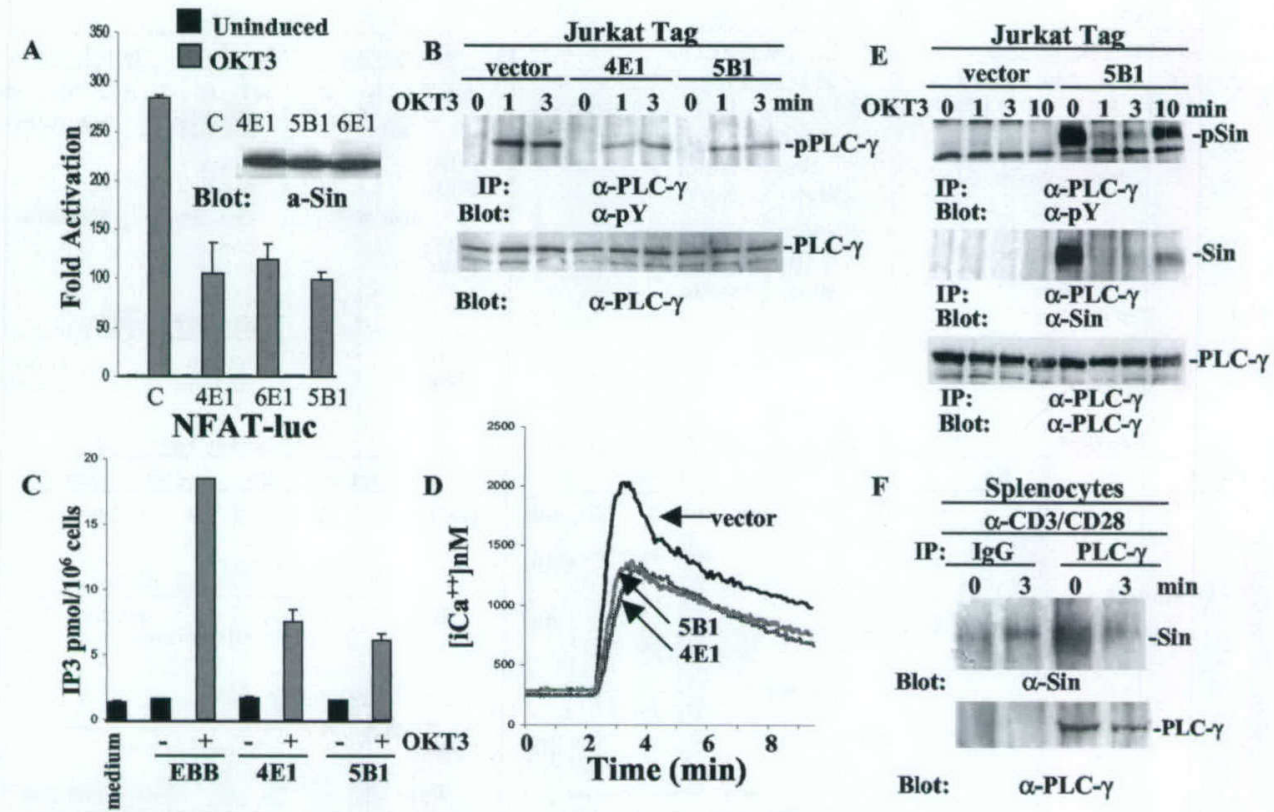

FIG. 5. Defective PLC- $\gamma$ phosphorylation and activation in Jurkat cells stably overexpressing Sin. (A) Sin overexpressing stable Jurkat Tag cells from three different lines were transiently transfected with NFAT-firefly- and HSV-TK-Renilla-luciferase reporters and stimulated with $5 \mu \mathrm{g}$ of OKT $3 / \mathrm{ml}$ as described in Materials and Methods. A representative of at least three experiments performed in triplicate is shown. The fold activation was determined as described in the legend to Fig. 4. Sin expression levels in these cell lines are shown in the inset. a-Sin, anti-Sin. (B) Jurkat cells $\left(10^{7}\right)$ from control (vector alone) and two different Sin-expressing cell lines were stimulated with OKT3 (5 $\left.\mu \mathrm{g} / \mathrm{ml}\right)$ for the indicated times, and cell lysates were immunoprecipitated with anti-PLC- $\gamma$-specific antibody. Immune complexes were separated by SDS-PAGE, and the Western blot was probed with an antiphosphotyrosine antibody. Total lysates of the same samples normalized for protein content were processed in parallel to reveal levels of endogenous PLC- $\gamma$. (C) IP3 levels were determined as described in Materials and Methods. One of three representative experiments is shown. (D) Intracellular calcium concentration in the presence or absence of Sin from one control and two stable cell lines was measured as described in Materials and Methods. Shown is a representative of at least four experiments. (E) Control or Sin-expressing Jurkat Tag cell lines $\left(5 \times 10^{7}\right)$ were stimulated with OKT3 $(5 \mu \mathrm{g} / \mathrm{ml})$ for the indicated times, and cell lysates were immunoprecipitated with PLC- $\gamma$-specific antibody. The separated immune complexes were transferred on nitrocellulose membrane, and the upper half of the membrane was probed with anti-PLC- $\gamma$ (bottom panel), whereas the lower half was probed first with anti-Sin ( $\alpha$-Sin) antibody (middle panel) and then stripped and reprobed with antiphosphotyrosine-specific antibody (top panel). (F) Extracts of $9 \times 10^{7}$ total splenocytes from wild-type mice stimulated with anti-CD3/CD28 ( $\alpha$-CD3/CD28) antibodies $(15 \mu \mathrm{g} / \mathrm{ml}$ each) were immunoprecipitated with anti-PLC- $\gamma$ or control IgG. The upper and lower halves of the membrane containing the immune complexes were probed with anti-PLC- $\gamma$ and anti-Sin ( $\alpha$-Sin) antibodies, respectively. Protein bands were visualized by enhanced chemiluminescence (ECL). $\alpha$-PLC- $\gamma$, anti-PLC- $\gamma$; pPLC- $\gamma$, phosphorylated PLC- $\gamma, \alpha-p Y$, antiphosphotyrosine; pSin, phosphorylated Sin.

resting and TCR-stimulated conditions. In Sin immunoprecipitates from Jurkat $\mathrm{T}$ cells, we found that both overexpressed full-length Sin (Fig. 6B, left panels) and the endogenous Sin isoforms (Fig. 6B, right panels) were phosphorylated in vitro in unstimulated Jurkat $\mathrm{T}$ cells by an associated kinase(s). In addition, we observed that Sin associated with several proteins that became phosphorylated in vitro in unstimulated cells (Fig. $6 \mathrm{~B}$, left and right panels). TCR stimulation disrupted the in vitro phosphorylation of $\mathrm{Sin}$ as well as that of associated substrates, suggesting either decreased kinase activity or dissociation of a kinase(s). The effects we observed were specific, as no phosphoproteins were detected from precipitates of isotypematched control IgG (Fig. 6B, right panel). Similar results were obtained with endogenous $\mathrm{Sin}$ when primary mouse thymocyte cell extracts were used for the kinase assays, although with delayed kinetics for rephosphorylation (Fig. 6C). This result may be due to differences between primary cells versus cell lines or thymocytes versus $\mathrm{T}$ cells. These results suggest that a similar mode of regulation exists for the phosphorylation of overexpressed $\mathrm{Sin}$ in T-cell lines and endogenous $\mathrm{Sin}$ in primary $\mathrm{T}$ lymphocytes, such that $\mathrm{Sin}$ is phosphorylated in resting cells and TCR stimulation results in a loss of associated kinase activity.

The constitutive phosphorylation of Sin on tyrosine residues in resting Jurkat cells suggested a constitutive interaction with a protein tyrosine kinase. Sin was identified as a ligand for Src kinase SH3 domains, and more recently, it was found that in thymocytes the truncated form of $\operatorname{Sin}, \operatorname{Sin} \Delta C$, also binds to and is constitutively phosphorylated by Fyn but not the related kinase Lck (6). Thus, we tested the association of Sin with Fyn in transiently transfected Jurkat T cells. Consistent with the above data, we found that transiently transfected Sin was constitutively phosphorylated in resting cells and became dephosphorylated after $2 \mathrm{~min}$ of stimulation (Fig. 6D, left panels). The coexpression of Sin with Fyn resulted in a Sin-Fyn association and a substantial increase in Sin phosphorylation in resting cells (Fig. 6D, middle panels). The Sin-Fyn association and $\mathrm{Sin}$ phosphorylation were reduced after $2 \mathrm{~min}$ of stimulation (Fig. 6D, middle panels). Similarly, Fyn immunoprecipitates from Jurkat cells stably expressing Sin revealed that more Sin was associated with Fyn under resting conditions than after TCR stimulation (Fig. 6E, middle panel) and that Fyn phos- 

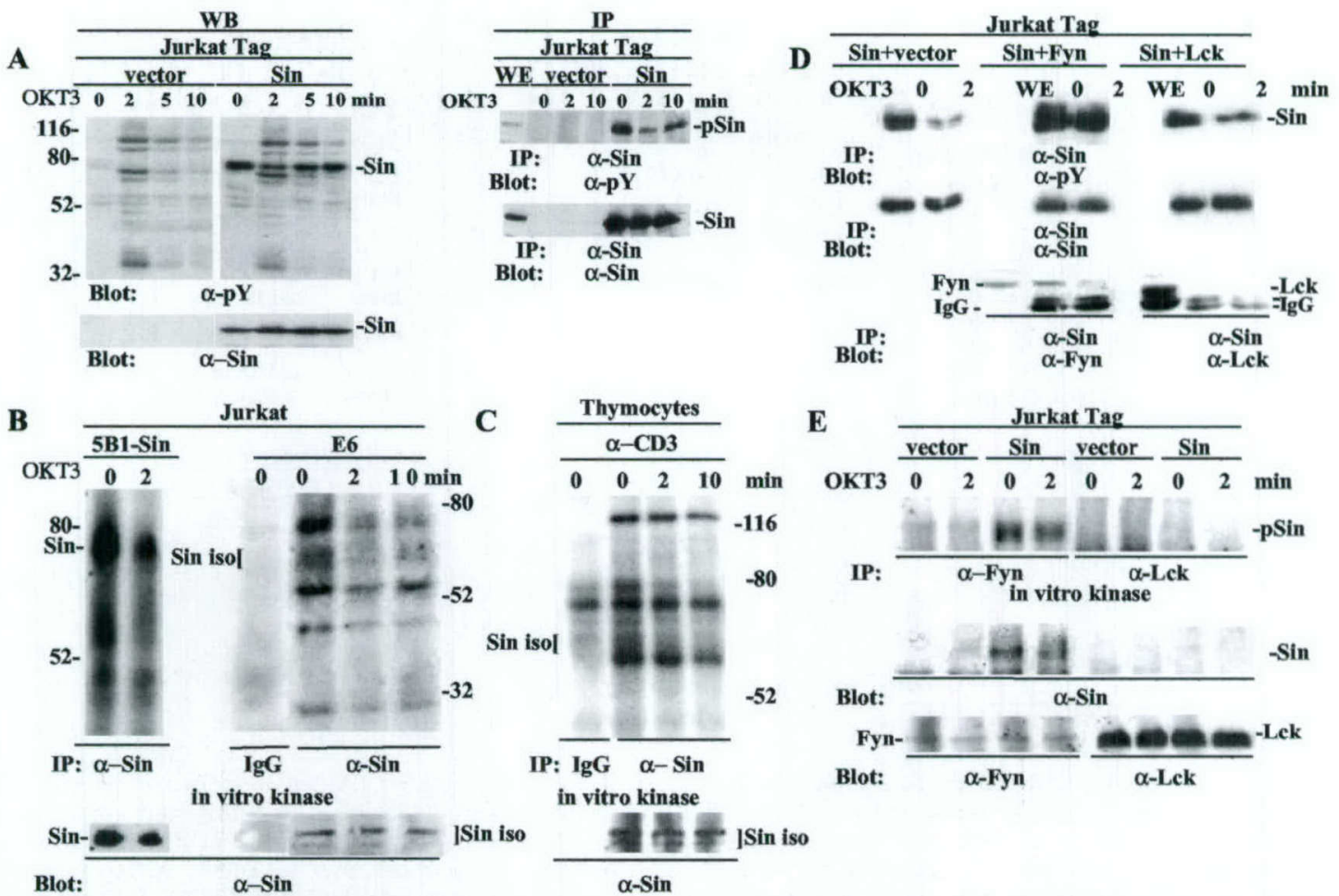

FIG. 6. Sin associates with and is constitutively phosphorylated by Fyn in resting cells. Sin is transiently dephosphorylated and dissociates from Fyn in response to TCR stimulation. (A) Jurkat cells $\left(10^{7}\right)$ stably transfected with vector alone or Sin-expressing plasmid were stimulated with OKT3 $(5 \mu \mathrm{g} / \mathrm{ml})$ at the indicated time points, and whole-cell extracts normalized for protein content were separated by SDS-PAGE and blotted with antiphosphotyrosine antibody. The blot was stripped and reprobed with anti-Sin to reveal total Sin levels (lower right panel). Similarly prepared extracts from vector or Sin-expressing cell lines were immunoprecipitated with Sin-specific antibody and first blotted with antiphosphotyrosine and then stripped and reprobed with Sin antibody (right panels). (B and C) Sin-expressing (5B1) or control Jurkat E6 cells (B) and $3 \times$ $10^{7}$ thymocytes from normal mice (C) were left unstimulated or were stimulated with anti-TCR antibodies as shown. Cell extracts were immunoprecipitated with Sin-specific antibody or isotype-matched control IgG, and immune complexes were incubated in vitro in the presence of $\left[{ }^{32} \mathrm{P}\right]$ ATP. Immune complexes were separated, proteins were transferred to nitrocellulose membrane, and membranes were exposed on film overnight. Subsequently, the filters were probed with Sin antibody to reveal total Sin levels. (D) Jurkat Tag cells $\left(5 \times 10^{6}\right)$ transiently transfected with Sin alone and Sin plus Fyn or Lck were immunoprecipitated with anti-Sin antibody and processed as described above for panel A. The blots were sequentially probed with antiphosphotyrosine, Sin, and Fyn or Lck antibodies as shown. (E) Control or Sin-expressing Jurkat Tag cells were stimulated for the indicated times with OKT3 antibody, and extracts were immunoprecipitated with Fyn- or Lck-specific antibodies. Immune complexes were subjected to in vitro kinase assays in the presence of radioactive ATP and subsequently separated on SDS-PAGE. Blots were exposed on film and then probed sequentially with Sin and Fyn or Lck antibodies as shown. $\alpha$-pY, antiphosphotyrosine; $\alpha$-Sin, anti-Sin; pSin, phosphorylated Sin; WE, whole-cell extracts; iso, isoforms; $\alpha$-Fyn, anti-Fyn; $\alpha$-Lck, anti-Lck.

phorylates $\mathrm{Sin}$ in vitro (Fig. 6E, top panel). Consistent with previous results, we found no association of $\mathrm{Sin}$ with the $\mathrm{Src}$ kinase Lck in these experiments (Fig. 6D, right panels, and E). Taken together, these data suggest that Fyn associates with and phosphorylates Sin under basal conditions, while TCR engagement disrupts this interaction. Our results also suggest that Fyn-mediated phosphorylation of Sin regulates the adapter function of Sin and its ability to form an inactive multiprotein complex in resting cells.

Endogenous $\mathrm{Sin}$ is required for TCR-induced transcriptional activation. Our experiments presented above show that constitutive, Fyn-mediated Sin phosphorylation correlates with the formation of a multiprotein complex in resting cells which includes Fyn and PLC- $\gamma$, among others. TCR stimulation leads to $\mathrm{Sin}$ dephosphorylation and the release of bound intermediates including Fyn and PLC- $\gamma$. These results, together with the observation that overexpressed Sin blocks TCR signaling, suggest that phosphorylated Sin acts to sequester signaling intermediates under steady-state conditions, thus limiting their availability and/or activity, while the release of these substrates upon stimulation mediates TCR-induced signal transduction. To further examine the function of Sin in T-cell activation, we sought to determine whether Sin regulates TCR signaling by acting solely as a tethering device for cytoplasmic intermediates in resting cells or whether Sin facilitates TCR signaling by targeting intermediates to the TCR signaling complex upon stimulation. To this end, we used inhibitory RNA oligonucleotides against endogenous Sin to assess the effect of Sin downregulation on TCR signaling. If the function of $\mathrm{Sin}$ is solely to sequester signaling intermediates in resting cells, we should observe increased signaling through the TCR in its absence. If, on the other hand, Sin actively participates in TCR signaling by targeting proteins to the greater TCR signaling complex, the downregulation of Sin expression should lead to an inhibition of TCR signaling.

Four different Sin-specific RNA oligonucleotides were tested for their ability to block the expression of overexpressed Sin in 293 HEK cells (Fig. 7A). Cotransfection of one of these 

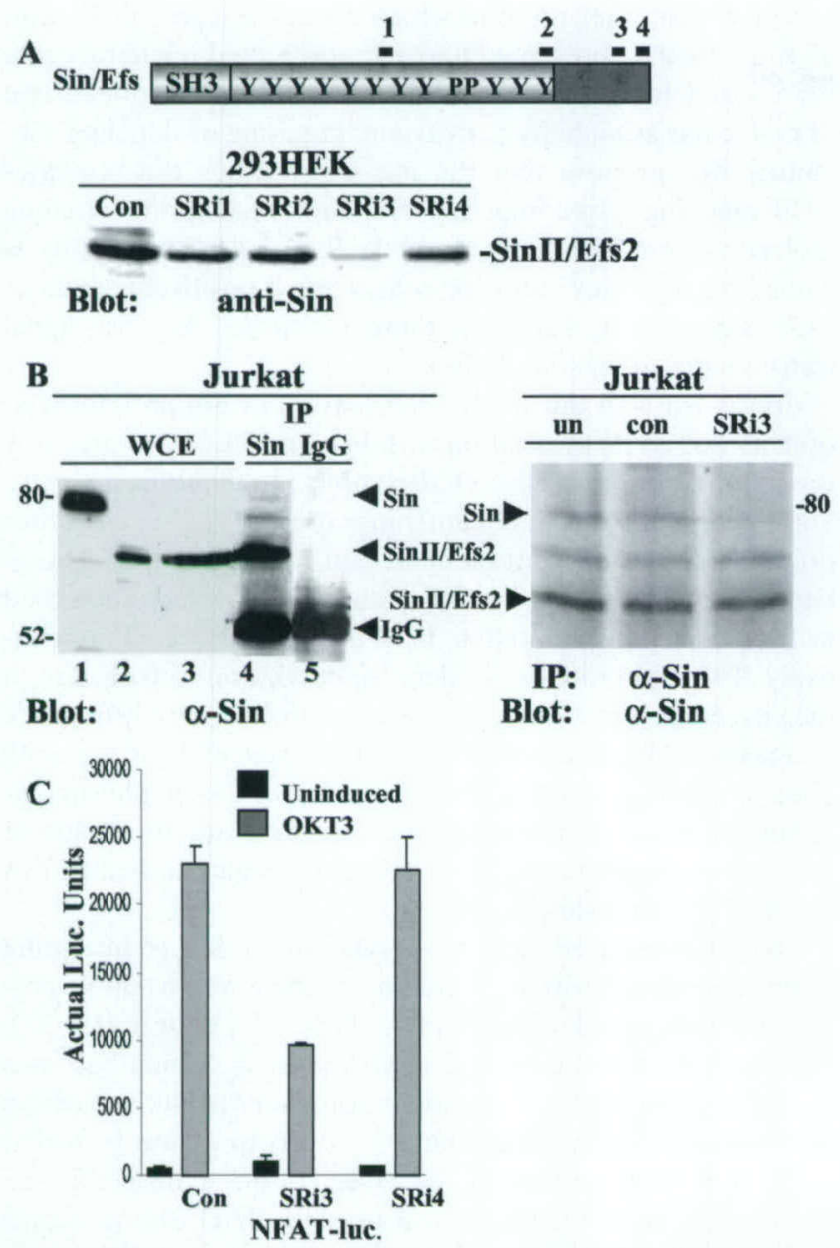

FIG. 7. Downregulation of Sin expression inhibits TCR-induced transcriptional regulation. (A) A total of $4 \times 10^{5} 293$ HEK cells were transfected with $100 \mathrm{ng}$ of a plasmid expressing human SinII/Efs2 along with $200 \mathrm{ng}$ of Sin-specific or control (Con) siRNA. Thirty-six hours after transfection, cells were harvested and lysed. Whole-cell extracts were normalized for protein content, and proteins were separated by SDS-PAGE. Western blots were probed with Sin-specific antibody, and protein bands were visualized by ECL. (B) Jurkat Tagcell extracts were immunoprecipitated with Sin-specific or control antibody, and Western blots of immune complexes separated by SDSPAGE were probed with anti-Sin ( $\alpha$-Sin) antibody (left panel). Wholecell extracts (WCE) from Jurkat cells overexpressing Sin (lane 1), SinII/Efs2 (lane 2), or untransfected cells (lane 3) were included as controls. Nine times more protein was loaded onto lane 3 compared to lane 2 to reveal endogenous protein levels of Sin isoforms. For downregulation of endogenous Sin expression, $4 \times 10^{5}$ Jurkat Tag cells/well in multiple wells were either left untransfected (un) or transfected with $400 \mathrm{ng}$ of control (con) or Sin-specific siRNA. After 24 to $36 \mathrm{~h}$, cells were lysed and extracts were immunoprecipitated with anti-Sin antibody. Western blots of immune complexes were probed with the same antibody and protein bands visualized by ECL (right panel). One of two independent experiments is shown. IP, immunoprecipitation. (C) Jurkat Tag cells $\left(4 \times 10^{5}\right)$ transfected with $400 \mathrm{ng}$ of control or Sin-specific siRNA, $40 \mathrm{ng}$ of NFAT-firefly-luciferase, and $1 \mathrm{ng}$ of pRL-TK-Renilla-luciferase plasmid DNA. Twenty-four hours after transfection, cells were induced with $1 \mu \mathrm{g}$ of OKT3/well for $8 \mathrm{~h}$, cells were harvested and lysed, and luciferase (luc.) assays were performed as described in the legend to Fig. 4 and Materials and Methods. Results from one of at least four independent experiments is shown. oligonucleotides, SRi3, along with a plasmid expressing human SinII/Efs2, dramatically inhibited Sin expression, while the other oligonucleotides were less effective in downregulating Sin expression (Fig. 7A). SRi3 was subsequently tested for its ability to downregulate endogenous Sin expression in Jurkat T cells. Three protein bands are detected in anti-Sin but not in control immunoprecipitates of Jurkat T-cell lysates, which comigrate with overexpressed full-length $\mathrm{Sin}$ and SinII/Efs2. A third band is also detected with the Sin monoclonal antibody that is not present in the mouse spleen and thymus and may represent a human-specific isoform of Sin (Fig. 7B, left panel). Transfection of SRi3 oligonucleotides inhibited full-length Sin expression (Fig. 7B, right panel), which correlated with reduced TCR-stimulated transcriptional activation of the NFATluciferase reporter (Fig. 7C). Although the SRi3 oligonucleotide targets human $\mathrm{Sin}$ on its extreme $\mathrm{C}$ terminus, which is common to the full-length and SinI/Efs2 isoform, expression of the SinII/Efs2 isoform was not detectably affected under these conditions. This may be due to the higher levels of expression of this isoform in Jurkat T cells in conjunction with the modest transfection efficiency $(\sim 30 \%)$ as determined by the transfection of a fluorescently labeled control siRNA (see Materials and Methods). In contrast, transfection of nontargeting control siRNA or SRi4, which did not significantly inhibit Sin expression in 293 HEK cells, had no effect on Sin expression or NFAT-mediated transcriptional activation. These results suggest that $\mathrm{Sin}$ is required for $\mathrm{T}$-cell activation and that it influences TCR signaling by regulating the activity and targeting of substrates in both resting and stimulated cells.

\section{DISCUSSION}

In this report, we identified Sin as a novel regulator of TCR signaling using overexpression as well as knockdown-of-protein-expression strategies. We found that the overexpression of two different forms of Sin inhibited TCR-induced IL-2 expression in two different cell systems. Specifically, in transgenic T cells, $\operatorname{Sin} \Delta \mathrm{C}$ expression resulted in defective proliferation and IL-2 secretion in response to TCR stimulation. Correspondingly, Sin expression in Jurkat T cells conferred defective TCRinduced transcriptional activation of IL-2-derived promoter constructs. The proliferative defect in the transgenic $\mathrm{T}$ cells resulted from disrupted proximal TCR signaling, as the cells proliferated normally when signals downstream of the TCR were engaged. Additionally, the impaired proliferative response in $\operatorname{Sin} \Delta \mathrm{C} T$ cells was a direct consequence of inadequate IL-2 secretion, as exogenous IL-2 treatment rescued the defect.

In Sin-expressing Jurkat $\mathrm{T}$ cells, the reduced activation of IL-2-promoter-derived constructs containing NFAT and AP-1 binding sites correlated with defective PLC- $\gamma$ phosphorylation as well as deficient IP3 and intracellular calcium release. Activated PLC- $\gamma$ cleaves the phosphoinositide PIP2 into the second messengers IP3 and DAG. IP3 production results in intracellular calcium release, which is required for NFAT activation and nuclear localization, while DAG activates PKC- $\theta$ and Ras-guanyl-releasing protein, resulting in increased AP-1 transcriptional activity. In T cells, NFAT and AP-1 then bind to the IL-2 promoter with other transcriptional activators to induce IL-2 expression $(19,26,37)$. Thus, the 
inhibition of IL-2 transcription in Sin cell lines could be traced back to a block in PLC- $\gamma$ activation and the calcium and transcriptional signaling pathways regulated by PLC- $\gamma$.

The exact mechanism Sin employs to block PLC- $\gamma$ activation is still unclear. In Sin-expressing stable cell lines, we observed a Sin-PLC- $\gamma$ interaction in resting cells and a reduction in PLC- $\gamma$ phosphorylation in activated cells. The negative effect Sin has on PLC- $\gamma$ phosphorylation may be attributed entirely to binding and sequestering PLC- $\gamma$ away from the transmembrane adapter LAT due to inefficient Sin dephosphorylation because of overexpression. Consistent with this, residual Sin phosphorylation was evident during 1 to $3 \mathrm{~min}$ of stimulation (Fig. 5E). However, since Sin/PLC- $\gamma$ association was undetectable immediately after TCR stimulation, we cannot rule out that Sin may also inhibit upstream signaling events that regulate PLC- $\gamma$ phosphorylation. In addition to binding LAT, PLC- $\gamma$ activation requires phosphorylation by both ZAP-70 and the Itk kinases $(14,29,42)$. It is conceivable that $\operatorname{Sin}$ binds to and interferes with Itk and/or ZAP-70 kinase activity, as Sin contains both Itk and ZAP-70 consensus binding motifs (2; unpublished observations). Thus, Sin may regulate PLC- $\gamma$ activity by direct association and sequestration as well as unidentified indirect mechanisms.

Alternatively, since Sin also binds Fyn, Sin may block Fynmediated phosphorylation of the TCR subunits and subsequent downstream events like PLC- $\gamma$ phosphorylation. Given that Jurkat $\mathrm{T}$ cells express approximately 30 -fold more Lck than Fyn (Fig. 6D) (5), a reasonable assumption is that blocking some Fyn activity while leaving Lck activity intact would not significantly affect proximal TCR phosphorylation events. In support of this assumption, the total TCR-induced tyrosine phosphorylation pattern in Sin-overexpressing versus control Jurkat T-cell lines does not appear notably different (Fig. 6A, left panels). Furthermore, we could not detect alterations of CD $3 \zeta$ chain phosphorylation in Sin-expressing Jurkat T cells compared to control cells (unpublished observations). Therefore, it is unlikely that the defect in PLC- $\gamma$ phosphorylation is due to a disruption in Fyn activity.

Evidence presented above reveals that the Src kinase Fyn constitutively phosphorylates Sin. This finding contradicts the general belief that Src kinases are inactive in resting $\mathrm{T}$ cells. We have previously shown that $\mathrm{Sin}$ can associate with Src kinases through an Src-SH3/Sin-proline interaction inducing Src kinase activity in the absence of any extracellular stimuli. The activated Src kinase can then phosphorylate Sin Y motifs and subsequently bind these motifs through the $\mathrm{Src}-\mathrm{SH} 2$ domain $(1,39)$. Thus, Sin can activate Fyn under basal conditions, but considering that both the Fyn $\mathrm{SH} 2$ and $\mathrm{SH} 3$ domains can bind $\mathrm{Sin}$, the affinity between the two proteins may prevent Fyn from phosphorylating other molecules. In support of this concept, Sin expression does not trigger Fyn-mediated TCR signaling events, such as $\mathrm{CD} 3 \zeta$ phosphorylation and activation of TCR transcriptional targets, in resting cells (Fig. 4 and unpublished observations).

In addition to overexpressing Sin, we used siRNA oligonucleotides to downregulate the expression of endogenous Sin in Jurkat cells and assess its effect on TCR signaling. As with Sin overexpression, we found that the expression of Sin-specific siRNA also inhibited TCR-induced transcriptional activation, a seemingly contradictory finding compared to results obtained with $\mathrm{Sin}$ overexpression. However, given that $\mathrm{Sin}$ is found in a complex with other proteins which dissociate upon TCR stimulation, the data presented here support a dual regulatory role for Sin in T-lymphocyte signaling that involves the modulation of molecular availability-activity and targeting of signaling substrates. We propose that the means by which Sin regulates TCR signaling is by competing with and sequestering signaling molecules away from the greater TCR complex, thus acting as a negative regulator in resting cells, while it positively regulates TCR signaling by releasing these substrates for fast signal transmission upon stimulation.

Consistent with our model, the pattern of Sin phosphorylation, as well as its association with Fyn and PLC- $\gamma$, is precisely the opposite of that of the TCR complex. In uninduced T cells, $\mathrm{Sin}$ is hyperphosphorylated and binds to Fyn, PLC- $\gamma$, and other proteins. After TCR engagement, Sin becomes dephosphorylated and disassociates from Fyn and PLC- $\gamma$, which then bind to the newly phosphorylated TCR complex and LAT, respectively. The rapid rate of Sin dephosphorylation is likely due to the enzymatic activity of a phosphatase and not simply to a lack of associated Fyn kinase activity. Attenuation of TCR signaling after $10 \mathrm{~min}$, evidenced as a reduction of total phosphotyrosine, coincides with Sin rephosphorylation and formation of an inactive complex of TCR signaling molecules, including Fyn and PLC- $\gamma$, with Sin (Fig. 8).

The TCR-induced dephosphorylation of Sin is intriguing given that most adapters, including positive and negative regulators, are phosphorylated after TCR stimulation $(15,27)$. This includes the Sin-related molecule CasL, which becomes phosphorylated upon TCR stimulation under conditions where Sin becomes dephosphorylated, i.e., overexpression in Jurkat cells. A notable exception, however, is the transmembrane protein PAG/Cbp $(3,16)$. In resting cells, PAG/Cbp regulates Src kinases by linking them to the Src kinase inhibitor Csk kinase. PAG/Cbp, like Sin, binds to and is phosphorylated by Fyn in resting cells $(4,41)$. Upon TCR stimulation, PAG/Cbp also becomes rapidly and transiently dephosphorylated, releasing Csk to the cytoplasm and allowing for Src kinase-mediated phosphorylation of the TCR subunits. The similarities between Sin and PAG/Cbp are intriguing and suggest that constitutive phosphorylation of adapter molecules by Fyn or other kinases may be a generalized mechanism for negatively regulating TCR signaling in resting cells, while TCR-stimulated dephosphorylation of the adapters attenuates their opposing influence.

It has previously been proposed that adapter molecules may be capable of generating both positive and negative signals depending on their phosphorylation state, tissue-specific expression, or subcellular localization (18). The finding that Sin also plays an active role in signal transmission during stimulation supports this idea, and to our knowledge, Sin represents the first example of such a positive-negative regulator whose dual function is regulated by changes in its phosphorylation state. Although we have identified Fyn as one of the possible kinases that phosphorylates $\mathrm{Sin}$, the phosphatase responsible for Sin dephosphorylation has not yet been characterized. However, it will be important to learn whether the same phosphatase is responsible for subsequent TCR complex dephosphorylation and signal attenuation. Future experiments will 

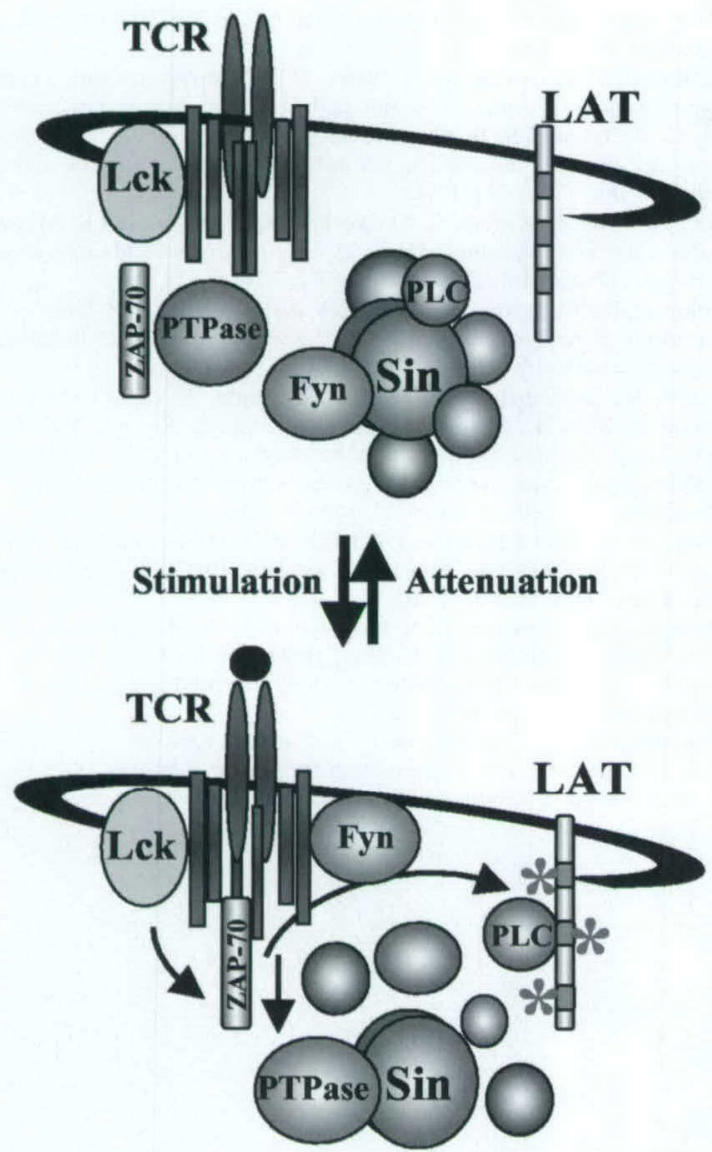

FIG. 8. Model for Sin-mediated regulation of TCR signaling. In resting T cells, Sin is constitutively phosphorylated by Fyn and bound to PLC- $\gamma$ and other proteins. TCR stimulation induces the dephosphorylation of Sin, likely through the action of a tyrosine phosphatase, which correlates with the rapid and transient release of associated substrates including Fyn and PLC- $\gamma$. Fyn and PLC- $\gamma$ bind to their respective targets to mediate TCR signaling. Attenuation of TCR signaling $10 \mathrm{~min}$ after stimulation results in the reassociation of Fyn and PLC- $\gamma$ with Sin and Sin phosphorylation, reformation of the inactive complex, and return to resting conditions.

address these questions as well as the identity of the putative phosphatase.

\section{ACKNOWLEDGMENTS}

We thank C. Roman, A. Pernis, and S. Greenberg for critically reading the manuscript. We also thank $\mathrm{A}$. Weiss for providing the Jurkat Tag cells and the SLP-76 expression construct.

This work was supported in part by the American Cancer Society grant RPG99-09-01MGO, by the Department of Defense grants DAMD17-99-1-9151 and DAMD17-99-1-915, by the National Institute of Allergy and Infectious Diseases (NIAID) grant RO1 AI49387-01, and by the American Cancer Society's Institutional Research grant number $177 \mathrm{~F}$.

Research related to the use of animals has complied with all relevant federal guidelines and institutional policies.

\section{REFERENCES}

1. Alexandropoulos, K., and D. Baltimore. 1996. Coordinate activation of c-Src by $\mathrm{SH} 3-$ and $\mathrm{SH} 2$-binding sites on a novel p130Cas-related protein, Sin. Genes Dev. 10:1341-1355.

2. Alexandropoulos, K., L. T. Donlin, L. Xing, and A. G. Regelmann. 2003. Sin: good or bad? A T lymphocyte perspective. Immunol. Rev. 192:181-195.

3. Brdicka, T., D. Pavlistova, A. Leo, E. Bruyns, V. Korinek, P. Angelisova, J.
Scherer, A. Shevchenko, I. Hilgert, J. Cerny, K. Drbal, Y. Kuramitsu, B. Kornacker, V. Horejsi, and B. Schraven. 2000. Phosphoprotein associated with glycosphingolipid-enriched microdomains (PAG), a novel ubiquitously expressed transmembrane adaptor protein, binds the protein tyrosine kinase Csk and is involved in regulation of T cell activation. J. Exp. Med. 191:15911604.

4. Davidson, D., M. Bakinowski, M. L. Thomas, V. Horejsi, and A. Veillette. 2003. Phosphorylation-dependent regulation of T-cell activation by PAG Cbp, a lipid raft-associated transmembrane adaptor. Mol. Cell. Biol. 23, 2017-2028.

5. Denny, M. F., B. Patai, and D. B. Straus. 2000. Differential T-cell antigen receptor signaling mediated by the Src family kinases Lck and Fyn. Mol. Cell. Biol. 20:1426-1435.

6. Donlin, L. T., C. A. Roman, M. Adlam, A. G. Regelmann, and K. Alexandropoulos. 2002. Defective thymocyte maturation by transgenic expression of a truncated form of the T lymphocyte adapter molecule and Fyn substrate, Sin. J. Immunol. 169:6900-6909.

7. Donovan, J. A., R. L. Wange, W. Y. Langdon, and L. E. Samelson. 1994. The protein product of the c-cbl protooncogene is the $120-\mathrm{kDa}$ tyrosine-phosphorylated protein in Jurkat cells activated via the $\mathrm{T}$ cell antigen receptor. J. Biol. Chem. 269:22921-22924.

8. Griffiths, E. K., C. Krawczyk, Y. Y. Kong, M. Raab, S. J. Hyduk, D. Bouchard, V. S. Chan, I. Kozieradzki, A. J. Oliveira-Dos-Santos, A. Wakeham, P. S. Ohashi, M. I. Cybulsky, C. E. Rudd, and J. M. Penninger. 2001. Positive regulation of $\mathrm{T}$ cell activation and integrin adhesion by the adapter Fyb/Slap. Science 293:2260-2263.

9. Grynkiewicz, G., M. Poenie, and R. Y. Tsien. 1985. A new generation of $\mathrm{Ca} 2+$ indicators with greatly improved fluorescence properties. J. Biol. Chem. 260:3440-3450.

10. Hughes, C. C., and J. S. Pober. 1996. Transcriptional regulation of the interleukin-2 gene in normal human peripheral blood T cells. Convergence of costimulatory signals and differences from transformed T cells. J. Biol. Chem. 271:5369-5377.

11. Isakov, N., and A. Altman. 2002. Protein kinase $\mathrm{C} \theta$ in $\mathrm{T}$ cell activation. Annu. Rev. Immunol. 20:761-794

12. Ishino, M., T. Ohba, J. Inazawa, H. Sasaki, Y. Arivama, and T. Sasaki. 1997. Identification of an Efs isoform that lacks the SH3 domain and chromosomal mapping of human Efs. Oncogene 15:1741-1745.

13. Ishino, M., T. Ohba, H. Sasaki, and T. Sasaki. 1995. Molecular cloning of a cDNA encoding a phosphoprotein, Efs, which contains a Src homology 3 domain and associates with Fyn. Oncogene 11:2331-2338.

14. Iwashima, M., B. A. Irving, N. S. van Oers, A. C. Chan, and A. Weiss. 1994. Sequential interactions of the TCR with two distinct cytoplasmic tyrosine kinases. Science 263:1136-1139.

15. Kanda, H., T. Mimura, N. Morino, K. Hamasaki, T. Nakamoto, H. Hirai, C. Morimoto, Y. Yazaki, and Y. Nojima. 1997. Ligation of the T cell antigen receptor induces tyrosine phosphorylation of p105CasL, a member of the p130Cas-related docking protein family, and its subsequent binding to the Src homology 2 domain of c-Crk. Eur. J. Immunol. 27:2113-2117.

16. Kawabuchi, M., Y. Satomi, T. Takao, Y. Shimonishi, S. Nada, K. Nagai, A. Tarakhovsky, and M. Okada. 2000. Transmembrane phosphoprotein Cbp regulates the activities of Src-family tyrosine kinases. Nature 404:999-1003.

17. Law, S. F., Y. Z. Zhang, S. J. Fashena, G. Toby, J. Estojak, and E. A Golemis. 1999. Dimerization of the docking/adaptor protein HEF1 via a carboxy-terminal helix-loop-helix domain. Exp. Cell Res. 252:224-235.

18. Leo, A., and B. Schraven. 2001. Adapters in lymphocyte signalling. Curr. Opin. Immunol. 13:307-316.

19. Leo, A., J. Wienands, G. Baier, V. Horejsi, and B. Schraven. 2002. Adapters in lymphocyte signaling. J. Clin. Investig. 109:301-309.

20. Liu, S. K., N. Fang, G. A. Koretzky, and C. J. McGlade. 1999. The hematopoietic-specific adaptor protein gads functions in T-cell signaling via interactions with the SLP-76 and LAT adaptors. Curr. Biol. 9:67-75.

21. Mizushima, S., and S. Nagata. 1990. pEF-BOS, a powerful mammalian expression vector. Nucleic Acids Res. 18:5322.

22. Motto, D. G., M. A. Musci, S. E. Ross, and G. A. Koretzky. 1996. Tyrosine phosphorylation of Grb2-associated proteins correlates with phospholipase C gamma 1 activation in T cells. Mol. Cell. Biol. 16:2823-2829.

23. Murphy, M. A., R. G. Schnall, D. J. Venter, L. Barnett, I. Bertoncello, C. B. Thien, W. Y. Langdon, and D. D. Bowtell. 1998. Tissue hyperplasia and enhanced T-cell signalling via ZAP-70 in c-Cbl-deficient mice. Mol. Cell. Biol. 18:4872-4882.

24. Myung, P. S., G. S. Derimanov, M. S. Jordan, J. A. Punt, Q. H. Liu, B. A. Judd, E. E. Meyers, C. D. Sigmund, B. D. Freedman, and G. A. Koretzky. 2001. Differential requirement for SLP-76 domains in T cell development and function. Immunity 15:1011-1026.

25. Naramura, M., H. K. Kole, R. J. Hu, and H. Gu. 1998. Altered thymic positive selection and intracellular signals in Cbl-deficient mice. Proc. Natl. Acad. Sci. USA 95:15547-15552.

26. Norian, L. A., and G. A. Koretzky. 2000. Intracellular adapter molecules. Semin. Immunol. 12:43-54.

27. Ohashi, Y., K. Tachibana, K. Kamiguchi, H. Fujita, and C. Morimoto. 1998 $\mathrm{T}$ cell receptor-mediated tyrosine phosphorylation of CasL, a 105-kDa Crk- 
associated substrate-related protein, and its association of Crk and C3G. J. Biol. Chem. 273:6446-6451.

28. O'Neill, G. M., S. J. Fashena, and E. A. Golemis. 2000. Integrin signalling: a new Cas $(\mathrm{t})$ of characters enters the stage. Trends Cell Biol. 10:111-119.

29. Paz, P. E., S. Wang, H. Clarke, X. Lu, D. Stokoe, and A. Abo. 2001. Mapping the Zap-70 phosphorylation sites on LAT (linker for activation of T cells) required for recruitment and activation of signalling proteins in $\mathrm{T}$ cells. Biochem. J. 356:461-471.

30. Peterson, E. J., M. L. Woods, S. A. Dmowski, G. Derimanov, M. S. Jordan, J. N. Wu, P. S. Myung, Q.-H. Liu, J. T. Pribila, B. D. Freedman, Y. Shimizu, and G. A. Koretzky. 2001. Coupling of the TCR to integrin activation by Slap-130/Fyb. Science 293:2263-2265.

31. Pivniouk, V., E. Tsitsikov, P. Swinton, G. Rathbun, F. W. Alt, and R. S. Geha. 1998. Impaired viability and profound block in thymocyte development in mice lacking the adaptor protein SLP-76. Cell 94:229-238.

32. Razani-Boroujerdi, S., L. D. Partridge, and M. L. Sopori. 1994. Intracellular calcium signaling induced by thapsigargin in excitable and inexcitable cells. Cell Calcium 16:467-474.

33. Shapiro, V. S., M. N. Mollenauer, and A. Weiss. 1998. Nuclear factor of activated $\mathrm{T}$ cells and AP-1 are insufficient for IL-2 promoter activation: requirement for CD28 up-regulation of RE/AP. J. Immunol. 161:6455-6458.

34. Sosinowski, T., N. Killeen, and A. Weiss. 2001. The Src-like adaptor protein downregulates the $\mathrm{T}$ cell receptor on $\mathrm{CD} 4^{+} \mathrm{CD} 8{ }^{+}$thymocytes and regulates positive selection. Immunity 15:457-466.

35. Sundvold, V., K. M. Torgersen, N. H. Post, F. Marti, P. D. King, J. A. Rottingen, A. Spurkland, and T. Lea. 2000. T cell-specific adapter protein inhibits T cell activation by modulating Lck activity. J. Immunol. 165:29272931.

36. Tang, J., S. Sawasdikosol, J. H. Chang, and S. J. Burakoff. 1999. SLAP, a dimeric adapter protein, plays a functional role in $\mathrm{T}$ cell receptor signaling. Proc. Natl. Acad. Sci. USA 96:9775-9780.

37. Tomlinson, M. G., J. Lin, and A. Weiss. 2000. Lymphocytes with a complex: adapter proteins in antigen receptor signaling. Immunol. Today 21:584-591.

38. Wu, L., Z. Yu, and S. H. Shen. 2002. SKAP55 recruits to lipid rafts and positively mediates the MAPK pathway upon $\mathrm{T}$ cell receptor activation. J. Biol. Chem. 277:40420-40427.

39. Xing, L., C. Ge, R. Zeltser, G. Maskevitch, B. J. Mayer, and K. Alexandropoulos. 2000. c-Src signaling induced by the adapters Sin and Cas is mediated by Rap1 GTPase. Mol. Cell. Biol. 20:7363-7377.

40. Yablonski, D., M. R. Kuhne, T. Kadlecek, and A. Weiss. 1998. Uncoupling of nonreceptor tyrosine kinases from PLC-gamma1 in an SLP-76-deficient T cell. Science 281:413-416.

41. Yasuda, K., M. Nagafuku, T. Shima, M. Okada, T. Yagi, T. Yamada, Y. Minaki, A. Kato, S. Tani-Ichi, T. Hamaoka, and A. Kosugi. 2002. Cutting edge: Fyn is essential for tyrosine phosphorylation of Csk-binding protein phosphoprotein associated with glycolipid-enriched microdomains in lipid rafts in resting T cells. J. Immunol. 169:2813-2817.

42. Zhang, W., J. Sloan-Lancaster, J. Kitchen, R. P. Trible, and L. E. Samelson. 1998. LAT: the ZAP-70 tyrosine kinase substrate that links T cell receptor to cellular activation. Cell 92:83-92.

43. Zhang, W., C. L. Sommers, D. N. Burshtyn, C. C. Stebbins, J. B. DeJarnette, R. P. Trible, A. Grinberg, H. C. Tsay, H. M. Jacobs, C. M. Kessler, E. O. Long, P. E. Love, and L. E. Samelson. 1999. Essential role of LAT in T cell development. Immunity 10:323-332.

44. Zhumabekov, T., P. Corbella, M. Tolaini, and D. Kioussis. 1995. Improved version of a human CD2 minigene based vector for T cell-specific expression in transgenic mice. J. Immunol. Methods 185:133-140. 
Mice deficient in Sin/EFS, a protein that maps within the human inflammatory bowel disease 4 locus, develop mucosal inflammation

Laura T. Donlin ${ }^{1}$, Nichole M. Danzl ${ }^{2}$, Celestine Wanjalla ${ }^{2}$, and Konstantina Alexandropoulos ${ }^{2}$ *

${ }^{1}$ Laboratory of Lymphocyte Signaling

The Rockefeller University

1230 York Ave

New York, NY 10021

${ }^{2}$ Department of Pharmacology

College of Physicians and Surgeons of

Columbia University

630 West $168^{\text {th }}$ Street

New York, NY 10032

* Corresponding author

Phone: 212-305-2705

Fax: 212-305-8780

email: ka141@columbia.edu

Abreviations: Crohn's disease (CD); ulcerative colitis (UC); Inflammatory bowel disease (IBD); medullary thymic epithelial cells (mTECs). 


\section{Summary}

Inflammatory bowel disease (IBD) consisting of Crohn's disease (CD) and ulcerative colitis (UC), develops as a result of an abnormal immune response against normally harmless antigens in food and the mucosal microenvironment. Recent linkage studies conducted with $\mathrm{CD}$ and UC patients have resulted in identification of multiple chromosomal loci correlating to the disease phenotype. Among these, the inflammatory bowel disease locus (IBD4) locus maps within region 14q11-12 and exhibits significant linkage to $\mathrm{CD}$ in replicated studies. Here we show that mice deficient in expression of $\mathrm{Sin} / \mathrm{EFS}$, a protein that maps within 14q11-12 and IBD4, exhibit exaggerated immune responses and develop inflammatory lesions of the small intestine. These lesions consist of infiltrating $\mathrm{CD}^{+} \mathrm{T}$ cells in the lamina propria (LP), which correlates with villus expansion and/or damage. The localization of the inflammatory lesions in $\mathrm{Sin}^{-1 /}$ mice is restricted in the small bowel, similar to a subset of human CD patients that develop diffuse inflammation of the small intestine. Taken together, these results suggest that Sin is an important regulator of $\mathrm{T}$ lymphocyte function and identify Sin as a candidate gene that may contribute to immune system dysfunction and development of CD and IBD. 


\section{Introduction}

Human inflammatory bowel disease is caused by abnormal immune responses against the mucosal microenvironment that can be manifested in any part of the gastrointestinal tract (CD) or restricted to the colon and rectum (UC). In mice, multiple models of mucosal inflammation relating to IBD particularly UC, have been developed by chemical, immunological, or genetic means (1-5). Although disease development is due to diverse etiologies, once established, these diseases share common components which almost always associate with loss of tolerance to foreign antigens, excessive $\mathrm{T}$ cell effector responses, and inflammation of the gut. Aberrant $\mathrm{T}$ cell responses are mediated by $\mathrm{CD}^{+} \mathrm{T}$ cells which make up the major cell population that infiltrates mucosal tissues in all experimental animal models studied so far.

Our experiments have concentrated on elucidating the role of the adapter protein Sin (모 interacting protein), also known as embryonal Fyn substrate (EFS), in $\mathrm{T}$ lymphocyte function. Sin is highly expressed in the thymus and was isolated as a ligand for the Src homology 3 (SH3) domain of Src kinases, which have been shown to regulate the function of $\mathrm{T}$ lymphocytes (6-8). As an adapter molecule, Sin has no known enzymatic activity but contains conserved modular domains and tyrosine-based motifs capable of mediating multiple protein-protein interactions in a phosphotyrosinedependent manner (7).

Previously, we found that overexpression of Sin results in defective thymocyte development and $\mathrm{T}$ cell proliferation, suggesting a negative role for $\mathrm{Sin}$ in $\mathrm{T}$ lymphocyte function $(9,10)$. In this report we show that although $\operatorname{Sin}$ knockout mice have apparently normal thymocyte development, these mice exhibit exaggerated immune responses 
shown by increased cytokine production and T-cell dependent antibody responses. More importantly, aged $\mathrm{Sin}^{+/-}$and $\mathrm{Sin}^{-/-}$mice developed inflammatory lesions in their small intestine in the form of infiltrating $\mathrm{CD}^{+} \mathrm{T}$ cells in the lamina propria (LP), correlating with villus expansion and/or destruction. Unlike other models of mucosal inflammation, inflammatory lesions in $\mathrm{Sin}^{-/-}$mice are confined to the small bowel with no evidence of inflammation in the colon. The localization of the inflammation in the gut of Sindeficient mice can be most closely related to human $\mathrm{CD}$, which can be manifested in any part of the gastrointestinal tract, including the terminal ileum, diffuse small bowel, or isolated colonic disease in decreasing order of frequency (11).

Recently, human linkage studies have identified multiple chromosomal loci that associate with IBD (12-14). Of these regions, 14q11-12 associates with the IBD4 locus which exhibits significant linkage to $\mathrm{CD}$ in replicated studies (15-17). The sin/efs genomic locus localizes in region q11.2-12 of mouse and human chromosome 14, and is flanked by microsatellite markers (D14S261,D14S50,D14S283,D14S80) used in linkage studies that identified the IBD4 locus $(16,17)$. These observations together with our results from $\operatorname{Sin}$ knockout mice support a role for $\operatorname{Sin}$ as a candidate gene that may contribute to the development of the CD form of IBD in humans.

\section{Methods}

Mice. Sin knockout mice were generated using homologous recombination mediated gene targeting using standard techniques (for detailed description see Supporting Methods, published as supporting information on the PNAS web site). Male chimeric mice were bred to C57BL/6J and 129/SvEv females to establish mixed 
(C57BL/6J/-129/SvEv) as well as pure $(129 / \mathrm{SvEv})$ strains of mice. Animals were bred and maintained in a Columbia University animal facility under specific-pathogen-free (SPF) conditions and Institutional Animal Care and Use Committee (IACUC) guidelines. Animals in a C57BL/6J/-129/SvEv as well as $129 / \mathrm{SvEv}$ were used in this study with similar results.

Immunoprecipitations and Western Blots. These assays were performed as previously described (6). Mouse monoclonal antibody against Sin was obtained from BD Transduction Laboratories.

T cell Purification and Cytokine Assays. Splenic $\mathrm{CD}^{+} \mathrm{T}$ cells were purified using the Dynabead/DETACHaBEAD Mouse $\mathrm{CD}^{+}$system (DYNAL Biotech). $2 \times 10^{5}$ $\mathrm{T}$ cells were plated per well of a 96-well plate. Cells were left untreated or induced with

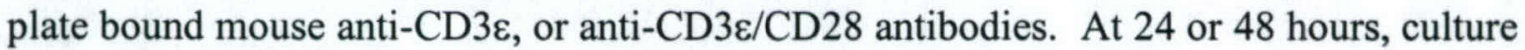
supernatants were collected and assayed for cytokine production using a Luminex Cytokine/Chemokine 6-plex bead kit (Biosource) according to the manufacturer's protocol.

ELISA Assays. For measuring T-cell-dependent responses mice were immunized with $100 \mu \mathrm{g}$ NP-keyhole limpet hemocyanin (KLH) by i.p. injection, and blood was collected on day 0 and 14 after injection. Relative levels of different Ig isotypes in response in NP-KLH immunization were determined using an ELISA kit (Southern Biotech) according to manufacturer's protocol.

Histological Analysiss and Immunohistochemistry. Sections of the proximal duodenum, ileum, and colon, were removed and fixed in $10 \%$ buffered formalin and paraffin embedded. Hematoxylin and eosin (H\&E) stained sections were examined under 
a light microscope with the help of a pathologist. The severity of mucosal lesions was characterized as mild, moderate, or severe, based on the extent of epithelium and lamina propria destruction. For staining paraffin-embedded or frozen sections slides were deparaffinized or fixed in $4 \%$ paraformaldehyde respectively, probed with specific primary and secondary antibodies, and visualized by fluorescent microscopy (for detailed protocol see Supporting Methods, published as supporting information on the PNAS web site).

\section{Results}

Generation of Sin-deficient Mice. To explore the physiologic role of Sin in T lymphocyte function we generated mice deficient in Sin expression by replacing a $4.3 \mathrm{~kb}$ fragment containing the coding region of the first exon, the first intron, and a short portion of the second exon with a neomycin-resistance cassette (Fig. 1A). Targeting was confirmed by analyzing tail DNA from different animals by Southern blotting using a 5' probe outside the targeted region (Fig. 1B) and by PCR (see Supporting Methods, published on the PNAS web site). The absence of the Sin protein in knockout animals was confirmed in cell extracts from the brain and thymus, which express the highest levels of Sin (7), by immunoprecipitation and western blotting (Fig. 1C).

\section{Normal T and B cell Development but Enhanced Immune Responses in Sin-}

deficient Mice. $\mathrm{Sin}^{-/}$mice appear normal and are fertile. Analysis of thymocyte subsets revealed no difference between wild type and knockout animals, as normal percentages of the different thymic populations and expression of the maturation markers CD3, TCR $\beta$, CD5, and CD69 were observed (Fig. 6A, published as supporting information on the PNAS web site). Normal percentages of $\mathrm{CD}^{+}{ }^{+}$and $\mathrm{CD} 8^{+}$mature $\mathrm{T}$ cells, $\mathrm{B}$ cells, and 
$\mathrm{B}$ to $\mathrm{T}$ cell ratios were also recovered in the spleen and lymph nodes of Sin-deficient animals (Fig. 6B, and Table 2, published as supporting information on the PNAS web site).

Previously, we found that Sin overexpression correlated with reduced mature $\mathrm{T}$ cell activation due to abnormal activation of intracellular signaling pathways leading to production of interleukin-2 (IL-2) $(9,10)$. In contrast, the cytokine responses of purified $\operatorname{Sin}^{-/-} \mathrm{T}$ cells were enhanced, shown by increased production of IL-2 as well as the $\mathrm{Th}_{1}$ interferon- $\gamma\left(\right.$ IFN- $\gamma$ ) and $\mathrm{Th}_{2}$ inteleukin-4, 5 (IL-4, IL-5) cytokines (Fig. 2A). Taken together, these data suggest that endogenous Sin plays an inhibitory role in T lymphocyte effector function.

To determine if there was a deficit in T-cell-mediated activation of B cell antibody responses, mice were immunized with NP-keyhole limpet hemocyanin (KLH) and the concentrations of isotype-specific antibodies in the sera of immunized mice were analyzed by ELISA assays. We found that the concentration of most immunoglobulin isotypes in immunized Sin knockout mice were not significantly different than wild type controls, suggesting that Sin deficiency does not interfere with $\mathrm{T}$ cell-dependent $\mathrm{B}$ cell responses (Fig. 2B). Instead, significant increases in antibody production were observed in Sin knockout animals in the case of $\mathrm{Th}_{1}$-dependent IgG2a (20-fold) and TGF $\beta / \mathrm{IL}-5$ dependent IgA (3-fold) isotypes (18), likely as a result of increased production of IFN- $\gamma$ and IL-5, by $\operatorname{Sin}^{-/-}$T cells (Fig. 2B).

\section{Sin Deficiency Results in Spontaneous Enteropathy in Aged Sin-deficient}

Mice. Previous studies with adapter proteins which play a negative role on T lymphocyte function have shown that deletion of negative regulators of $\mathrm{T}$ cells leads to increased 
proliferative responses and development of spontaneous autoimmunity in older mice (1921). To address the effect of Sin deficiency on development of spontaneous autoimmunity, mice were allowed to age and histopathological analysis of litter-mate wild type, heterozygous, and Sin knockout animals was performed at various ages ranging from 7-14 months. Although inflammatory infiltrates were observed in H\&E stains in some organs of $\mathrm{Sin}^{-/}$mice (data not shown), strikingly we found that the tissue most seriously and consistently affected was the small intestine (Fig. 3A, top panels). A direct comparison of H\&E sections of the duodenum/proximal jejunum from 11-monthold mice revealed crypt hyperplasia and extensive lymphocytic infiltration of the lamina propria, correlating with damage of the intestinal mucosa in $\mathrm{Sin}^{-/-}$mice as compared to wild type controls (Fig. 3A, compare left to right panels). Interestingly, similar sections derived from heterozygous itter-mates exhibited an intermediate phenotype manifested as shortened, blunt villi, enlarged crypts, and widening of the lamina propria (Fig. 3A, middle panels). These effects likely represent an intermediate phase of the disease that precedes the destruction of the epithelium observed in the small intestine of $\mathrm{Sin}^{-/}$ animals.

The effects of Sin deficiency on villus expansion and damage were analyzed in multiple mice and classified according to their severity. While wild type mice had normal mucosa, most Sin heterozygote mice $(75 \%)$ had villi with expanded lamina propria, of which a small percentage $(\sim 30 \%)$ also exhibited mild destruction at the tips of their villi. More dramatically, the majority (70\%) of Sin deficient mice exhibited marked infiltration of the lamina propria accompanied by moderate $(3 / 5)$ or severe $(2 / 5)$ villus destruction (Table 1, Fig. 3A middle and bottom right panels, respectively). Similar effects were also 
observed in H\&E sections derived from the ileum of Sin-deficient animals $\sim 60 \%$ of which exhibited inflammation in the form of lamina propria expansion, crypt enlargement, and altered epithelial cell morphology (Fig. 3B). In all but one case, inflammation in the duodenum/proximal jejunum coincided with inflammation in the ileum. In contrast to most existing animal models of mucosal inflammation that usually develop colitis, no inflammation was found in the colon of Sin-deficient animals (Fig. $3 C)$.

Inflammatory Infiltrates in the Small Intestine of Sin Deficient Mice Consist of $\mathbf{T}$ and Plasma B Cells. In experimental models of intestinal inflammation villus expansion is characterized by infiltration of the lamina propria and the intestinal epithelium by inflammatory cells, particularly T lymphocytes (1). To further analyze the nature of the inflammatory infiltrates in the lamina propria and epithelium of Sindeficient mice, serial small intestine sections derived from the mice shown in Fig. 3A and an additional set of mice were stained with anti-CD3 $\varepsilon$ antibody to detect the presence of $\mathrm{T}$ cells. Immunostaining revealed increased presence of $\mathrm{CD}^{+} \mathrm{T}$ cells in the lamina propria in sections derived from $\mathrm{Sin}^{+/}$and $\mathrm{Sin}^{-/}$mice as compared to wild type controls (Fig. 4A). The presence of $\mathrm{CD}^{+} \mathrm{T}$ cells was less evident in the small intestine of $\mathrm{Sin}^{-/}$ mice with extensive villus damage, although dense staining was present in remnants of the villi (Fig. 4A, lower right panel) and in mice with less extensive destruction (Fig. 4A, bottom right panel). Consistent with the increased $\mathrm{CD}^{+} \mathrm{T}$ cell-specific staining in the lamina propria of Sin deficient mice, increased numbers of peripheral $\mathrm{CD}^{+} \mathrm{T}$ cells were observed in the same mice analyzed by anti-CD3 antibody staining and FACS analysis (Fig. 4B and C). Serial sections of the same tissues used in Fig. 3A (middle panels) were 
also stained with anti-kappa light chain antibody, which revealed increased presence of plasma B cells in a staining pattern similar to that obtained with anti-CD3 antibody (Fig. 7A, published as supporting information on the PNAS web site). Despite this increase in the gut however, the levels of most serum immunoglobulin isotypes of unimmunized, aged $\mathrm{Sin}^{+/}$and $\mathrm{Sin}^{-/-}$mice were not significantly different from their normal counterparts, suggesting that the antibody responses to environmental antigens are normal in Sin deficient mice (Fig. 7B, published as supporting information on the PNAS web site).

Increased Infiltration of the Lamina Propria by $\mathrm{CD}^{+} \mathrm{CD}^{+} 5^{+} \mathrm{T}$ cells in the Small Intestine of Sin-deficient Mice. As mentioned above, in all IBD experimental animal models studied so far, $\mathrm{CD}^{+} \mathrm{T}$ cells make up the major cell population that infiltrates mucosal tissues (1). To further characterize the nature of the infiltrates present in the small intestine of Sin deficient mice, we costained frozen small intestine sections with $\mathrm{CD} 3 / \mathrm{CD} 4$ and $\mathrm{CD} 3 / \mathrm{CD} 8$ antibodies. We found a dramatic infiltration of the lamina propria by $\mathrm{CD}^{+} \mathrm{T}$ cells in Sin knockout mice, which correlated with shortening and expansion of the villi (Fig. 5A). This observation is consistent with evidence obtained with other mucosal inflammation mouse models showing increased infiltration of the intestinal mucosa by $\mathrm{CD}^{+} \mathrm{T}$ cells (1). The effect of Sin deficiency on infiltration of the intestinal epithelium by $\mathrm{CD} 8^{+} \mathrm{T}$ cells was less dramatic as we did not observe significant differences in the presence of intraepithelial $\mathrm{CD} 8^{+} \mathrm{T}$ lymphocytes (IEL) in the villi of wild type versus knockout animals, although a consistent increase in $\mathrm{CD}^{+}$IELs was observed in the intestinal epithelium of Sin heterozygote mice (Fig. 8A arrows, published as supporting information on the PNAS web site). Consistent with this, although $\mathrm{CD} 8^{+} \mathrm{T}$ cells are present in the intestinal epithelium and are expanded in some mouse models of 
intestinal inflammation, they do not appear to play a decisive pathologic role in disease development in most models (1).

$\mathrm{Sin}^{-/-} \mathrm{T}$ cells exhibit enhanced immune responses suggesting an activated state for these cells (Fig. 2). T cell receptor (TCR)-mediated stimulation of $\mathrm{T}$ cells is known to upregulate expression surface markers such as CD69 and the IL-2 receptor CD25. Staining of small intestine sections with anti-CD4 and anti-CD25 antibody revealed increased presence of $\mathrm{CD} 4^{+} \mathrm{CD} 25^{+} \mathrm{T}$ cells in the lamina propria of the small intestine of Sin deficient mice as compared to wild type controls (Fig. 8B, published as supporting information on the PNAS web site). The $\mathrm{CD}^{+} \mathrm{CD} 25^{+} \mathrm{T}$ cells present in the lamina propria likely represent activated rather than regulatory $\mathrm{T}$ cells $\left(\mathrm{T}_{\text {reg }}\right)$, since similar results were obtained with staining small intestine sections with anti-CD69 antibody (data not shown). In addition, we did not observe differences in the percentages of $\mathrm{CD} 4^{+} \mathrm{CD} 25^{+} \mathrm{T}$ cells recovered from the spleen of Sin knockout animals (Table 2, published as supportive information on the PNAS web site). This suggests that the inflammatory effects we observe in the gut of $\mathrm{Sin}^{-/}$animals are not due to defective development and/or suppressor function of $\mathrm{T}_{\text {reg }}$ but are likely due to inappropriate $\mathrm{T}$ cell responses to intestinal antigens.

\section{Discussion}

In this report we examined the role of the adapter molecule and signaling protein Sin in the function of the immune system, particularly $\mathrm{T}$ lymphocytes, using mice deficient in Sin expression. We found that Sin deficiency led to exaggerated $\mathrm{T}$ lymphocyte-mediated immune responses such as cytokine and T-cell-dependent antibody 
production in young mice, and inflammatory lesions involving $\mathrm{T}$ cells in aged animals. Specifically, we found that Sin haploinsufficiency resulted in increased production of inflammatory infiltrates in the small intestine of mice, whereas ablation of Sin expression led to profound lymphocyte infiltration and destruction of the intestinal mucosa. The effects of Sin deficiency in the small intestine correlated with increased presence of activated $\mathrm{CD}^{+} \mathrm{T}$ cells in the lamina propria. These results suggest that endogenous Sin is a regulator of $\mathrm{T}$ lymphocyte function and its absence leads to aberrant activation of $\mathrm{T}$ cells and development of tissue-specific, T cell-mediated inflammatory responses.

The inflammation evident in Sin-deficient mice is different from other mouse models of mucosal inflammation, in that whereas mucosal inflammation in most experimental models involves the colon and ileum, inflammatory lesions in $\mathrm{Sin}^{-/-}$mice are restricted to the small bowel. The histopathology associated with Sin ablation or haploinsufficiency characterized by chronic inflammation, villus infiltration by $\mathrm{CD} 4^{+} \mathrm{T}$ cells, crypt enlargement, and changes in epithelial cell architecture, most closely resembles inflammatory lesions of the senescence accelerated mice P1/Yit (SAMP/Yit). These mice have been shown to develop spontaneous and chronic ileitis that is similar to human $\mathrm{CD}$ (22). Therefore, our mouse model together with the fact that the human sin/efs genomic locus localizes within the CD-associated IBD4 locus, collectively support a role for $\mathrm{Sin}$ in the development of a CD-like enteropathy and IBD.

The inflammatory lesions in the gut of Sin-deficient mice are likely due to increased cytokine production and presence of activated $\mathrm{CD}^{+} \mathrm{T}$ cells in the lamina propria. Consistent with a role of activated $\mathrm{T}$ cells and enhanced cytokine production in the development of inflammation associated with Sin deficiency, injection of normal 
mice with anti-CD3 antibodies leads to profound destruction of the villi of the small intestine (23). Similarly, mice injected with IL-12, IFN- $\gamma$ and TNF cytokines develop severe damage of the intestinal epithelium shown by increased apoptosis, necrosis, and shrinkage (24). Moreover, infiltration of the lamina propria by $\mathrm{CD}^{+} \mathrm{T}$ cells and enhanced production of Th1 cytokines has been shown to play a key role in the immunopathology associated with chemically induced, spontaneous, or genetically manipulated animal models of mucosal inflammation (1).

If indeed the enhanced effector responses of Sin deficient $\mathrm{T}$ lymphocytes are responsible for the development of mucosal inflammation and destruction in Sin knockout mice, what is the cause of increased T cell stimulation? In previous experiments we found that $\mathrm{Sin}$ overexpression correlated with negative effects on $\mathrm{T}$ lymphocyte development and activation (9) due to Sin-mediated interference with intracellular signaling events such as PLC- $\gamma$ activation and intracellular calcium release (10). In contrast, $\mathrm{Sin}^{-/} \mathrm{T}$ cells displayed increased cytokine responses suggesting a negative role for Sin in T lymphocyte regulation. However, we did not observe lymphoproliferation in aged $\mathrm{Sin}^{-/-}$mice, which typically associates with intrinsic defects in T cell activation (19, $20,25)$, suggesting that a different mechanism is involved in the regulation of $T$ cell function in these mice.

We have recently found high expression of Sin in the thymic stroma, particularly in the thymic medulla (unpublished observations). Furthermore, a recent independent report using GeneChip arrays has shown that Sin expression is enriched in a subset of epithelial cells in the medulla, the medullary thymic epithelial cells (mTECs) (26). mTECS are thought to play an important role in thymocyte development and have been 
shown to ectopically express a variety of tissue specific proteins for the purpose of eliminating autoreactive $\mathrm{T}$ cells and preventing autoimmunity.

Although the significance of Sin expression in the mTECs is currently unclear, our observations raise the possibility that Sin may be involved in the establishment of self tolerance by regulating mTECs-mediated elimination of autoreactive $\mathrm{T}$ cells in the thymus. Thus, it is possible that the spontaneous inflammatory effects we observe in $\operatorname{Sin}^{-}$ ${ }^{1-}$ mice are due to the presence of autoreactive $\mathrm{T}$ cells against certain antigens and not to intrinsic defects in $\mathrm{T}$ lymphocyte signaling. The possibility that Sin plays a role in mTEC-mediated T lymphocyte selection is supported by our results showing an intermediate phenotype associated with Sin haploinsufficiency. It has previously been shown that reduced expression levels of insulin in mTECs due to mutations within the insulin promoter, correlates with increased susceptibility to diabetes. Thus, appropriate expression levels of self antigens in the thymus are important for establishing self tolerance $(27,28)$. It is possible that Sin regulates the expression of specific self-proteins in mTECs, in which case hemizygocity should have an effect in T cell selection. A potential role for Sin in self-antigen expression in mTECs is intriguing in light of the observation that positional candidate genes for IBD include genes involved in antigen presentation such as a cluster of HLA alleles in IBD3 and components of the proteosome responsible for MHC class I antigen presentation in IBD4. Future experiments will address the role of Sin in mTECs and self antigen presentation, further analyze the role of Sin in central tolerance and autoimmunity, and together with human studies may lead to the identification of $\sin / e f s$ as a susceptibility locus for IBD. 


\section{Acknowledgements}

We are grateful to Drs. Alessandra Pernis, Jessica Fanzo, and So Young Jang for technical advice and reagents; Drs. Raphael Clynes and Ramon Parsons for providing fluorescent microscopes; Drs. Kevan Herold and Qiong-Fen Guo for assistance with the cytokine assays; Dr. Mathias Szabolcs for evaluating histology sections. This work was supported in part by the American Cancer Society Grant RPG99-09-01MGO, by the Department of Defense Grants DAMD17-99-1-9151 and DAMD17-99-1-915, and the National Institute of Allergy and Infectious Disease (NIAID) Grant RO1 AI49387-01. 


\section{Figure Legends}

Fig. 1. Generation of Sin knockout mice. A) Schematic representation of the sin/efs genomic locus, the targeting construct, and the targeted sin/efs locus. B) Genomic tail DNA from different mice was digested with $\mathrm{XbaI}$ to reveal $\mathrm{a} \sim 5.2 \mathrm{~kb}$ wild type and a $\sim 5.7 \mathrm{~kb}$ targeted fragment on Southern blots using a 5' flanking probe (left panel). C) Cell lysates from whole thymus and brain from $\mathrm{Sin}^{+/+}, \mathrm{Sin}^{+/-}$, and $\mathrm{Sin}^{-/-}$mice were immunoprecipitated with Sin-specific antibodies, separated on SDS-PAGE, transferred onto nitrocellulose membranes and probed with Sin antibody to reveal Sin protein levels.

Fig. 2. Sin-deficient T lymphocytes exhibit exaggerated immune responses. A) $2 \times 10^{5} \mathrm{CD}^{+}$splenic $\mathrm{T}$ cells were plated per well coated with anti-CD3 $(0.5 \mu \mathrm{g} / \mathrm{ml})$ antibody alone or anti-CD3e $(0.5 \mu \mathrm{g} / \mathrm{ml})$ and CD28 $(5 \mu \mathrm{g} / \mathrm{ml})$, for 24 (IL-2) or $48 \mathrm{hrs}$. Culture supernatants were removed and cytokine concentrations were determined in triplicate samples as described in experimental procedures. Bars represent mean \pm S.D. Four mice of each genotype were analyzed. B) NP-KLH-specific antibody production was measured using serum from mice immunized with NP-KLH at day 14 after immunization, as described in experimental procedures. Lines represent the average antibody concentration from five animals for each genotype. Student's t test was used to calculate statistical significance for differences in measurements between two Ig isotypes (IgG2a and $\operatorname{IgA}$ ) in wild type and $\mathrm{Sin}^{-/-}$mice. P value of $<0.005$ was considered to be statistically significant.

Fig. 3. Increased villus atrophy/destruction and infiltration in the small intestine of $\mathrm{Sin}^{+/-}$and $\mathrm{Sin}^{-/-}$mice. A) Paraffin embedded sections of duodenum/proximal jejunum derived from 11-month-old litter-mate wild type, heterozygous, and Sin knockout mice 
(two different animals of each genotype) were stained with H\&E and visualized by light microscopy. Sections shown on top and middle panels were derived from the same animals shown under two different magnifications. Arrow and arrowhead indicate the lamina propria (LP) and crypts (C). Paraffin-embedded sections of the ileum of two littermate wild type and two $\mathrm{Sin}^{-/ /}$animals (B), and the colon of one each $\mathrm{Sin}^{+/ /}$and $\mathrm{Sin}^{-/ /}$mice (C) were stained with H\&E.

Fig. 4. Increased infiltration of the intestinal lamina propria of $\mathrm{Sin}^{+/}$and $\mathrm{Sin}^{-1-}$ mice by $\mathrm{CD}^{+} \mathrm{T}$ cells. Serial sections from the small intestine of animals shown in $3 \mathrm{~A}$ (middle panels) and a different set of litter mate control, $\mathrm{Sin}^{+/-}$and $\mathrm{Sin}^{-/-}$mice with moderate villus destruction, were stained with anti-CD3 antibody. B) $1 \times 10^{6}$ total splenocytes isolated from the same mice shown in 4A (left panels) were stained with antiCD4, -CD8, and CD3 antibodies, and total levels of CD3 (histogram) were determined by FACS. The filled curve represents $\mathrm{Sin}^{+/+}$mice, the black line $\mathrm{Sin}^{+/}$, and the gray line $\mathrm{Sin}^{-/-}$mice. C) Total numbers of splenic $\mathrm{CD}^{+} \mathrm{T}$ cells from at least three mice for each genotype were determined by FACS (bar graph, mean \pm S.D.).

Fig. 5. Increased infiltration by activated $\mathrm{CD}^{+} \mathrm{T}$ cells in the lamina propria of $\mathrm{Sin}^{-/-}$mice. Frozen sections of 11-month old mice were costained with anti-CD4 and CD3-specific antibodies and T cells were visualized with anti-rat Rhodamine-conjugated (CD4) and anti-rabbit AlexaFluor488 (CD3) secondary antibodies and fluorescent microscopy. 


\section{References}

1. Strober, W., Fuss, I. J. \& Blumberg, R. S. (2002) Annu Rev Immunol 20, 495-549.

2. Bouma, G. \& Strober, W. (2003) Nat Rev Immunol 3, 521-33.

3. Blumberg, R. S., Saubermann, L. J. \& Strober, W. (1999) Curr Opin Immunol 11, 648-56.

4. Hibi, T., Ogata, H. \& Sakuraba, A. (2002) J Gastroenterol 37, 409-17.

5. Pizarro, T. T., Arseneau, K. O., Bamias, G. \& Cominelli, F. (2003) Trends Mol Med 9, 218-22.

6. Alexandropoulos, K. \& Baltimore, D. (1996) Genes Dev 10, 1341-55.

7. Alexandropoulos, K., Donlin, L. T., Xing, L. \& Regelmann, A. G. (2003) Immunol Rev 192, 181-95.

8. Ishino, M., Ohba, T., Inazawa, J., Sasaki, H., Ariyama, Y. \& Sasaki, T. (1997) Oncogene 15, 1741-5.

9. Donlin, L. T., Roman, C. A., Adlam, M., Regelmann, A. G. \& Alexandropoulos, K. (2002) J Immunol 169, 6900-9.

10. Xing, L., Donlin, L. T., Miller, R. H. \& Alexandropoulos, K. (2004) Mol Cell Biol $24,4581-4592$.

11. Hendrickson, B. A., Gokhale, R. \& Cho, J. H. (2002) Clin Microbiol Rev 15, 7994.

12. van Heel, D. A., Fisher, S. A., Kirby, A., Daly, M. J., Rioux, J. D. \& Lewis, C. M. (2004) Hum Mol Genet 13, 763-70.

13. Mathew, C. G. \& Lewis, C. M. (2004) Hum Mol Genet 13 Spec No 1, R161-8. 
14. Ahmad, T., Satsangi, J., McGovern, D., Bunce, M. \& Jewell, D. P. (2001) Aliment Pharmacol Ther 15, 731-48.

15. Ma, Y., Ohmen, J. D., Li, Z., Bentley, L. G., McElree, C., Pressman, S., Targan, S. R., Fischel-Ghodsian, N., Rotter, J. I. \& Yang, H. (1999) Inflamm Bowel Dis 5, 271-8.

16. Duerr, R. H., Barmada, M. M., Zhang, L., Pfutzer, R. \& Weeks, D. E. (2000) Am J Hum Genet 66, 1857-62.

17. Vermeire, S., Rutgeerts, P., Van Steen, K., Joossens, S., Claessens, G., Pierik, M., Peeters, M. \& Vlietinck, R. (2004) Gut 53, 980-6.

18. Stavnezer, J. (1996) Curr Opin Immunol 8, 199-205.

19. Murphy, M. A., Schnall, R. G., Venter, D. J., Barnett, L., Bertoncello, I., Thien, C. B., Langdon, W. Y. \& Bowtell, D. D. (1998) Mol Cell Biol 18, 4872-82.

20. Naramura, M., Kole, H. K., Hu, R. J. \& Gu, H. (1998) Proc Natl Acad Sci U S A $95,15547-52$.

21. Sosinowski, T., Killeen, N. \& Weiss, A. (2001) Immunity 15, 457-66.

22. Matsumoto, S., Okabe, Y., Setoyama, H., Takayama, K., Ohtsuka, J., Funahashi, H., Imaoka, A., Okada, Y. \& Umesaki, Y. (1998) Gut 43, 71-8.

23. Musch, M. W., Clarke, L. L., Mamah, D., Gawenis, L. R., Zhang, Z., Ellsworth, W., Shalowitz, D., Mittal, N., Efthimiou, P., Alnadjim, Z., Hurst, S. D., Chang, E. B. \& Barrett, T. A. (2002) J Clin Invest 110, 1739-47.

24. Guy-Grand, D., DiSanto, J. P., Henchoz, P., Malassis-Seris, M. \& Vassalli, P. (1998) Eur J Immunol 28, 730-44. 
25. Bachmaier, K., Krawczyk, C., Kozieradzki, I., Kong, Y. Y., Sasaki, T., Oliveirados-Santos, A., Mariathasan, S., Bouchard, D., Wakeham, A., Itie, A., Le, J., Ohashi, P. S., Sarosi, I., Nishina, H., Lipkowitz, S. \& Penninger, J. M. (2000) Nature 403, 211-6.

26. Gotter, J., Brors, B., Hergenhahn, M. \& Kyewski, B. (2004) J Exp Med 199, 15566.

27. Pugliese, A., Zeller, M., Fernandez, A., Jr., Zalcberg, L. J., Bartlett, R. J., Ricordi, C., Pietropaolo, M., Eisenbarth, G. S., Bennett, S. T. \& Patel, D. D. (1997) Nat Genet 15, 293-7.

28. Pugliese, A., Awdeh, Z. L., Alper, C. A., Jackson, R. A. \& Eisenbarth, G. S. (1994) J Autoimmun 7, 687-94. 
赵

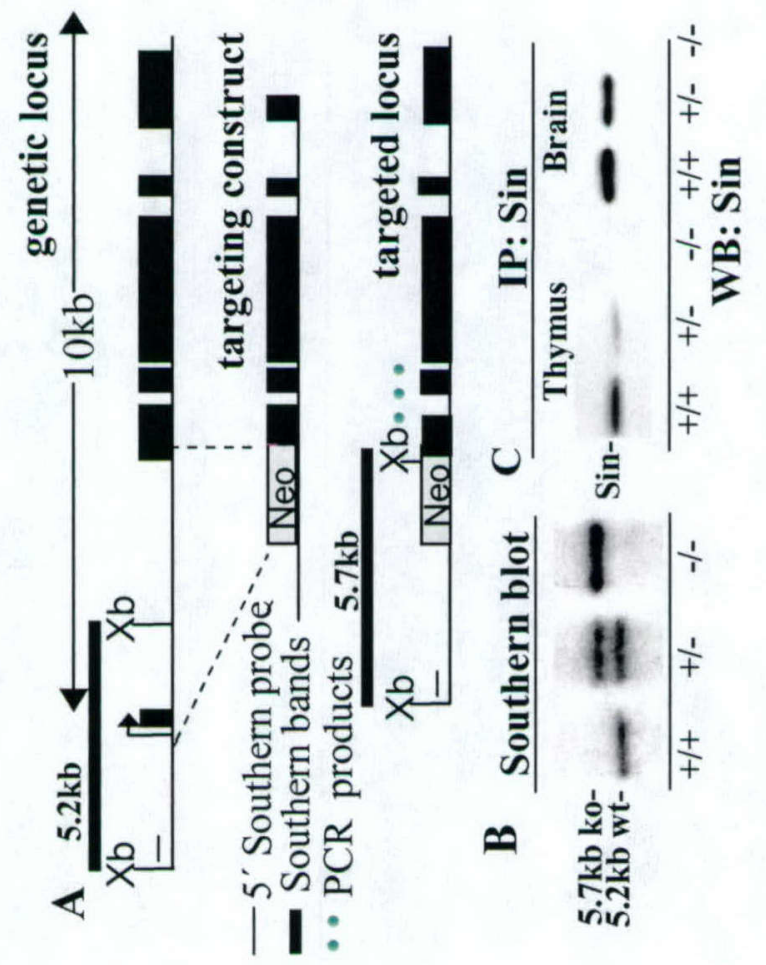


일

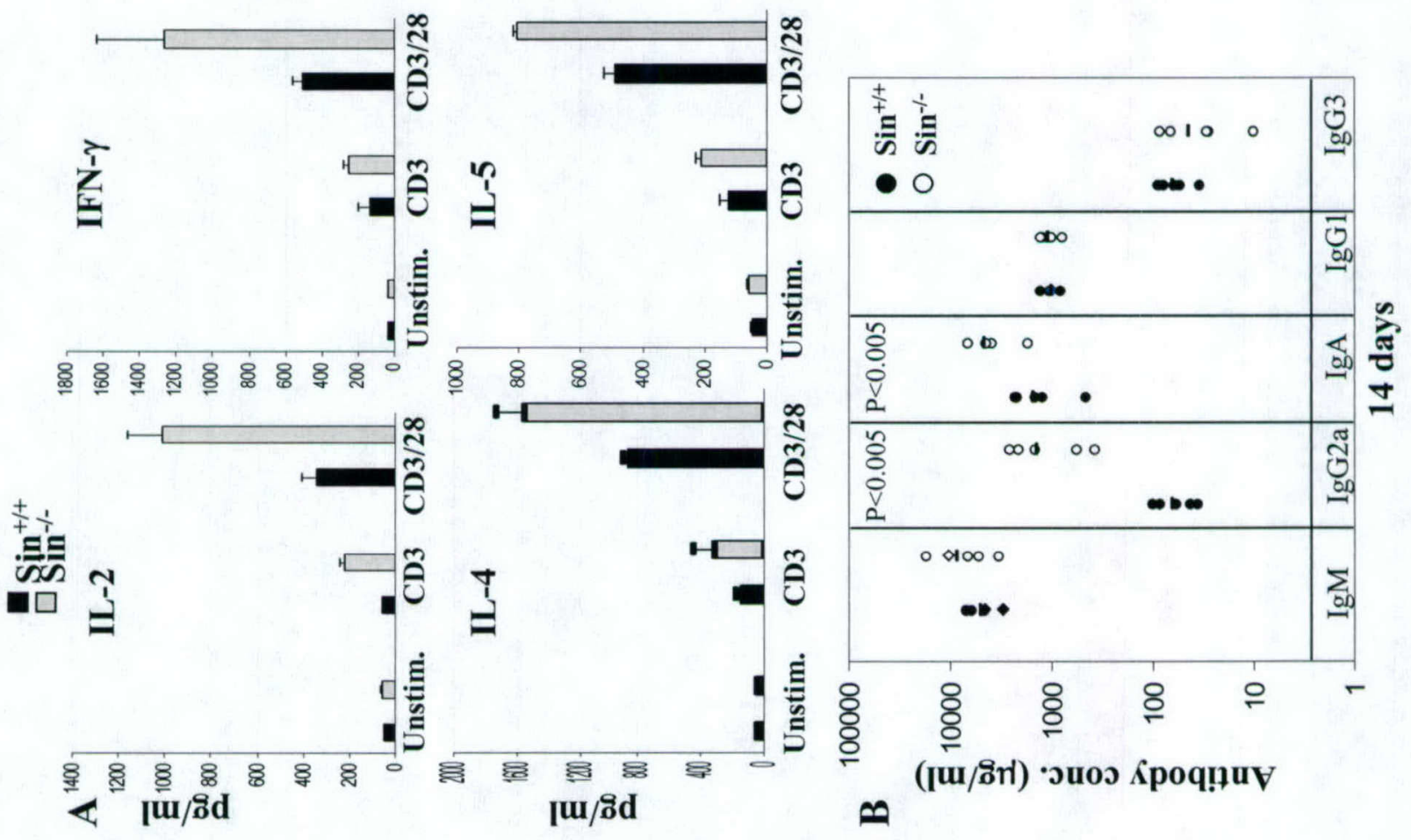


m
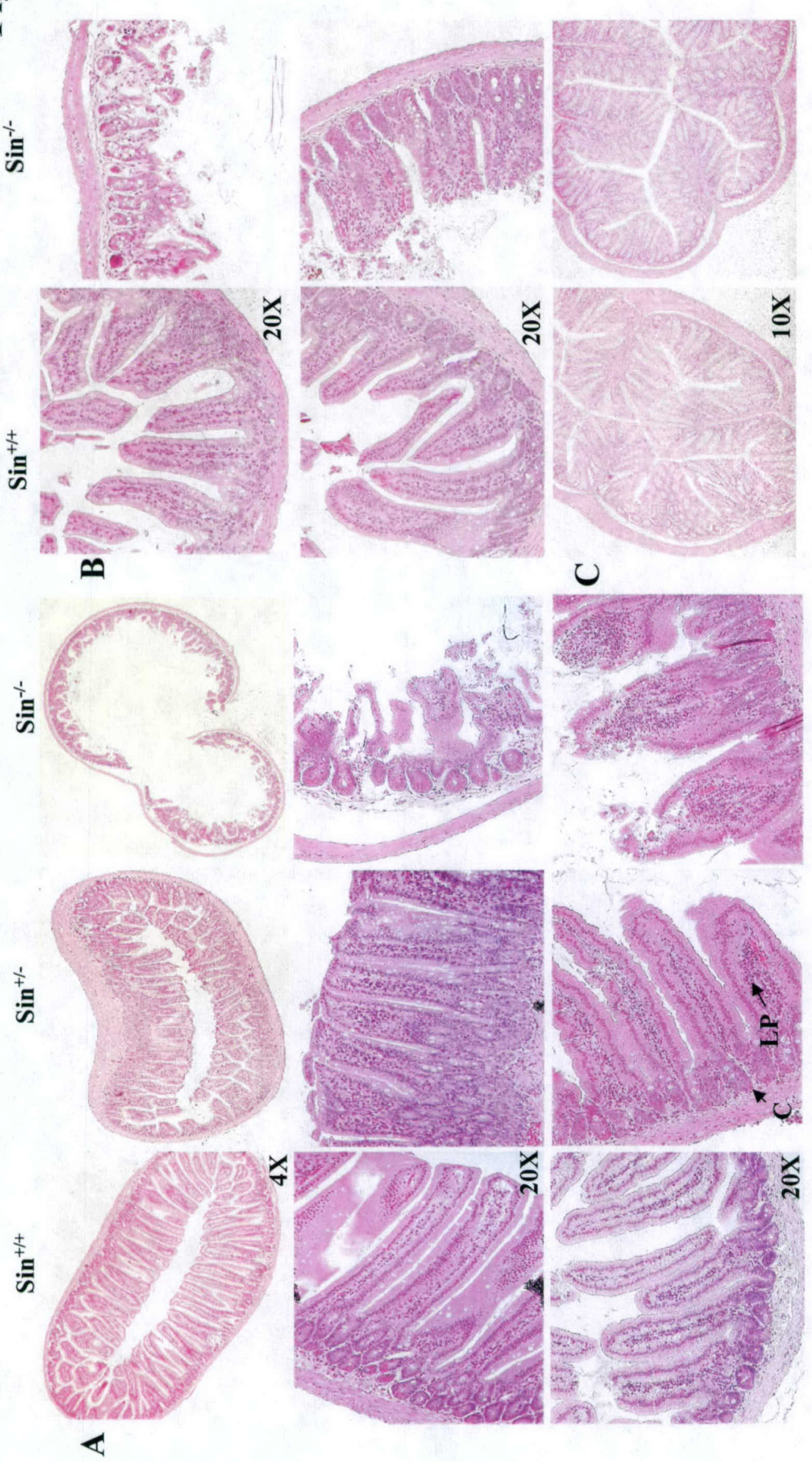
$\underset{1}{+0}$

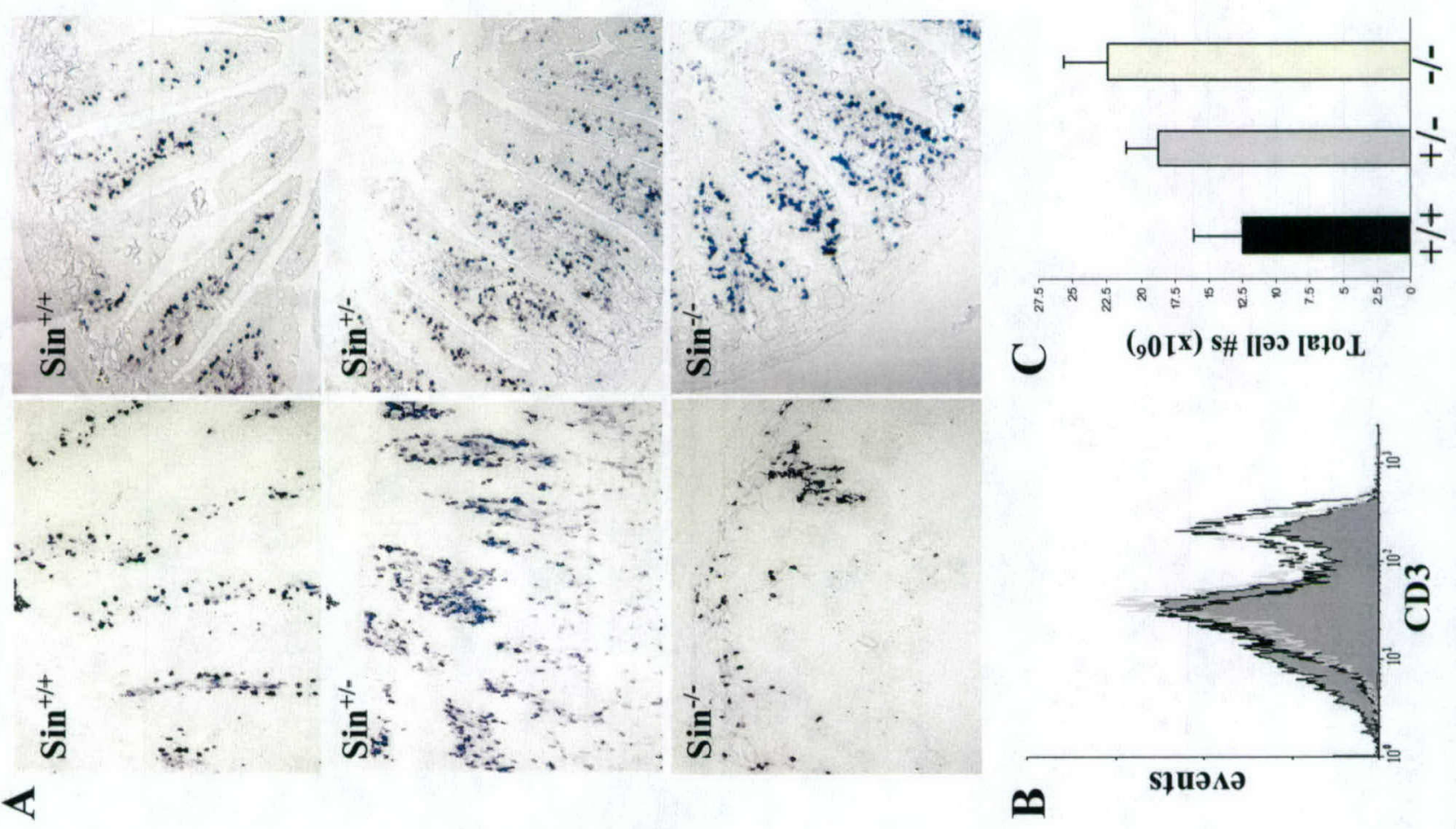


in

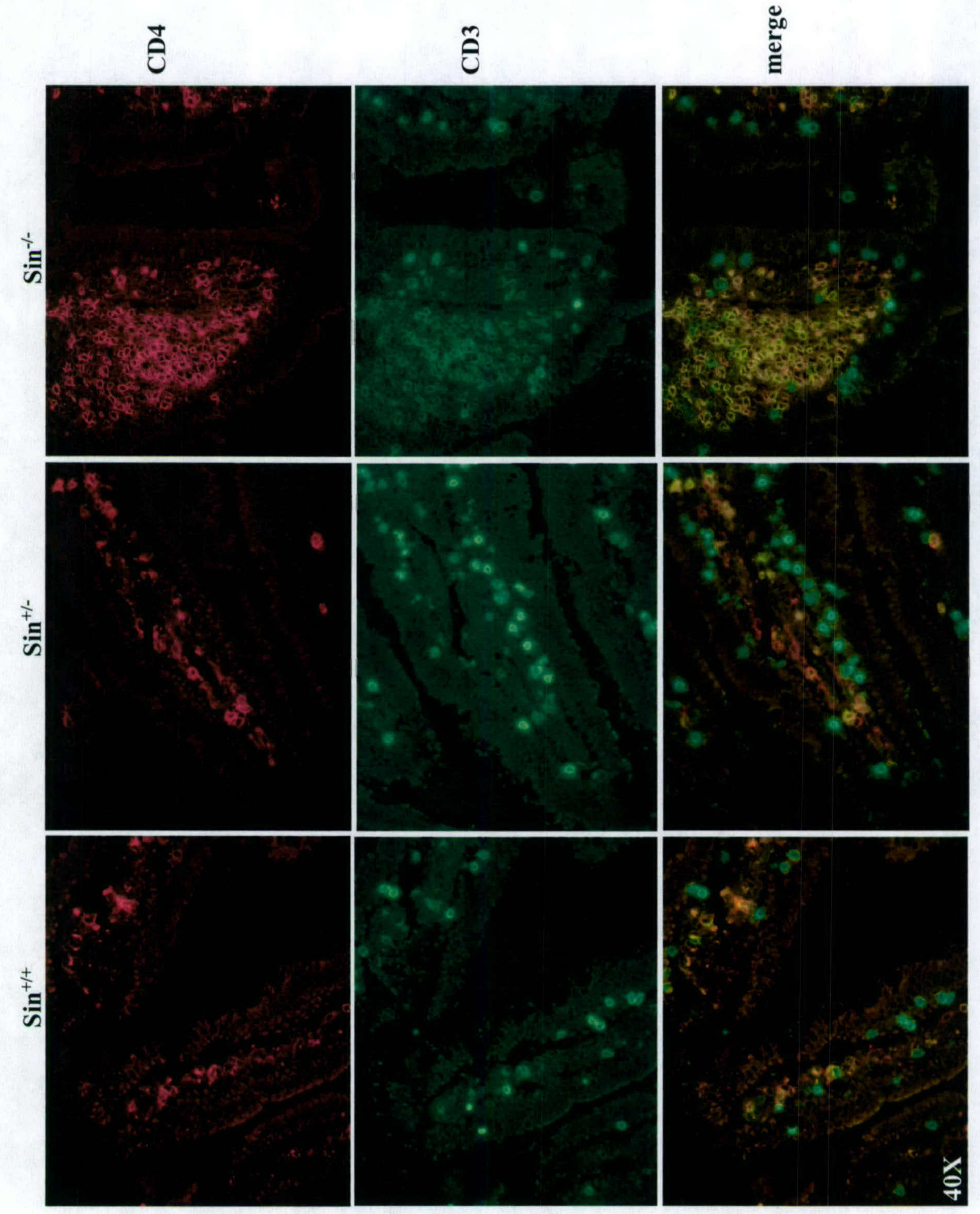




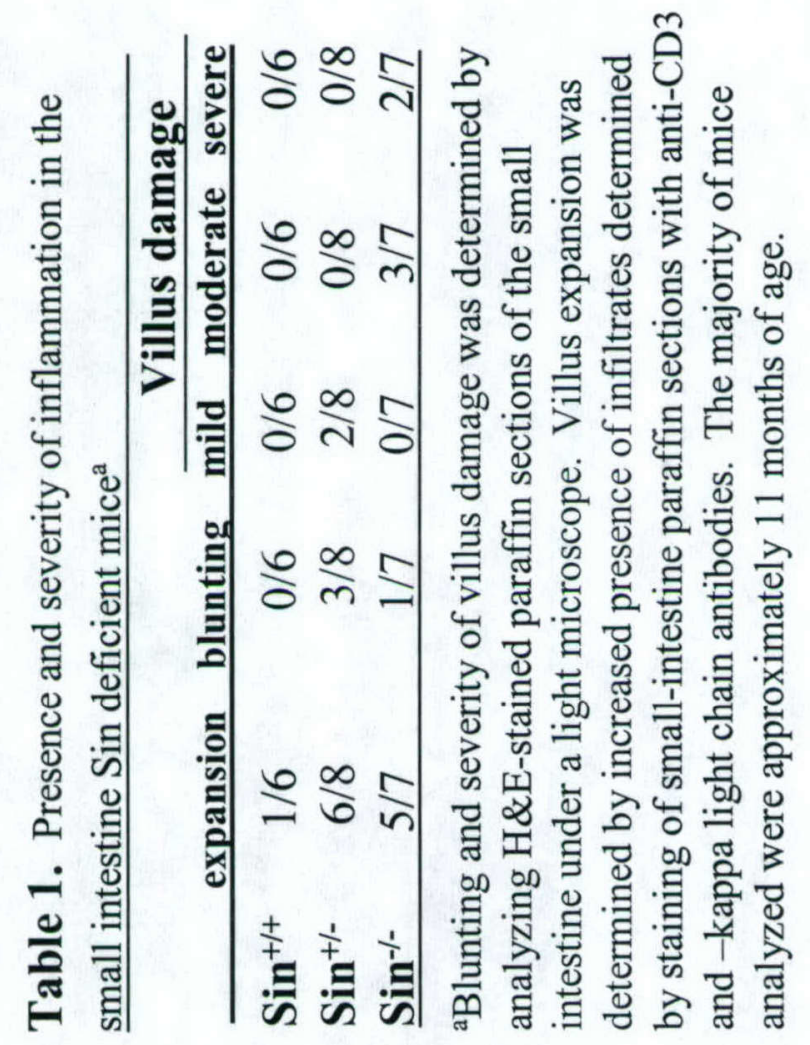




\section{Supporting Methods}

Generation of Sin knockout mice. A bacteria artificial chromosome (BAC) mouse genomic library (Incyte Corp.) was screened for the Sin locus. Four BAC clones containing the Sin genomic locus were identified on high density filters through hybridization with a Sin cDNA probe spanning the entire coding region (1-560aa/1- 1680 bp). The BAC clones were used to amplify sequences comprising the 5' and 3' arms of the targeting construct. The sequence for the primers was obtained from two continguous sequences obtained from the ENSEMBL mouse genome database (http://www.ensembl.org/Mus_musculus/ with the gene identifier ENSMUSG00000022203). The targeting construct plasmid was pCS which is a combination of the pBluescript II SK(+) plasmid (Stratagene) and fragments containing the neomycin phosphotransferase (Neo) gene under the control of the PGK promoter which allows for positive selection with the neomycin analog G418. The 5'arm of the targeting sequence was cloned in an XhoI site while the 3' in a KpnI site. The targeting construct was electroporated into embryonic stem (ES) cells and after antibiotic selection four targeted clones were isolated. Two positive clones were injected into blastocysts which were then surgically implanted into recipient Swiss Webster mice. Male chimeric mice were then bred to C57BL/6J and 129/SvEv females to establish mixed (C57BL/6J/$129 / \mathrm{SvEv})$ as well as pure (129/SvEv) strains of mice. Germline transmission of the targeted Sin locus was confirmed by analyzing tail DNA through PCR and Southern blot analysis.

PCR Analysis. The Long Template PCR kit (Roche) was used for PCR genotyping. 5'primer for the Sin wild type locus 
[GAGGAGGAGTGTGCCCTCCATGACGCTGGCAGG] and the targeted locus [ATGGGATCGGCCATTG AACAAGATGGATTG] were used for amplification. The 3' primer for both loci was [GGGACATGATGAGCCAGGCTGGGTGGGAGATGC]. These primers amplify a $300 \mathrm{bp}$ wild type and $1.3 \mathrm{~kb}$ knockout band.

Flow Cytometry Analysis. $1 \times 10^{6}$ freshly isolated thymocytes or splenocytes from 6-8 week old mice were incubated with the specified antibodies and stained in MACS buffer (2mM EDTA, $0.03 \% \mathrm{NaN}_{3}, 1 \%$ BSA, $1 \times$ PBS) for $15 \mathrm{~min}$ on ice. Cells were spun down and washed three times with MACS buffer, fixed in BD Cytofix ${ }^{\mathrm{TM}}$ Buffer (BD Pharmingen) and analyzed by flow cytometry using a FACS Calibur and CELLQUEST software (BD Biosciences). Anti- CD4-Allophycocyanin (APC), CD8Peridinin Chlorophyll-a Protein (PerCP), CD3-Fluorescein Isothiocyanate (FITC), CD69FITC, CD5-FITC, TCR- $\beta$-FITC, CD45-R(B220)-APC conjugated antibodies were purchased from BD Pharmingen.

Immunohistochemistry. For staining paraffin embedded sections, slides were deparaffinized with xylene washed with ethanol and after antigen retrieval (boiling for 15 min, in $1 \mathrm{mM}$ EDTA pH 7.5, followed by methanol washes) slides were blocked in $5 \%$ dry milk in TBST $(0.05 \mathrm{M}$ Tris $\mathrm{pH} 7.5,0.15 \mathrm{M} \mathrm{NaCl}, 0.01 \%$ Tween 20$)$ and incubated with primary antibodies (anti-CD3, anti-kappa light chain) overnight at RT in a humidified chamber. Slides were then washed with TBST and incubated with alkaline phosphatase (AP)- or hydrogen peroxidase (HRP)-conjugated secondary antibodies for $30 \mathrm{~min}$ at RT. Specific staining was visualized by incubating slides in developing solutions NBT/BCIP (AP, Roche), or AEC (HRP). For staining frozen sections slides were fixed in $4 \%$ paraformaldehyde in phosphate buffered saline (PBS, pH 7.4) for 20 
min, washed with PBS and, permeabilized/blocked with permeabilization buffer (RPMI medium, $0.05 \%$ saponin, $10 \mathrm{mM}$ glycine, $5 \%$ normal donkey serum). After washing, the slides were incubated with primary antibodies 1:100 dilution [purified anti-CD4 (BD Pharmingen) and anti-CD3 (Dakocytomation )] and incubated for $30 \mathrm{~min}$ at RT. After washing, slides were incubated with AlexaFluor 488 (Molecular Probes) or anti-rat Rhodamine (Jackson ImmunoResearch) at 1:400 dilution for $30 \mathrm{~min}$ RT, and specific staining was visualized by fluorescent microscopy using a Nikon eclipse E600 microscope.

\section{Supportive Figure Legends}

Fig. 6. Sin deficient animals exhibit normal thymocyte development. A) $1 \times 10^{6}$ thymocytes from wild type and $\mathrm{Sin}^{-/-}$animals were stained with anti-CD4-APC, -CD8PerCP, and -CD3-, TCR $\beta-$, CD5-, or CD69-FITC antibodies to reveal different thymocyte populations (dot plots). Histograms showing total CD3, TCR $\beta$, CD5 and CD69 levels are shown at the bottom. B) $1 \times 10^{6}$ total splenocytes and lymph node cells from normal and $\mathrm{Sin}^{-/}$mice were stained with anti-B220-APC and anti-CD3-FITC antibodies or with anti-CD4-APC/CD8-PerCR and analyzed by FACS. Numbers represent percentage of cells within the boxed areas. At least five mice for each wild type and Sin knockout phenotype were analyzed for the experiments in A and B.

Fig. 7. Normal antibody responses to environmental antigens in $\mathrm{Sin}^{-/ 2}$ mice. A) Paraffin embedded sections were stained with anti-kappa light chain antibodies to reveal the presence of plasma B cells. B) Levels of immunoglobulin isotypes in the serum of aged, unimmunized animals were determined using an isotype-specific ELISA kit 
(Southern Biotech) according to manufacturer's protocol. Black circles represent wild type, gray circles heterozygous, and open circles knockout animals. Lines represent the average antibody concentration from at least six animals for each genotype.

Fig. 8. Increased presence of $\mathrm{CD} 4^{+} \mathrm{CD} 25^{+} \mathrm{T}$ cells in the lamina propria of Sindeficient mice. A) Frozen sections of 11-month old mice were costained with anti-CD8 and -CD3-specific antibodies and $\mathrm{T}$ cells were visualized with anti-rat Rhodamineconjugated (CD8) and anti-rabbit AlexaFluor488 (CD3) secondary antibodies and fluorescent microscopy. B) Frozen sections of 11-month old mice were costained with anti-CD4, and anti-CD25FITC-specific antibodies and $\mathrm{CD}_{4}^{+} \mathrm{CD} 25^{+} \mathrm{T}$ cells were visualized with anti-rat Rhodamine-conjugated (CD4) secondary antibody and fluorescent microscopy. 
官
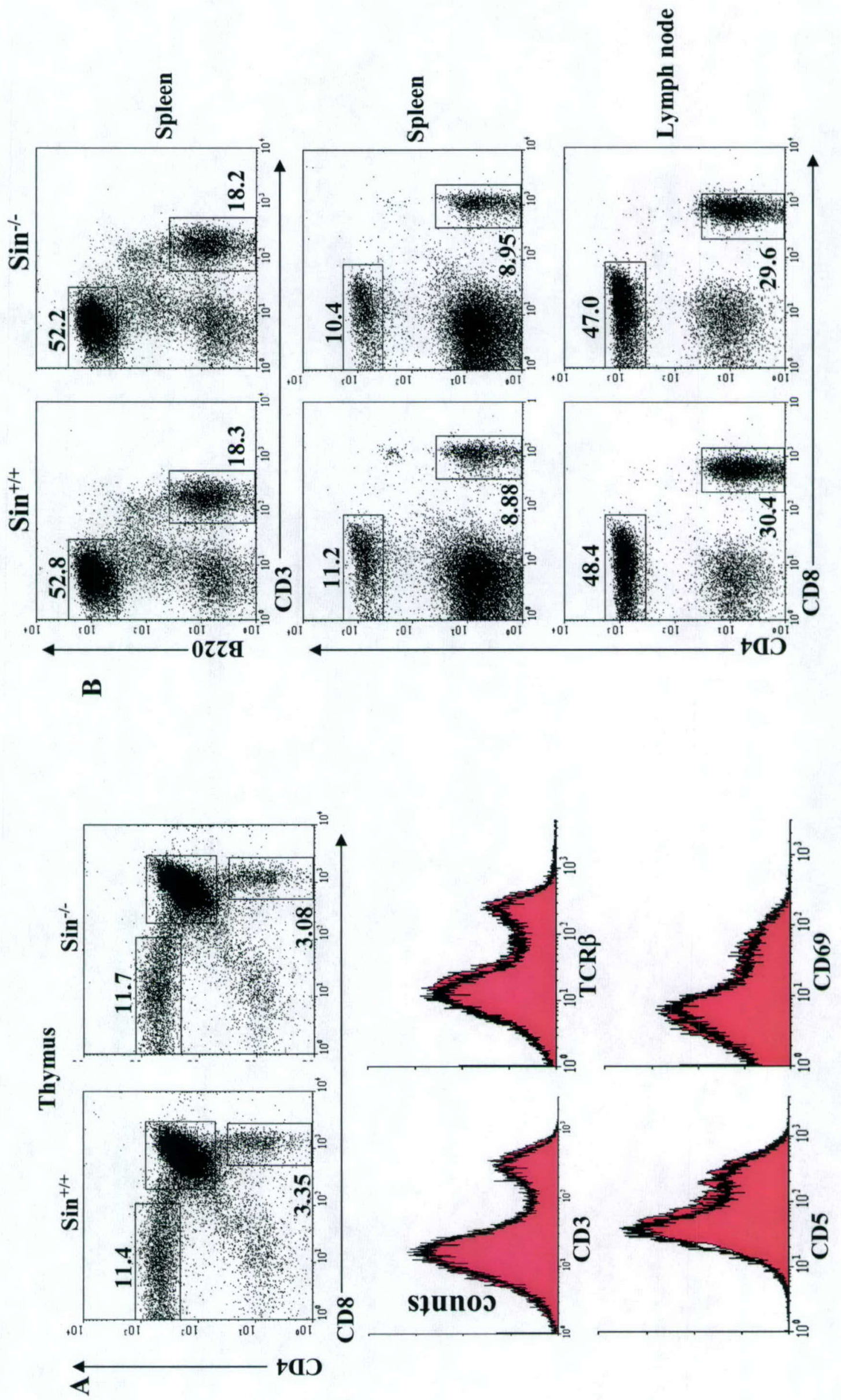


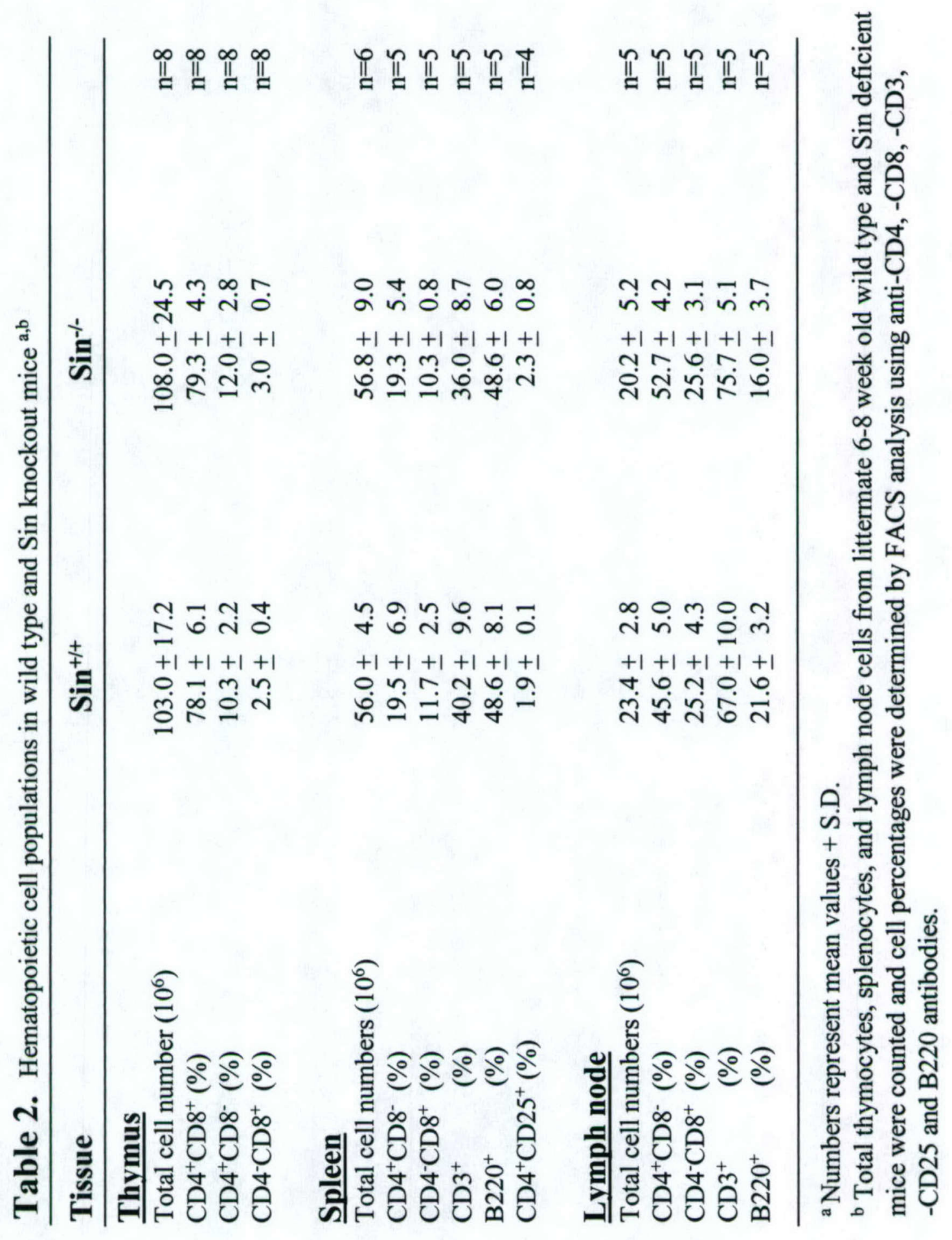


옹

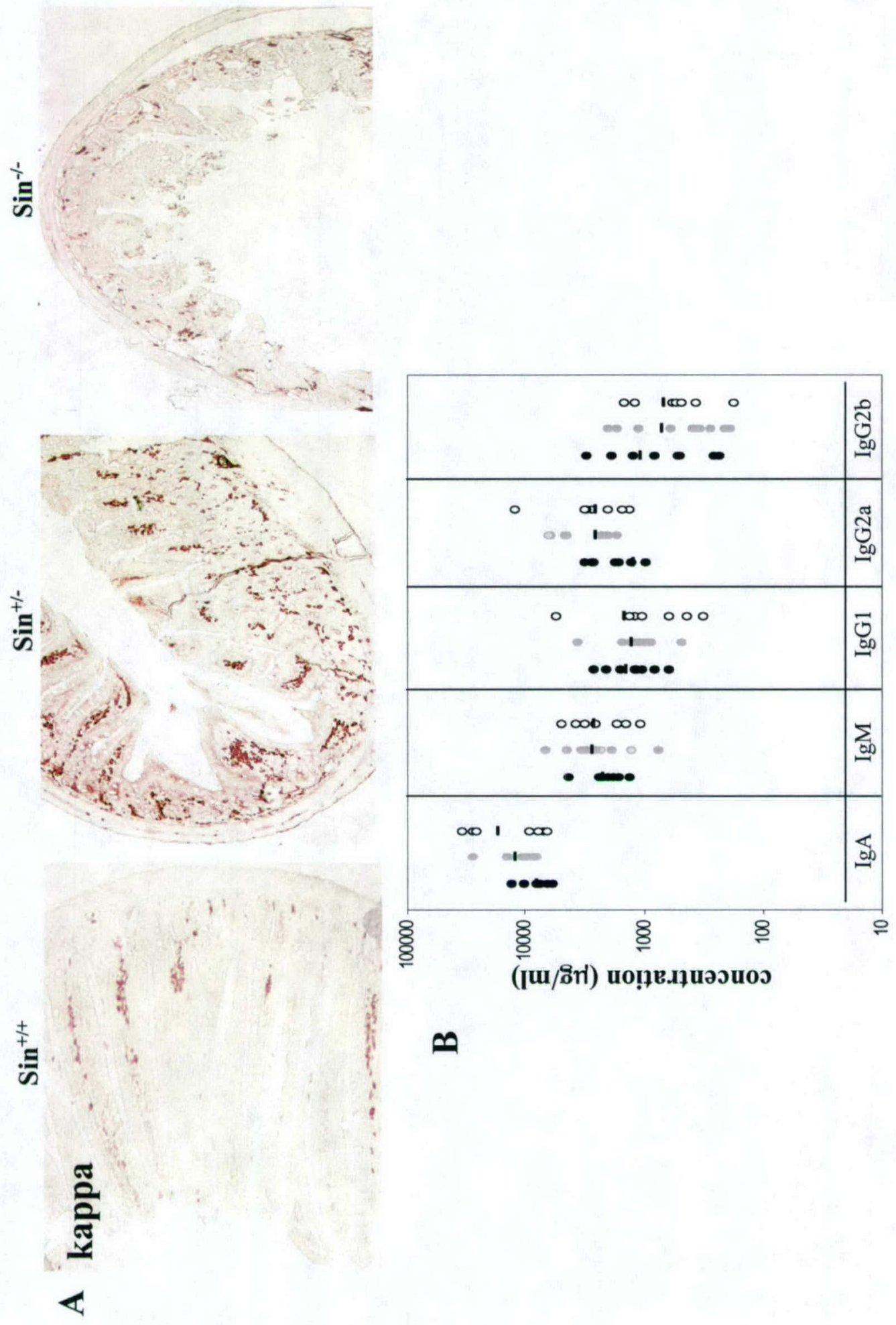




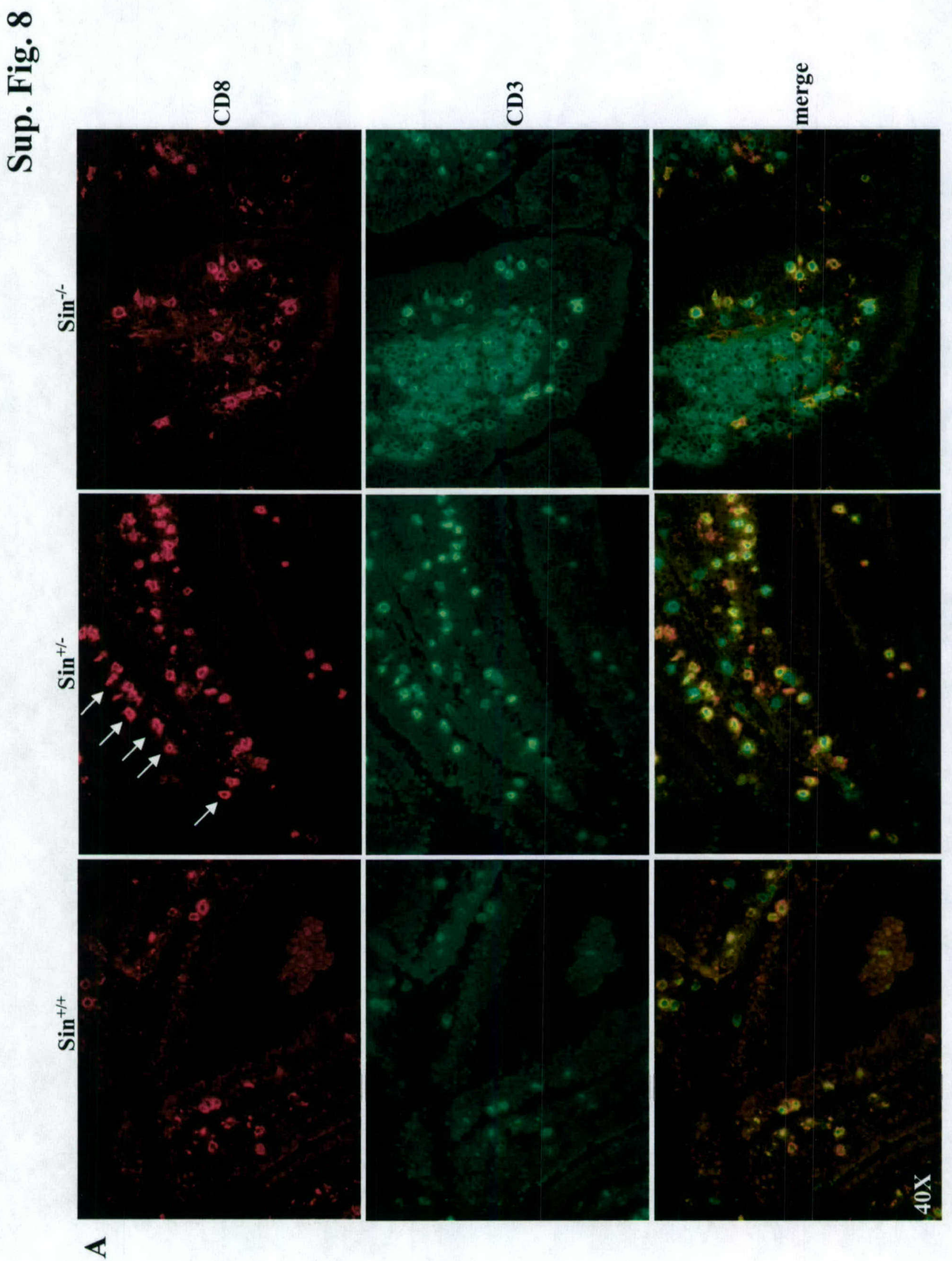




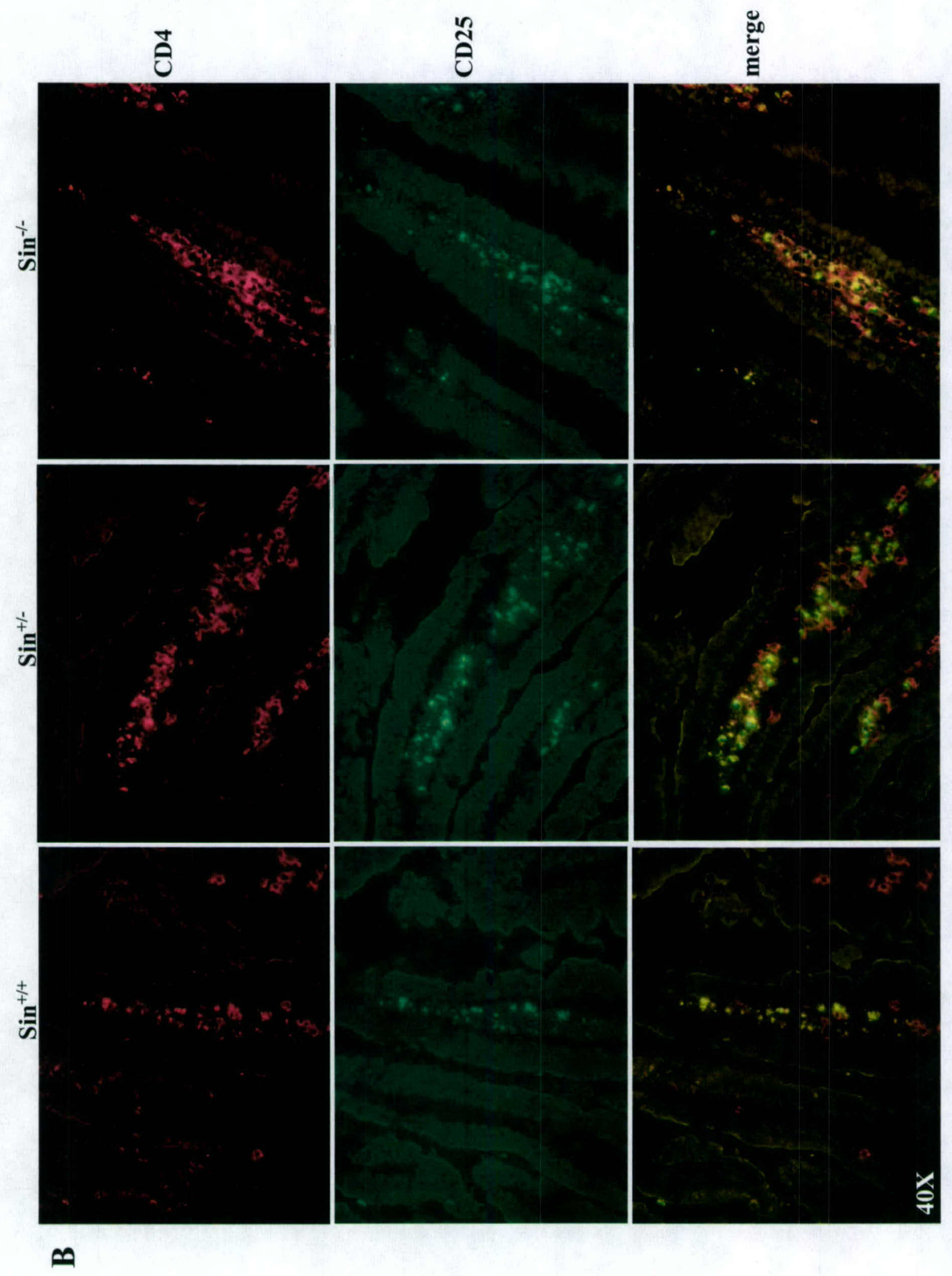

